\title{
AN EXPERIMENTAL STUDY OF STRAIN RATE EFFECTS ON MILD STEEL
}

\author{
Submitted by \\ Jianwei Chen \\ A thesis submitted to the Faculty of Graduate Studies and \\ Research in partial fulfillment of the requirements for the \\ degree of \\ Master of Applied Science \\ Ottawa-Carleton Institute for Civil Engineering \\ Department of Civil and Environmental Engineering \\ Carleton University \\ Ottawa, Ontario, Canada
}

January, 2010

(C) Jianwei Chen, 2010 


$\begin{array}{ll}\begin{array}{l}\text { Library and Archives } \\ \text { Canada }\end{array} & \begin{array}{l}\text { Bibliotheque et } \\ \text { Archives Canada }\end{array} \\ \begin{array}{l}\text { Published Heritage } \\ \text { Branch }\end{array} & \begin{array}{l}\text { Direction du } \\ \text { Patrimoine de l'édition }\end{array} \\ \begin{array}{l}\text { 395 Wellington Street } \\ \text { Ottawa ON K1A ON4 }\end{array} & \begin{array}{l}\text { 395, rue Wellington } \\ \text { Ottawa ON K1A ON4 } \\ \text { Canada }\end{array} \\ \text { Canada }\end{array}$

Your file Votre référence

ISBN: 978-0-494-71525-3

Our file Notre référence

ISBN: 978-0-494-71525-3

NOTICE:

The author has granted a nonexclusive license allowing Library and Archives Canada to reproduce, publish, archive, preserve, conserve, communicate to the public by telecommunication or on the Internet, loan, distribute and sell theses worldwide, for commercial or noncommercial purposes, in microform, paper, electronic and/or any other formats.

The author retains copyright ownership and moral rights in this thesis. Neither the thesis nor substantial extracts from it may be printed or otherwise reproduced without the author's permission.
AVIS:

L'auteur a accordé une licence non exclusive permettant à la Bibliothèque et Archives Canada de reproduire, publier, archiver, sauvegarder, conserver, transmettre au public par télécommunication ou par l'Internet, prêter, distribuer et vendre des thèses partout dans le monde, à des fins commerciales ou autres, sur support microforme, papier, électronique et/ou autres formats.

L'auteur conserve la propriété du droit d'auteur et des droits moraux qui protège cette thèse. $\mathrm{Ni}$ la thèse ni des extraits substantiels de celle-ci ne doivent être imprimés ou autrement reproduits sans son autorisation.
In compliance with the Canadian Privacy Act some supporting forms may have been removed from this thesis.

While these forms may be included in the document page count, their removal does not represent any loss of content from the thesis.
Conformément à la loi canadienne sur la protection de la vie privée, quelques formulaires secondaires ont été enlevés de cette thèse.

Bien que ces formulaires aient inclus dans la pagination, il n'y aura aucun contenu manquant. 


\begin{abstract}
An experimental study has been carried out to investigate the strain rate effects on mild steels at room temperature. In this study, a testing procedure that enables a round coupon to be tested under close to a constant strain rate up to fracture by using the diametral extensometer to control the loading rate has been developed. Non-standard round coupons with a tapered profile were used to permit the diameter at the minimum section to be measured continuously during the test. Due to necking of the tension coupon, a procedure has also been developed to correct for the effect of the non-uniaxial hydrostatic stress on the measured stress. This stress correction allows the true stress-true plastic strain curve of the material at various strain rates to be determined directly from the measured load and cross-section dimension. The procedure has been verified with the finite element analyses.
\end{abstract}

Rectangular and round specimens were tested under monotonic tensile loading at the strain rate range from $10^{-5} \mathrm{~s}^{-1}$ to $1 \mathrm{~s}^{-1}$. The rupture strain was found not to be influenced by the loading rate at the strain rate range considered. From the true stress-true plastic strain curves determined from the tests at various strain rates, the effect of strain rate on the flow stress was observed to diminish at a large plastic strain before the coupon fractured. The mixed-mode hardening plasticity model by Lemaitre and Chaboche (1990) was found to be able to closely reproduce the true stress-true plastic strain curves of the tests. 


\section{ACKNOWLEDGEMENTS}

I would like to thank Dr. Heng Aik Khoo, supervisor of this thesis, for his guidance, advice and support.

Thanks should also go to Zhiqi Wen, who gave valuable advice during the research, and Civil and Environmental Engineering laboratory technicians at Carleton University.

Last but not the least I would like to thank my parents, my wife and my daughter

(Leaah) for their understanding and encouragement during the period of the research.

Funding for this research was provided by Natural Sciences and Engineering Research Council of Canada. 
Chapter Page

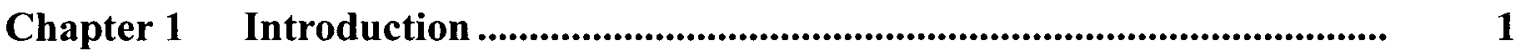

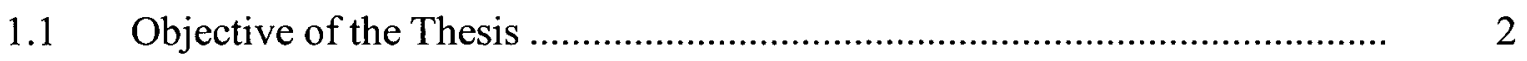

1.2 Methodology Used in the Research ................................................. 2

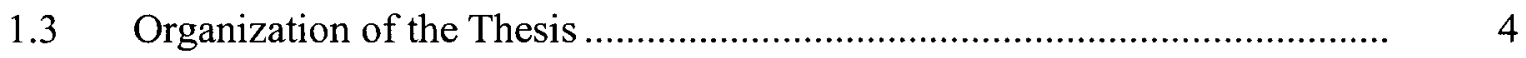

Chapter 2 Literature Review................................................................ 5

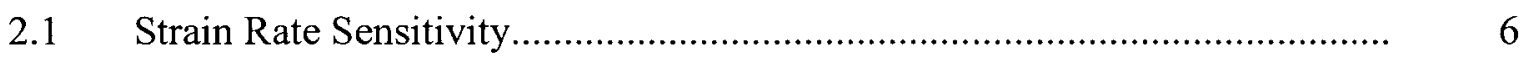

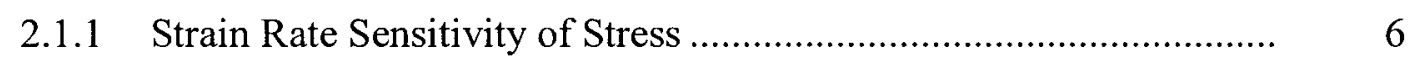

2.1.2 Strain Rate Sensitivity of Rupture Strain ................................. 9

2.2 Material Properties and Constitutive Equations .................................. 10

2.2.1 Mechanical Properties .................................................. 10

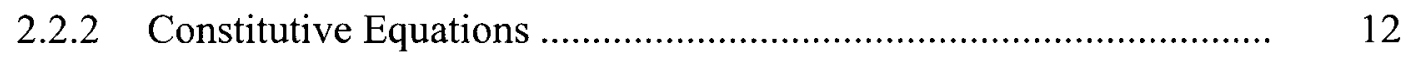

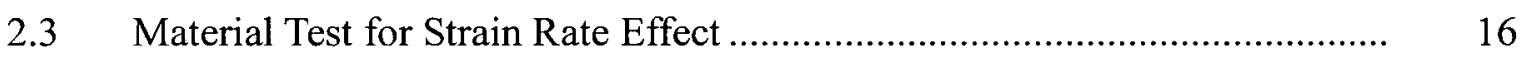

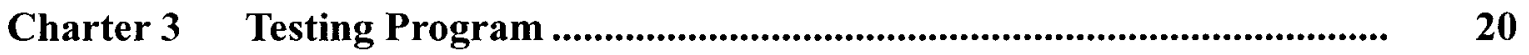

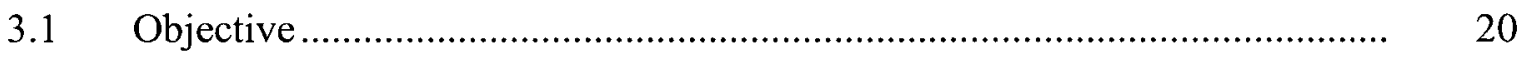

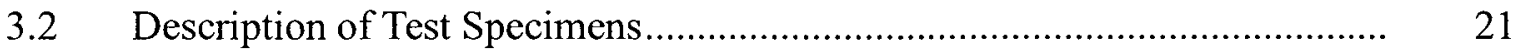

3.2.1 Specimen Designation ..................................................... 22

3.2.2 Rectangular Specimen ................................................... 23

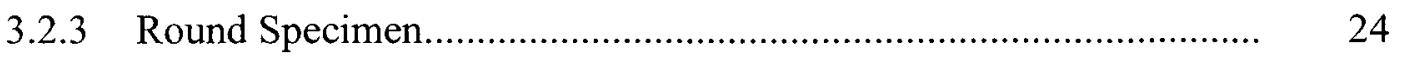

3.3 Manual Measurement.................................................................. 27 
$3.4 \quad$ Tests setup and Instrumentation................................................................... 27

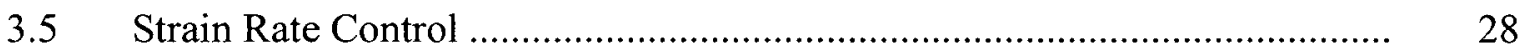

Charter 4 Test Results and Discussions ............................................................ 41

4.1 Results and Analyses of Rectangular Specimen Test .................................. 41

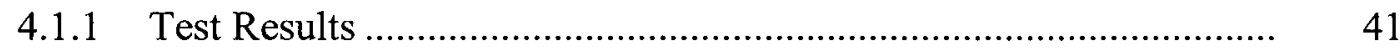

4.1.2 Analysis of Test Results ...............................................................

4.1.3 Empirical Equation for True Stress Correction after Necking .......... 46

4.1.4 Modeling of Strain Rate Effect on True Stress-True Plastic Strain

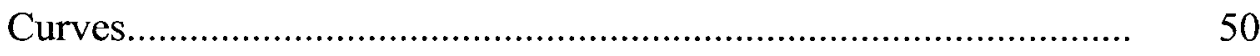

4.2 Results and Analyses of Round Specimen Tests ........................................ 53

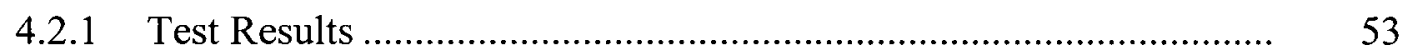

4.2.2 Discussions of Test Results ............................................................ 55

4.2.3 Correction for the Minimum Diameter Measured by Diametral

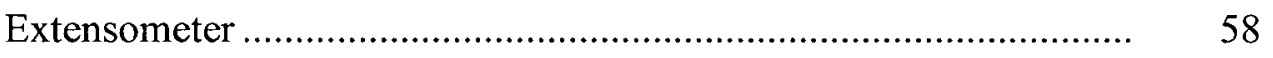

4.2.4 Empirical Equation for True Stress Correction after Necking .......... 62

4.2.5 Modeling of Strain Rate Effect on True Stress-True Plastic Strain Curves

Charter 5 Conclusions and Recommendations ................................................. 131

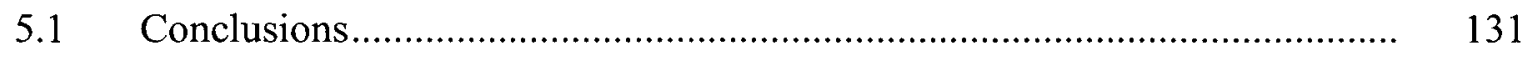

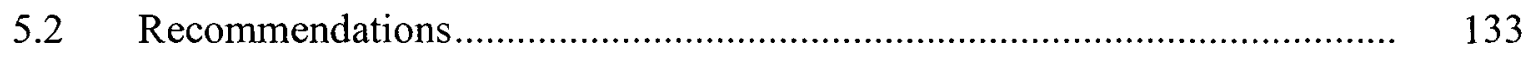

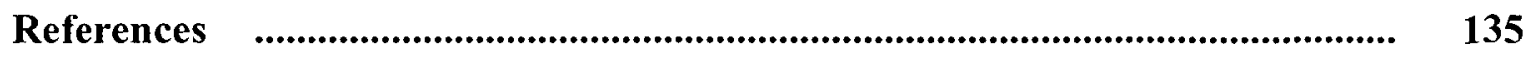


Appendix A Comparison of Static Reading Results with Axial Extensometer

Control and Stroke Control................................................... 143

Appendix B Comparison of Test Results of Tapered and Non-tapered Round

Specimens.................................................................... 150

Appendix C Comparison of Engineering Strain at Fracture for Tests Conducted

at the Same Target Strain Rate ............................................. 153

Appendix D Comparisons of Test Results and Finite Element Analyses for

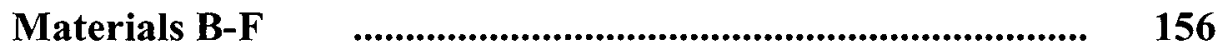

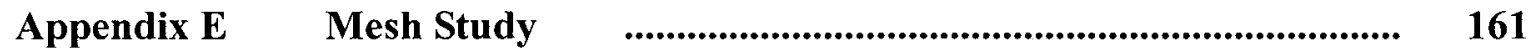




\section{List of Tables}

Table

3.1 Materials in the test and designation............................................... 33

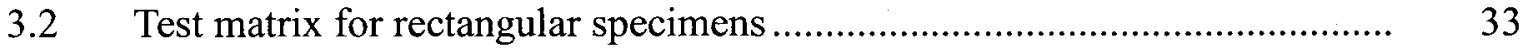

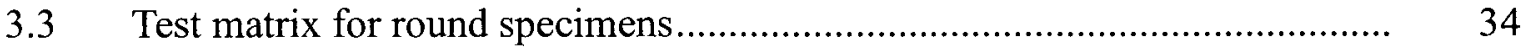

4.1 Yield stress, ultimate stress and elastic modulus for materials A-F............ $\quad 70$

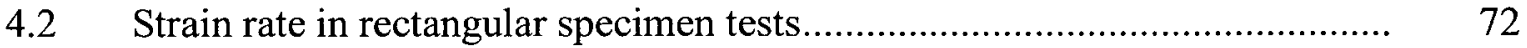

4.3 Ratio of dynamic engineering yield and ultimate stresses to average stroke control equivalent static stresses.

4.4 Constants for Cowper-Symonds power law equation for materials A-F .......

4.5 Fracture strain calculated based on elongation and reduction of cross-section area for materials A-F

4.6 Values of $A_{0}^{P}$ calculated from engineering strain at peak stress and measured from the specimens

4.7 Material $E$ test data used to determine parameter $B$ for modified Cowper-Symonds power law Eq. (2.13) by Jones (2001)

4.8 Test data used to determine parameters $\mathrm{C}$ and $\gamma$ for the mixed-mode hardening model by Lemaitre and Chaboche (1990)

4.9 Yield stress, ultimate stress and elastic modulus for materials $\mathrm{G}$ and $\mathrm{H}$.......

4.10 Actual strain rate in round specimen tests

4.11 Ratio of dynamic engineering yield and ultimate stress to the respective 
static stroke control test stresses for materials $\mathrm{G}$ and $\mathrm{H}$.

4.12 Constants for Cowper-Symonds power law for materials $\mathrm{G}$ and H............. 81

4.13 Strain at fracture for materials $\mathrm{G}$ and $\mathrm{H}$

4.14 Material $\mathrm{H}$ test data used to determine parameter $\mathrm{B}$ for modified Cowper-Symonds power law Eq. (2.13) by Jones (2001)

4.15 Test data used to determine parameters $\mathrm{C}$ and $\gamma$ for the mixed-mode hardening model by Lemaitre and Chaboche (1990)

A.1 Comparisons of the drop in the stress when taking static readings at various strains between axial extensometer and stroke controls

A.2 Comparison of the drop in stress when taking static readings before and after switching from axial extensometer control to stroke control

A.3 Comparisons of static yield stress from different loading rate controls and the yield stress calibrated for Cowper-Symonds power law equation for materials $\mathrm{G}$ and $\mathrm{H}$

B.1 Comparison of yield and ultimate stress between tapered and non-tapered profile $\mathrm{H}$ 


\section{List of Figures}

Figure $\quad$ Page

2.1 Typical engineering stress-engineering strain curve of mild steel.............. 19

2.2 Relationship of the stresses for the mixed-mode hardening model .............. 19

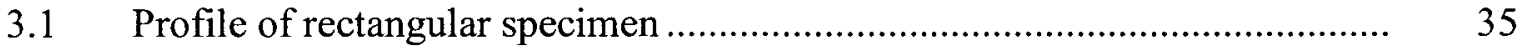

3.2 Profile of $9 \mathrm{~mm}$ diameter tapered $(\mathrm{T})$ and non-tapered $(\mathrm{N})$ round

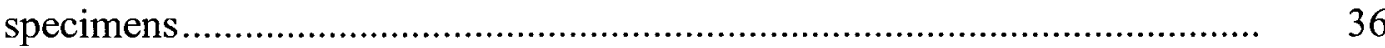

3.3 Profile of $14 \mathrm{~mm}$ diameter non-tapered (D) round specimen ...................... 37

3.4 Measurement for rectangular specimens after necking ........................... 38

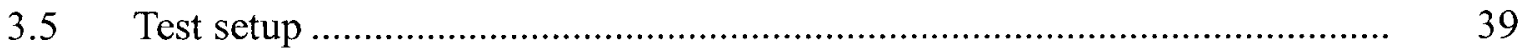

3.6 Relationship between the diameter change and true strain ........................ 40

4.1 Engineering stress - engineering strain curve of material A ....................... 85

4.2 Engineering stress - engineering strain curve of material B .................... 85

4.3 Engineering stress - engineering strain curve of material C ...................... 86

4.4 Engineering stress - engineering strain curve of material D..................... 86

4.5 Engineering stress - engineering strain curve of material E ........................ 87

4.6 Engineering stress - engineering strain curve of material F ..................... 87

4.7 Ratio of yield stress versus logarithm of strain rate for materials A-F ......... 88

4.8 Ratio of ultimate stress versus logarithm of strain rate for materials A-F .... $\quad 88$

4.9 Comparison of test and predicted yield stress ratio based on Cowper-Symonds power law for materials A-F 
4.10 Necking occurred in two regions on specimen AR5E1bE........................... 90

4.11 Engineering strain (average) at fracture versus strain rate for materials A-F 91

4.12 Rupture strain (average) versus strain rate for materials A-F ....................... 91

4.13 Finite element model for $1 / 8$ of rectangular coupon...................................... 92

4.14 Corrected and uncorrected static true stress versus true plastic strain curves for AR1E4(a-b)ES

4.15 Comparisons of the corrected true stress versus true plastic strain curves different engineering strain at peak stress for AR1E4bES

4.16 Test and predicted stress versus cross-section change for AR1E4(a-b)ES ....

4.17 Test and predicted true stress-true plastic strain curves with Cowper-Symonds power law Eq. (2.8) for material A

4.18 Test and predicted true stress-true plastic strain curves with Cowper-Symonds power law Eq. (2.8) for material B

4.19 Test and predicted true stress-true plastic strain curves with Cowper-Symonds power law Eq. (2.8) for material C

4.20 Test and predicted true stress-true plastic strain curves with Cowper-Symonds power law Eq. (2.8) for material D

4.21 Test and predicted true stress-true plastic strain curves with Cowper-Symonds power law Eq. (2.8) for material E

4.22 Test and predicted true stress-true plastic strain curves with Cowper-Symonds power law Eq. (2.8) for material F 
4.23 Test and predicted true stress-true plastic strain curves with

Cowper-Symonds power law Eq. (2.8) for material A (up to strain of 0.2)...

4.24 Test and predicted true stress-true plastic strain curves with

Cowper-Symonds power law Eq. (2.8) for material B (up to strain of 0.2) ..

4.25 Test and predicted true stress-true plastic strain curves with

Cowper-Symonds power law Eq. (2.8) for material C (up to strain of 0.2) ..

4.26 Test and predicted true stress-true plastic strain curves with

Cowper-Symonds power law Eq. (2.8) for material D (up to strain of 0.2)..

4.27 Test and predicted true stress-true plastic strain curves with Cowper-Symonds power law Eq. (2.8) for material E (up to strain of 0.2)...

4.28 Test and predicted true stress-true plastic strain curves with Cowper-Symonds power law Eq. (2.8) for material F (up to strain of 0.2)...

4.29 Test and predicted true stress-true plastic strain curves with modified Cowper-Symonds power law for material E (up to strain of 0.2 )

4.30 Test and predicted true stress-true plastic strain curves with mixed-mode hardening model for material $\mathrm{E}$ (up to strain of 0.2 )

4.31 Engineering stress-engineering strain curves for material $\mathrm{G}$

4.32 Engineering stress-engineering strain curves for material $\mathrm{H}$

4.33 Comparison of true strain calculated with Eqs. (4.4) and (4.5) for GT1E5aE 


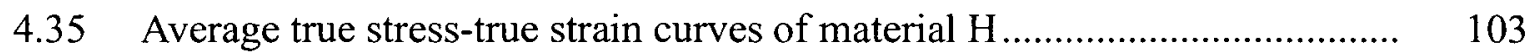

4.36 Yield and ultimate stress ratios versus actual loading rate …........................ 104

4.37 Comparisons of the test and predicted yield stress with Cowper-Symonds

power law equation .............................................................................. 104

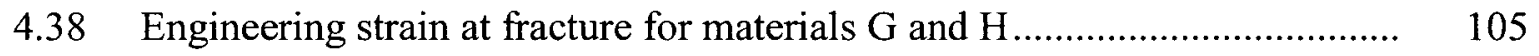

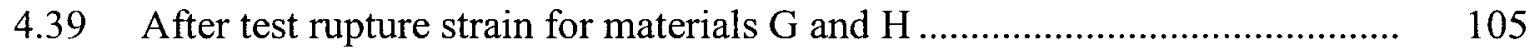

4.40 Measured true strain-engineering strain curve for GT1E5aE and GT1E5bE 106

4.41 Measured true strain-engineering strain relationships for material G ........... 106

4.42 Measured true strain-engineering strain relationships for material $\mathrm{H} \ldots \ldots \ldots \ldots . . . \quad 107$

4.43 Curve fitting parabolic and measured true strain-engineering strain curves

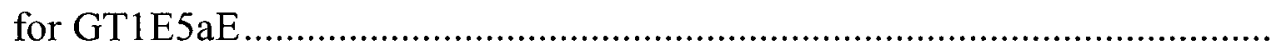

4.44 Curve fitting parabolic and measured true strain-engineering strain curves for HT1E1E

4.45 Curve fitting parabolic and measured true strain-engineering strain curves for GT5E5ED

4.46 Curve fitting parabolic and measured true strain-engineering strain curves for HT1E3ED

4.47 Model for one-half of round specimen

4.48 Static true stress versus true plastic strain curves for GT1E4S with and without Eq. (4.26) correction

4.49 Static true stress versus true plastic strain curves for HT1E4S with and xii 
without Eq. (4.26) correction.

4.50 Test and predicted static engineering stress versus change in cross-section area ratio for GT1E4S with and without Eq. (4.26)

4.51 Test and predicted static engineering stress versus change in cross-section area ratio for HT1E4S with and without Eq. (4.26) correction

4.52 Test and predicted engineering stress versus change in cross-section area ratio for GT1E5E with Eq. (4.26) correction

4.53 Test and predicted engineering stress versus change in cross-section area ratio for GT5E5ED with Eq. (4.26) correction.

4.54 Test and predicted engineering stress versus change in cross-section area ratio for GT1E4ED with Eq. (4.26) correction.

4.55 Test and predicted engineering stress versus change in cross-section area ratio for GT1E3ED with Eq. (4.26) correction.

4.56 Test and predicted engineering stress versus change in cross-section area ratio for GT1E2ED with Eq. (4.26) correction.

4.57 Test and predicted engineering stress versus change in cross-section area ratio for GT1E1E with Eq. (4.26) correction

4.58 Test and predicted engineering stress versus change in cross-section area ratio for GT1E0E with Eq. (4.26) correction

4.59 Test and predicted engineering stress versus change in cross-section area ratio for HT1E5E with Eq. (4.26) correction. 
4.60 Test and predicted engineering stress versus change in cross-section area ratio for HT5E5ED with Eq. (4.26) correction

4.61 Test and predicted engineering stress versus change in cross-section area ratio for HT1E4ED with Eq. (4.26) correction

4.62 Test and predicted engineering stress versus change in cross-section area ratio for HT1E3ED with Eq. (4.26) correction

4.63 Test and predicted engineering stress versus change in cross-section area ratio for HT1E2ED with Eq. (4.26) correction

4.64 Test and predicted engineering stress versus change in cross-section area ratio for HT1E1E with Eq. (4.26) correction.

4.65 Test and predicted engineering stress versus change in cross-section area ratio for HT1E0E with Eq. (4.26) correction.

4.66 Test and predicted average true stress versus true strain curves for GT1E3ED with and without diameter correction

4.67 Test and predicted engineering stress versus change in cross-section area ratio curves for GT1E3ED with and without diameter correction.

4.68 Test and predicted average true stress versus true strain curves for HT1E2ED with and without diameter correction

4.69 Test and predicted engineering stress versus change in cross-section area ratio curves for HT1E2ED with and without diameter correction.

4.70 Test and predicted average true stress versus true strain curves for xiv 
GT1E4ED with and without diameter correction

4.71 Test and predicted engineering stress versus change in cross-section area ratio curves for GT1E4ED with and without diameter correction.

4.72 Test and predicted average true stress versus true strain curves for HT1E4ED with and without diameter correction

4.73 Test and predicted engineering stress versus change in cross-section area ratio curves for HT1E4ED with and without diameter correction

4.74 Rupture strain after fracture with diameter correction for materials $\mathrm{G}$ and $\mathrm{H}$

4.75 Average true stress-true strain curves for material $\mathrm{G}$ after correction for the diameter.

4.76 Average true stress-true strain curves for material $\mathrm{H}$ after correction for the diameter.

4.77 True stress-true plastic strain curves for material $\mathrm{G}$ after correction for non-uniaxial state hydrostatic tension and diameter

4.78 True stress-true plastic strain curves for material $\mathrm{H}$ after correction for non-uniaxial state hydrostatic tension and diameter

4.79 Test and predicted true stress-true plastic strain curves with Cowper-Symonds power law for material $\mathrm{G}$

4.80 Test and predicted true stress-true plastic strain curves with Cowper-Symonds power law for material G (up to strain of 0.2 ) 
4.81 Test and predicted true stress-true plastic strain curves with Cowper-Symonds power law for material $\mathrm{H}$

4.82 Test and predicted true stress-true plastic strain curves with Cowper-Symonds power law for material $\mathrm{H}$ (up to strain of 0.2)

4.83 Test and predicted true stress-true plastic strain curves with modified Cowper-Symonds power law for material $\mathrm{H}$

4.84 Test and predicted true stress-true plastic strain curves with modified Cowper-Symonds power law for material $\mathrm{H}$ (up to strain of 0.2)

4.85 Test and predicted true stress-true plastic strain curves with mixed-mode hardening model for material $\mathrm{H}$

4.86 Test and predicted true stress-true plastic strain curves with mixed-mode hardening model for material $\mathrm{H}$ (up to strain of 0.2 ).

A.1 Comparison of the different drop in stress between extensometer control and stroke control for CR1E4aES and CR1E4bES

A.2 Comparison of the different drop in stress between extensometer control and stroke control for CR1E4aS and CR1E4bS

A.3 Comparison of static readings at different loading rate in tests with stroke control

A.4 Comparison of static readings at different loading rate in tests with axial extensometer control

B.1 Comparisons of the engineering stress-strain curve for the tapered and 
non-tapered round specimens for material $\mathrm{G}$ at the strain rate of $10^{-2} \mathrm{~s}^{-1} \ldots \ldots$

B.2 Comparisons of the engineering stress-strain curve for the tapered and non-tapered round specimens for material $\mathrm{H}$ at the strain rate of $10^{-4} \mathrm{~s}^{-1} \ldots \ldots$

C.1 Comparisons of the engineering stress-strain curves for material $G$ at the strain rate of $10^{-5} \mathrm{~s}^{-1}$

C.2 Comparisons of the stress-strain curves for material $G$ at the strain rate of $10^{-2} \mathrm{~s}^{-1}$

C.3 Comparisons of the stress-strain curves for material $\mathrm{G}$ at the strain rate of $10^{-4} \mathrm{~s}^{-1}$

D.1 Corrected and uncorrected static true stress versus true plastic strain curves for BR1E4(a-b)ES

D.2 Corrected and uncorrected static true stress versus true plastic strain curves for CR1E4(a-b)ES

D.3 Corrected and uncorrected static true stress versus true plastic strain curves for DR1E4(a-b)ES

D.4 Corrected and uncorrected static true stress versus true plastic strain curves for ER1E4(a-b)ES

D.5 Corrected and uncorrected static true stress versus true plastic strain curves for FR1E4(a-b)ES.

D.6 Results of simulations and tests for stress versus cross-section change for BR1E4(a-b)ES 
D.7 Results of simulations and tests for stress versus cross-section change for

CR1E4(a-b)ES

D.8 Results of simulations and tests for stress versus cross-section change for DR1E4(a-b)ES

D.9 Results of simulations and tests for stress versus cross-section change for ER1E4(a-b)ES

D.10 Results of simulations and tests for stress versus cross-section change for FR1E4(a-b)ES.

E.1 Finite element mesh scheme-1 at the mid-length of AR1E4bES

E.2 Finite element mesh scheme-2 at the mid-length of AR1E4bES

E.3 Finite element mesh scheme-3 at the mid-length of GT1E4S

E.4 Finite element mesh scheme-4 at the mid-length of GT1E4S

E.5 Analytical average true stress versus true strain for AR1E4bES with different scheme.

E.6 Analytical stress versus change in cross-section area change for AR1E4bES with different scheme.

E.7 Analytical average true stress versus true strain for GT1E4S with different scheme

E.8 Analytical stress versus change in cross-section area change for GT1E4S with different scheme. 


\section{List of Symbols}

a

$a_{c}$

A

$\mathrm{A}_{0}$

$\mathrm{A}_{\mathrm{f}}$

$A_{0}^{P}$

b

B

c

C

$\mathrm{C}_{\mathrm{F}}$

D

$\mathrm{D}_{0}$

$\mathrm{D}_{\mathrm{b}}$

$\mathrm{D}_{\mathrm{cor}}$

$D_{0}^{P}$

$\mathrm{D}_{\mathrm{r}}$

$\dot{D}$

E

$\mathrm{f}_{\mathrm{S}}$
- material constant

- curvature of the profile at the necking region

- current cross-section area

- undeformed cross-section area

- cross-section area at fracture

- cross-section area at peak stress

- material constant

- material constant

- material constant

- material constants

- correction factor

- material constant or the current diameter

- undeformed diameter

- diameter measured after test

- corrected diameter at the minimum cross-section

- diameter at peak stress

- measured diameter at fracture

- changing in diameter rate

- elastic modulus of steel

- stress of steel 


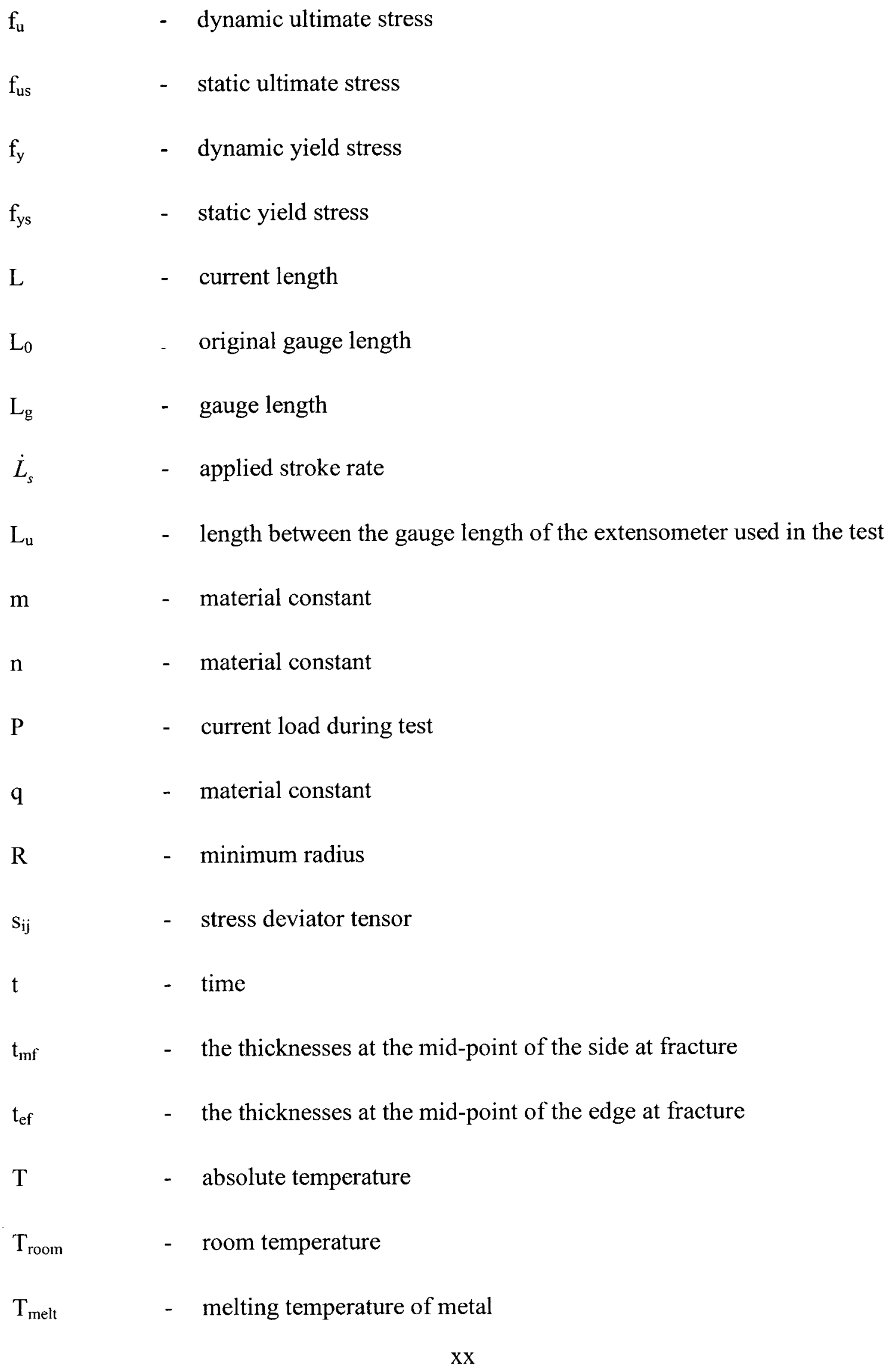




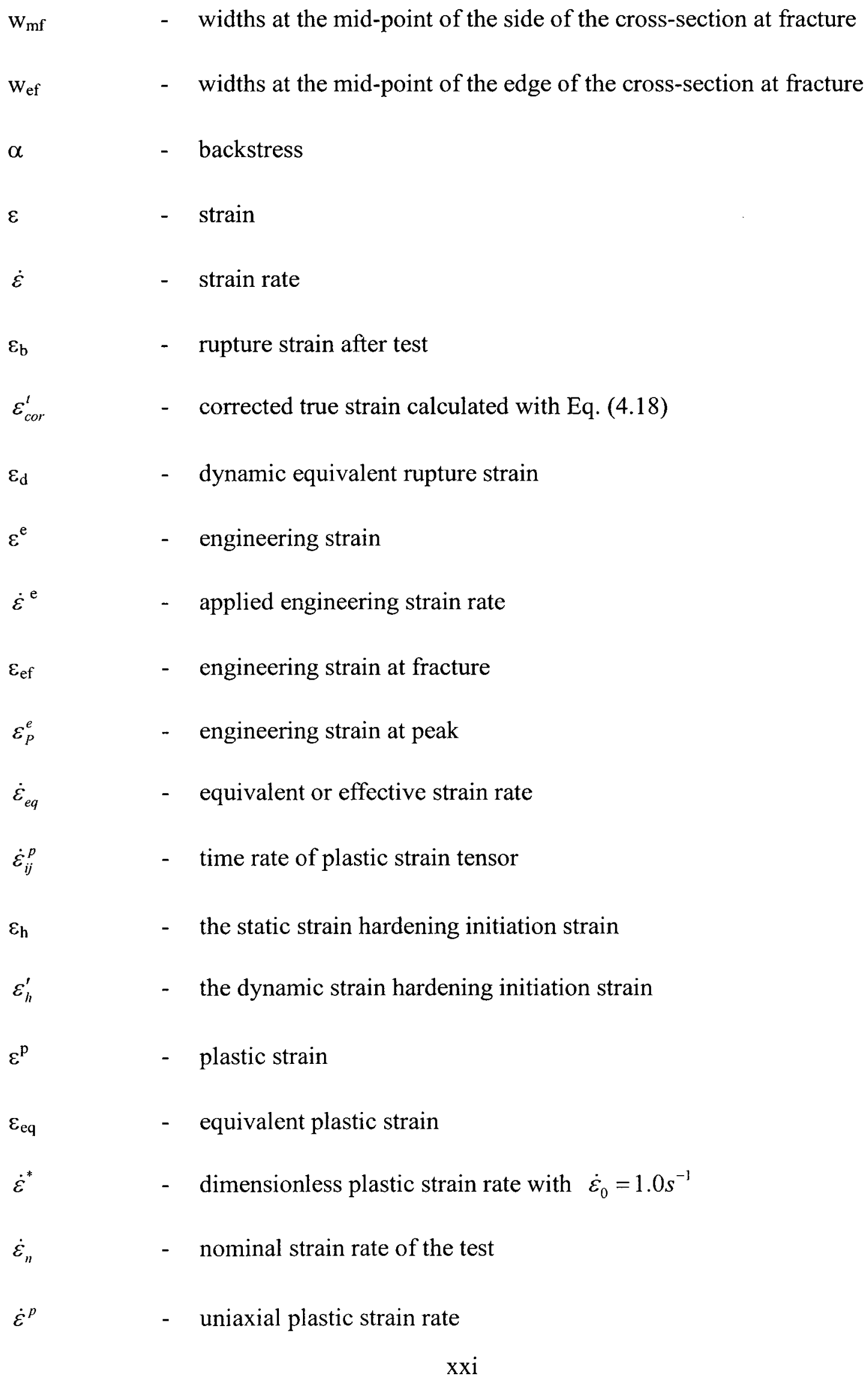


$\varepsilon_{p k 0}^{e}$

$\varepsilon_{p k 0}^{t}$

$\varepsilon_{p k}^{e}$

$\varepsilon_{p k}^{t}$

$\varepsilon_{\mathrm{r}}$

$\varepsilon_{\mathrm{s}}$

$\varepsilon^{t}$

$\varepsilon_{\mathrm{u}}$

$\varepsilon_{1}^{\prime}$

$\delta_{i j}$

$\Delta_{\mathrm{D}}$

$\Delta_{\mathrm{g}}$

$\Delta \mathrm{L}_{\mathrm{f}}$

$\Delta \sigma$

$\Delta \sigma^{\mathrm{ex}}$

$\Delta \sigma_{s w}^{e x}$

$\Delta \sigma_{s w}^{s t}$
- engineering strain at the ultimate stress of the prototype curve

- true strain at the ultimate stress of the prototype curve

- engineering strain at the ultimate stress of the test

- true strain at the ultimate stress of the test

- rupture strain at fracture

- $\quad$ static equivalent rupture strain

- true strain

- $\quad$ strain at the static ultimate

- $\quad$ strain at the dynamic ultimate

- Kronecker delta

- reduction in diameter

- extension within the gauge length

- the extension over the gauge length at fracture

- the drop in stress when taking static reading

- the drop in stress when taking the static reading in coupon test under axial extensometer control

- the average stress drop at the last two static readings before switching to stroke control

- the average stress drop at the first two static readings right after switching from axial extensometer to stroke control

- material constant 


$\begin{array}{lll}\sigma_{0} & - & \text { uniaxial static flow stress } \\ \sigma_{0}^{\prime} & - & \text { dynamic flow stress } \\ \sigma_{10}^{\prime} & - & \text { dynamic true stresses for isotropic hardening } \\ \sigma_{10} & - & \text { static true stresses for isotropic hardening } \\ \sigma_{\text {avg }}^{t} & - & \text { average true stress } \\ \sigma_{c o r}^{t} & - & \text { true stress with hydrostatic stress correction } \\ \sigma^{\mathrm{dy}} & - & \text { dynamic stress before the pause when taking static reading } \\ \sigma^{\mathrm{st}} & & \text { stress before the loading is resumed when taking static reading } \\ \sigma_{e q}^{\prime} & - & \text { equivalent or effective dynamic flow stress } \\ \sigma_{\mathrm{ij}} & & \text { stress tensor } \\ \sigma_{s t a}^{t} & & \text { back calculated static true stress from dynamic true stress }\end{array}$




\section{Chapter 1 Introduction}

The design and analysis of a structure require the knowledge of the material properties and behavior. In steel structures, the design is normally based on the quasi-static material properties. However, structural steel can behave differently when subjected to dynamic loading. It has been found that the mechanism of failure changes when structural steel members are subjected to a high deformation rate during an earthquake. Under a high deformation rate, the response of a steel structure becomes more brittle and many structural elements have been found to suffer damage near the connections. Many studies have shown that the post-yield plastic flow of mild steel is affected considerably by the strain rate. The flow stress at yielding has been found to increase by up to a factor of 2 at a strain rate of $10 \mathrm{~s}^{-1}$ when it is compared to the quasi-static yield stress.

In most experiments, constant axial strain rate is employed in the tensile test to study the effect of strain rate up to the loading rate of $10 \mathrm{~s}^{-1}$. However in these tests, a constant strain rate loading can only be maintained up to the peak load before necking starts. Similarly, the true stress-true strain data can only be calculated up to the peak load as the cross-section dimensions at the necking region are not measured in these tests. For a mild steel, the true strain at the peak load is normally less than 0.2 while the true strain at fracture is around 1.0. For numerical modeling purposes, it will be helpful if the true stress-true strain relationship of the material up to fracture is known. 


\subsection{Objective of the Thesis}

The objective of the thesis is to develop a testing procedure that allows the true stress-true plastic strain curve of the material up to fracture at various strain rates to be determined directly from the test and to study the effects of strain rate on material properties of mild steel. Rectangular and round coupons will be tested under various strain rates for the yield stress, ultimate stress, engineering stress versus engineering strain and true stress versus true strain relationships, engineering strain at fracture and rupture strain. Due to necking of the tension coupon, a procedure to correct the measured true stress for the effect of the non-uniaxial hydrostatic stress state has to be developed and validated. Findings from this study will allow for a better characterization of the strain rate effect on the behavior of mild steel. This will lead to an improved modeling and a more accurate prediction of the steel structure behavior and performance.

\subsection{Methodology Used in the Research}

Tension coupons from eight heats of mild steel of various structural steel grades were tested at a constant strain rate ranging from $10^{-5} \mathrm{~s}^{-1}$ to $10^{0} \mathrm{~s}^{-1}$. Six heats were considered for rectangular coupons and two for round coupons. Rectangular coupons were fabricated from flat bars and round coupons from round rods. All rectangular specimens had a straight profile while round coupons mainly had a tapered profile that has the minimum diameter at the mid-length. A tapered profile was prescribed for the 
round specimens to allow for the correct placement of the diametral extensometer to enable the minimum diameter at the necking region to be measured, so that the true stress can be calculated and a relatively constant strain rate to be applied in the tests using the diametral deformation as the control input.

Tests were carried out with stroke control, axial extensometer control and diametral extensometer control. For some tests, the loading was put on pause at a regular interval to measure the static readings. Straight profiled round specimens were also tested to study the differences in the yield stress, ultimate stress and the engineering stress-engineering strain curve between the straight and tapered profiled specimens.

Most of the tapered round specimens were tested under diametral extensometer control after necking so that a more consistent constant strain rate can be applied. Before the test, the tapered round specimens were inspected with a shadow graph to identify the location of minimum diameter for the placement of the diametral extensometer. The coupons were also smoothened with sandpapers to facilitate the sliding of the diametral extensometer to the location of minimum diameter during the test. Nevertheless, a procedure was been developed to correct for the minimum diameter in the situation where the diametral extensometer may not be at the position of the minimum cross-section. In addition, another procedure was also developed to enable the true stress-true strain curve of the material to be calculated directly from the test data by correcting for the effect of the non-uniaxial hydrostatic stress state due to necking. Both of these procedures were validated through finite element analyses. 
Based on results of the tests, effects of strain rate on various mechanical properties were discussed. A number of strain rate dependent constitutive models were also evaluated against the measured true stress-true strain curves.

\subsection{Organization of the Thesis}

Chapter 2 presents a brief literature review of previous studies on effects of strain rate on mechanical properties of steel. Some basic effects of strain rate are discussed.

The testing program is presented in Chapter 3. This chapter describes the test setup, tension coupon material and profile, testing procedure, loading control and measurements.

In Chapter 4, test results of rectangular and round coupons are presented. Effects of the testing procedure and loading control on the measured data are discussed. Procedures that have been developed to correct for the minimum diameter at the necking region and the true stress due to the non-uniaxial stress state are described and verified. Effects of strain rate on various mechanical properties are also discussed.

Chapter 5 consists of conclusions and recommendations.

Additional test data and analyses results are presented in the appendices. 


\section{Chapter 2 Literature Review}

The mechanical properties used in the design and analysis of structures are based on quasi-static tensile test according to ASTM E8-04 (ASTM 2004), which is around $0.05 \mathrm{~min}^{-1}$ to $0.5 \mathrm{~min}^{-1}$. A typical engineering stress-engineering strain curve of mild steel tested according to ASTM E8-04 is shown in Fig. 2.1 together with the ultimate stress, yield stress and elastic modulus. However in some extreme events, such as in a major earthquake or impact loading, the structure will experience a much higher deformation rate. Gibson et al. (2002) found that the strain rate in a structure can be as high as $10^{-1} \mathrm{~s}^{-1}$ to $10 \mathrm{~s}^{-1}$ in a major earthquake. At these strain rates, conventional quasi-static material properties may no longer be representative of the material response. Therefore, it is essential that the appropriate rate dependent material properties be used in the design and analysis of the structure for seismic load.

Strain rate can be defined as the rate of change in the length between two points as

$$
\dot{\varepsilon}=\frac{1}{L} \frac{d L}{d t}=\frac{d \varepsilon}{d t}
$$

where $\mathrm{L}$ is the current length, $\mathrm{t}$ is the time and $\varepsilon$ is the strain. and the superposed "." represents the time rate of change. Blazynski (1983) has roughly categorized quasi-static strain rate to range from $10^{-4} \mathrm{~s}^{-1}$ to $10^{-2} \mathrm{~s}^{-1}$; intermediate strain rate from $10^{0} \mathrm{~s}^{-1}$ to $10^{2} \mathrm{~s}^{-1}$; and high strain rate from $10^{3} \mathrm{~s}^{-1}$ and higher. At quasi-static strain rate, the distribution of stress in a solid body can be considered to be time independent and static equilibrium 
applies. At intermediate strain rate, the deformation rate is fast enough that even though the distribution of stress is still a continuous function, the inertia effect has to be taken into account when analyzing material tension test data (Harding 1980). At high strain rate, the stress wave propagation effect in addition to the inertia effect will also have to be considered.

\subsection{Strain Rate Sensitivity}

Many studies have been carried out to study the effects of strain rate on the mechanical properties of metals. Properties that are important in the design and analysis of a structure include the yield and ultimate strengths, flow stress and rupture strain.

\subsubsection{Strain Rate Sensitivity of Stress}

Manjoine (1944) tested mild steel with strain rates ranging from $10^{-6} \mathrm{~s}^{-1}$ up to $10^{3} \mathrm{~s}^{-1}$ under different temperatures. It was found that the true yield stress and true stress at various strains increased with the strain rate. Marsh and Campbell (1963) conducted constant strain rate tests on cylindrical specimens of mild steel with four different mean ferrite grain sizes at intermediate strain rate using a modified rapid-loading hydraulic test machine. Results of the tests also showed that yield strength increased with the strain rate.

Campbell and Cooper (1966) tested annealed low-carbon steel with a strain rate range of $10^{-3} \mathrm{~s}^{-1}$ to $10^{2} \mathrm{~s}^{-1}$. The upper yield stress was found to increase by $110 \%$, the 
lower yield stress by $100 \%$, and the ultimate stress by only $30 \%$. Kassar and Yu (1992) conducted a large number of tensile and compressive tests on AISI 035XF (hot-rolled sheet steel), 050XF (cold-rolled sheet steel) and 100XF (cold-rolled sheet steel) steels at various strain rates. It was found that the proportional limit, yield and ultimate strengths increase with the strain rate. The strain rate sensitivity was found to be higher for yield strength than ultimate strength.

Maiden and Green (1966) also conducted uniaxial compressive tests on 6061-T6 and 7075-T6 aluminum alloys, 6AI-4V titanium and some other non-metallic materials at the strain rate from $10^{-3} \mathrm{~s}^{-1}$ to $10^{4} \mathrm{~s}^{-1}$. Mechanical properties of both aluminum alloys were found to be strain rate insensitive, while titanium was found to be strain rate sensitive. The mechanical properties rate sensitivity was found to vary with the material.

For mild steel and other strain rate sensitive metals, the following strain rate effects were generally observed in the test.

a. The elastic modulus is not affected by strain rate.

b. The yield stress increases with the increase in the strain rate. Generally, the rate of yield stress increase is higher when the yield stress is lower;

c. The ultimate strength increases with the strain rate, but lower than the increase in the yield strength. As a result, the ratio of the ultimate to yield strength decreases with the increase in strain rate.

The increase in yield and ultimate strengths with strain rate increases the load carrying capacity of the structure. However, this does not necessary improve the 
performance of structures in an earthquake. In a seismic design, structural members and details are proportioned to accommodate plastic deformations at the specific locations. However, the plastic deformation may not occur at these designated locations due to the change in the force demand, member strength and connection resistance because of the strain rate sensitivity of the mechanical properties. In 1995 Kobe Earthquake, the moment frames experienced brittle fracture in the weldment, heat affected zone and webs instead of deforming plastically in the designated zones (Kaneko 1997).

In addition to constant strain rate tests, variable strain rate tests have been carried out to investigate the effect of varying the strain rate during the test. Eleiche and Campbell (1976) used a torsional Split Hopkinson Bar to test the strain rate history effect on shear stress of copper, titanium and mild steel. During the test, the applied strain rate jumped from a quasi-static rate of $6 \times 10^{-3} \mathrm{~s}^{-1}$ to a rate of $1200 \mathrm{~s}^{-1}$. Test results of the three metals showed the strain rate history effect is minor. The post-jump flow stress was found to be only slightly greater than that at the same strain in a constant strain rate test. Similar findings were observed by Wilson et al. (1979) in the variable strain rate tests.

Krempl (1979) performed tests that involved both monotonic and cyclic loadings on AISI Type 304 stainless steel, and hot and cold rolled mild steels of similar chemical composition. The strain rate history effect was found to be minimal in both the monotonic tension and cyclic tests. In the cyclic test, the transition from one stabilized hysteresis loop at a strain rate to another rate was found to be fully reversible. 


\subsubsection{Strain Rate Sensitivity of Rupture Strain}

In tests by Campbell and Cooper (1966), the axial rupture strain for mild steel was found to decrease with the increase in strain rate. However, there have been conflicting observations on the strain rate sensitivity of the rupture strain. Hsu and Jones (2004) observed that there was no clear relationship between the elongation at rupture and strain rate for $6063 \mathrm{~T} 6$ aluminum alloy tested at the strain rate range from $5 \times 10^{-4} \mathrm{~s}^{-1}$ to $118 \mathrm{~s}^{-1}$. Kaneko (1997) also found that the reduction in cross-section area for SS400 and SM490 steels tested at the strain rate range of $10^{-4} \mathrm{~s}^{-1}$ to $10 \mathrm{~s}^{-1}$ to be insensitive to strain rate. Kawata et al. (1968) observed that the elongation at rupture to be correlated to the lattice system of the metal. For mild steel (bcc), the elongation was found to decrease with the increase in strain rate for a strain rate greater than $1.0 \mathrm{~s}^{-1}$. However for fcc metals (such as aluminum and aluminum alloy 2024C), the elongation was found to peak at a strain rate of around $100 \mathrm{~s}^{-1}$, and decrease thereafter. Nevertheless, Jones (2001) has proposed an equation to predict the rupture strain for ductile material as

$$
\varepsilon_{d}=\varepsilon_{s}\left(1+\left(\frac{\dot{\varepsilon}}{D}\right)^{\frac{1}{q}}\right)^{-1}
$$

where $\varepsilon_{d}$ and $\varepsilon_{s}$ are the dynamic and static equivalent rupture strains respectively, and $\mathrm{D}$ and $\mathrm{q}$ are material constants.

From quasi-static tests, Bridgman (1944) observed that the rupture strain decreased as the hydrostatic tension or mean stress increased. Alves and Jones (1999) investigated the influence of hydrostatic stress on tensile failure for dynamic loading 
using notch specimens. Calculating the strain based on the change in cross-section area, test results show that strain rate only has a minor influence on the strain at fracture. Nevertheless, the fracture strain was also found to decrease with a higher hydrostatic tension stress.

\subsection{Material Properties and Constitutive Equations}

A number of constitutive equations and empirical equations have been proposed to characterize the strain rate effects on steel. Most of these equations were developed based on the observed trend in the experimental results.

\subsubsection{Mechanical Properties}

Based on the trend of the data, numerous equations have been proposed to predict the material mechanical properties in terms of strain rate. A few of these equations are presented. Wright and Hall (1964) considered effects of loading rate (deformation rate) and temperature on the yield stress. Based on test data of Manjoine (1944), the yield stress for mild steel at the room temperature of $20^{\circ} \mathrm{C}$ was expressed as

$$
\frac{f_{y}}{f_{y s}}=1+2.77 \exp [0.372(\log \dot{\varepsilon}-3.74)] \text { for } 10^{-6}<\dot{\varepsilon}<10^{3}
$$

where $f_{y}$ and $f_{y s}$ are the dynamic and static yield stress respectively.

Nagaraja et al. (1966) conducted tests on specimens of ASTM A36, A 441 and A514 steels to investigate the strain rate effect on the yield stress. An equation to predict 
the dynamic yield stress was proposed as

$$
\frac{f_{y}}{f_{y s}}=1+k(\dot{\varepsilon})^{n} \text { for } 0<\dot{\varepsilon}<1.4 \times 10^{-3}
$$

with $\mathrm{k}$ and $\mathrm{n}$ equal to 0.021 and 0.26 for A36 steel, 0.020 and 0.18 for A441 steel, and 0.023 and 0.08 for A 514 steel.

Soroushian et al. (1987) proposed an engineering stress versus engineering strain relationship for steel based on results of tensile tests on structural steel, reinforcing bar and deformed wire with the yield strength ranging from 179.4 to $683.8 \mathrm{MPa}$ for the strain rate range of $10^{-4} \mathrm{~s}^{-1}$ to $10 \mathrm{~s}^{-1}$. The stress of the steel can be expressed as

$$
f_{s}=\left\{\begin{array}{l}
E \cdot \varepsilon, \quad \text { for } \varepsilon<\frac{f_{y}}{E} \\
f_{y}, \quad \text { for } \frac{f_{y}}{E}<\varepsilon<\varepsilon_{h}^{\prime} \\
f_{y}\left[\frac{112\left(\varepsilon-\varepsilon_{h}^{\prime}\right)+2}{60\left(\varepsilon-\varepsilon_{h}^{\prime}\right)+2}+\frac{\varepsilon-\varepsilon_{h}^{\prime}}{\varepsilon_{u}^{\prime}-\varepsilon_{h}^{\prime}}\left(\frac{f_{u}}{f_{y}}-1.7\right)\right], \text { for } \varepsilon_{h}^{\prime}<\varepsilon<\varepsilon_{u}^{\prime},
\end{array}\right.
$$

in which $\mathrm{f}_{\mathrm{y}}, \mathrm{f}_{\mathrm{u}}, \varepsilon_{h}^{\prime}$ and $\varepsilon_{u}^{\prime}$ can be calculated as

$$
\begin{aligned}
& \frac{f_{y}}{f_{y s}}=1.46-4.51 \times 10^{-7} f_{y s}+\left(0.0927-9.20 \times 10^{-7} f_{y s}\right) \log \dot{\varepsilon} \\
& \frac{f_{u}}{f_{u s}}=1.15-7.71 \times 10^{-7} f_{y s}+\left(0.04969-2.44 \times 10^{-7} f_{y s}\right) \log \dot{\varepsilon} \\
& \frac{\varepsilon_{h}^{\prime}}{\varepsilon_{h}}=4.46-4.21 \times 10^{-5} f_{y s}+\left(0.693-8.41 \times 10^{-6} f_{y s}\right) \log \dot{\varepsilon} \\
& \frac{\varepsilon_{u}^{\prime}}{\varepsilon_{u}}=1.4-8.93 \times 10^{-6} f_{y s}+\left(0.0827-1.79 \times 10^{-6} f_{y s}\right) \log \dot{\varepsilon}
\end{aligned}
$$

where $E$ is the elastic modulus, $f_{u s}$ and $f_{u}$ are the static and dynamic ultimate strengths, 
$\varepsilon_{h}$ and $\varepsilon_{h}^{\prime}$ are the static and dynamic strain hardening initiation strains, $\varepsilon_{u}$ and $\varepsilon_{u}^{\prime}$ are the strains at the static and dynamic ultimate stresses.

Kassar et al. (1992) proposed using a parabolic curve to represent the dynamic yield stress versus logarithmic strain rate relationship of the material. Three set of parameters for the second order polynomial function were obtained for AISI 035XF, 050XF and 100XF steels for the strain rate range of $10^{-4}<\dot{\varepsilon}<10^{0}$. These functions were

$$
\begin{aligned}
& \frac{f_{y}}{f_{y s}}=42.37+3.595 \log \dot{\varepsilon}+0.305(\log \dot{\varepsilon})^{2} \text { for 035XF steel, } \\
& \frac{f_{y}}{f_{y s}}=54.66+1.770 \log \dot{\varepsilon}+0.120(\log \dot{\varepsilon})^{2} \text { for 050XF steel and } \\
& \frac{f_{y}}{f_{y s}}=128.91+1.945 \log \dot{\varepsilon}+0.195(\log \dot{\varepsilon})^{2} \text { for } 100 \mathrm{XF} \text { steel. }
\end{aligned}
$$

\subsubsection{Constitutive Equations}

Cowper and Symonds (1957) studied the effect of impact loading on cantilever beams both analytical and through experiment. The differences found between the analytical and experimental results were attributed to effects of strain hardening and strain rate. Based on the study, a constitutive equation that is widely referred to as the Cowper-Symonds power law equation was proposed. This equation can be expressed as

$$
\dot{\varepsilon}^{p}=D\left(\frac{\sigma_{0}^{\prime}}{\sigma_{0}}-1\right)^{q}
$$

where $\sigma_{0}^{\prime}$ is the dynamic flow stress at the uniaxial plastic strain rate $\dot{\varepsilon}^{p}, \sigma_{0}$ is the associated static flow stress, $D$ and $\mathrm{q}$ are material constants for a specific material 
(usually at room temperature). Equation (2.7) can be rewritten as

$$
f_{P}\left(\dot{\varepsilon}^{p}\right)=\frac{\sigma_{0}^{\prime}}{\sigma_{0}}=1+\left(\frac{\dot{\varepsilon}^{p}}{D}\right)^{\frac{1}{q}}
$$

where $\mathrm{f}_{\mathrm{p}}\left(\dot{\varepsilon}^{p}\right)$ is the ratio of dynamic to static stress at a specific plastic strain. For mild steel, Symonds (1967) suggested that material constants of $D=40.4 \mathrm{~s}^{-1}$ and $\mathrm{q}=5$ may be used if the actual values are not available. For strain-rate insensitive materials, a very high value of $\mathrm{D}$ is adopted.

Jones (1997) extended Eq. (2.8) to a three dimensional stress and strain space, and expressed the equation in terms of equivalent plastic strain and equivalent stress as

$$
\begin{aligned}
& \frac{\sigma_{e q}^{\prime}}{\sigma_{0}}=1+\left(\frac{\dot{\varepsilon}_{e q}}{D}\right)^{\frac{1}{q}} \text { with } \\
& \sigma_{e q}^{\prime}=\sqrt{\frac{3}{2} s_{i j} s_{i j}} \text { and } \\
& \dot{\varepsilon}_{e q}=\sqrt{\frac{2}{3} \dot{\varepsilon}_{i j}^{p} \dot{\varepsilon}_{i j}^{p}}
\end{aligned}
$$

where $\sigma_{e q}^{\prime}$ is the equivalent or effective dynamic flow stress, $\dot{\varepsilon}_{e q}$ is the equivalent or effective plastic strain rate, $\dot{\varepsilon}_{i j}^{p}$ is the time rate of change of the plastic strain tensor and $s_{i j}$ is the stress deviator tensor, which is given by

$$
s_{i j}=\sigma_{i j}-\frac{1}{3} \sigma_{k k} \delta_{i j}
$$

where $\sigma_{i j}$ is the stress tensor and $\delta_{i j}$ is the Kronecker delta.

Jones (2001) suggested that Eq. (2.8) should only be used for up to $2 \%-4 \%$ strain depending on the material. Hashmi (1980) reported that Eq. (2.8) is valid for mild steel up to the strain of $0.2 \%$ and the strain rate of up to $10^{5} \mathrm{~s}^{-1}$. Jones (2001) further modified 
Eq. (2.8) to

$$
f_{J}\left(\dot{\varepsilon}^{p}, \varepsilon^{p}\right)=\frac{\sigma_{0}^{\prime}}{\sigma_{0}}=1+\left(\frac{\dot{\varepsilon}^{p}}{D+B \varepsilon^{p}}\right)^{\frac{1}{q}}
$$

where $\mathrm{f}_{\mathrm{J}}\left(\dot{\varepsilon}^{p}, \varepsilon^{p}\right)$ is the ratio of dynamic to static stress, D, B and $\mathrm{q}$ are material constants. The modification was proposed to reflect on the observed drop in the dynamic to static flow stress ratio as the strain increases.

Lemaitre and Chaboche (1990) have proposed a version of mixed-mode hardening plasticity model where only the isotropic hardening part of the model is a direct function of strain rate, while the backstress for the kinematic hardening is not directly affected. The effect of strain rate can be accounted for with a power law function. Figure 2.1 shows the relationship of the dynamic flow stress, static flow stress and backstress under uniaxial monotonic tension. In Fig. 2.1, $\sigma_{0}^{\prime}$ is the dynamic flow stress, $\sigma_{0}$ denotes the static flow stress, $\alpha$ is the backstress, and $\sigma_{10}^{\prime}$ and $\sigma_{10}$ are dynamic and static true stresses that define the size of the yield surface for isotropic hardening. Using Cowper-Symonds power law as given by Eq. (2.8) to account for the strain rate effect in isotropic hardening, the relationship between the stresses can be expressed as

$$
\begin{aligned}
& \sigma_{0}^{\prime}=\sigma_{10}^{\prime}+\alpha, \\
& \sigma_{10}^{\prime}=\sigma_{10} f_{P}\left(\dot{\varepsilon}^{p}\right) \text { and } \\
& \sigma_{0}=\sigma_{10}+\alpha
\end{aligned}
$$

Under uniaxial condition, the rate of change in backstress is given by

$$
\dot{\alpha}=C \dot{\varepsilon}^{p}-\alpha \gamma \dot{\varepsilon}^{p}
$$


where $\mathrm{C}$ and $\gamma$ are material constants. Integrating Eq. (2.17) for uniaxial monotonic tension condition gives the backstress as

$$
\alpha\left(\varepsilon^{p}\right)=\frac{C}{\gamma}\left(1-e^{-\gamma \varepsilon^{p}}\right)
$$

Combining Eqs. (2.14) and (2.15), the dynamic to static true stress ratio for uniaxial monotonic tension can be expressed as

$$
\begin{aligned}
f_{M}\left(\dot{\varepsilon}, \varepsilon^{p}\right) & =\frac{\sigma_{0}^{\prime}}{\sigma_{0}}=\frac{f_{P} \sigma_{10}+\alpha\left(\varepsilon^{p}\right)}{\sigma_{0}} \text { or } \\
& =\frac{\left[1+\left(\frac{\dot{\varepsilon}}{D}\right)^{\frac{1}{q}}\right] \sigma_{10}+\alpha\left(\varepsilon^{p}\right)}{\sigma_{0}}
\end{aligned}
$$

The Cowper-Symonds power law based equation is considered to be valid up to the intermediate strain rate. At a very high strain rate, the deformation is normally accompanied with the temperature increase that is high enough to affect the mechanical properties of the material. A constitutive equation for the dynamic equivalent flow stress that takes into consideration the effect of temperature has been proposed by Johnson and Cook (1985) as

$$
\sigma_{e q}^{\prime}=\left(a+b \varepsilon_{e q}{ }^{n}\right)\left(1+c \ln \dot{\varepsilon}^{*}\right)\left(1-T^{*_{m}}\right)
$$

where $\sigma_{0}^{\prime}$ is the flow stress, $\varepsilon_{\text {eq }}$ is the equivalent plastic strain, $\dot{\varepsilon}^{*}=\dot{\varepsilon}_{e q} / \dot{\varepsilon}_{0}$ is the dimensionless plastic strain rate for $\dot{\varepsilon}_{0}=1.0 \mathrm{~s}^{-1}$. a, b, c, n, and $\mathrm{m}$ are material constants, $\mathrm{T}^{*}$ is defined as 


$$
T^{*}=\frac{T-T_{\text {room }}}{T_{\text {melt }}-T_{\text {room }}}
$$

where $T$ is the absolute temperature, $T_{\text {room }}$ is the room temperature and $T_{\text {melt }}$ is the melting temperature of the metal. The terms in the first parenthesis of Eq. (2.21) defines the flow stress as a function of strain when $\dot{\varepsilon}^{*}=1.0$ and $\mathrm{T}^{*}=0$. Those in the second parenthesis relate the strain rate to flow stress, while the expressions in the last parenthesis relate the temperature to flow stress.

Numerical studies have also been carried out by Worswick et al. (1995), Uenishi and Teodosiu (2004), Ogawa et al. (2005) and Rohr et al. (2005) to model the effect of strain rate.

\subsection{Material Test for Strain Rate Effect}

There have been many tests conducted to study the dynamic mechanical properties of metals. These tests involved monotonic tension and compression, cyclic and other complex loading sequences, but were predominantly in monotonic tension. A brief of summary of some of these tests is provided below.

Monotonic loading tests in tension or compression at quasi-static to intermediate strain rate are usually conducted in a hydraulic testing machine with the coupon tested at an approximately constant strain rate. The loading rate is normally controlled by using either the axial extensometer or machine stroke. However with the axial extensometer and stroke controls, the actual loading strain rate can be considered to be constant only up 
to the peak load before necking starts and the deformation localizes at the necking region. Some of these tests have already been discussed in Section 2.1. There were also other monotonic uniaxial strain rate tests carried out by Kassar and Yu (1992), Wang et al. (2001), Al-Kharat and Rogers (2007), Peixinho et al. (2002) and Hsu and Jones (2004).

There were fewer experimental studies conducted with dynamic cyclic tests. Benson and Hancock (1974) conducted cyclic tests on 7075-T6 aluminum, 6061-T651 aluminum, brass, copper-beryllium and $4340 \mathrm{E}$ steel. The tests were carried out at a constant strain rate with repeated cycles of loading block consisting of the strain range that varies from zero to a maximum, then back to zero. Strain rate was found to have little effect on the cyclic stress-strain behavior. Another study on the strain rate effect on steels under cyclic loading was carried out by Dusicka et al. (2006). A709M 345W, A709M HPS 485W, BT-HT440C, BT-LP100 and BT-LP225 steels were tested up to 4\% strain at a constant strain rate of either $0.001 \mathrm{~s}^{-1}$ or $0.1 \mathrm{~s}^{-1}$. Comparisons of the results at the two strain rates showed that there is a slight strain rate effect in the first few cycles, but the difference diminished under repeated cyclic loading. The fatigue life was found to be independent of strain rate. On the other hand, Krempl (1979) reported that cyclic response of AISI Type 304 stainless steel to be strain rate dependent. Kang et al. (2005) has also conducted ratcheting experiments to study the time-dependent cyclic characteristics of SS304 stainless steel.

In tests at a strain rate greater than $10^{0} \mathrm{~s}^{-1}$ (Blazynski 1983), the heat generated in an adiabatic condition from the plastic deformation may cause the temperature to increase 
significantly in the specimen. This will affect the mechanical properties measured in a test. For the cyclic test of mild steel, a strain rate smaller than $0.1 \mathrm{~s}^{-1}$ is recommended to avoid overheating the specimen.

Studies on other loading sequences have also been carried out. Gerard and Papirno (1957), Lindholm and Yeakley (1966) and $\mathrm{Ng}$ et al. (1979) investigated the strain rate effect on biaxial stress. Klepaczko (1969), Nicholas and Campbell (1972), and Harding and Huddart (1979), studied the strain rate effect on shear stress, and Rawlings (1963) on pure flexure. Studies on the effect of strain rate in a complex stress state, such as the one in a real steel structure, have been carried out by Rawlings et al. (1970), Wallace and Krawinkler (1989), and Filiatrault and Tremblay (1996), Nakashima et al. (1998), Suita et al. (1998) and Sanchez and Plumier (2000). 


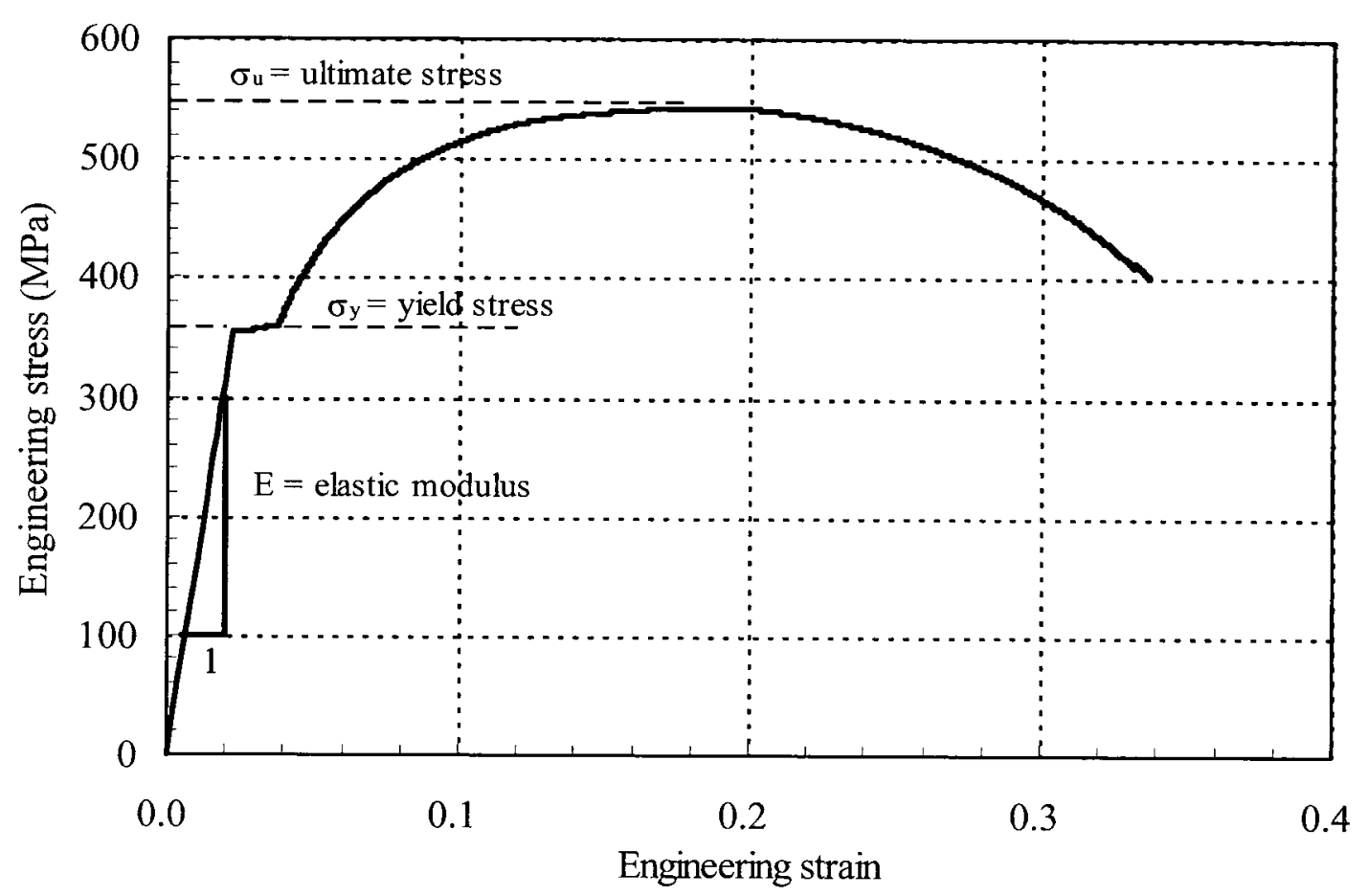

Figure 2.1 Typical engineering stress-engineering strain curve of mild steel

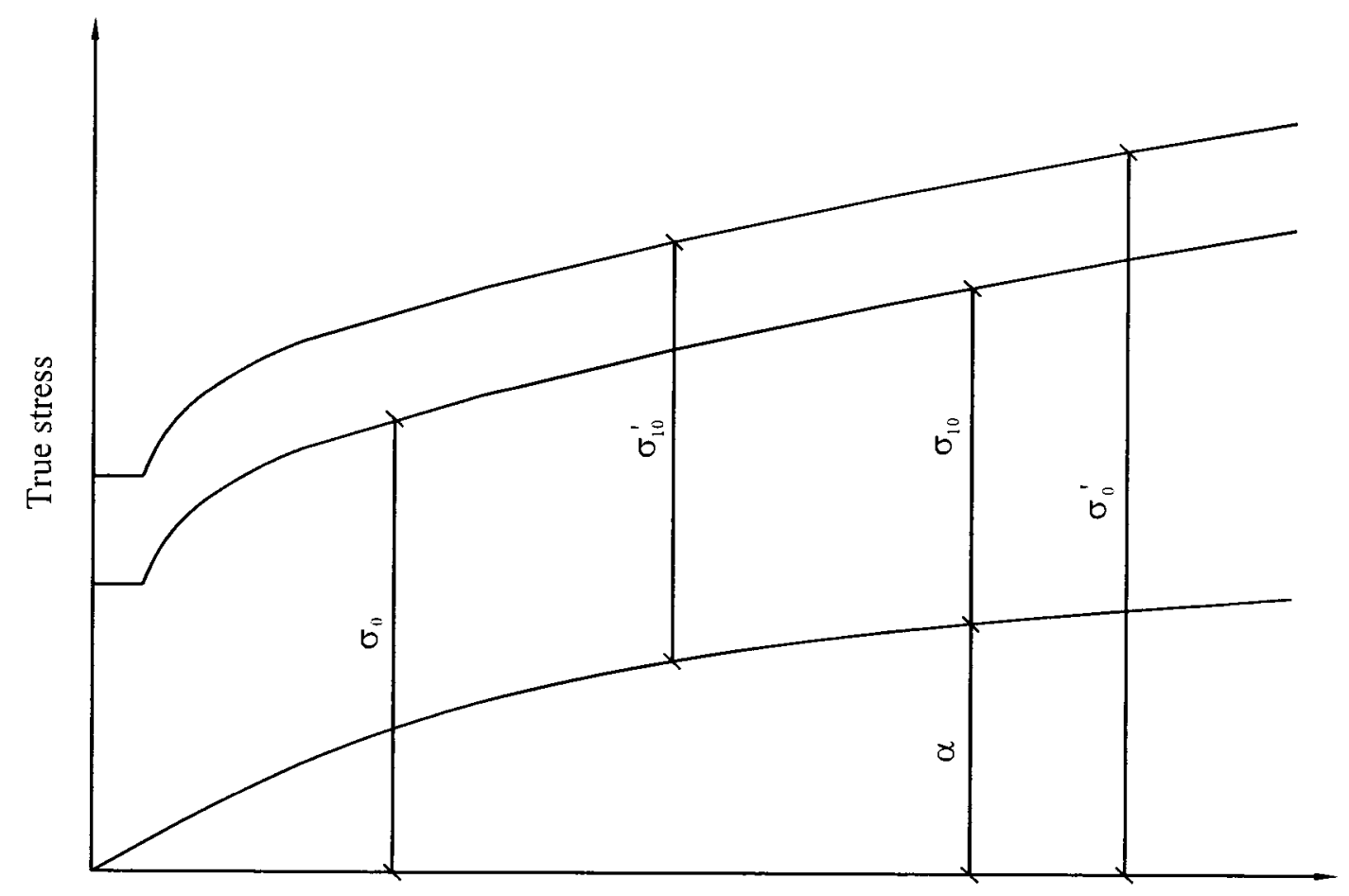

True plastic strain

Figure 2.2 Relationship of the stresses for the mixed-mode hardening model 


\section{Chapter 3 Testing Program}

Manjoine (1944), Marsh and Campbell (1963), and Campbell and Cooper (1966) have tested mild steel for the dynamic mechanical properties under monotonic loading. Since then, other tests have also been conducted. Other than a few studies, most of the monotonic tension tests only measured the engineering stress-engineering strain data. However, the true stress versus true strain relationship of the material is needed in a finite element analysis that involve large strain and large deformation. The direct conversion of engineering stress-engineering strain to true stress-true strain is only valid up to the peak engineering stress, which is normally a strain below 0.2 . However, the true strain at fracture can be as high as 1.0 in a monotonic tension test. Thus, about $80 \%$ of the remaining true stress-true strain relationship from the initiation of necking to fracture cannot be obtained from most of these tests.

For this reason, non-standard tests were developed and carried out in this thesis. These tests were conducted to study the dynamic true stress-true strain curve of steel up to fracture. Details of the specimens and testing procedures are described below.

\subsection{Objective}

The objective of the test program is to demonstrate and validate a test procedure that allows the true stress-true plastic strain curve of a material up to fracture to be determined directly from the test and also to investigate the dynamic mechanical 
properties of mild steel, especially the true stress versus true strain relationship up to fracture. Specimens from different heat and grade of steel were designed and tested, and procedures developed to estimate the true stress versus true strain relationship of the specimen up to fracture.

\subsection{Description of Test Specimens}

Specimens of rectangular and round cross-sectional shapes were tested. The profile of rectangular specimens was fabricated according to ASTM 8E-04 (ASTM 2004). Three non-standard profiles were used for round specimens. The profile of the rectangular specimen is shown in Fig. 3.1, profiles of $9 \mathrm{~mm}$ diameter tapered and non-tapered round specimens are shown in Fig. 3.2, and the profile of $14 \mathrm{~mm}$ diameter non-tapered round specimen is shown in Fig. 3.3. Reasons for using three round specimen profiles instead of one will be explained in later sections. Specimens were machined from flat and round bars of CAN/CSA G40.20/21 Grade 300W (44W) and ASTM A572 Grade $50(345 \mathrm{MPa})$ steels, which have the respective nominal yield strength of $300 \mathrm{MPa}$ and $345 \mathrm{MPa}$.

All rectangular specimens were cut from flat bars as it is more convenient to test and fabricate a rectangular coupon from a thin flat strip. Round specimens were fabricated from $25.4 \mathrm{~mm}(1 ")$ diameter round rods. The round specimens are the main specimen group tested in this study. Materials used and their designation are shown in Table 3.1. All flat bars were CSA Grade 300W except for FB 76x7.9 and FB 127x7.9, 
which were dual graded as $300 \mathrm{~W}$ and $50 \mathrm{~W}(345 \mathrm{MPa})$ steels. The flat bar was either 4.8 $\mathrm{mm}\left(3 / 16^{\prime \prime}\right)$ or $7.9 \mathrm{~mm}\left(5 / 16^{\prime \prime}\right)$ thick. Six flat bar materials were studied. Tests on flat bars were carried out as the material tests for another research that used the same flat bars to study the feasibility of using strap tension-only bracing in a seismic design. For this reason, no other additional flat bar was tested. For the round coupon, the specimens were machined from $25.4 \mathrm{~mm}(1 ")$ diameter rods of CSA Grade 300W (44W) and ASTM A572 Grade $50(345 \mathrm{MPa})$ steels. ASTM A572 Grade 50 can essentially be considered to be similar to CSA 50W (345MPa).

\subsubsection{Specimen Designation}

The following designation is adopted to describe the material, profile, loading rate and loading control for the specimen.

$\alpha \beta \eta E \tau \delta \chi \chi$

a) $\alpha$

The first alphabet represents the material A to $\mathrm{H}$ according to Table 3.1.

b) $\beta$

The second alphabet describes the coupon profile. It is either R, T, N or D for the rectangular, $9 \mathrm{~mm}$ diameter tapered, $9 \mathrm{~mm}$ diameter non-tapered, or $14 \mathrm{~mm}$ diameter non-tapered coupon profile respectively.

c) $\eta E \tau$

This is the nominal loading strain rate defined as $\eta \times 10^{-\top} \mathrm{s}^{-1}$. 
d) $\delta$

This is a lowercase alphabet starting with "a" for the first specimen in a set of specimens that have same material, coupon profile, loading rate and loading control combination. Duplicate specimens are identified alphabetically with " $\mathrm{b}$ " and so on. This parameter is omitted in the specimen identification if there is only one specimen with the material, coupon profile, loading rate and loading control combination.

e) $\chi \chi$

This is either one or two alphabets of $\mathrm{E}, \mathrm{D}$ or $\mathrm{S}$ in accordance to the loading sequence of the tests for the loading control using axial extensometer, diametral extensometer or machine stroke control respectively.

For example, GT1E3ED is a specimen of material $G$ with a tapered profile that is tested at a strain rate of $10^{-3} \mathrm{~s}^{-1}$ under axial extensometer control at the beginning of the test and is switched to diametral extensometer control loading in the middle of the test until the end.

\subsubsection{Rectangular Specimen}

At least six specimens for each material were tested. Two specimens were tested at each strain rate to check for the repeatability of the test results. Thus, each material was tested only at three strain rates of $10^{-4} \mathrm{~s}^{-1}, 10^{-2} \mathrm{~s}^{-1}$ and $0.5 \mathrm{~s}^{-1}$. In addition to the three strain rates, the test at $10^{-4} \mathrm{~s}^{-1}$ strain rate was put on pause for around half a minute at a regular interval to record the static readings and measure the cross-section dimensions. 
All the tests were conducted with axial extensometer strain rate control except for the test at $10^{-4} \mathrm{~s}^{-1}$ strain rate, which was switched from axial extensometer control to stroke control after the peak load. For material type $C$, two additional tests were carried out exclusively under stroke control at the strain rate of $10^{-4} \mathrm{~s}^{-1}$ to compare the effect of loading control used on the static stress. The cross-section dimension measurements are required in estimating the true stress-true strain relationship after the initiation of necking. However, due to the interference of the extensometer, the extensometer was removed when using the micrometer to measure the cross-section once necking started and the loading switched to stroke control. Thickness and width measurements were made using the digital caliper and micrometer at the cross-section edges and between mid-points of the side, shown in Fig. 3.4, after necking has started. The test matrix for the rectangular specimens is shown in Table 3.2 .

\subsubsection{Round Specimen}

Three round specimen profiles shown in Figs. 3.2 and 3.3 were considered in this study. The main profile used in this study is the $9 \mathrm{~mm}$ diameter tapered $(\mathrm{T})$ profile. Only material $\mathrm{H}(345 \mathrm{~W})$ coupons were fabricated with $9 \mathrm{~mm}$ diameter non-tapered $(\mathrm{N})$ profile, and material $\mathrm{G}(300 \mathrm{~W})$ coupons for the $14 \mathrm{~mm}$ diameter non-tapered (D) profile. The $14 \mathrm{~mm}$ diameter non-tapered round coupons for material $\mathrm{G}$ were fabricated for cyclic loading tests in another research program. They were added to provide additional test data for this study. 
The cross-section dimension of the coupon is required in estimating the true stress-true strain relationship after the initiation of necking. This can be measured continuously with a diametral extensometer placed at the narrowest section at the location of necking. A reasonable taper can be machined into the coupon profile to ensure that necking occurs at the designated location to allow for the placement of the diametral extensometer at the right location from the start of the test. There are two factors that influence the profile choice of the taper. First, the reduction in the cross-section area due to the taper is large enough that necking will be guaranteed to occur at the designated location, but not so large that it will change the stress state in the coupon significantly from the uniaxial condition. Second, the magnitude of the cross-section reduction has to be at least a few times larger than the machining accuracy so that the tapered profile can be machined into the specimen. Thus, a taper with a slope profile of $0.5 \%$ that produces a $4 \%$ cross-section area reduction at the mid-length was selected. A shadowgraph was used in locating the section with the minimum diameter for the placement of the diametral extensometer. The region around this section was further smoothened with sandpapers (grit 400 to 1500) to help the extensometer slide to the location of minimum cross-section area during the test when necking occurs. A $9 \mathrm{~mm}$ diameter coupon is about the maximum diameter that can be accommodated based on the limit of the diametral extensometer travel for the expected test coupon cross-section reduction at fracture.

Before necking, the tapered specimen is assumed to behave essentially the same as a non-tapered specimen. Thus, test results from tapered and non-tapered specimens 
will be compared to assess the validity and limitation of the above assumption. The comparisons were primarily carried out between non-tapered and $9 \mathrm{~mm}$ diameter tapered specimens.

Table 3.3 shows the test matrix for round specimens. The range of strain rate from $10^{-5} \mathrm{~s}^{-1}$ to $1.0 \mathrm{~s}^{-1}$ was considered in the test, with $1.0 \mathrm{~s}^{-1}$ being the upper loading rate limit achievable with the testing machine for the specimen size used. Three types of loading control were employed. The test was carried out either with the stroke, axial extensometer or diametral extensometer control alone or in combination. Effects of strain rate and loading control on the static readings were investigated at the strain rates of $10^{-4} \mathrm{~s}^{-1}$ and $10^{-2} \mathrm{~s}^{-1}$. Some of the tests were paused for around half a minute at regular interval to measure the static readings. The cross-section of a non-tapered specimen was measured with a caliper when static readings were taken.

Most of the tapered specimens were loaded using axial extensometer control at the start of the test, but switched to diametral control at the strain of $0.1 . A 10^{-5} \mathrm{~s}^{-1}$ strain rate diametral control test requires around 30 hours to complete, which is about three times the time required for an axial extensometer control test. Due to the length of time required, only axial extensometer control test was carried at a strain rate of $10^{-5} \mathrm{~s}^{-1}$. At a high strain rate, a good loading control cannot be achieved using the diametral extensometer control. Thus, only an axial extensometer control was used in 0.1 and $1.0 \mathrm{~s}^{-1}$ strain rate tests. More detailed discussions on loading rate control are provided in a later section. 


\subsection{Manual Measurement}

Before the test, a caliper was used in measuring both the width and thickness of rectangular specimens, and the diameter of round specimens. The measurement of a tapered specimen was made at the location of the minimum cross-section. During the test when static readings were taken, cross-section dimensions at the necking region of rectangular specimens were also measured with the caliper and micrometer, and the diameter for non-tapered round specimens with the caliper.

\subsection{Tests setup and Instrumentation}

Tests were conducted in a $500 \mathrm{kN}$ capacity MTS 810 Material Testing System. MTS 634.25E-24 $50.8 \mathrm{~mm}(2 ")$ and MTS 634.12E-24 $25.4 \mathrm{~mm}$ (1") extensometers were used to measure the axial strain in the rectangular and round specimens respectively. MTS 632.18E-20 diametral extensometer was used to measure the change of diameter of a round specimen except when it had to be removed to enable the diameters measurement to be made with a caliper in the tests with non-tapered round specimens that take static readings.

The test setup is shown in Fig. 3.5. Running time, stroke displacement, load, and extensometer readings were recorded continuously at a reasonable frequency through the data acquisition system during the test. 


\subsection{Strain Rate Control}

Three types of loading rate controls, designated as stroke control, axial extensometer control and diametral extensometer control according to the source data used in controlling the actuator movement, were used in the testing program. When using extensometer control, the testing machine has to adjust the actuator stoke to achieve the target deformation based on the extensometer readings. Thus, among the three controls, the best control can be achieved with the stroke readings. This is followed by readings from the axial extensometer, and lastly the diametral extensometer. Since the movement in the axial extensometer is more directly related to the actuator stroke than the diametral extensometer, a better control can be achieved with the axial extensometer. Furthermore, the magnitude of the deformation measured by the axial extensometer used in this test program is also larger than that of the diametral extensometer. Thus, the axial extensometer can give a better resolution of the deformation than the diametral extensometer.

Before necking, the deformation is almost uniform within the gauge length of the extensometer. Thus, the engineering strain or the axial extensometer strain can be assumed to be given by

$$
\varepsilon^{e}=\frac{\Delta_{g}}{L_{g}}
$$

where $\Delta_{\mathrm{g}}$ is the extension within the gauge length and $\mathrm{L}_{\mathrm{g}}$ is the gauge length. The true strain is related to engineering strain through 


$$
\varepsilon^{t}=\ln \left(1+\varepsilon^{e}\right)
$$

Assuming no volume change, Eq. (3.2) can be rewritten as

$$
\varepsilon^{t}=\ln \left(\frac{A_{0}}{A}\right)
$$

where $\mathrm{A}_{0}$ is the undeformed cross-section area and $\mathrm{A}$ is the current cross-section area at the section with the minimum cross-section area. Taking the derivative of Eqs. (3.2) and (3.3) with time gives

$$
\begin{aligned}
\dot{\varepsilon}^{t} & =\frac{1}{\left(1+\varepsilon^{e}\right)} \dot{\varepsilon}^{e} \\
& =-\frac{\dot{A}}{A}
\end{aligned}
$$

where the superposed "." represents the time rate of change. So even if a constant axial extensometer strain or $\Delta_{\mathrm{g}}$ extension rate is applied, the true strain rate in fact decreases as the strain increases. For steel, the engineering strain at peak stress is normally below 0.2 . Thus, up to and before necking starts, the difference between $\dot{\varepsilon}^{t}$ and $\dot{\varepsilon}^{e}$ is small, and a constant axial extensometer strain rate can be considered as a constant true strain rate.

After necking starts, any additional deformation will be localized to the necking region, and Eqs. (3.2) and (3.4) are no longer valid. Even though the strain is not uniform over the cross-section, the true strain in an average sense can be approximated with Eqs. (3.3) and (3.5) since these two equations are based on the local deformation. For round coupons, Eqs. (3.3) and (3.5) respectively can be rewritten in terms of the diameters as 


$$
\begin{aligned}
\varepsilon^{t} & =\ln \left(\frac{D_{0}}{D}\right)^{2}=2 \ln \left(\frac{D_{0}}{D}\right) \\
\dot{\varepsilon}^{t} & =-\frac{2 \dot{D}}{D}
\end{aligned}
$$

where $\mathrm{D}$ is the current diameter at the minimum section and $\mathrm{D}_{0}$ is the undeformed diameter. Rearranging Eq. (3.6) gives

$$
\frac{D_{0}}{D}=e^{\frac{\varepsilon^{\prime}}{2}}
$$

The diametral extensometer measures the change in diameter. Taking the reduction in diameter as positive, Eq. (3.8) can be rewritten as

$$
\begin{aligned}
& \frac{D_{0}-\Delta_{D}}{D_{0}}=e^{-\frac{\varepsilon^{i}}{2}} \text { and } \\
& \frac{\Delta_{D}}{D_{0}}=1-e^{-\frac{\varepsilon^{\prime}}{2}}
\end{aligned}
$$

where $\Delta_{D}$ is the reduction in diameter. Equation (3.10) is shown in Fig. 3.6 up to the true strain of 1.0, which is about the maximum true strain at fracture expected for the material being tested. It can be seen in Fig. 3.6 that Eq. (3.10) can be approximated by a linear relationship between $\Delta_{\mathrm{D}} / \mathrm{D}_{0}$ and $\varepsilon^{\mathrm{t}}$, or

$$
\begin{aligned}
& \frac{\Delta_{D}}{D_{0}}=0.3935 \varepsilon^{t} \text { and } \\
& \dot{D}=-0.3935 D_{0} \dot{\varepsilon}^{t}
\end{aligned}
$$

If an applied constant diametral change rate is calculated based on Eq. (3.12) for a target constant strain rate, the actual applied true strain rate calculated according to Eqs. (3.6) and (3.7) are respectively $79 \%$ and $121 \%$ of the target strain rate at the true strains of 0.0 
and 1.0 .

From the preliminary tests, the actual true strain rate at the necking region can be found to be as high as 7 times the applied axial extensometer strain rate. Thus, a better constant strain rate loading can be maintained over the full range of the test with an applied constant diameter change rate. Before necking starts, both constant axial and diametral extensometer rate are comparable. However, the axial extensometers can give a better measurement accuracy of the strain than the diametral extensometer because the magnitude of the change in the extension over the axial extensometer gauge length is larger compared to the change in diameter. Thus, it is more desirable to use axial extensometer control in the test as long as possible up to the peak load. For this reason, in most of the tapered round specimen tests, an axial extensometer control loading rate was employed up to the engineering strain of 0.1 before switching to diametral extensometer control loading rate.

In the test, the following loading rates were applied under various loading controls for the specified nominal strain rate. For the axial extensometer control, the loading rate is the applied engineering strain rate

$$
\dot{\varepsilon}^{e}=\dot{\varepsilon}_{n}
$$

where $\dot{\varepsilon}_{n}$ is the nominal strain rate of the test. For the diametral extensometer control, the loading rate is the change in the diameter rate given by

$$
\dot{D}=-0.3935 D_{0} \dot{\varepsilon}_{n}
$$

When stroke control is used, the applied stroke rate is calculated as 


$$
\dot{L}_{s}=L_{n} \dot{\varepsilon}_{n}
$$

where $L_{u}$ is a length between the gauge length of the extensometer used in the test and the length of the reduced segment of the coupon. 
Table 3.1 Materials in the test and designation

\begin{tabular}{|c|c|c|}
\hline $\begin{array}{l}\text { Material } \\
\text { type }\end{array}$ & Cross-section & Grade \\
\hline A & FB 76x4.8 (3"x3/16") & CSA $300 \mathrm{~W}(44 \mathrm{~W})$ \\
\hline B & FB 76x7.9 (3"x5/16") & $\begin{array}{l}\text { CSA } 300 \mathrm{~W}(44 \mathrm{~W}) \text { and } 50 \mathrm{~W} \\
(345 \mathrm{MPa})\end{array}$ \\
\hline $\mathrm{C}$ & FB $102 \times 7.9(4 " x 5 / 16 ")$ & CSA 300W $(44 \mathrm{~W})$ \\
\hline $\mathrm{D}$ & FB $127 \times 7.9(5 " x 5 / 16 ")$ & $\begin{array}{l}\text { CSA } 300 \mathrm{~W}(44 \mathrm{~W}) \text { and } 50 \mathrm{~W} \\
(345 \mathrm{MPa})\end{array}$ \\
\hline $\mathrm{E}$ & FB $64 \times 4.8\left(2-1 / 2 " x 3 / 16^{\prime \prime}\right)$ & CSA 300W (44W) \\
\hline $\mathrm{F}$ & FB $64 \times 7.9(2-1 / 2 " \times 5 / 16 ")$ & CSA $300 \mathrm{~W}(44 \mathrm{~W})$ \\
\hline $\mathrm{G}$ & Round $25.4 \phi$ & CSA $300 W(44 W)$ \\
\hline $\mathrm{H}$ & Round $25.5 \phi$ & ASTM A572 Grade $50(345 \mathrm{MPa})$ \\
\hline
\end{tabular}

Table 3.2 Test matrix for rectangular specimens

\begin{tabular}{|l|c|c|}
\hline \multicolumn{1}{|c|}{ Specimen } & $\begin{array}{c}\text { Nominal loading rate } \\
\left(\mathrm{s}^{-1}\right)\end{array}$ & Stroke rate $(\mathrm{mm} / \mathrm{s})$ \\
\hline (A-F)R1E4(a-b)ES & $1.00 \mathrm{E}-04$ & 0.00508 \\
\hline CR1E4(a-b)S & $1.00 \mathrm{E}-04$ & 0.00508 \\
\hline (A-F)R1E2(a-b)E & $1.00 \mathrm{E}-02$ & --- \\
\hline (A-F)R5E1(a-b)E & $5.00 \mathrm{E}-01$ & --- \\
\hline
\end{tabular}


Table 3.3 Test matrix for round specimens

\begin{tabular}{|l|c|c|}
\hline \multicolumn{1}{|c|}{ Specimen } & $\begin{array}{c}\text { Nominal } \\
\text { loading rate } \\
\left(\mathrm{s}^{-1}\right)\end{array}$ & $\begin{array}{c}\text { Loading control (E-axial strain rate, D-diameter } \\
\text { change rate, S-stroke displacement rate) }\end{array}$ \\
\hline GT1E5(a-b)E & $1.00 \mathrm{E}-05$ & $\mathrm{E}=0.00001 \mathrm{~mm} / \mathrm{mm} / \mathrm{s}$ \\
\hline GT5E5(a-b)ED & $5.00 \mathrm{E}-05$ & $\mathrm{E}=0.00005 \mathrm{~mm} / \mathrm{mm} / \mathrm{s}, \mathrm{D}=-0.0001735 \mathrm{~mm} / \mathrm{s}$ \\
\hline GT1E4ED & $1.00 \mathrm{E}-04$ & $\mathrm{E}=0.0001 \mathrm{~mm} / \mathrm{mm} / \mathrm{s}, \mathrm{D}=-0.0003471 \mathrm{~mm} / \mathrm{s}$ \\
\hline GT1E4S & $1.00 \mathrm{E}-04$ & $\mathrm{~S}=0.003 \mathrm{~mm} / \mathrm{s}$ \\
\hline GD1E4S & $1.00 \mathrm{E}-04$ & $\mathrm{~S}=0.003 \mathrm{~mm} / \mathrm{s}$ \\
\hline GT1E3ED & $1.00 \mathrm{E}-03$ & $\mathrm{E}=0.001 \mathrm{~mm} / \mathrm{mm} / \mathrm{s}, \mathrm{D}=-0.003471 \mathrm{~mm} / \mathrm{s}$ \\
\hline GT1E2ED & $1.00 \mathrm{E}-02$ & $\mathrm{E}=0.01 \mathrm{~mm} / \mathrm{mm} / \mathrm{s}, \mathrm{D}=-0.03471 \mathrm{~mm} / \mathrm{s}$ \\
\hline GT1E2E & $1.00 \mathrm{E}-02$ & $\mathrm{E}=0.01 \mathrm{~mm} / \mathrm{mm} / \mathrm{s}$ \\
\hline GT1E2D & $1.00 \mathrm{E}-02$ & $\mathrm{D}=-0.03471 \mathrm{~mm} / \mathrm{s}$ \\
\hline GT1E2S & $1.00 \mathrm{E}-02$ & $\mathrm{~S}=0.3 \mathrm{~mm} / \mathrm{s}$ \\
\hline GD1E2S & $1.00 \mathrm{E}-02$ & $\mathrm{~S}=0.3 \mathrm{~mm} / \mathrm{s}$ \\
\hline GT1E1E & $1.00 \mathrm{E}-01$ & $\mathrm{E}=0.1 \mathrm{~mm} / \mathrm{mm} / \mathrm{s}$ \\
\hline GT1E0E & $1.00 \mathrm{E}+00$ & $\mathrm{E}=1.0 \mathrm{~mm} / \mathrm{mm} / \mathrm{s}$ \\
\hline GD1E4S & $1.00 \mathrm{E}-04$ & $\mathrm{~S}=0.003 \mathrm{~mm} / \mathrm{s}$ \\
\hline GD1E2S & $1.00 \mathrm{E}-02$ & $\mathrm{~S}=0.3 \mathrm{~mm} / \mathrm{s}$ \\
\hline HT1E5E & $1.00 \mathrm{E}-05$ & $\mathrm{E}=0.00001 \mathrm{~mm} / \mathrm{mm} / \mathrm{s}$ \\
\hline HT5E5ED & $5.00 \mathrm{E}-05$ & $\mathrm{E}=0.00005 \mathrm{~mm} / \mathrm{mm} / \mathrm{s}, \mathrm{D}=-0.0001735 \mathrm{~mm} / \mathrm{s}$ \\
\hline HT1E4ED & $1.00 \mathrm{E}-04$ & $\mathrm{E}=0.0001 \mathrm{~mm} / \mathrm{mm} / \mathrm{s}, \mathrm{D}=-0.0003471 \mathrm{~mm} / \mathrm{s}$ \\
\hline HT1E4S & $1.00 \mathrm{E}-04$ & $\mathrm{~S}=0.003 \mathrm{~mm} / \mathrm{s}$ \\
\hline HN1E4E & $1.00 \mathrm{E}-04$ & $\mathrm{E}=0.001 \mathrm{~mm} / \mathrm{mm} / \mathrm{s}$ \\
\hline HT1E3ED & $1.00 \mathrm{E}-03$ & $\mathrm{E}=0.001 \mathrm{~mm} / \mathrm{mm} / \mathrm{s}, \mathrm{D}=-0.003471 \mathrm{~mm} / \mathrm{s}$ \\
\hline HT1E2ED & $1.00 \mathrm{E}-02$ & $\mathrm{E}=0.01 \mathrm{~mm} / \mathrm{mm} / \mathrm{s}, \mathrm{D}=-0.03471 \mathrm{~mm} / \mathrm{s}$ \\
\hline HN1E2E & $1.00 \mathrm{E}-02$ & $\mathrm{~mm} / \mathrm{s}$ \\
\hline HT1E1E & $1.00 \mathrm{E}-01$ & $\mathrm{~mm} / \mathrm{mm} / \mathrm{s}$ \\
\hline HT1E0E & $1.00 \mathrm{E}+00$ & \\
\hline
\end{tabular}




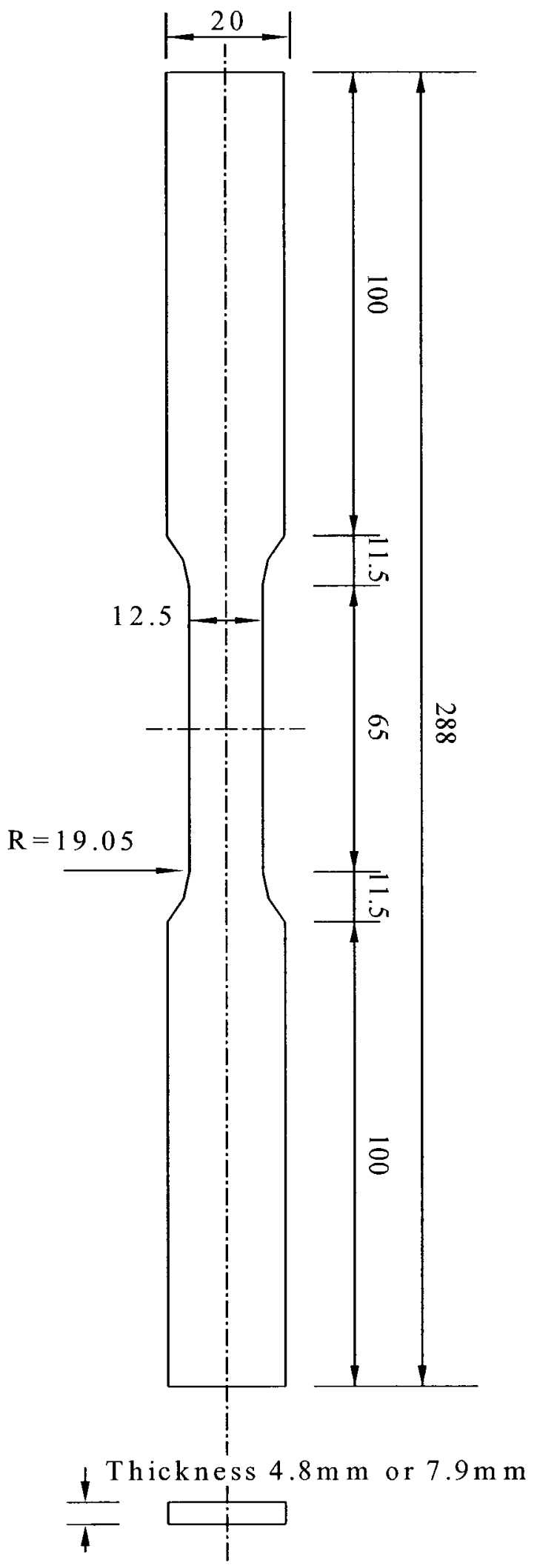

Figure 3.1 Profile of rectangular specimen 

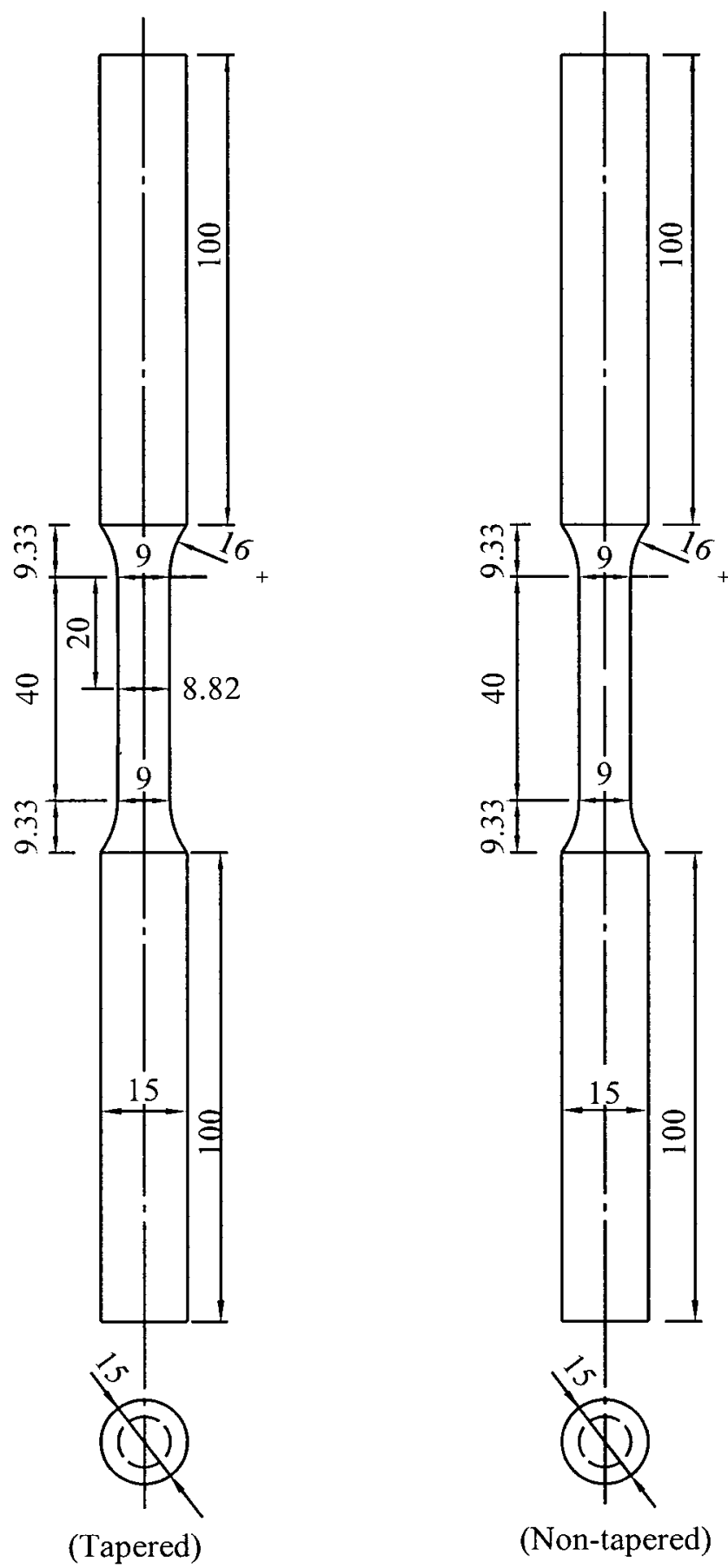

Figure 3.2 Profiles of $9 \mathrm{~mm}$ diameter tapered $(\mathrm{T})$ and non-tapered $(\mathrm{N})$ round specimens 


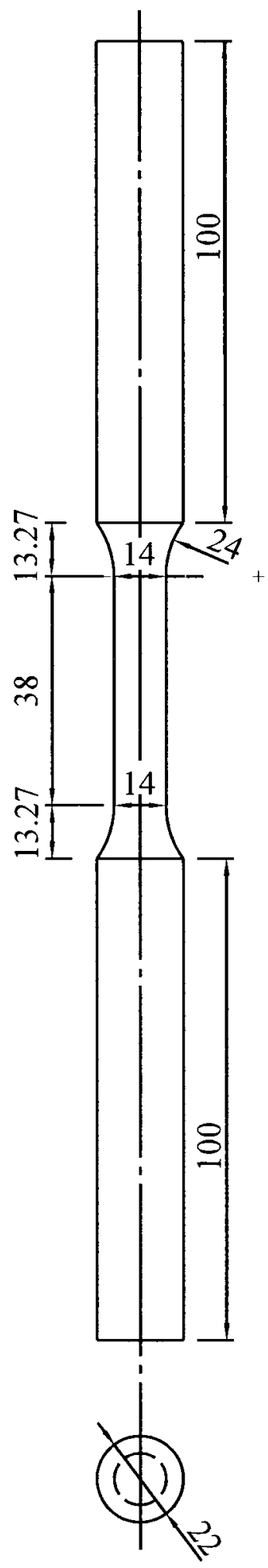

Figure 3.3 Profile of $14 \mathrm{~mm}$ diameter non-tapered (D) round specimen 


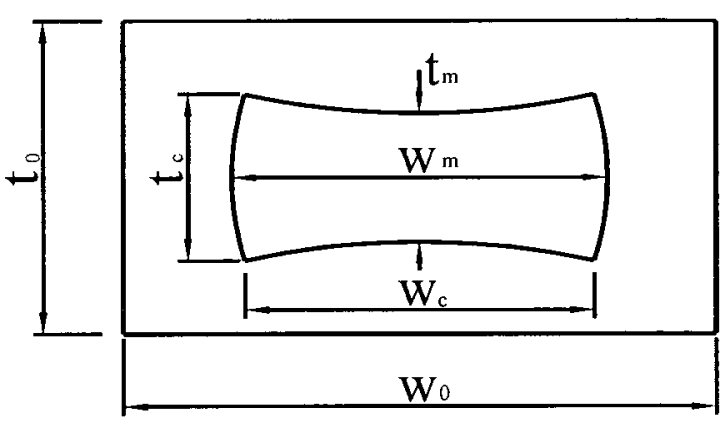

a) $W_{0} / t_{0}>3$

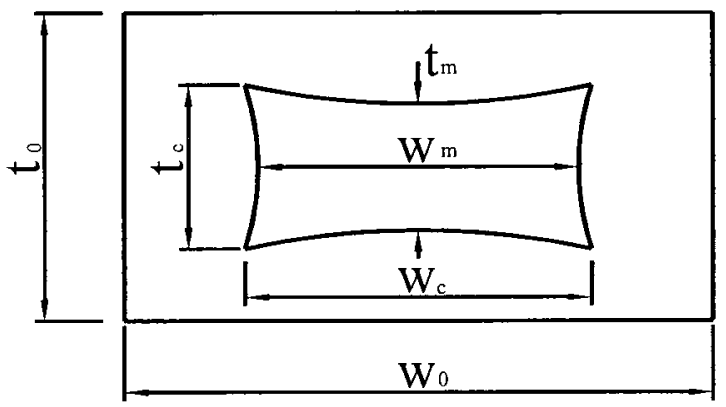

b) $W_{0} / t_{0}$ close to 1

Figure 3.4 Measurement for rectangular specimens after necking 


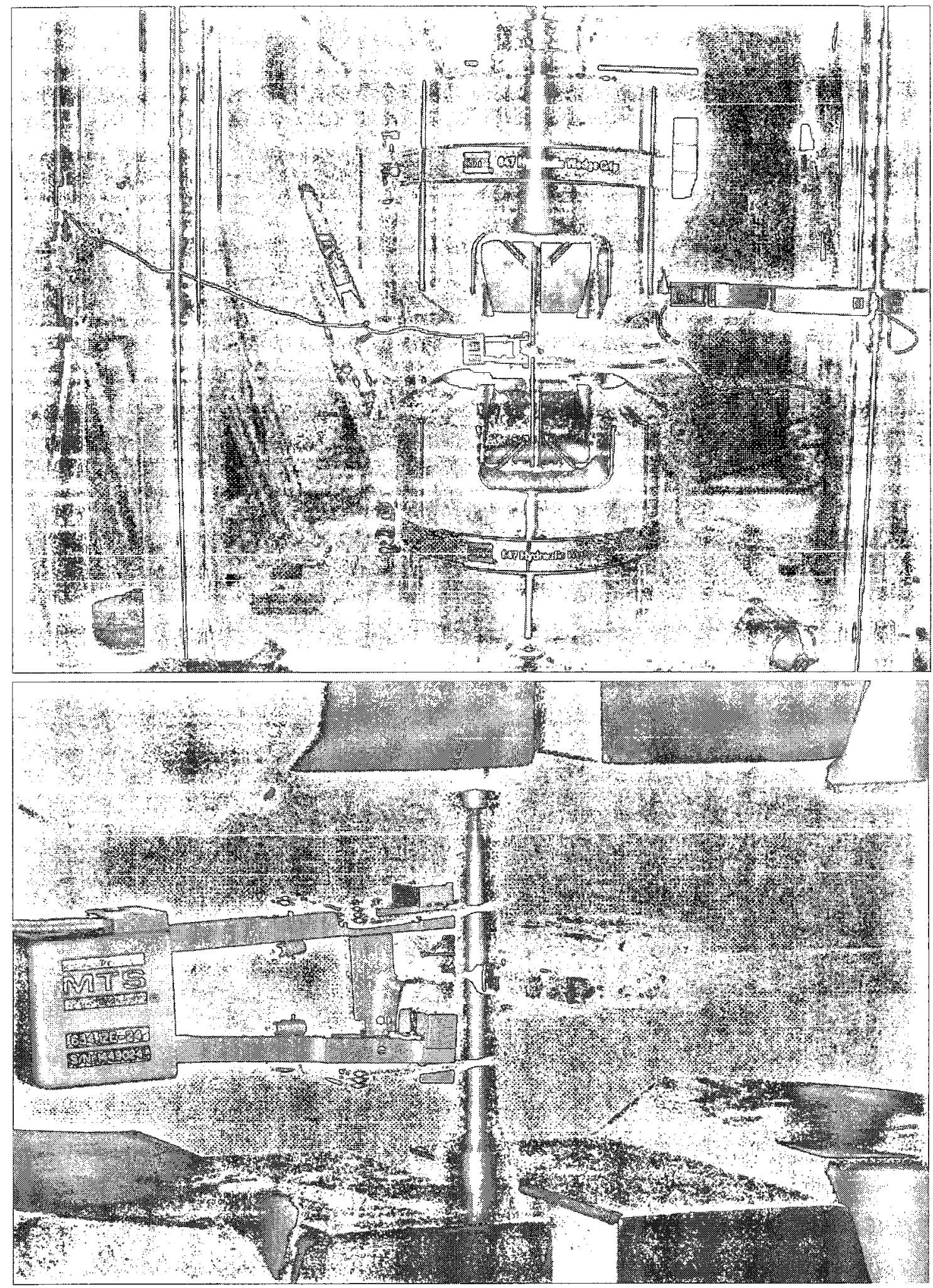

Figure 3.5 Test setup 


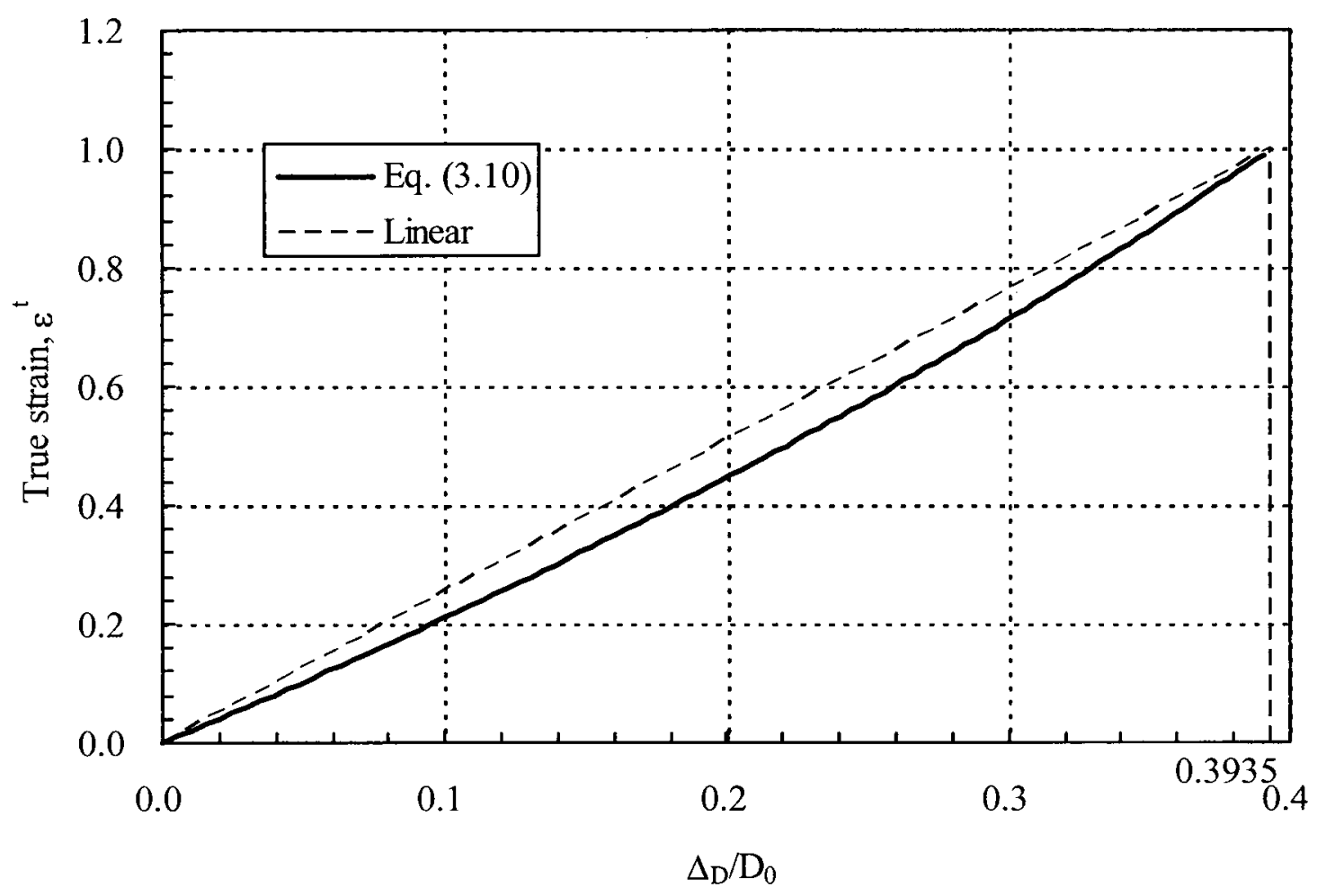

Figure 3.6 Relationship between the diameter change and true strain 


\section{Chapter 4 Test Results and Discussions}

In this chapter, test results of different materials under dynamic tensile loading are analysed and presented. Effects of strain rate and loading control on the engineering stress-engineering strain curve, rupture strain, and true stress-true strain curve of mild steels are discussed. Material constants are calculated for equations to establish and study the relationship between the loading rate and mechanical properties.

\subsection{Results and Analyses of Rectangular Specimen Test}

Dynamic monotonic tensile tests on rectangular specimen tests were conducted mainly using the axial extensometer readings for the loading control. Thus, the true stress-true strain curve up to fracture can be calculated from the test data of the specimen only if the cross-section area after necking is measured during the tests. However, a procedure still has to be established to correct the calculated true stress to account for necking.

\subsubsection{Test Results}

Engineering stress versus engineering strain of all rectangular specimens are shown in Figs. 4.1 to 4.6. Similar to other studies (Manjoine 1944, Campbell and Cooper 1966), the length of yield plateau was observed to increase with the strain rate. In the figures, the spike in the stress shown by the tests at $10^{-4} \mathrm{~s}^{-1}$ is due to the pause in the 
loading when static readings were taken and the cross-sectional dimensions measured. The marker at the bottom of each spike is the static engineering stress, which is the low point of the stress for each instance the testing machine was put on pause. For static readings, a sudden reduction in the drop in stress at the spike can be observed after the strain of 0.2 . The reduction in the drop is associated to a point after the axial extensometer was removed and the loading switched to stroke control. After the removal of the extensometer, the stress-strain curves of the tests at $10^{-4} \mathrm{~s}^{-1}$ were constructed using the engineering strain increment been reconstructed using the stroke increment divided by the gauge length of the extensometer. The difference between the static readings with the axial extensometer and stroke controls is discussed in greater detail in Appendix A.

In most cases, almost the same peak stress was achieved for duplicate specimens except for AR1E4(ab)ES in Fig. 4.1 and CR1E4(ab)ES in Fig. 4.3. There is a noticeable vertical shift in the stress-strain curves of these duplicate specimens. This may be attributed to the present of a slightly larger pre-tension or pre-compression that was not accounted for when the readings were initialized to zero before the start of test.

The engineering yield stress, ultimate stress and elastic modulus at different strain rates are shown in Table 4.1. Two static stresses are presented. The static stress based on the axial extensometer control is identified with (E), and the equivalent static stress using stroke control is identified with (S). The equivalent static stress for stroke control was calculated from the static stress of the test under extensometer control using the procedure outlined in Appendix A. Even though the tests were supposed to be carried out 
at a constant strain rate, the actual loading rate varied. The target and actual strain rates of tests are shown in Table 4.2 for all the rectangular specimens. During the test, the testing machine needed time to ramp up the rate from zero to the target strain rate. For low strain rate tests, the target strain rate can be achieved before yielding. It can be seen in Table 4.2 that the loading control was good throughout the quasi-static test at the strain rate of $10^{-4}$ $\mathrm{s}^{-1}$. However for tests at strain rates of $0.01 \mathrm{~s}^{-1}$ and $0.5 \mathrm{~s}^{-1}$, the actual rate at yielding was lower than the target strain rate. The actual rate for tests at $0.5 \mathrm{~s}^{-1}$ was found to be much lower in proportion to the target rate than the tests at $0.01 \mathrm{~s}^{-1}$. It can be seen in Table 4.2 that both $0.01 \mathrm{~s}^{-1}$ and $0.5 \mathrm{~s}^{-1}$ were able to achieve the target rate at the point of ultimate stress, but the control was better for tests at $0.01 \mathrm{~s}^{-1}$.

\subsubsection{Analyses of Test Results}

Similar to findings from other studies, Table 4.1 shows that the elastic modulus was not affected by strain rate. The calculated ratios of the dynamic engineering yield $\left(\sigma_{\mathrm{y}} / \sigma_{\mathrm{ys}}\right)$ and ultimate $\left(\sigma_{\mathrm{u}} / \sigma_{\mathrm{us}}\right)$ stresses over the corresponding average static stresses are listed in Table 4.3. Taking the average of the strain rate and stress ratios for the duplicate specimens, the yield and ultimate stress ratios are plotted versus logarithm strain rate in Figs. 4.7 and 4.8. It can be seen that the rate of change in both the yield and ultimate stress ratios are not linear but increases with the logarithm of strain rate. Materials A-F also have different strain rate sensitivity in the stresses as there is a considerable scatter in the ratios shown in figures. Nevertheless, all materials have a greater strain rate 
sensitivity in yield than ultimate stress.

Cowper-Symonds power law Eq. (2.8) has been widely used to characterize the effect of strain rate on the flow stress, and particularly the yield stress. Constants in the Eq. (2.8) for the materials tested were determined through a non-linear regression analysis using the actual engineering strain rate at yielding in Table 4.2 , and the static (corrected for stroke control) and dynamic true yield stresses listed in Table 4.1. These constants are shown in Table 4.4 together with the coefficient of determination. Reasons for using the equivalent static stress for a stroke control test instead of the static stress from the axial extensometer control test are provided in Section 4.2 .1 based on the study of static readings under various loading controls. It was found that the static stress from a test under stroke control was independent of strain rate. For this reason, the static stress from the stroke control test is taken as the reference static stress. The engineering strain rate was used instead of the true strain rate as the engineering and true strain rates at yielding are almost the same. Even at peak stress, the engineering strain rate is only slightly higher than the true strain rate, as can be seen in Table 4.2. Comparisons of the test and predicted yield stress ratio using Cowper-Symonds power law Eq. (2.8) are shown in Fig. 4.9. As indicated by the coefficient of determination that is close to unity in Table 4.4, there is also a good agreement shown between the test and predicted yield stress ratio in Fig. 4.9. Thus, Eq. (2.8) is able to describe the strain rate effect on the yield stress. Equation (2.8) is also being plotted in Fig. 4.9 using the suggested constants for mild steel by Symonds (1967) of $D=40.4 \mathrm{~s}^{-1}$ and $\mathrm{q}=5$. It can be seen that Eq. (2.8) 
cannot closely predict the strain rate effect on the yield stress of materials A-F with the suggested constants by Symonds (1967).

One of the objectives in this study is to investigate the effect of strain rate on the rupture strain. Unlike round specimens, no effective method is provided to measure the cross-section dimensions automatically in the dynamic tensile test of rectangular specimens. However, the elongation over the extensometer gauge length can be recorded continuously and the cross-section area of the specimen can be measured after fracture. The engineering strain at fracture has been widely used to define the ductility of a material. It can be defined as

$$
\varepsilon_{e f}=\frac{\Delta L_{f}}{L_{0}}
$$

where $\Delta \mathrm{L}_{\mathrm{f}}$ is the extension over the gauge length at fracture and $\mathrm{L}_{0}$ is the original gauge length. For these tests, the original gauge length of the extensometer $\mathrm{L}_{0}$ is $50.8 \mathrm{~mm}$. For a straight specimen, minor local necking may develop in multiple regions before a dominant one takes over, as can be seen in Fig. 4.10 for AR5E1bE. Thus, the elongation over a gauge length is not an accurate measure of the ductility for a straight coupon. Alternatively, the rupture strain can be calculated based on the cross-section area as

$$
\varepsilon_{r}=\ln \left(\frac{A_{0}}{A_{f}}\right)
$$

where $A_{0}$ is the undeformed cross-section area and $A_{f}$ is the cross-section area at fracture. The cross-section area at fracture can be taken as the product of the average of thickness and width (Fig. 3.4) as 


$$
A_{f}=\frac{1}{4}\left(t_{m f}+t_{e f}\right) \times\left(w_{m f}+w_{e f}\right)
$$

where $t_{m f}$ and $t_{e f}$ are the thicknesses at the mid-point of the side and the edge, and $\mathrm{w}_{\mathrm{mf}}$ and $\mathrm{w}_{\mathrm{ef}}$ are the widths at the mid-point of the side and the edge of the cross-section at fracture. Since the cross-section dimension was not measured continuously in the rectangular specimen tests, the less representative cross-section dimensions that were measured after

the specimen has fractured were used to calculate the rupture strain instead. Results of the engineering strain at fracture and the rupture strain for rectangular specimens are shown in Table 4.5. Taking the average for the duplicate specimens, the engineering strain at fracture and the rupture strain are plotted against the nominal strain rate in Figs. 4.11 and 4.12 respectively. As can be seen in Figs. 4.11 and 4.12, no clear strain rate dependency can be observed for both the engineering strain at fracture and the rupture strain at the strain rate range tested.

\subsubsection{Empirical Equation for True Stress Correction after Necking}

In a tensile test, the stress state in a coupon can be considered as uniaxial before necking. Before necking, the true strain can be taken as

$$
\begin{aligned}
\mathcal{E}^{t} & =\ln \left(1+\mathcal{E}^{e}\right) \quad \text { or } \\
& =\ln \left(\frac{A_{0}}{A}\right) \quad \text { with } \\
\frac{A_{0}}{A} & =1+\varepsilon^{e}
\end{aligned}
$$

where $\varepsilon^{\mathrm{e}}$ is the engineering strain, $\mathrm{A}_{0}$ is the undeformed cross-section area and $A$ is the 
current cross-section area. The true stress is given by

$$
\begin{aligned}
\sigma^{t} & =\frac{P}{A} \text { or } \\
& =\frac{P}{A_{0}}\left(1+\mathcal{E}^{e}\right)
\end{aligned}
$$

where $P$ is the current load. After necking, the average true stress can be calculated as

$$
\sigma_{\text {avg }}^{t}=\frac{P}{A}
$$

where $\mathrm{A}$ is the current minimum cross-section area at the necking region taken for a rectangular coupon as

$$
A=A_{\text {avg }}=\frac{1}{4}\left(t_{m}+t_{e}\right)\left(w_{m}+w_{e}\right)
$$

where $t_{m}$ and $w_{m}$ are the thickness and width at the mid-point of the sides, and $t_{e}$ and $w_{e}$ are the thickness and width at the edge of the cross-section (Fig. 3.4). Thus, taking the cross-section area A to be the average for the rectangular coupon according to Eq. (4.10), Eq. (4.5) can be used to approximate the true strain at the necking region. For the purpose of constructing the true stress-true strain curve after necking, the true strain can be considered to be given by Eq. (4.5) while its corresponding true stress can be calculated from the average true stress in Eq. (4.9) as

$$
\sigma_{c o r}^{t}=\sigma_{a v g}^{t} \times C_{F}
$$

where $\mathrm{C}_{\mathrm{F}}$ is the correction factor. A correction factor was applied to account for the non-uniaxial state of stress due to necking.

Bridgman (1943) proposed a correction factor for a round coupon based on the curvature of the profile and the minimum radius at the necking region as 


$$
\frac{1}{C_{F}}=\left(1+2 \frac{R}{a_{c}}\right) \log \left(1+\frac{1}{2} \frac{a_{c}}{R}\right)
$$

where $\mathrm{C}_{\mathrm{F}}$ is the correction factor, $\mathrm{a}_{\mathrm{c}}$ is the curvature of the profile at the necking region, and $\mathrm{R}$ is the minimum radius. However, the curvature at the necking region is difficult to measure during the test. Instead, a variation of the correction factor by Bridgman (1943) was developed using the cross-section at peak stress in place of the curvature. The new correction factor is assumed to be a function of the current minimum cross-section area to the cross-section area at peak stress ratio. Through finite element analysis simulations of tensile coupon tests with various true stress-true plastic strain curves, the correction factor was established as

$$
C_{F}=0.5 \times\left(1+\sqrt{\left(\frac{A}{A_{0}^{P}}\right)}\right)
$$

and the corrected true stress as

$$
\sigma_{\text {cor }}^{t}=0.5 \sigma_{\text {avg }}^{t} \times\left(1+\sqrt{\left(\frac{A}{A_{0}^{P}}\right)}\right)
$$

where $A_{0}^{P}$ is the cross-section area at peak stress and $\mathrm{A}$ is the current minimum cross-section area modified accordingly with Eq. (4.10) for rectangular coupons. Equation (4.13) was established by fitting a curve through the points of $\sigma_{\text {avg }}^{t} / \sigma^{t}$ versus $\mathrm{A} / A_{0}^{P}$ where $\sigma^{\mathrm{t}}$ is the true stress at the true strain of $\ln \left(\mathrm{A}_{0} / \mathrm{A}\right)$ of the material in the numerical simulation and $\sigma_{a v g}^{t}$ is the average stress from the numerical simulation at the true strain of $\ln \left(\mathrm{A}_{0} / \mathrm{A}\right)$. For rectangular specimens, the cross-section dimensions were only measured for tests at $10^{-4} \mathrm{~s}^{-1}$ strain rate. Thus, the true stress correction can only be 
applied to the average true stress from these tests.

Numerical analyses were carried out with ABAQUS (Simulia 2008) to assess the validity of the proposed correction factor Eq. (4.13) applied to a tensile coupon test. Static readings of the tests were used in the study. In all the analyses, Poisson's ratio is taken as 0.3 and the elastic modulus is taken as $200 \mathrm{GPa}$ since the measured elastic modulus is around $200 \mathrm{GPa}$ for all the specimens. As shown in Fig. 4.13, the coupon was modeled with C3D20R, a three dimensional tri-quadratic isoparametric element with reduced integration, for $1 / 8$ of the specimen. The static true stress-true plastic strain curves for material A before and after the correction with Eq. (4.14) are presented in Fig 4.14. The true plastic strain is taken as

$$
\varepsilon^{p}=\varepsilon^{t}-\frac{\sigma^{t}}{E}
$$

where $\varepsilon^{t}$ is the true strain and $\sigma^{t}$ is the true stress, which is either $\sigma_{a v g}^{t}$ or $\sigma_{\text {cor }}^{t}$ depending on whether the stress correction has been applied. The value of $A_{0}^{P}$ used in the study was calculated from the engineering strain at peak stress $\left(\varepsilon_{p}^{e}\right)$ of the experimental stress-strain curve with Eq. (4.6). Alternatively, $A_{0}^{P}$ can be taken as the measured cross-section area of the specimen outside the region of necking after the completion of the test. Table 4.6 shows values of $A_{0}^{P}$ calculated from the engineering strain at peak stress and the measured cross-section area. It can be seen that there is only a small difference between $A_{0}^{P}$ determined from both methods. Nevertheless, the small difference in $A_{0}^{P}$ will not significantly affect the value of corrected true stress as Eq. 
(4.14) is not very sensitive to changes in $A_{0}^{P}$. As can be seen in Fig. 4.15 , the difference in the corrected true stress-true plastic strain curves for AR1E4bES calculated with two values of $A_{0}^{P}$ based on engineering strains at peak stress $\left(\varepsilon_{P}^{e}\right)$ of 0.16 and 0.19 is small. Engineering strains at peak stress of 0.16 and 0.19 are equal to $\ln \left(\mathrm{A}_{0} / A_{0}^{P}\right)$ or the true strain of 0.148 and 0.174 . The difference in $\ln \left(\mathrm{A}_{0} / A_{0}^{P}\right)$ considered here is larger than the difference between using $A_{0}^{P}$ calculated from $\mathcal{E}_{P}^{e}$ and measured after the test for any of the specimens shown in Table 4.6.

Comparisons of the test and predicted load versus cross-section change for AR1E4(ab)ES are shown in Fig. 4.16. Results of the analysis for AR1E4bES without applying the true stress correction are also presented. The change in cross-sectional area from the tests was calculated using Eq. (4.6) up to the engineering strain of 0.10 . It can be seen that there is a good agreement between the test and predicted stress versus cross-section change curves after the average true stress has been corrected using Eq. (4.14). However without applying the stress correction, there is a significant error in the predicted stress versus deformation curve. Similarly, there is a good agreement between the test and predicted stress versus cross-section change curves for materials B to $\mathrm{F}$ after applying the stress correction. Results of these comparisons and the static true stress-true plastic strain curve before and after the stress correction for materials B to $\mathrm{F}$ are presented in Appendix D. 


\subsubsection{Modeling of Strain Rate Effect on True Stress-True Plastic Strain Curves}

There are a number of equations (models) proposed to account for the effect of strain rate on flow stress. Three of these equations are being evaluated in this study. The predicted true stress-true plastic strain curves generated using Cowper-Symonds power law, modified power law by Jones (2001) and mixed-mode hardening model by Lemaitre and Chaboche (1990) with only the isotropic hardening affected by strain rate are compared to the test results. This is not intended to be a detailed study of the material modeling. Thus, only test results of material $\mathrm{E}$ were used in the study for models by Jones (2001) and Lemaitre and Chaboche (1990). Using constants established in Table 4.4 and the corrected static true stress, the true stress-true plastic strain curves generated with Cowper-Symonds power law Eq. (2.8) are compared to test results for various strain rates in Figs. 4.17 to 4.22 . The true stress-true plastic strain curves at strain rates of $0.01 \mathrm{~s}^{-1}$ and $0.5 \mathrm{~s}^{-1}$ can only be presented up to the point of peak engineering stress because the cross-section dimensions were not measured during the tests at these two loading rates. For clarity, the same true stress-true plastic strain curves in Figs. 4.17 to 4.22 are shown up to the true plastic strain of 0.2 in Figs. 4.23 to 4.28 .

It can be seen in Figs. 4.23 to 4.28 that Cowper-Symonds power law equation significantly over predicts the flow stress at strain rates of $10^{-2} \mathrm{~s}^{-1}$ and $0.5 \mathrm{~s}^{-1}$, while there is a good agreement with the flow stress at $10^{-4} \mathrm{~s}^{-1}$ strain rate for materials $\mathrm{A}, \mathrm{D}, \mathrm{E}$ and $\mathrm{F}$. However, a greater delay in strain hardening (the longer yield plateau length) with the increase strain rate observed in the tests is not replicated with Eq. (2.8). 
Jones (2001) proposed Eq. (2.13) to improve on the Cowper-Symonds power law in predicting the flow stress. Only the parameter B in Eq. (2.13) has to be determined since the other parameters D and $\mathrm{q}$ have already been established in Table 4.4 for the Cowper-Symonds power law equation. Based on the least-square-error fit of the measured true stress at the true plastic strain of 0.14 shown in Table 4.7 , the parameter B for material $\mathrm{E}$ was determined to be 3724 . Comparisons of test and predicted true stress-true plastic strain curves for material $\mathrm{E}$ are shown in Fig. 4.29. Overall, a vastly improved prediction of the flow stress was achieved with the modified power law Eq. (4.13) at the strain rate of $10^{-2} \mathrm{~s}^{-1}$ and $0.5 \mathrm{~s}^{-1}$, but not at the strain rate of $10^{-4} \mathrm{~s}^{-1}$.

Test data for material $\mathrm{E}$ was also used in assessing the true stress-true plastic strain curves generated by the mixed-mode hardening model proposed by Lemaitre and Chaboche (1990). Using similar constants determined for the Cowper-Symonds power law equation in Table 4.4 to account for the strain rate effect on isotropic hardening, the kinematic hardening constants $\mathrm{C}$ and $\gamma$ in Eq. (2.18) were determined through a non-linear regression analysis with the measured true stress at true plastic strains at 0.05 , 0.10 and 0.14 . Table 4.8 shows the test data used in estimating backstress $\alpha$ by the least-square-error fit for the stresses at these three strains. The parameters $C$ and $\gamma$ were determined by fitting Eq. (2.18) through the backstresses at the plastic strains of 0.05 , 0.10 and 0.14 . For material $\mathrm{E}$, the constants were calculated to be $\mathrm{C}=11948$ and $\gamma=32.65$. Comparisons of test and predicted true stress-true plastic strain curves for material $\mathrm{E}$ with the mixed-mode hardening model are shown in Fig. 4.30. The predicted dynamic true 
stress agrees well with the measured stress at strain rates of $0.01 \mathrm{~s}^{-1}$ and $0.5 \mathrm{~s}^{-1}$, but not that well at the strain rate of $10^{-4} \mathrm{~s}^{-1}$.

\subsection{Results and Analyses of Round Specimen Tests}

Material $\mathrm{G}$ and $\mathrm{H}$ were tested at strain rates of $10^{-5} \mathrm{~s}^{-1}, 5 \times 10^{-5} \mathrm{~s}^{-1}, 10^{-4} \mathrm{~s}^{-1}, 10^{-3} \mathrm{~s}^{-1}$, $10^{-2} \mathrm{~s}^{-1}, 10^{-1} \mathrm{~s}^{-1}$ and $1 \mathrm{~s}^{-1}$ under various loading controls. Effects of loading control, strain rate and error in minimum diameter measurement are discussed and presented.

\subsubsection{Test Results}

Engineering stress and engineering strain curves of tapered specimens for materials $\mathrm{G}$ and $\mathrm{H}$ are shown in Figs. 4.31 and 4.32. The engineering stress-engineering strain curves of round specimens show the same strain rate effect as that of the rectangular specimens on the length of yield plateau, the yield and ultimate stresses.

When taking static readings during the test, it was observed that the drop in the stress was higher when the loading was controlled using readings from the diametral extensometer compared to that from the axial extensometer. The difference can be seen in Figs. 4.31 and 4.32 for GT1E4ED and HT1E4ED before and after the strain of 0.1 . Additional tests were also carried out with stroke control to study the effect of loading control on the static readings. It was observed that static stresses at different loading rates for tests with stroke control were almost the same, but the static stresses were lower at a higher loading rate for tests with axial extensometer control. Taking constants D and q, 
and the static yield stress $\sigma_{0}$ as unknowns, the static yield stress determined through a non-linear regression analysis of Eq. (2.8) was found to be closer to the static yield stress from the stroke control test. For these reasons, static stresses from stroke control tests were taken as the reference static stresses and used in all subsequent calculations. A more detailed discussion on the relationship between the loading control and static reading is presented in Appendix A.

For non-tapered specimens, the strain can be considered to be uniform within the gauge length of the axial extensometer up to peak stress. After yielding, the true strain calculated with Eq. (4.4) is almost the same as Eq. (4.5). However, that is not true for tapered specimens. For a tapered specimen, Eq. (4.4) can only be considered to give the average within the gauge length, while Eq. (4.5) is more representative of the actual local deformation at the minimum cross-section. Nevertheless, the difference given by Eq. (4.4) and Eq. (4.5) is still small when the strain is not too large. Figure 4.33 shows the comparison of the true strain calculated with Eqs. (4.4) and Eq. (4.5) for specimen GT1E5aE. It can be seen that the difference between the true strain given by Eqs. (4.4) and (4.5) is very small up to the strain of 0.1. Since the axial extensometer is more accurate than the diametral extensometer in measuring the small initial deformation, the true strain has been calculated with Eq. (4.4) up to the strain of 0.09 and Eq. (4.5) thereafter.

Figures 4.34 and 4.35 present the average true stress versus true strain curves for materials $\mathrm{G}$ and $\mathrm{H}$ respectively. It can be seen in the figures that the diametral 
extensometer was not measuring the minimum diameter for some of the specimens based on the trend of the stress-strain curve shape expected with the increase strain rate, particularly GT1E4ED and HT1E4ED, and possibly GT1E0E. In general, the strain rate has the biggest effect on the average true stress at the initial stage of strain hardening, but the effect seems to diminish at the later stage of deformation, except for specimens tested at the strain rate of $1.0 \mathrm{~s}^{-1}$.

The engineering yield and ultimate stresses, and the elastic modulus for materials $\mathrm{G}$ and $\mathrm{H}$ are shown in Table 4.9. The true stress at first yielding and the ultimate stress calculated with Eq. (4.9) are also listed. The actual strain rates at yield and ultimate stresses and the engineering strain at peak stress for each specimen are listed in Table 4.10. The calculated ratios of dynamic engineering yield and ultimate stresses over the respective stroke control static stresses are listed in Table 4.11 and shown in Fig. 4.36 versus the logarithm of the strain rate. It can be seen that the strain rate has a greater effect on the yield stress of material G, which also has a lower static yield stress compared to material $\mathrm{H}$. This is consistent with other studies where strain rate was found to have a greater effect on the yield stress of mild steel than a high strength steel. Again, the effect of strain rate is also greater on the yield stress than the ultimate stress.

\subsubsection{Discussions of Test Results}

Similar to the rectangular specimens, results in Table 4.9 shows that the elastic modulus was not affected by strain rate. Figures 4.31 to 4.32 also show that the yield and 
ultimate stresses also increase with the increase in the loading strain rate. Using the static true yield stress from the stroke control test, the dynamic yield stress and the actual test strain rate at yielding, the constants for Cowper-Symonds power law Eq. (2.8) were determined through non-linear regression analyses. The calibrated constants for materials $\mathrm{G}$ and $\mathrm{H}$ are listed in Table 4.12 together with the coefficient of determination. Comparisons of the test and predicted yield stress with the Cowper-Symonds power law Eq. (2.8) are shown in Fig. 4.37. There is a good agreement between the test and predicted yield stress shown in Fig. 4.37. This is also indicated by the coefficient of determination that is close to unity in Table 4.12. Equation (2.8) is also being plotted in Fig. 4.37 using the suggested constant for mild steel by Symonds (1967) of $D=40.4 \mathrm{~s}^{-1}$ and $q=5$. It can be seen that Eq. (2.8) cannot closely predict the strain rate effect on the yield stress of materials $G$ and $H$ with the suggested constant by Symonds (1967).

The introduction of a tapered profile to the round specimen enables a consistent engineering strain at fracture to be measured in the test. This can be seen in Appendix B where the engineering strain at fracture for duplicate tests with the same target strain rate is almost the same. The strains at fracture for materials $\mathrm{G}$ and $\mathrm{H}$ are shown in Table 4.13. The engineering strain at fracture is taken as the strain at the point where the large sudden drop of the load occurs. The engineering strain at fracture for materials $\mathrm{G}$ and $\mathrm{H}$ are shown in Fig. 4.38. It can be seen in Fig. 4.38 that there is no clear relationship between the engineering strain at fracture and strain rate for material $\mathrm{H}$ for the range of strain rates considered. On the other hand, the engineering strain at fracture peaks at the strain rate of 
$10^{-3} \mathrm{~s}^{-1}$ for material $\mathrm{G}$. The maximum difference between the engineering strain at fracture is around 0.03 . Thus, the effect of strain rate on the engineering strain at fracture can be considered to be small for materials $\mathrm{G}$ and $\mathrm{H}$ at the strain rate range considered.

Two rupture strains are listed in Table 4.13. The after test rupture strain is based on the diameter measured after the test has completed, which is given by

$$
\varepsilon_{b}=2 \ln \left(\frac{D_{0}}{D_{b}}\right)
$$

where $D_{b}$ is the measured diameter after the specimen has been removed from the testing machine upon the completion of the test and $\mathrm{D}_{0}$ is the original undeformed diameter. If the correct minimum diameter has been measured in the test, a more accurate rupture strain can be calculated based on the measured minimum diameter at the point of fracture where the large sudden drop of the load occurs at the end of the test. Thus, the rupture strain at fracture can be calculated as

$$
\varepsilon_{r}=2 \ln \left(\frac{D_{0}}{D_{r}}\right)
$$

where $D_{r}$ is the measured diameter at fracture by the diametral extensometer at the point where the sudden drop in the load occurs. As can be seen in Figs. 4.34 and 4.35, the diametral extensometer may not have always measured the diameter at the minimum cross-section. Thus, a procedure has been developed to apply a correction to obtain the minimum diameter when the diametral extensometer is not measuring the diameter at the minimum cross-section. The procedure will be discussed in the following section.

Figure 4.39 shows the after test rupture strain $\varepsilon_{\mathrm{b}}$ versus the nominal test strain rate. 
There has no clear relationship between the rupture strain $\varepsilon_{b}$ and strain rate for both materials. When the specimen separated after fracture, there is an additional reduction in the cross-section diameter. Consequently, the rupture strain $\varepsilon_{b}$ calculated based on the diameter measured after the test is not a accurate measure to compare the relative ductility of the specimen.

\subsubsection{Correction for the Minimum Diameter Measured by Diametral Extensometer}

In a conventional tensile test, the axial extensometer strain or the machine stroke is used to control the loading rate in a constant strain rate test. However, the constant strain rate applied through axial extensometer or stroke control can only be maintained up to the peak load. After the initiation of necking, the deformation starts to localize at the necking region. Close to fracture, the real local strain rate can be several times that of the loading strain rate applied based on the axial extensometer strain or machine stroke. Thus when feasible, the loading control through diametral extensometer was used in round specimen tests just before the initiation of necking until fracture.

The strain rate of the test with the loading controlled through the diametral extensometer can be maintained at close to constant up to the strain of 1 , which is around the expected fracture limit of mild steel in a tensile test at normal room temperature and pressure. Even though using tapered specimens with diametral extensometer control can allow for a more constant loading strain rate to be maintained and the diameter at the minimum cross-section to be measured throughout the whole test, there were a few new 
problems encountered during the test associated by using diametral extensometer control. In most tests, the diameter measured is close to be the minimum diameter. However in some tests, the diametral extensometer was set a little off the minimum cross-section point and the surface may also not have been smooth enough to allow the diametral extensometer to slide to the point of minimum cross-section as the specimen necked. As a result, the recorded reading may not be that of the minimum diameter. It follows that the calculated true strain and average true stress with Eq. (4.5) and Eq. (4.7) will also be underestimated.

Duplicated tests GT1E5aE and GT1E5bE were conducted at a strain rate of $10^{-5} \mathrm{~s}^{-1}$ with axial extensometer control. During the test on GT1E5bE, the diametral extensometer was found not to be at the location of the minimum diameter. Consequently, the diametral extensometer was shifted several times during the test towards the point of the minimum diameter. It was feasible to shift the position of the diametral extensometer during the test for GT1E5bE because the loading was controlled entirely by the axial extensometer. The comparison of true strain-engineering strain curve between GT1E5aE and GT1E5bE in Fig. 4.40 shows that the curve of GT1E5bE moves closer towards that of GT1E5aE after every shifting of the diametral extensometer, and eventually meets just before fracture. This implies that for tests conducted at the same strain rate, the true strain versus engineering strain curve will be identical to each other.

It can be observed in Figs. 4.41 and 4.42 that for the same material, the relationship between the true and the engineering strains may either slightly be or not 
affected by the strain rate. Thus, two diameter correction procedures have been proposed, with one procedure based on the assumption that the true strain-engineering strain curve is not affected by strain rate, and the other being that the true strain-engineering strain curve is only slightly affected. Assuming that the strain rate has no effect on the true strain versus engineering strain curve, the uppermost curve in Figs. 4.41 and 4.42 can be considered as being from the test with the most accurate minimum diameter measurement. Thus in the first procedure, the true strain (minimum diameter) of other tests are corrected to match the uppermost curve. For material $\mathrm{G}$, the uppermost curve belongs to GT1E5aE. For material $\mathrm{H}$ in Fig. 4.42, the true strain-engineering strain curves for HT1E5E, HT5E5ED, HT1E1E and HT1E0E are almost identical, and anyone of these can be taken as the uppermost curve.

The second diameter correction procedure assumed that the strain rate has a small effect on the true strain versus engineering strain curve. A test with the inaccurate minimum diameter measurements can be corrected to match the closer of the higher true strain versus engineering strain curve at the next closest strain rate that has a reasonably accurate minimum diameter measurement. The slope of the true strain-engineering strain curve is expected to increase with the engineering strain, but the slope for GT1E4ED and HT1E4ED decreases close to the end of the test before fracture. Based on the curves shown in Figs. 4.41 and 4.42, GT1E4ED and HT1E4ED are the two obvious tests where the measured diameter requires the correction.

In order to carry out the diameter correction, a quadratic function $\mathrm{f}_{\mathrm{D}}$ was used to 
fit through the prototype true strain-engineering strain curve after the start of necking. The corrected true strain for the other tests can then be calculated as

$$
\varepsilon_{c o r}^{t}=\left(\varepsilon_{p k}^{t}-\varepsilon_{p k 0}^{t}\right)+f_{D}\left(\varepsilon^{e}-\varepsilon_{p k}^{e}+\varepsilon_{p k 0}^{e}\right)
$$

where $\varepsilon_{p k 0}^{e}$ and $\varepsilon_{p k 0}^{t}$ are the engineering strain and true strain at the ultimate stress of the prototype curve, $f_{\mathrm{D}}$ is the quadratic function, $\varepsilon^{\mathrm{e}}$ is the engineering strain, and $\varepsilon_{p k}^{e}$ and $\varepsilon_{p k}^{t}$ are the engineering strain and true strain at the ultimate stress of the test where the measured diameter has to be corrected.

Rewriting Eq. (4.5), the true strain can be defined as

$$
\mathcal{E}^{t}=2 \ln \left(\frac{D_{0}}{D}\right)
$$

where $\mathrm{D}_{0}$ is the diameter of undeformed cross-section, $\mathrm{D}$ is the current diameter (taken as the diameter at the minimum cross-section after necking starts), the corrected diameter at the minimum cross-section can be calculated as

$$
\begin{aligned}
& \varepsilon_{c o r}^{t}=2 \ln \left(\frac{D_{0}}{D_{c o r}}\right) \text { or } \\
& D_{c o r}=D_{0} e^{-\left(\frac{\varepsilon_{c o r}^{t}}{2}\right)}
\end{aligned}
$$

where $\varepsilon_{c o r}^{\prime}$ is the corrected true strain calculated with Eq. (4.18) and $\mathrm{D}_{\text {cor }}$ is the corrected diameter at the minimum cross-section.

Figures 4.43 and 4.44 show the quadratic function $f_{D}(x)$ fitted through the true strain-engineering curves of GT1E5aE and HT1E1E. The quadratic function for GT1E5aE was determined to be 


$$
f_{D}(x)=15.061 x^{2}-3.348 x+0.3176
$$

and for HT1E1E, it was determined to be

$$
f_{D}(x)=17.507 x^{2}-3.7726 x+0.3392
$$

For the second procedure, GT5E5ED is chosen as the prototype curve for correcting GT1E4ED, HT1E3ED for HT1E4ED. Figures 4.45 and 4.46 show the quadratic function $f_{D}(x)$ fitted through the true strain-engineering curves of GT5E5ED and HT1E3ED. The quadratic function for GT5E5ED was determined to be

$$
f_{D}(x)=15.856 x^{2}-4.1035 x+0.4155
$$

and for HT1E3ED, was determined to be

$$
f_{D}(x)=13.008 x^{2}-2.2788 x+0.2154
$$

The verification of the diameter correction procedure has been carried out in the following section through numerical simulations.

Even though a correction can be made on the measured diameter, it is not possible to correct for the effect of the wrongly applied loading strain rate due to the error in the diameter reading. However, this effect is not expected to be too big unless the placement of the diametral extensometer is greatly off position.

\subsubsection{Empirical Equation for True Stress Correction after Necking}

The proposed factor for correcting the average true stress to true stress after necking is given by Eq. (4.14). For round specimens, it can be rewritten as 


$$
\sigma_{c o r}^{t}=0.5 \sigma_{a v g}^{t}\left(1+\frac{D}{D_{0}^{P}}\right)
$$

where $D_{0}^{P}$ is the diameter at peak stress. Results of the correction for the hydrostatic tension stress effect non-uniaxial stress state are compared to test results of round specimens through numerical simulations with ABAQUS (SIMULIA 2008). The round specimen was modeled with CAX8R, a bi-quadratic axisymmetric element with reduced integration. Only the segment between the gauge length of the axial extensometer was modeled in order to allow the actual recorded deformation rate of the test to be applied. Figure 4.47 shows the finite element model for one half of the specimen used in the numerical simulation. The numerical simulation was carried out with the built-in strain rate dependent isotropic hardening plasticity material model using Cowper-Symonds power law with the parameters in Table 4.12. In the analysis, the elastic modulus was taken as $200 \mathrm{GPa}$ and Poisson's ratio taken as 0.3 . The loading rate in the simulation was applied exactly according to the recorded axial extensometer readings.

Uncorrected and corrected static true stress-true plastic strain curves with Eq. (4.26) for stroke control test GT1E4S and HT1E4S are shown in Figs 4.48 and 4.49. Numerical simulations were carried out using the uncorrected and corrected static true stress-true plastic strain data. Test and predicted static engineering stress versus change in cross-section area ratio curves are shown in Fig. 4.50 and 4.51 for GT1E4S and HT1E4S respectively. It can be seen that the curve from the numerical simulation using the true stress with the correction agrees well with the test data, but the simulation using the true 
stress without the correction significantly overestimates the stress after the peak.

The static true stress-true plastic strain data of the material are needed as the input in the finite element analysis. Therefore, in order to consider the strain rate effect in the numerical simulation, the static true stress-true plastic strain data used in the finite element analysis were back calculated from the measured true stress versus true plastic strain data using the equation

$$
\sigma_{s i a}^{t}=\sigma_{c o r}^{t} \frac{1}{f_{P}\left(\dot{\varepsilon}_{n}\right)}
$$

where $\sigma_{s t a}^{t}$ is the back calculated static true stress for the input, $\sigma_{c o r}^{t}$ is the dynamic true stress corrected with Eq. (4.26), $\mathrm{f}_{\mathrm{p}}\left(\dot{\mathcal{E}}_{n}\right)$ is the dynamic to static stress ratio calculated with the Cowper-Symonds power law Eq. (2.8) at the nominal strain rate $\dot{\varepsilon}_{n}$ of the test. Since the analysis was carried out using Cowper-Symonds power law based strain rate dependent isotropic hardening plasticity model, this allows the dynamic true stress in the simulation to be close to the measured dynamic true stress at the strain rate $\dot{\varepsilon}_{n}$. Comparisons of the test and predicted engineering stress versus change in cross-section area ratio curves using the static true stress calculated with Eq. (4.27) are shown in Figs. 4.52 to 4.58 for material $\mathrm{G}$ and Figs. 4.59 to 4.65 for material $\mathrm{H}$. It can be seen from Figs. 4.52 to 4.65 that results of the numerical simulations with the correction for non-uniaxial state hydrostatic stress agree with that from the tests except for GT1E4ED and HT1E4ED, which have the obvious incorrect minimum diameter measurements as stated earlier. The difference between the test and predicted curves in Figs. 4.52, 4.59 and 4.64 for GT1E5E, 
HT1E5E and HT1E1E is due to the local strain rate that was actually higher than the nominal strain rate close to the end of the test because these tests were conducted entirely under axial extensometer control. In Figs. 4.56 to 4.58 , and 4.65, the predicted curves stop at a much lower cross-section deformation than the test because the necking process for these specimens in the simulation was slower than in the test. Thus, the extension applied in the numerical simulation was insufficient to induce the same level of cross-section deformation as the test.

Simulations were also carried out for GT1E3ED and HT1E2ED to verify the diameter correction with the first procedure in Section 4.2 .3 where the strain rate is assumed to have no effect on the true strain-engineering strain curve. The uppermost curves GT1E5aE and HT1E1E were chosen as the prototype curves for the diameter correction with the functions ( $\left.f_{D}\right)$ defined in Eqs. (4.22) and (4.23) respectively. In the simulation, the static true stress and true plastic strain data used were back calculated with Eq. (4.27) from the dynamic true stress that has been corrected with Eq. (4.26) for the non-uniaxial state hydrostatic stress. Numerical simulations were carried out with the static true stress versus true plastic strain data calculated from the measured dynamic stress versus true plastic strain data with and without the diameter correction. Comparisons of test and predicted average true stress versus true strain, and engineering stress versus change in cross-section area ratio curves are shown in Figs. 4.66 to 4.69. It can be seen that results of numerical simulations with the uncorrected diameter fit better with the test data, especially for GT1E3ED. This shows that correcting true strain versus 
engineering strain curve to uppermost curve is not appropriate and the true strain-engineering curve cannot be considered to be independent of strain rate.

Simulations were also carried out for GT1E4ED and HT1E4ED to assess the second diameter correction procedure that uses the closer of the higher true strain versus engineering strain curve at the next closest strain rate that has a reasonably accurate minimum diameter measurement as the prototype curve. From comparisons of the test and predicted engineering stress versus change in cross-section area ratio curves in Figs. 4.52 to 4.65 and the shape of the true strain-engineering strain curves in Figs. 4.41 and 4.42, all tests other than GT1E4ED and HT1E4ED appear to have a reasonably accurate minimum diameter measurement. For GT1E2ED, GT1E1E, GT1E0E and HT1E0E, the assessment was based mainly on the shape of the curve in Figs. 4.41 and 4.42 since the predicted engineering stress versus change in cross-section area ratio curves stop at a much lower cross-section deformation compared to the test. Thus, the true strain-engineering strain curves for GT5E5ED and HT1E3ED were chosen as the prototype curves to correct for the minimum diameter measurement for GT1E4ED and HT1E4ED respectively. The quadratic equations used in the correction have been determined in the previous section to be Eqs. (4.24) and (4.25) for GT5E5ED and HT1E3ED. Comparisons of the test and predicted average true stress versus true strain, and engineering stress versus change in cross-section area ratio curves are shown in Figs. 4.70 to 4.73 . There is good agreement between the test and predicted curves using the corrected diameter. This shows that the second procedure that uses the closer of the 
higher true strain versus engineering strain curve of the test at the next closest strain rate can be used to correct the diameter measurement.

Using the second procedure, the diameter was corrected for GT1E4ED and HT1E4ED, and their corresponding diameters and rupture strains at fracture are shown in Table 4.13 (in parenthesis). Figure 4.74 shows the plot of rupture strain at fracture versus the nominal strain rate for materials $\mathrm{G}$ and $\mathrm{H}$. There is no clear relationship that can be established between the rupture strain at fracture and strain rate for these two materials at the strain rate range tested. However, there is a considerable drop in the rupture strain with the strain rate for material $\mathrm{G}$ at the rate greater than $10^{-2} \mathrm{~s}^{-1}$. The rupture strain for material $\mathrm{G}$ at the strain rate of $1.0 \mathrm{~s}^{-1}$ was about $14 \%$ lower than the peak rupture strain.

The average true stress versus true strain curves for materials $\mathrm{G}$ and $\mathrm{H}$ after correcting the diameter for GT1E4ED and HT1E4ED are shown in Figs. 4.75 and 4.76. Similar curves after correction for the non-uniaxial hydrostatic stress are shown in Figs. 4.77 and 4.78 . It can be seen that the effect of strain rate on the flow stress for the strain rate range considered is only significant up to around strain of 0.4 , after which the flow stress tends to converge at the true plastic strain close to fracture except for GT1E0E, which has the nominal loading strain rate of $1 \mathrm{~s}^{-1}$. For GT1E0E, the true stress at close to fracture is significantly lower than other tests. This may be caused by the temperature increase in the specimen due to the higher rate of heat released for the test at the strain rate of $1.0 \mathrm{~s}^{-1}$. The flow stress of steel normally reduces with the increase in temperature. 


\subsubsection{Modeling of Strain Rate Effect on True Stress-True Plastic Strain Curves}

Figure 4.79 to 4.82 show the test and predicted true stress versus true plastic strain curves generated with Cowper-Symonds power law Eq. (2.8) using constants in Table 4.12. The static true stress versus true plastic strain curve of stroke control test with Eq. (4.26) correction for non-uniaxial hydrostatic tension was used. It can be seen that there is reasonably good agreement between test and predicted curves up to the strain rate of $10^{-3} \mathrm{~s}^{-1}$. However, Eq. (2.8) significantly over predicts the flow stress at the strain rate of $10^{-2} \mathrm{~s}^{-1}$ and higher. In addition, the predicted flow stress for different strain rates also does not converge at the true plastic strain close to fracture.

Since this is not intended to be a detailed study of the material modeling, only test data for material $\mathrm{H}$ were used in assessing the true stress-true plastic strain curves generated by the modified Cowper-Symonds power law Eq. (2.13) by Jones (2001) and mixed-mode hardening model by Lemaitre and Chaboche (1990). Similar to rectangular specimens, only the parameter B in Eq. (2.13) by Jones (2001) has to be determined since the other parameters $\mathrm{D}$ and $\mathrm{q}$ have already been established in Table 4.12 for the Cowper-Symonds power law equation. Based on the least-square-error fit of the measured true stress at true plastic strains of 0.15 and 0.6 shown in Table 4.14 , the parameter $\mathrm{B}$ for material $\mathrm{H}$ was determined to be 36305 . Comparisons of test and predicted true stress-true plastic strain curves for material $\mathrm{H}$ are shown in Figs. 4.83 and 4.84. Overall, a much better flow stress prediction was achieved with Eq. (2.13) than Eq. (2.8), especially at the strain rate of $10^{-2} \mathrm{~s}^{-1}$ and higher. 
Using similar constants determined for the Cowper-Symonds power law equation in Table 4.12 to account for the strain rate effect on isotropic hardening, the kinematic hardening constants $\mathrm{C}$ and $\gamma$ in Eq. (2.18) for mixed-mode hardening model by Lemaitre and Chaboche (1990) were determined through a non-linear regression analysis with measured true stress at true plastic strains of $0.05,0.09,0.15,0.30$ and 0.60 . Table 4.15 shows the test data used in estimating the backstress $\alpha$ by least-square-error fit for the stresses at these five true plastic strains. For material $\mathrm{H}$, the constants $\mathrm{C}$ and $\gamma$ were determined by fitting Eq. (2.18) through the backstresses at the plastic strains of $0.05,0.09,0.15,0.30$ and 0.60 . For material $\mathrm{H}$, the constants were calculated to be $\mathrm{C}=1856.0$ and $\gamma=1.93$. Comparisons of test and predicted true stress-true plastic strain curves for material $\mathrm{E}$ with the mixed-mode hardening model are shown in Figs. 4.85 and 4.86. It can be seen in Fig. 4.85 that the predicted dynamic true stress agrees really well with the measured stress at the true plastic strain larger than 0.2. However, the predicted dynamic true stress is slightly overestimated at the true plastic strain lower than 0.2 , as can be seen in Fig. 4.86. Nevertheless as a whole, it can be said that there is good agreement between the test and predicted curves with the mixed-mode hardening model. Based on the comparisons of the test and predicted true stress-true plastic strain curves for the three models investigated, the best predicted true stress-true plastic strain curves were generated with the mixed-mode hardening model by Lemaitre and Chaboche (1990). 
Table 4.1 Yield stress, ultimate stress and elastic modulus for materials A-F

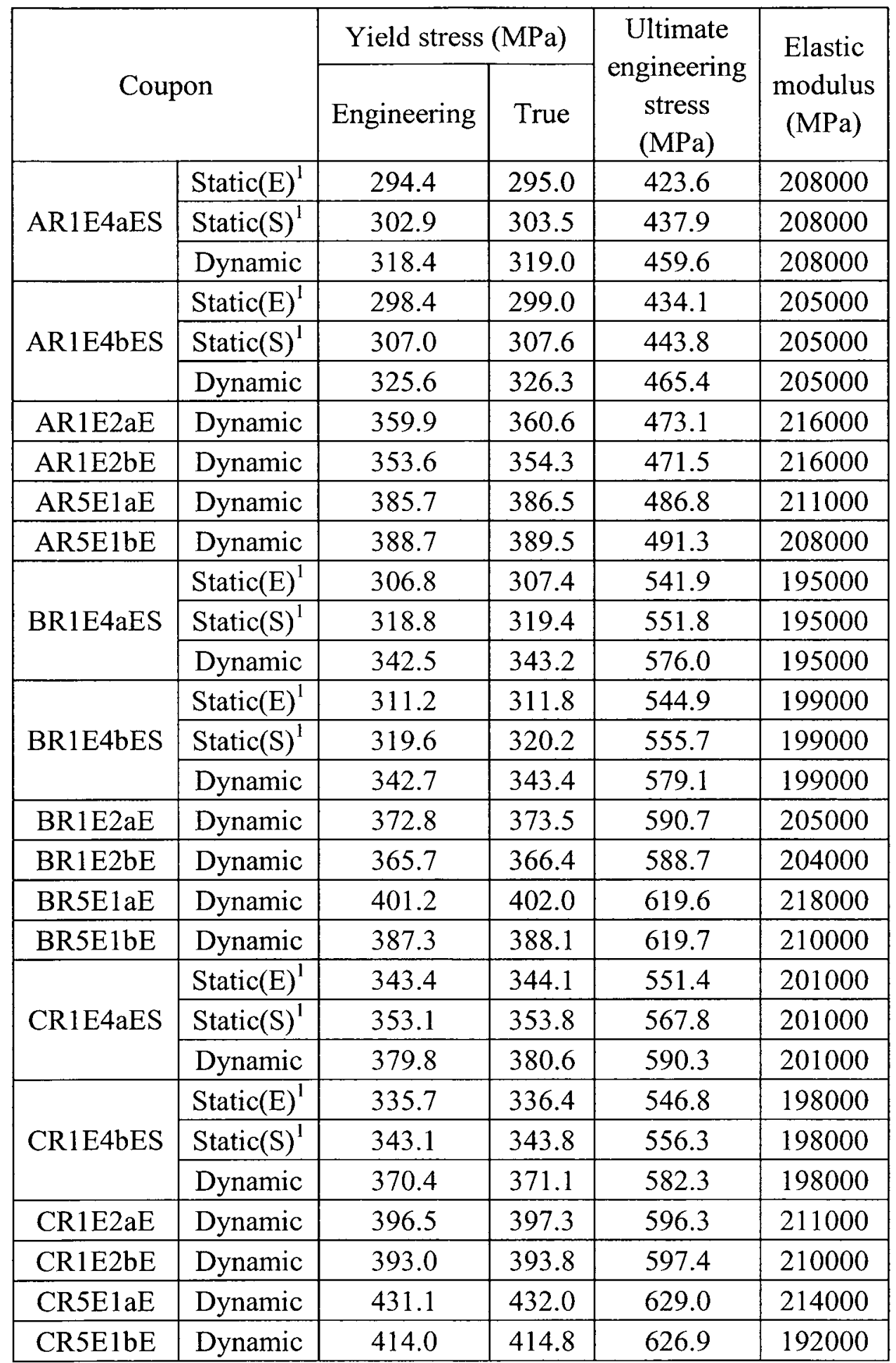


Table $4.1 \quad$ (continued)

\begin{tabular}{|c|c|c|c|c|c|}
\hline \multirow{2}{*}{\multicolumn{2}{|c|}{ Coupon }} & \multicolumn{2}{|c|}{ Yield stress $(\mathrm{MPa})$} & \multirow{3}{*}{$\begin{array}{c}\text { Ultimate } \\
\text { engineering } \\
\text { stress } \\
(\mathrm{MPa}) \\
484.4\end{array}$} & \multirow{3}{*}{$\begin{array}{c}\begin{array}{c}\text { Elastic } \\
\text { modulus } \\
(\mathrm{MPa})\end{array} \\
194000\end{array}$} \\
\hline & & \multirow{2}{*}{$\begin{array}{c}\text { Engineering } \\
321.2 \\
\end{array}$} & \multirow{2}{*}{$\begin{array}{l}\text { True } \\
321.8\end{array}$} & & \\
\hline \multirow{3}{*}{ DR1E4aES } & Static $(E)^{1}$ & & & & \\
\hline & Static(S) & 329.6 & 330.3 & 493.0 & 194000 \\
\hline & Dynamic & 346.3 & 347.0 & 518.1 & 194000 \\
\hline \multirow{3}{*}{ DR1E4bES } & Static(E) ${ }^{1}$ & 322.7 & 323.3 & 483.6 & 200000 \\
\hline & Static(S) ${ }^{1}$ & 327.4 & 328.1 & 495.4 & 200000 \\
\hline & Dynamic & 345.4 & 346.1 & 518.6 & 200000 \\
\hline DR1E2aE & Dynamic & 358.7 & 359.4 & 522.7 & 218000 \\
\hline DR1E2bE & Dynamic & 364.7 & 365.4 & 525.7 & 215000 \\
\hline DR5E1aE & Dynamic & 411.3 & 412.1 & 553.5 & 215000 \\
\hline DR5E1bE & Dynamic & 406.1 & 406.9 & 552.0 & 207000 \\
\hline \multirow{3}{*}{ ER1E4aES } & Static(E) ${ }^{1}$ & 330.8 & 331.5 & 479.0 & 217000 \\
\hline & Static(S) ${ }^{1}$ & 339.4 & 340.1 & 492.4 & 217000 \\
\hline & Dynamic & 351.3 & 352.0 & 514.4 & 217000 \\
\hline \multirow{3}{*}{ ER1E4bES } & Static(E) ${ }^{1}$ & 328.8 & 329.5 & 477.6 & 228000 \\
\hline & Static(S) & 335.7 & 336.4 & 489.0 & 228000 \\
\hline & Dynamic & 351.7 & 352.4 & 517.1 & 228000 \\
\hline ER1E2aE & Dynamic & 371.7 & 372.4 & 521.3 & 207000 \\
\hline ER1E2bE & Dynamic & 375.2 & 376.0 & 521.8 & 203000 \\
\hline ER5E1aE & Dynamic & 417.8 & 418.6 & 546.9 & 213000 \\
\hline ER5E1bE & Dynamic & 418.5 & 419.3 & 548.9 & 209000 \\
\hline \multirow{3}{*}{ FR1E4aES } & Static(E) ${ }^{1}$ & 315.5 & 316.1 & 483.8 & 212000 \\
\hline & Static(S) & 323.6 & 324.2 & 496.1 & 212000 \\
\hline & Dynamic & 337.6 & 338.3 & 517.0 & 212000 \\
\hline \multirow{3}{*}{ FR1E4bES } & Static(E) ${ }^{1}$ & 316.7 & 317.3 & 485.7 & 213000 \\
\hline & Static(S) & 326.8 & 327.5 & 498.6 & 213000 \\
\hline & Dynamic & 342.2 & 342.9 & 520.2 & 213000 \\
\hline FR1E2aE & Dynamic & 364.6 & 365.3 & 527.2 & 217000 \\
\hline FR1E2bE & Dynamic & 361.7 & 362.4 & 528.3 & 216000 \\
\hline FR5E1aE & Dynamic & 407.4 & 408.2 & 554.2 & 213000 \\
\hline FR5E1bE & Dynamic & 407.2 & 408.0 & 556.4 & 210000 \\
\hline
\end{tabular}

Notes:

1 Static (E) denotes static stress with axial extensometer control, Static (S) denotes equivalent static stress with stroke control. 
Table 4.2 Strain rate in rectangular specimen tests

\begin{tabular}{|l|c|c|c|c|c|}
\hline \multirow{2}{*}{ Specimen } & \multirow{2}{*}{ Target } & Engineering strain rate $\mathrm{s}^{-1}$ ) & \multirow{2}{*}{\begin{tabular}{c} 
Actual rate at stress point \\
\cline { 3 - 4 }
\end{tabular}} & $\begin{array}{c}\text { True strain } \\
\text { rate at peak } \\
\text { stress }\end{array}$ & $\begin{array}{c}\text { Engineering } \\
\text { strain at } \\
\text { peak stress } \\
\varepsilon_{p}^{e}\end{array}$ \\
\hline AR1E4aES & $1.00 \mathrm{E}-04$ & $1.00 \mathrm{E}-04$ & $1.00 \mathrm{E}-04$ & $8.26 \mathrm{E}-05$ & 0.211 \\
\hline AR1E4bES & $1.00 \mathrm{E}-04$ & $1.00 \mathrm{E}-04$ & $1.00 \mathrm{E}-04$ & $8.20 \mathrm{E}-05$ & 0.220 \\
\hline AR1E2aE & $1.00 \mathrm{E}-02$ & $6.00 \mathrm{E}-03$ & $1.00 \mathrm{E}-02$ & $8.48 \mathrm{E}-03$ & 0.179 \\
\hline AR1E2bE & $1.00 \mathrm{E}-02$ & $6.00 \mathrm{E}-03$ & $1.00 \mathrm{E}-02$ & $8.39 \mathrm{E}-03$ & 0.191 \\
\hline AR5E1aE & $5.00 \mathrm{E}-01$ & $1.00 \mathrm{E}-01$ & $5.32 \mathrm{E}-01$ & $4.45 \mathrm{E}-01$ & 0.194 \\
\hline AR5E1bE & $5.00 \mathrm{E}-01$ & $1.00 \mathrm{E}-01$ & $5.29 \mathrm{E}-01$ & $4.43 \mathrm{E}-01$ & 0.194 \\
\hline BR1E4aES & $1.00 \mathrm{E}-04$ & $1.00 \mathrm{E}-04$ & $1.00 \mathrm{E}-04$ & $8.54 \mathrm{E}-05$ & 0.171 \\
\hline BR1E4bES & $1.00 \mathrm{E}-04$ & $1.00 \mathrm{E}-04$ & $1.00 \mathrm{E}-04$ & $8.68 \mathrm{E}-05$ & 0.152 \\
\hline BR1E2aE & $1.00 \mathrm{E}-02$ & $7.00 \mathrm{E}-03$ & $1.00 \mathrm{E}-02$ & $8.73 \mathrm{E}-03$ & 0.145 \\
\hline BR1E2bE & $1.00 \mathrm{E}-02$ & $8.00 \mathrm{E}-03$ & $1.00 \mathrm{E}-02$ & $8.74 \mathrm{E}-03$ & 0.144 \\
\hline BR5E1aE & $5.00 \mathrm{E}-01$ & $1.00 \mathrm{E}-01$ & $5.41 \mathrm{E}-01$ & $4.72 \mathrm{E}-01$ & 0.145 \\
\hline BR5E1bE & $5.00 \mathrm{E}-01$ & $1.10 \mathrm{E}-01$ & $5.33 \mathrm{E}-01$ & $4.66 \mathrm{E}-01$ & 0.145 \\
\hline CR1E4aES & $1.00 \mathrm{E}-04$ & $1.00 \mathrm{E}-04$ & $1.00 \mathrm{E}-04$ & $8.69 \mathrm{E}-05$ & 0.151 \\
\hline CR1E4bES & $1.00 \mathrm{E}-04$ & $1.00 \mathrm{E}-04$ & $1.00 \mathrm{E}-04$ & $8.69 \mathrm{E}-05$ & 0.151 \\
\hline CR1E2aE & $1.00 \mathrm{E}-02$ & $7.00 \mathrm{E}-03$ & $1.00 \mathrm{E}-02$ & $8.77 \mathrm{E}-03$ & 0.140 \\
\hline CR1E2bE & $1.00 \mathrm{E}-02$ & $7.00 \mathrm{E}-03$ & $1.00 \mathrm{E}-02$ & $8.83 \mathrm{E}-03$ & 0.132 \\
\hline CR5E1aE & $5.00 \mathrm{E}-01$ & $9.00 \mathrm{E}-02$ & $5.38 \mathrm{E}-01$ & $4.73 \mathrm{E}-01$ & 0.138 \\
\hline CR5E1bE & $5.00 \mathrm{E}-01$ & $1.00 \mathrm{E}-01$ & $5.32 \mathrm{E}-01$ & $4.64 \mathrm{E}-01$ & 0.147 \\
\hline DR1E4aES & $1.00 \mathrm{E}-04$ & $1.00 \mathrm{E}-04$ & $1.00 \mathrm{E}-04$ & $8.36 \mathrm{E}-05$ & 0.196 \\
\hline DR1E4bES & $1.00 \mathrm{E}-04$ & $1.00 \mathrm{E}-04$ & $1.00 \mathrm{E}-04$ & $8.51 \mathrm{E}-05$ & 0.176 \\
\hline DR1E2aE & $1.00 \mathrm{E}-02$ & $6.50 \mathrm{E}-03$ & $1.00 \mathrm{E}-02$ & $8.66 \mathrm{E}-03$ & 0.154 \\
\hline DR1E2bE & $1.00 \mathrm{E}-02$ & $6.40 \mathrm{E}-03$ & $1.00 \mathrm{E}-02$ & $8.67 \mathrm{E}-03$ & 0.153 \\
\hline DR5E1aE & $5.00 \mathrm{E}-01$ & $9.27 \mathrm{E}-02$ & $5.19 \mathrm{E}-01$ & $4.47 \mathrm{E}-01$ & 0.161 \\
\hline DR5E1bE & $5.00 \mathrm{E}-01$ & $9.72 \mathrm{E}-02$ & $5.29 \mathrm{E}-01$ & $4.53 \mathrm{E}-01$ & 0.169 \\
\hline
\end{tabular}


Table 4.2 (continued)

\begin{tabular}{|c|c|c|c|c|c|}
\hline \multirow{3}{*}{ Specimen } & \multicolumn{3}{|c|}{ Engineering strain rate $\left(\mathrm{s}^{-1}\right)$} & \multirow{3}{*}{$\begin{array}{l}\text { True strain } \\
\text { rate at peak } \\
\text { stress }\end{array}$} & \multirow{3}{*}{$\begin{array}{c}\text { Engineering } \\
\text { strain at } \\
\text { peak stress }\end{array}$} \\
\hline & \multirow{2}{*}{ Target } & \multicolumn{2}{|c|}{ Actual rate at stress point } & & \\
\hline & & Yield & Ultimate & & \\
\hline ER1E4aES & 1.00E-04 & $1.00 \mathrm{E}-04$ & $1.00 \mathrm{E}-04$ & 8.33E-05 & 0.201 \\
\hline ER1E4bES & $1.00 \mathrm{E}-04$ & $1.00 \mathrm{E}-04$ & $1.00 \mathrm{E}-04$ & $8.40 E-05$ & 0.191 \\
\hline ER1E2aE & $1.00 \mathrm{E}-02$ & $7.90 \mathrm{E}-03$ & $9.90 \mathrm{E}-03$ & $8.46 \mathrm{E}-03$ & 0.170 \\
\hline ER1E2bE & $1.00 \mathrm{E}-02$ & $7.40 \mathrm{E}-03$ & $1.00 \mathrm{E}-02$ & $8.54 \mathrm{E}-03$ & 0.171 \\
\hline ER5E1aE & $5.00 \mathrm{E}-01$ & $1.02 \mathrm{E}-01$ & $5.27 \mathrm{E}-01$ & $4.54 \mathrm{E}-01$ & 0.160 \\
\hline ER5E1bE & $5.00 \mathrm{E}-01$ & $1.03 \mathrm{E}-01$ & 5.32E-01 & $4.56 \mathrm{E}-01$ & 0.167 \\
\hline FR1E4aES & $1.00 \mathrm{E}-04$ & $1.00 \mathrm{E}-04$ & $1.00 \mathrm{E}-04$ & $8.33 \mathrm{E}-05$ & 0.201 \\
\hline FR1E4bES & $1.00 \mathrm{E}-04$ & $1.00 \mathrm{E}-04$ & $1.00 \mathrm{E}-04$ & $8.40 \mathrm{E}-05$ & 0.191 \\
\hline FR1E2aE & $1.00 \mathrm{E}-02$ & $5.30 \mathrm{E}-03$ & $1.00 \mathrm{E}-02$ & $8.59 \mathrm{E}-03$ & 0.165 \\
\hline FR1E2bE & $1.00 \mathrm{E}-02$ & $4.60 \mathrm{E}-03$ & $9.80 \mathrm{E}-03$ & 8.39E-03 & 0.169 \\
\hline FR5E1aE & $5.00 \mathrm{E}-01$ & $9.19 \mathrm{E}-02$ & $5.29 \mathrm{E}-01$ & $4.54 \mathrm{E}-01$ & 0.166 \\
\hline FR5E1bE & $5.00 \mathrm{E}-01$ & $9.53 \mathrm{E}-02$ & $5.28 \mathrm{E}-01$ & $4.52 \mathrm{E}-01$ & 0.168 \\
\hline
\end{tabular}


Table 4.3 Ratio of dynamic engineering yield and ultimate stresses to average stroke control equivalent static stresses

\begin{tabular}{|l|c|c|}
\hline \multirow{2}{*}{ Specimen } & \multicolumn{2}{|c|}{ Dynamic increase factor } \\
\cline { 2 - 3 } & Yield $\left(\sigma_{\mathrm{y}} / \sigma_{\mathrm{ys}}\right)$ & Ultimate $\left(\sigma_{\mathrm{u}} / \sigma_{\mathrm{us}}\right)$ \\
\hline AR1E4aES & 1.044 & 1.053 \\
\hline AR1E4bES & 1.068 & 1.063 \\
\hline AR1E2aE & 1.180 & 1.073 \\
\hline AR1E2bE & 1.160 & 1.070 \\
\hline AR5E1aE & 1.265 & 1.104 \\
\hline AR5E1bE & 1.275 & 1.114 \\
\hline BR1E4aES & 1.073 & 1.040 \\
\hline BR1E4bES & 1.074 & 1.046 \\
\hline BR1E2aE & 1.168 & 1.067 \\
\hline BR1E2bE & 1.146 & 1.063 \\
\hline BR5E1aE & 1.250 & 1.119 \\
\hline BR5E1bE & 1.225 & 1.119 \\
\hline CR1E4aES & 1.091 & 1.050 \\
\hline CR1E4bES & 1.064 & 1.036 \\
\hline CR1E2aE & 1.138 & 1.061 \\
\hline CR1E2bE & 1.129 & 1.063 \\
\hline CR5E1aE & 1.223 & 1.119 \\
\hline CR5E1bE & 1.192 & 1.115 \\
\hline DR1E4aES & 1.054 & 1.048 \\
\hline DR1E4bES & 1.051 & 1.049 \\
\hline DR1E2aE & 1.092 & 1.058 \\
\hline DR1E2bE & 1.110 & 1.064 \\
\hline DR5E1aE & 1.252 & 1.120 \\
\hline DR5E1bE & 1.236 & 1.117 \\
\hline ER1E4aES & 1.041 & 1.048 \\
\hline ER1E4bES & 1.042 & 1.054 \\
\hline ER1E2aE & 1.101 & 1.062 \\
\hline ER1E2bE & 1.112 & 1.063 \\
\hline ER5E1aE & 1.238 & 1.115 \\
\hline ER5E1bE & 1.240 & 1.119 \\
\hline
\end{tabular}


Table 4.3 (continued)

\begin{tabular}{|l|c|c|}
\hline \multirow{2}{*}{ Specimen } & \multicolumn{2}{|c|}{ Ratio } \\
\cline { 2 - 3 } & Yield $\left(\sigma_{\mathrm{y}} / \sigma_{\mathrm{ys}}\right)$ & Ultimate $\left(\sigma_{\mathrm{u}} / \sigma_{\mathrm{us}}\right)$ \\
\hline FR1E4aES & 1.038 & 1.040 \\
\hline FR1E4bES & 1.052 & 1.046 \\
\hline FR1E2aE & 1.121 & 1.060 \\
\hline FR1E2bE & 1.112 & 1.062 \\
\hline FR5E1aE & 1.253 & 1.114 \\
\hline FR5E1bE & 1.252 & 1.119 \\
\hline
\end{tabular}

Table 4.4 Constants for Cowper-Symonds power law equation for materials A-F

\begin{tabular}{|c|c|c|c|}
\hline Material & $\mathrm{D}\left(\mathrm{s}^{-1}\right)$ & $\mathrm{q}$ & $\begin{array}{c}\text { Coefficient of } \\
\text { determination }\left(\mathrm{R}^{2}\right)\end{array}$ \\
\hline $\mathrm{A}$ & 61.6 & 4.9 & 0.9961 \\
\hline $\mathrm{B}$ & 847.4 & 6.2 & 0.9996 \\
\hline $\mathrm{C}$ & 2919.5 & 6.6 & 0.9978 \\
\hline $\mathrm{D}$ & 13.5 & 3.4 & 0.9873 \\
\hline $\mathrm{E}$ & 15 & 3.4 & 0.9962 \\
\hline $\mathrm{F}$ & 20.9 & 3.9 & 0.9998 \\
\hline
\end{tabular}


Table 4.5 Fracture strain calculated based on elongation and reduction of cross-section area for materials A-F

\begin{tabular}{|c|c|c|c|c|c|}
\hline Specimen & $\Delta \mathrm{L}_{\mathrm{f}}(\mathrm{mm})$ & $\varepsilon_{\mathrm{ef}}$ & $\mathrm{A}_{0}\left(\mathrm{~mm}^{2}\right)$ & $\mathrm{A}_{\mathrm{f}}\left(\mathrm{mm}^{2}\right)$ & $\varepsilon_{T}$ \\
\hline AR1E4aES & 17.5 & 0.344 & 57.25 & 21.36 & 0.986 \\
\hline AR1E4bES & 17.8 & 0.350 & 57.31 & 20.96 & 1.006 \\
\hline AR1E2aE & 15.9 & 0.313 & 58.15 & 23.54 & 0.904 \\
\hline AR1E2bE & 16.5 & 0.325 & 58.20 & 22.76 & 0.939 \\
\hline AR5E1aE & 18.8 & 0.370 & 58.56 & 23.12 & 0.929 \\
\hline AR5E1bE & 19.9 & 0.392 & 58.58 & 22.83 & 0.942 \\
\hline BR1E4aES & 15.0 & 0.295 & 98.20 & 41.38 & 0.864 \\
\hline BR1E4bES & 13.9 & 0.274 & 98.46 & 43.15 & 0.825 \\
\hline BR1E2aE & 14.6 & 0.287 & 98.14 & 39.99 & 0.898 \\
\hline BR1E2bE & 15.1 & 0.297 & 98.29 & 39.96 & 0.900 \\
\hline BR5E1aE & 13.9 & 0.274 & 97.40 & 40.01 & 0.890 \\
\hline BR5E1bE & 14.6 & 0.287 & 97.66 & 41.11 & 0.865 \\
\hline CR1E4aES & 16.5 & 0.325 & 97.71 & 42.77 & 0.826 \\
\hline CR1E4bES & 15.9 & 0.313 & 97.49 & 37.52 & 0.955 \\
\hline CR1E2aE & 15.3 & 0.301 & 97.54 & 37.94 & 0.944 \\
\hline CR1E2bE & 15.9 & 0.313 & 97.45 & 38.86 & 0.919 \\
\hline CR5E1 aE & 15.5 & 0.305 & 98.14 & 40.22 & 0.892 \\
\hline CR5E1bE & 15.7 & 0.309 & 98.17 & 40.46 & 0.886 \\
\hline DR1E4aES & 17.3 & 0.341 & 97.08 & 36.44 & 0.980 \\
\hline DR1E4bES & 16.7 & 0.329 & 96.44 & 38.34 & 0.923 \\
\hline DR1E2aE & 16.0 & 0.315 & 96.00 & 37.79 & 0.932 \\
\hline DR1E2bE & 15.7 & 0.309 & 96.86 & 39.44 & 0.899 \\
\hline DR5E1aE & 17.1 & 0.337 & 96.58 & 37.87 & 0.936 \\
\hline DR5E1bE & 17.5 & 0.344 & 95.94 & 38.13 & 0.923 \\
\hline ER1E4aES & 14.8 & 0.291 & 59.04 & 26.23 & 0.811 \\
\hline ER1E4bES & 14.3 & 0.281 & 58.92 & 26.62 & 0.795 \\
\hline ER1E2aE & 15.7 & 0.309 & 59.48 & 24.45 & 0.889 \\
\hline ER1E2bE & 15.7 & 0.309 & 59.43 & 24.45 & 0.888 \\
\hline ER5E1aE & 16.7 & 0.329 & 59.61 & 24.65 & 0.883 \\
\hline ER5E1bE & 16.1 & 0.317 & 59.47 & 24.73 & 0.877 \\
\hline
\end{tabular}


Table 4.5 (continue)

\begin{tabular}{|l|c|c|c|c|c|}
\hline Specimen & $\Delta \mathrm{L}_{\mathrm{f}}(\mathrm{mm})$ & $\varepsilon_{\text {ef }}$ & $\mathrm{A}_{0}\left(\mathrm{~mm}^{2}\right)$ & $\begin{array}{c}\mathrm{A}_{\mathrm{f}} \\
\left(\mathrm{mm}^{2}\right)\end{array}$ & $\varepsilon_{\mathrm{r}}$ \\
\hline FR1E4aES & 17.1 & 0.337 & 98.46 & 41.47 & 0.865 \\
\hline FR1E4bES & 16.9 & 0.333 & 98.25 & 41.87 & 0.853 \\
\hline FR1E2aE & 17.0 & 0.335 & 98.18 & 40.56 & 0.884 \\
\hline FR1E2bE & 16.5 & 0.325 & 97.86 & 41.91 & 0.848 \\
\hline FR5E1aE & 18.0 & 0.354 & 97.87 & 41.74 & 0.852 \\
\hline FR5E1bE & 17.0 & 0.335 & 97.94 & 41.48 & 0.859 \\
\hline
\end{tabular}

Table 4.6 Values of $A_{0}^{P}$ calculated from engineering strain at peak stress and measured from the specimens

\begin{tabular}{|c|c|c|c|c|c|c|}
\hline \multirow{2}{*}{ Specimen } & \multirow{2}{*}{$\varepsilon_{p}^{e}$} & \multicolumn{2}{|c|}{$A_{0}^{P}$} & \multirow{2}{*}{$\begin{array}{l}\text { Undeformed } \\
\text { area, } \mathrm{A}_{0} \\
\left(\mathrm{~mm}^{2}\right)\end{array}$} & \multicolumn{2}{|c|}{$\ln \left(\mathrm{A}_{0} / A_{0}^{P}\right)$} \\
\hline & & Strain & Measured & & Strain & Measured \\
\hline AR1E4aES & 0.211 & 47.29 & 47.19 & 57.25 & 0.191 & 0.193 \\
\hline AR1E4bES & 0.220 & 46.97 & 47.26 & 57.31 & 0.199 & 0.193 \\
\hline BR1E4aES & 0.171 & 83.86 & 85.09 & 98.20 & 0.158 & 0.143 \\
\hline BR1E4bES & 0.152 & 85.27 & 84.84 & 98.20 & 0.141 & 0.146 \\
\hline CR1E4aES & 0.151 & 84.89 & 83.92 & 97.70 & 0.141 & 0.152 \\
\hline CR1E4bES & 0.151 & 84.71 & 83.90 & 97.49 & 0.141 & 0.150 \\
\hline DR1E4aES & 0.196 & 81.20 & 80.90 & 97.08 & 0.179 & 0.182 \\
\hline DR1E4bES & 0.176 & 82.04 & 80.95 & 96.44 & 0.162 & 0.175 \\
\hline ER1E4aES & 0.201 & 49.17 & 49.75 & 59.04 & 0.183 & 0.171 \\
\hline ER1E4bES & 0.191 & 49.49 & 49.82 & 58.92 & 0.174 & 0.168 \\
\hline FR1E4aES & 0.201 & 82.00 & 81.15 & 98.46 & 0.183 & 0.193 \\
\hline FR1E4bES & 0.191 & 82.53 & 81.40 & 98.25 & 0.174 & 0.188 \\
\hline
\end{tabular}


Table 4.7 Material $E$ test data used to determine parameter $B$ for modified Cowper-Symonds power law Eq. (2.13) by Jones (2001)

\begin{tabular}{|c|c|c|c|c|c|c|}
\hline Specimen & $\begin{array}{c}\text { True } \\
\text { stress, } \sigma^{\mathrm{t}} \\
(\mathrm{MPa})\end{array}$ & $\begin{array}{c}\text { True } \\
\text { plastic } \\
\text { strain }\end{array}$ & $\begin{array}{c}\text { Nominal } \\
\text { strain } \\
\text { rate }\end{array}$ & $\begin{array}{c}\text { Static true } \\
\text { stress, } \sigma_{s}^{t} \\
(\mathrm{MPa})\end{array}$ & $\begin{array}{c}\text { Dynamic } \\
\text { stress ratio } \\
\left(\sigma^{\mathrm{t}} / \sigma_{s}^{t}\right)\end{array}$ & $\mathrm{B}$ \\
\hline ER1E4aES & 586.5 & 0.14 & $1.00 \mathrm{E}-04$ & 558.2 & 1.051 & \\
\hline ER1E4bES & 589.1 & 0.14 & $1.00 \mathrm{E}-04$ & 558.2 & 1.055 & \\
\hline ER1E2aES & 591.6 & 0.14 & $1.00 \mathrm{E}-02$ & 558.2 & 1.060 & \multirow{3}{*}{3724} \\
\hline ER1E2bES & 598.9 & 0.14 & $1.00 \mathrm{E}-02$ & 558.2 & 1.073 & \\
\hline ER5E1aES & 619.8 & 0.14 & $5.00 \mathrm{E}-01$ & 558.2 & 1.110 & \\
\hline ER5E1bES & 627.9 & 0.14 & $5.00 \mathrm{E}-01$ & 558.2 & 1.125 & \\
\hline
\end{tabular}

Table 4.8 Test data used to determine parameters $\mathrm{C}$ and $\gamma$ for the mixed-mode hardening model by Lemaitre and Chaboche (1990)

\begin{tabular}{|c|c|c|c|c|c|c|}
\hline Specimen & $\begin{array}{c}\text { True } \\
\text { stress, } \sigma^{\mathrm{t}} \\
(\mathrm{MPa})\end{array}$ & $\begin{array}{c}\text { Norminal } \\
\text { strain } \\
\text { rate }\end{array}$ & $\begin{array}{c}\text { Static } \\
\text { true } \\
\text { stress, } \\
\sigma_{s}^{t}(\mathrm{MPa})\end{array}$ & $\begin{array}{c}\text { Dynamic } \\
\text { stress } \\
\text { ratio } \\
\left(\sigma^{t} / \sigma_{s}^{t}\right)\end{array}$ & $\begin{array}{c}\text { True } \\
\text { plastic } \\
\text { strain }\end{array}$ & $\alpha(\mathrm{MPa})$ \\
\hline ER1E4aES & 464.5 & $1.00 \mathrm{E}-04$ & 447.5 & 1.038 & \multirow{6}{*}{0.05} & \multirow{6}{*}{294.7} \\
\hline ER1E4bES & 470.5 & $1.00 \mathrm{E}-04$ & 447.5 & 1.051 & & \\
\hline ER1E2aES & 474.4 & $1.00 \mathrm{E}-02$ & 447.5 & 1.060 & & \\
\hline ER1E2bES & 477.2 & $1.00 \mathrm{E}-02$ & 447.5 & 1.066 & & \\
\hline ER5E1aES & 493.3 & $5.00 \mathrm{E}-01$ & 447.5 & 1.102 & & \\
\hline ER5E1bES & 505.3 & $5.00 \mathrm{E}-01$ & 447.5 & 1.129 & & \\
\hline ER1E4aES & 548.8 & $1.00 \mathrm{E}-04$ & 527.4 & 1.040 & \multirow{6}{*}{0.1} & \multirow{6}{*}{351.2} \\
\hline ER1E4bES & 558.1 & $1.00 \mathrm{E}-04$ & 527.4 & 1.058 & & \\
\hline ER1E2aES & 559.5 & $1.00 \mathrm{E}-02$ & 527.4 & 1.061 & & \\
\hline ER1E2bES & 562.8 & $1.00 \mathrm{E}-02$ & 527.4 & 1.067 & & \\
\hline ER5E1aES & 583.2 & $5.00 \mathrm{E}-01$ & 527.4 & 1.106 & & \\
\hline ER5E1bES & 589.8 & $5.00 \mathrm{E}-01$ & 527.4 & 1.118 & & \\
\hline ER1E4aES & 586.5 & $1.00 \mathrm{E}-04$ & 558.2 & 1.051 & \multirow{6}{*}{0.14} & \multirow{6}{*}{362.8} \\
\hline ER1E4bES & 589.1 & $1.00 \mathrm{E}-04$ & 558.2 & 1.055 & & \\
\hline ER1E2aES & 591.6 & $1.00 \mathrm{E}-02$ & 558.2 & 1.060 & & \\
\hline ER1E2bES & 598.9 & $1.00 \mathrm{E}-02$ & 558.2 & 1.073 & & \\
\hline ER5E1aES & 619.8 & $5.00 \mathrm{E}-01$ & 558.2 & 1.110 & & \\
\hline ER5E1bES & 627.9 & $5.00 \mathrm{E}-01$ & 558.2 & 1.125 & & \\
\hline
\end{tabular}


Table 4.9 Yield stress, ultimate stress and elastic modulus for materials $\mathrm{G}$ and $\mathrm{H}$

\begin{tabular}{|c|c|c|c|c|c|}
\hline \multirow{2}{*}{ Specimen } & \multicolumn{2}{|c|}{ Yield stress (MPa) } & \multicolumn{2}{|c|}{ Ultimate stress (MPa) } & \multirow{2}{*}{$\begin{array}{c}\text { Elastic } \\
\text { modulus } \\
(\mathrm{MPa})\end{array}$} \\
\hline & Engineering & True & Engineering & True & \\
\hline GT1E5aE & 349.2 & 349.9 & 539.7 & 648.3 & 205000 \\
\hline GT1E5bE & 348.7 & 349.4 & 538.5 & 641.3 & 206000 \\
\hline GT5E5ED & 352.7 & 353.4 & 543.4 & 643.5 & 206000 \\
\hline GT1E4ED & 353.6 & 354.3 & 547.7 & 651.3 & 205000 \\
\hline GT1E4S & 352.1 & 352.8 & 545.0 & 647.7 & 206000 \\
\hline GT1E4S(s) ${ }^{1}$ & 347.0 & 347.4 & 522.2 & 635.4 & 206000 \\
\hline GT1E3ED & 359.7 & 360.4 & 553.1 & 649.4 & 206000 \\
\hline GT1E2ED & 380.3 & 381.8 & 563.0 & 661.5 & 210000 \\
\hline GT1E1E & 396.4 & 398.0 & 575.6 & 668.7 & 210000 \\
\hline GT1E0E & 419.5 & 422.0 & 592.4 & 695.3 & 209000 \\
\hline HT1E5E & 383.4 & 384.2 & 574.5 & 656.0 & 207000 \\
\hline HT5E5ED & 383.7 & 384.5 & 569.3 & 651.4 & 210000 \\
\hline HT1E4ED & 384.5 & 385.3 & 573.0 & 666.1 & 208000 \\
\hline HT1E4S & 382.5 & 383.3 & 574.7 & 667.4 & 206000 \\
\hline${\mathrm{HT} 1 \mathrm{E} 4 \mathrm{~S}(\mathrm{~s})^{1}}^{1}$ & 375.1 & 377.1 & 552.9 & 641.2 & 206000 \\
\hline HT1E3ED & 388.1 & 388.9 & 583.1 & 670.8 & 213000 \\
\hline HT1E2ED & 397.5 & 399.1 & 585.6 & 669.8 & 208000 \\
\hline HT1E1E & 418.9 & 420.6 & 599.5 & 687.9 & 208000 \\
\hline HT1E0E & 449.1 & 451.3 & 620.9 & 714.9 & 204000 \\
\hline
\end{tabular}

Notes:

I GT1E4S(s) and HT1E4S(s) denote static reading of tests GT1E4E and HT1E4E 
Table 4.10 Actual strain rate and engineering strain at peak stress in round specimen tests

\begin{tabular}{|l|c|c|c|c|}
\hline \multirow{2}{*}{ Specimen } & \multirow{2}{*}{$\begin{array}{c}\text { Target } \\
\text { strain rate } \\
\left(\mathrm{s}^{-1}\right)\end{array}$} & \multicolumn{2}{|c|}{$\begin{array}{c}\text { Real strain rate at stress } \\
\text { point }\end{array}$} & $\begin{array}{c}\text { Engineering } \\
\text { strain at } \\
\text { peak stress }\end{array}$ \\
\cline { 3 - 5 } & Yield & Ultimate & 0.170 \\
\hline GT1E5aE & $1.00 \mathrm{E}-05$ & $1.01 \mathrm{E}-05$ & $1.75 \mathrm{E}-05$ & --- \\
\hline GT5E5ED & $5.00 \mathrm{E}-05$ & $4.96 \mathrm{E}-05$ & $4.33 \mathrm{E}-05$ & 0.167 \\
\hline GT1E4ED & $1.00 \mathrm{E}-04$ & $1.00 \mathrm{E}-04$ & $8.70 \mathrm{E}-05$ & 0.165 \\
\hline GT1E4S & $1.00 \mathrm{E}-04$ & $2.95 \mathrm{E}-05$ & $1.23 \mathrm{E}-04$ & ---- \\
\hline GT1E4S(s) & ---- & ---- & ---- & ---- \\
\hline GT1E3ED & $1.00 \mathrm{E}-03$ & $1.11 \mathrm{E}-03$ & $9.53 \mathrm{E}-04$ & 0.161 \\
\hline GT1E2ED & $1.00 \mathrm{E}-02$ & $8.40 \mathrm{E}-03$ & $8.64 \mathrm{E}-03$ & 0.155 \\
\hline GT1E1E & $1.00 \mathrm{E}-01$ & $4.54 \mathrm{E}-02$ & $1.27 \mathrm{E}-01$ & 0.149 \\
\hline GT1E0E & $1.00 \mathrm{E}+00$ & $1.73 \mathrm{E}-01$ & $1.09 \mathrm{E}+00$ & 0.148 \\
\hline HT1E5E & $1.00 \mathrm{E}-05$ & $9.95 \mathrm{E}-06$ & $1.37 \mathrm{E}-05$ & 0.130 \\
\hline HT5E5ED & $5.00 \mathrm{E}-05$ & $4.97 \mathrm{E}-05$ & $4.23 \mathrm{E}-05$ & 0.126 \\
\hline HT1E4ED & $1.00 \mathrm{E}-04$ & $1.00 \mathrm{E}-04$ & $8.67 \mathrm{E}-05$ & 0.136 \\
\hline HT1E4S & $1.00 \mathrm{E}-04$ & $3.03 \mathrm{E}-05$ & $7.47 \mathrm{E}-05$ & $-\cdots$ \\
\hline HT1E4S(s) & ---- & ---- & ---- & ---- \\
\hline HT1E3ED & $1.00 \mathrm{E}-03$ & $9.74 \mathrm{E}-04$ & $8.55 \mathrm{E}-04$ & 0.130 \\
\hline HT1E2ED & $1.00 \mathrm{E}-02$ & $8.59 \mathrm{E}-03$ & $8.73 \mathrm{E}-03$ & 0.128 \\
\hline HT1E1E & $1.00 \mathrm{E}-01$ & $5.18 \mathrm{E}-02$ & $1.34 \mathrm{E}-01$ & 0.132 \\
\hline HT1E0E & $1.00 \mathrm{E}+00$ & $1.74 \mathrm{E}-01$ & $1.46 \mathrm{E}+00$ & 0.136 \\
\hline
\end{tabular}


Table 4.11 Ratio of dynamic engineering yield and ultimate stresses to the respective static stroke control test stresses for materials $\mathrm{G}$ and $\mathrm{H}$

\begin{tabular}{|l|c|c|}
\hline \multirow{2}{*}{ Specimen } & \multicolumn{2}{|c|}{ Dynamic increase factor } \\
\cline { 2 - 3 } & $\begin{array}{c}\text { Yield } \\
\left(\sigma_{\mathrm{y}} / \sigma_{\mathrm{ys}}\right)\end{array}$ & Ultimate $\left(\sigma_{\mathrm{u}} / \sigma_{\mathrm{us}}\right)$ \\
\hline GT1E5aE & 1.004 & 1.030 \\
\hline GT5E5ED & 1.025 & 1.037 \\
\hline GT1E4ED & 1.031 & 1.046 \\
\hline GT1E3ED & 1.038 & 1.056 \\
\hline GT1E2ED & 1.123 & 1.076 \\
\hline GT1E1E & 1.166 & 1.100 \\
\hline GT1E0E & 1.235 & 1.132 \\
\hline HT1E5E & 1.021 & 1.038 \\
\hline HT5E5ED & 1.024 & 1.028 \\
\hline HT1E4ED & 1.026 & 1.033 \\
\hline HT1E3ED & 1.041 & 1.052 \\
\hline HT1E2ED & 1.060 & 1.057 \\
\hline HT1E1E & 1.115 & 1.082 \\
\hline HT1E0E & 1.203 & 1.120 \\
\hline
\end{tabular}

Table 4.12 Constants for Cowper-Symonds power law for materials $\mathrm{G}$ and $\mathrm{H}$

\begin{tabular}{|l|c|c|c|}
\hline Material & $\mathrm{D}\left(\mathrm{s}^{-1}\right)$ & $\mathrm{q}$ & $\begin{array}{c}\text { Coefficient of } \\
\text { determination }\left(\mathrm{R}^{2}\right)\end{array}$ \\
\hline $\mathrm{G}$ & 44.409 & 3.744 & 0.9917 \\
\hline $\mathrm{H}$ & 6.019 & 2.051 & 0.9988 \\
\hline
\end{tabular}


Table 4.13 Strain at fracture for materials $\mathrm{G}$ and $\mathrm{H}$

\begin{tabular}{|c|c|c|c|c|c|c|c|}
\hline \multirow{2}{*}{ Specimen } & \multicolumn{2}{|c|}{$\begin{array}{l}\text { Diameter } \\
(\mathrm{mm})\end{array}$} & \multicolumn{2}{|c|}{ Rupture strain } & \multirow{2}{*}{$\begin{array}{c}\text { Engineering } \\
\text { strain at } \\
\text { fracture, } \\
\mathcal{E}_{f}^{e}\end{array}$} & \multirow{2}{*}{$\begin{array}{c}\text { Target } \\
\text { strain } \\
\text { rate }\left(\mathrm{s}^{-1}\right)\end{array}$} & \multirow{2}{*}{ Notes } \\
\hline & $\mathrm{D}_{\mathrm{b}}$ & $\mathrm{D}_{\mathrm{r}}$ & $\varepsilon_{\mathrm{b}}$ & $\varepsilon_{\mathrm{r}}$ & & & \\
\hline GT1E5E & 5.76 & 6.08 & 0.852 & 0.745 & 0.315 & $1.00 \mathrm{E}-05$ & $\begin{array}{c}\text { Not } \\
\text { separated }\end{array}$ \\
\hline GT5E5ED & 5.78 & 6.1 & 0.845 & 0.736 & 0.322 & $5.00 \mathrm{E}-05$ & \\
\hline GT1E4ED & 5.79 & $\begin{array}{c}6.24 \\
(6.03)^{1} \\
\end{array}$ & 0.842 & $\begin{array}{c}0.692 \\
(0.759)^{1} \\
\end{array}$ & 0.324 & $1.00 \mathrm{E}-04$ & \\
\hline GT1E3ED & 5.63 & 5.96 & 0.898 & 0.785 & 0.342 & $1.00 \mathrm{E}-03$ & \\
\hline GT1E2ED & 5.74 & 6.03 & 0.859 & 0.759 & 0.333 & $1.00 \mathrm{E}-02$ & \\
\hline GT1E1E & 5.84 & 6.19 & 0.825 & 0.709 & 0.312 & $1.00 \mathrm{E}-01$ & \\
\hline GT1E0E & 5.66 & 6.28 & 0.887 & 0.680 & 0.317 & $1.00 \mathrm{E}+00$ & \\
\hline HT1E5E & 5.33 & 5.74 & 1.007 & 0.860 & 0.314 & $1.00 \mathrm{E}-05$ & \\
\hline HT5E5ED & 5.35 & 5.73 & 1.000 & 0.863 & 0.313 & $5.00 \mathrm{E}-05$ & $\begin{array}{c}\text { Not } \\
\text { separated }\end{array}$ \\
\hline HT1E4ED & --- & $\begin{array}{c}6.28 \\
(5.60)^{1} \\
\end{array}$ & --- & $\begin{array}{c}0.679 \\
(0.907)^{1} \\
\end{array}$ & 0.318 & $1.00 \mathrm{E}-04$ & $\begin{array}{c}\text { Buckle } \\
\text { after failure }\end{array}$ \\
\hline HT1E3ED & 5.67 & 5.97 & 0.884 & 0.781 & 0.312 & $1.00 \mathrm{E}-03$ & $\begin{array}{c}\text { Not } \\
\text { fracture }^{2} \\
\end{array}$ \\
\hline HT1E2ED & 5.39 & 5.78 & 0.985 & 0.846 & 0.314 & $1.00 \mathrm{E}-02$ & \\
\hline HT1E1E & 5.39 & 5.69 & 0.985 & 0.878 & 0.315 & $1.00 \mathrm{E}-01$ & \\
\hline HT1E0E & 5.36 & 5.82 & 0.996 & 0.830 & 0.306 & $1.00 \mathrm{E}+00$ & \\
\hline
\end{tabular}

Notes:

1 The number in the parenthesis is the value corrected for the minimum diameter.

2 Specimen HT1E3ED did not fracture. The drop in stress at the end of the curve in Fig. 4.32 was accompanied by the drop in axial strain. Thus, the drop in stress was due to the reversal of the applied stroke and not the fracture of the specimen. 
Table 4.14 Material $\mathrm{H}$ test data used to determine parameter $\mathrm{B}$ for modified Cowper-Symonds power law Eq. (2.13) by Jones (2001)

\begin{tabular}{|c|c|c|c|c|c|c|}
\hline Specimen & $\begin{array}{c}\text { True } \\
\text { stress } \\
(\mathrm{MPa})\end{array}$ & $\begin{array}{l}\text { True } \\
\text { plastic } \\
\text { strain }\end{array}$ & $\begin{array}{c}\text { Norminal } \\
\text { strain } \\
\text { rate }\end{array}$ & $\begin{array}{l}\text { Static true } \\
\text { stress, } \sigma_{s}^{t} \\
(\mathrm{MPa})\end{array}$ & $\begin{array}{c}\text { Dynamic } \\
\text { stress } \\
\text { ratio } \\
\left(\sigma^{t} / \sigma_{s}^{t}\right)\end{array}$ & B \\
\hline HT5E5ED & 659.4 & \multirow{6}{*}{0.15} & $5.00 \mathrm{E}-05$ & 644.3 & 1.023 & \multirow{12}{*}{36305} \\
\hline HT1E4ED & 659.6 & & $1.00 \mathrm{E}-04$ & 644.3 & 1.024 & \\
\hline HT1E3ED & 675.8 & & $1.00 \mathrm{E}-03$ & 644.3 & 1.049 & \\
\hline HT1E2ED & 677.4 & & $1.00 \mathrm{E}-02$ & 644.3 & 1.051 & \\
\hline HT1E1E & 689.1 & & $1.00 \mathrm{E}-01$ & 644.3 & 1.070 & \\
\hline HT1E0E & 719.8 & & $1.00 \mathrm{E}+00$ & 644.3 & 1.117 & \\
\hline HT5E5ED & 780.5 & \multirow{6}{*}{0.60} & $5.00 \mathrm{E}-05$ & 779.4 & 1.001 & \\
\hline HT1E4ED & 788.7 & & $1.00 \mathrm{E}-04$ & 779.4 & 1.012 & \\
\hline HT1E3ED & 797.6 & & $1.00 \mathrm{E}-03$ & 779.4 & 1.023 & \\
\hline HT1E2ED & 798.6 & & $1.00 \mathrm{E}-02$ & 779.4 & 1.025 & \\
\hline HT1E1E & 786.5 & & $1.00 \mathrm{E}-01$ & 779.4 & 1.009 & \\
\hline HT1E0E & 799.2 & & $1.00 \mathrm{E}+00$ & 779.4 & 1.025 & \\
\hline
\end{tabular}


Table 4.15 Test data used to determine parameters $C$ and $\gamma$ for the mixed-mode hardening model by Lemaitre and Chaboche (1990)

\begin{tabular}{|c|c|c|c|c|c|c|}
\hline Specimen & $\begin{array}{c}\text { True } \\
\text { stress } \\
(\mathrm{MPa})\end{array}$ & $\begin{array}{l}\text { Nominal } \\
\text { strain } \\
\text { rate }\end{array}$ & $\begin{array}{l}\text { Static } \\
\text { true } \\
\text { stress } \\
(\mathrm{MPa})\end{array}$ & $\begin{array}{c}\text { Dynamic } \\
\text { stress } \\
\text { ratio }\end{array}$ & $\begin{array}{c}\text { True } \\
\text { plastic } \\
\text { strain }\end{array}$ & $\alpha(\mathrm{MPa})$ \\
\hline HT5E5ED & 560.9 & $5.00 \mathrm{E}-05$ & 540.9 & 1.037 & \multirow{6}{*}{0.05} & \multirow{6}{*}{140.8} \\
\hline HT1E4ED & 562.8 & $1.00 \mathrm{E}-04$ & 540.9 & 1.040 & & \\
\hline HT1E3ED & 573.3 & $1.00 \mathrm{E}-03$ & 540.9 & 1.060 & & \\
\hline HT1E2ED & 576.8 & $1.00 \mathrm{E}-02$ & 540.9 & 1.066 & & \\
\hline HT1E1E & 586.7 & $1.00 \mathrm{E}-01$ & 540.9 & 1.085 & & \\
\hline HT1E0E & 610.1 & $1.00 \mathrm{E}+00$ & 540.9 & 1.128 & & \\
\hline HT5E5ED & 616.8 & $5.00 \mathrm{E}-05$ & 595.1 & 1.036 & \multirow{6}{*}{0.09} & \multirow{6}{*}{151.1} \\
\hline HT1E4ED & 619.1 & $1.00 \mathrm{E}-04$ & 595.1 & 1.040 & & \\
\hline HT1E3ED & 630.9 & $1.00 \mathrm{E}-03$ & 595.1 & 1.060 & & \\
\hline HT1E2ED & 635.2 & $1.00 \mathrm{E}-02$ & 595.1 & 1.067 & & \\
\hline HT1E1E & 650.4 & $1.00 \mathrm{E}-01$ & 595.1 & 1.093 & & \\
\hline HT1E0E & 669.5 & $1.00 \mathrm{E}+00$ & 595.1 & 1.125 & & \\
\hline HT5E5ED & 659.4 & $5.00 \mathrm{E}-05$ & 644.3 & 1.023 & \multirow{6}{*}{0.15} & \multirow{6}{*}{230.5} \\
\hline HT1E4ED & 659.6 & $1.00 \mathrm{E}-04$ & 644.3 & 1.024 & & \\
\hline HT1E3ED & 675.8 & $1.00 \mathrm{E}-03$ & 644.3 & 1.049 & & \\
\hline HT1E2ED & 677.4 & $1.00 \mathrm{E}-02$ & 644.3 & 1.051 & & \\
\hline HT1E1E & 689.1 & $1.00 \mathrm{E}-01$ & 644.3 & 1.070 & & \\
\hline HT1E0E & 719.8 & $1.00 \mathrm{E}+00$ & 644.3 & 1.117 & & \\
\hline HT5E5ED & 710.5 & $5.00 \mathrm{E}-05$ & 706.2 & 1.006 & \multirow{6}{*}{0.30} & \multirow{6}{*}{412.00} \\
\hline HT1E4ED & 709.1 & $1.00 \mathrm{E}-04$ & 706.2 & 1.004 & & \\
\hline HT1E3ED & 731.1 & $1.00 \mathrm{E}-03$ & 706.2 & 1.035 & & \\
\hline HT1E2ED & 730.1 & $1.00 \mathrm{E}-02$ & 706.2 & 1.034 & & \\
\hline HT1E1E & 738.2 & $1.00 \mathrm{E}-01$ & 706.2 & 1.045 & & \\
\hline HT1E0E & 760.7 & $1.00 \mathrm{E}+00$ & 706.2 & 1.077 & & \\
\hline HT5E5ED & 790.5 & $5.00 \mathrm{E}-05$ & 779.4 & 1.001 & \multirow{6}{*}{0.60} & \multirow{6}{*}{663.60} \\
\hline HT1E4ED & 788.7 & $1.00 \mathrm{E}-04$ & 779.4 & 1.012 & & \\
\hline HT1E3ED & 797.6 & $1.00 \mathrm{E}-03$ & 779.4 & 1.023 & & \\
\hline HT1E2ED & 798.6 & $1.00 \mathrm{E}-02$ & 779.4 & 1.025 & & \\
\hline HT1E1E & 786.5 & $1.00 \mathrm{E}-01$ & 779.4 & 1.009 & & \\
\hline HT1E0E & 799.2 & $1.00 \mathrm{E}+00$ & 779.4 & 1.025 & & \\
\hline
\end{tabular}




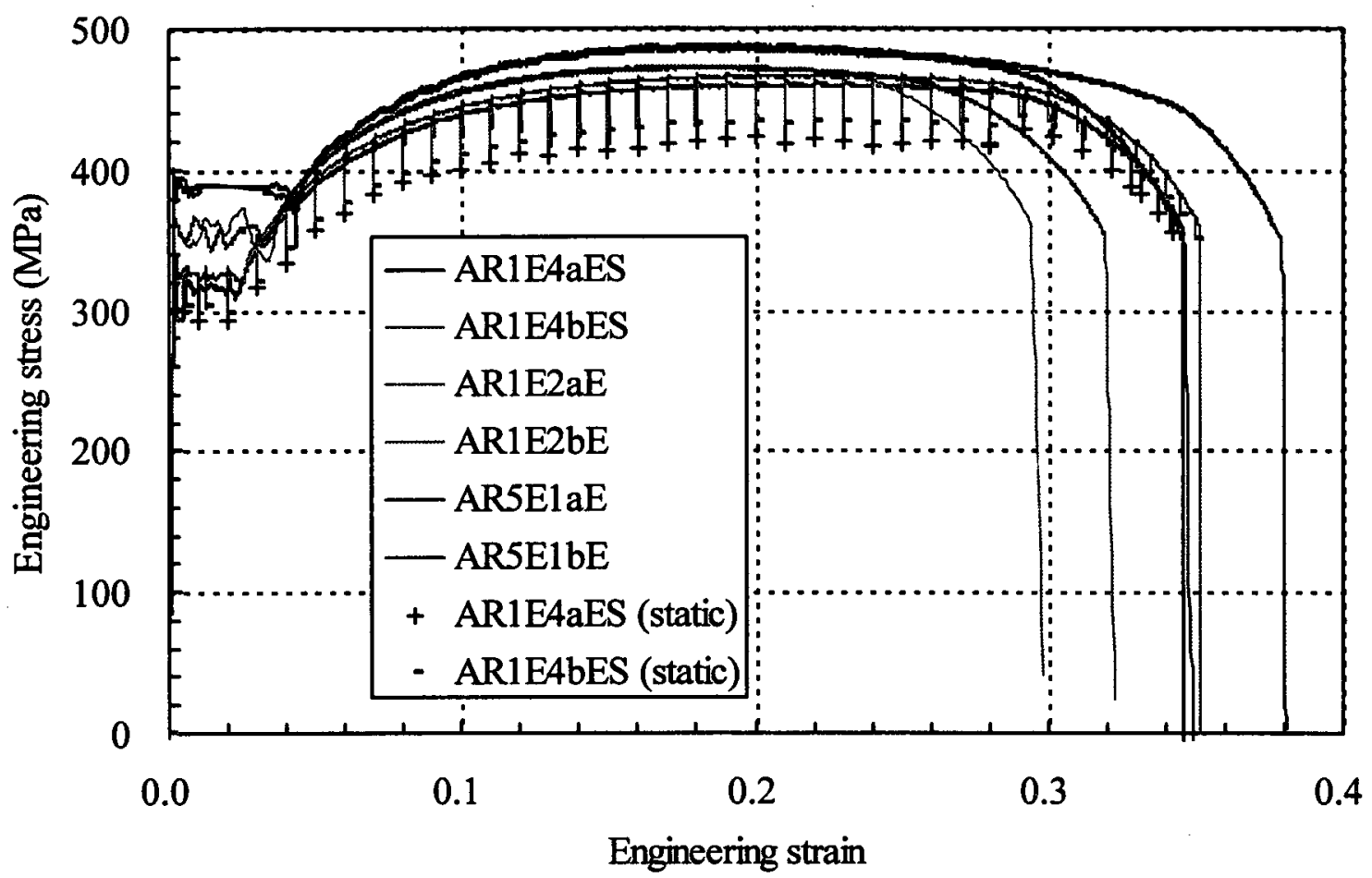

Figure 4.1 Engineering stress - engineering strain curve of material A

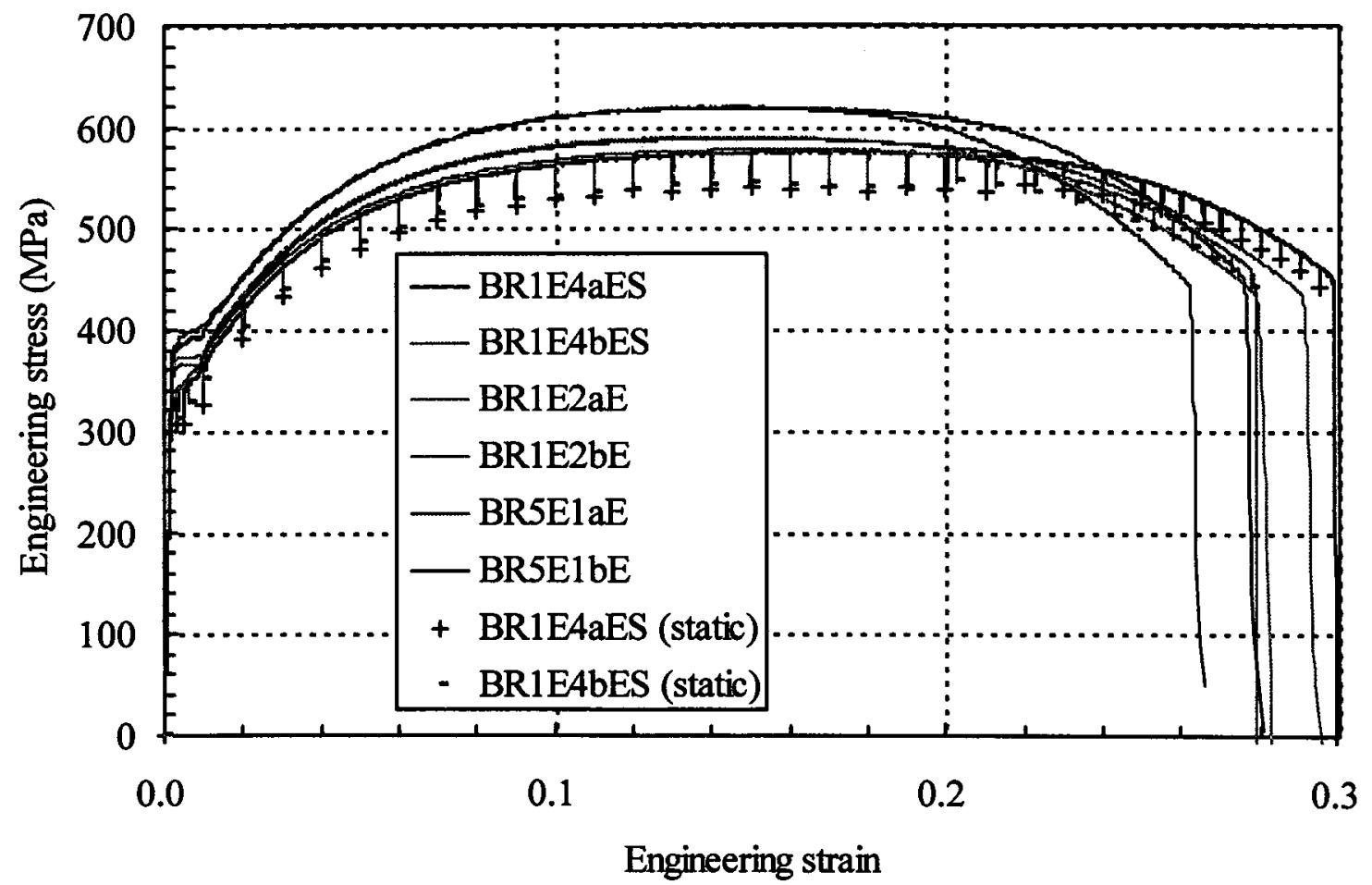

Figure 4.2 Engineering stress - engineering strain curve of material B 


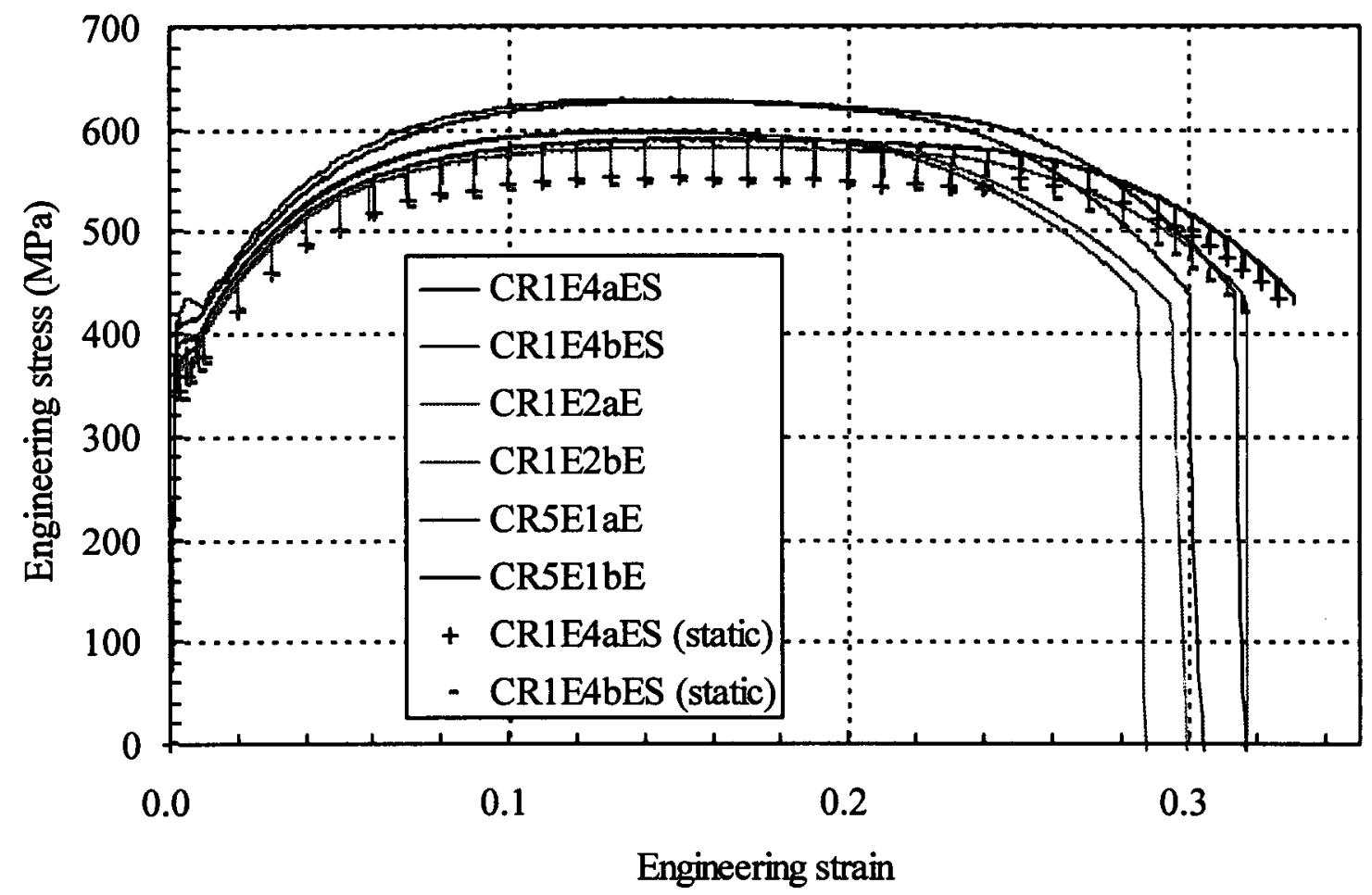

Figure 4.3 Engineering stress-engineering strain curve of material C

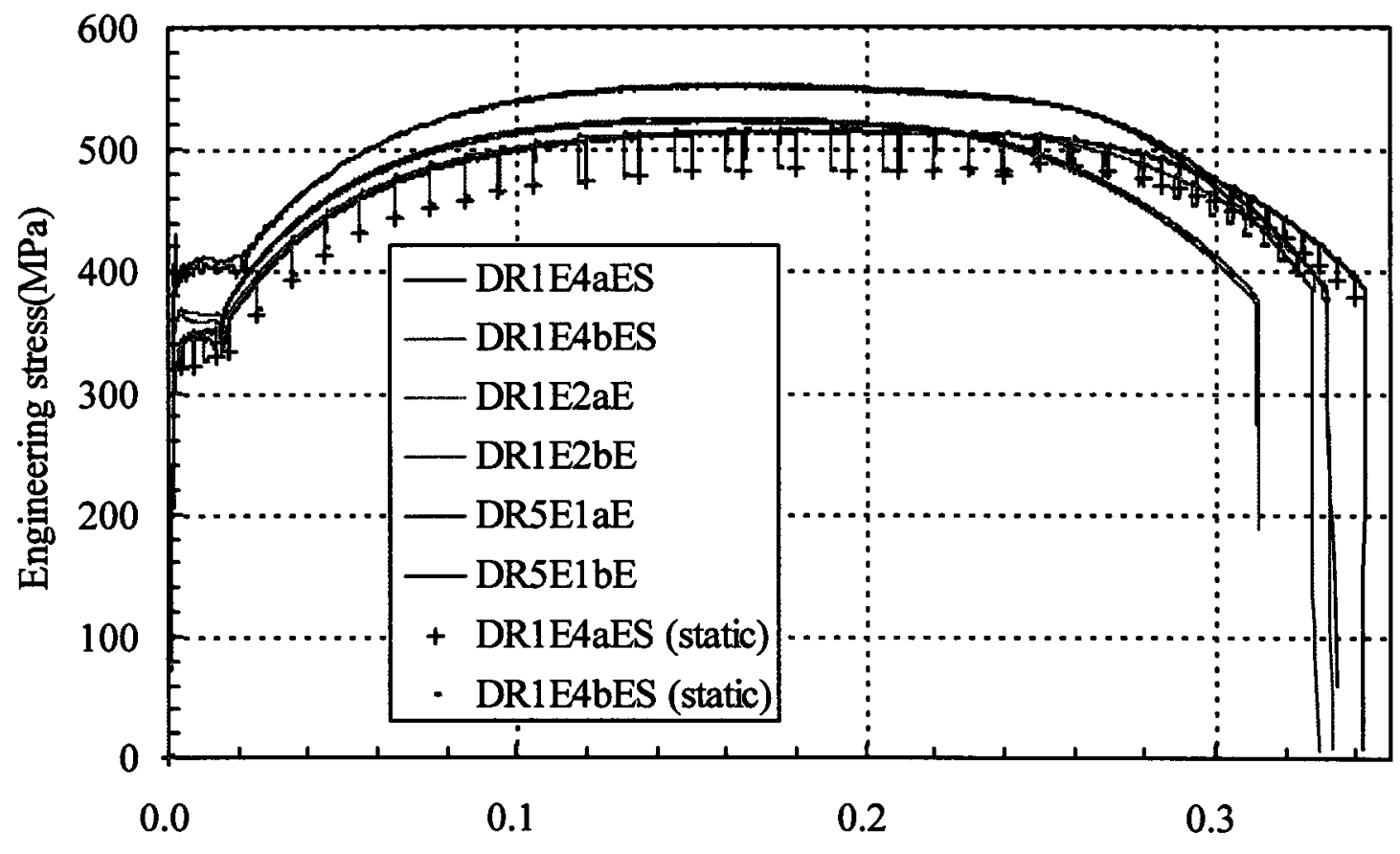

Engineering strain

Figure 4.4 Engineering stress-engineering strain curve of material D 


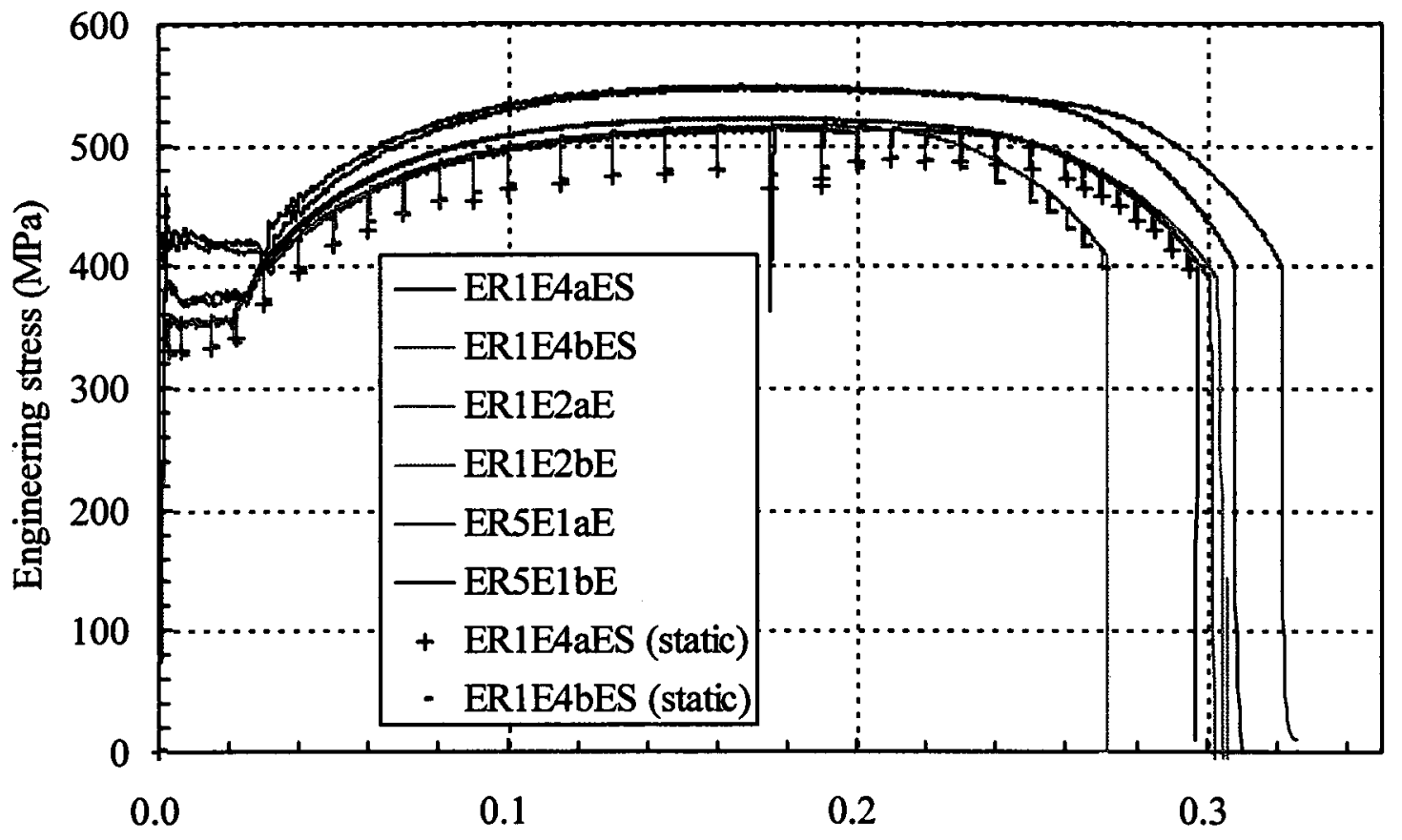

Engineering strain

Figure 4.5 Engineering stress-engineering strain curve of material E

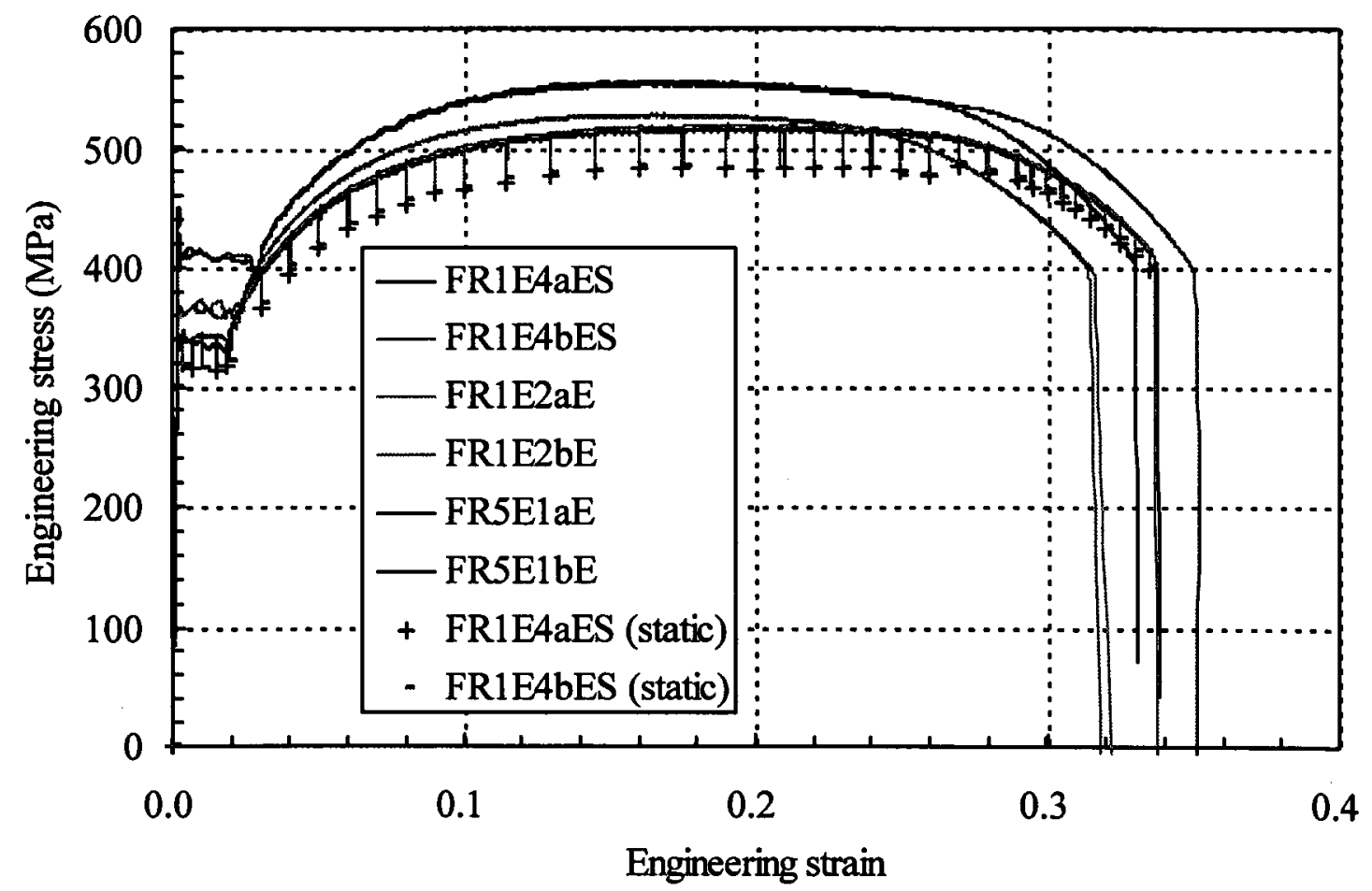

Figure 4.6 Engineering stress-engineering strain curve of material F 


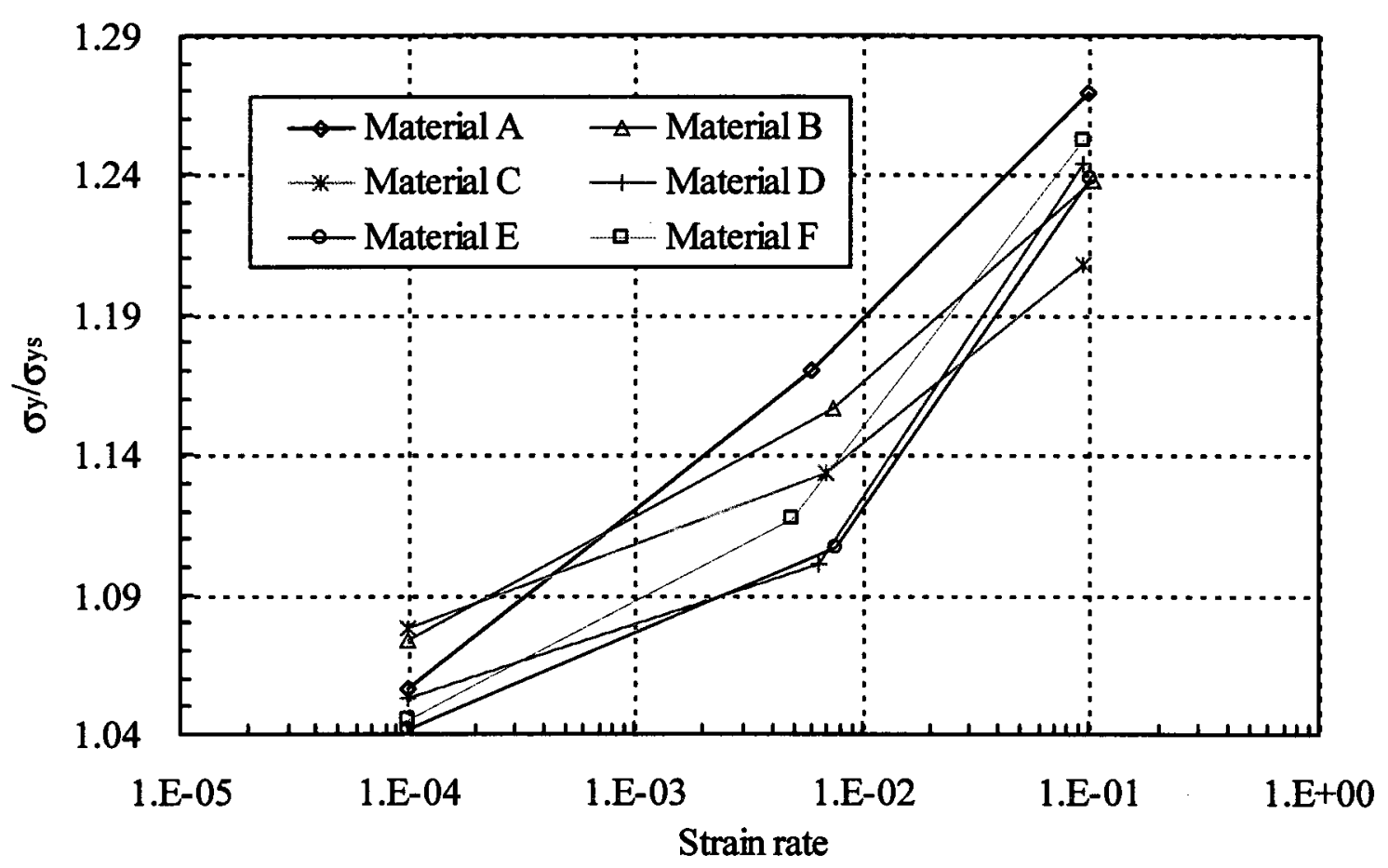

Figure 4.7 Ratio of yield stress versus logarithm of strain rate for materials A-F

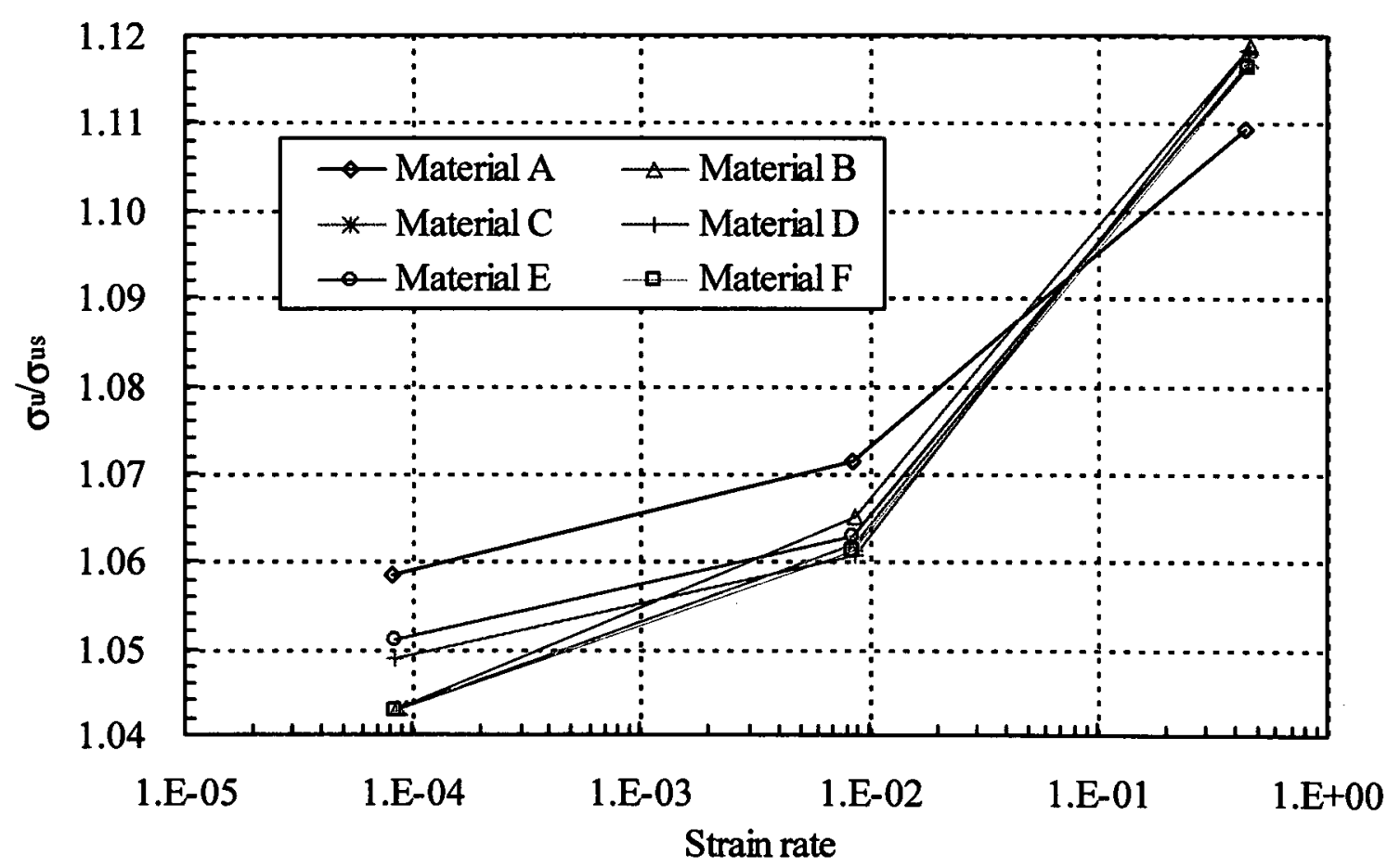

Figure 4.8 Ratio of ultimate stress versus logarithm of strain rate for materials A-F 


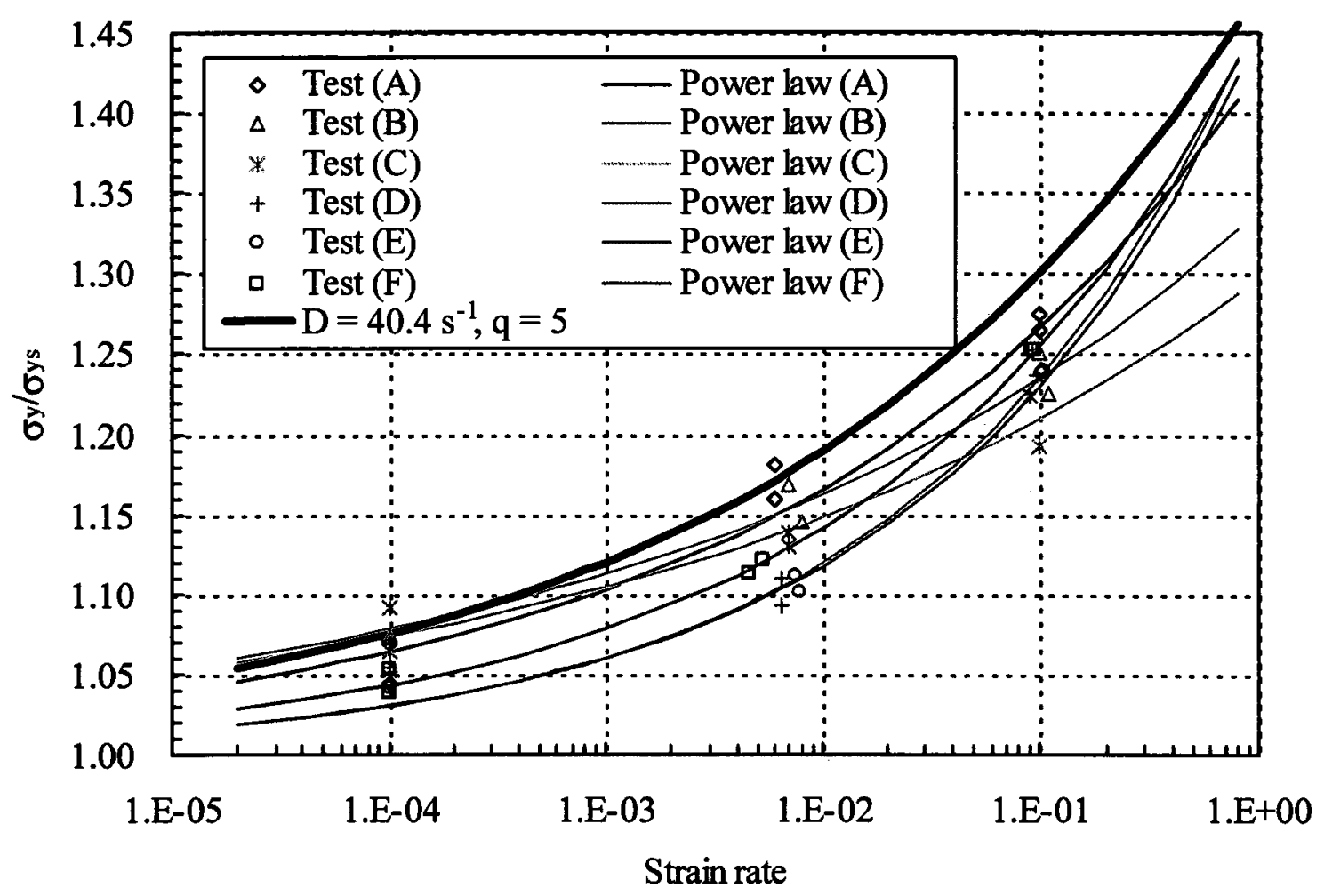

Figure 4.9 Comparison of test and predicted yield stress ratio based on Cowper-Symonds power law for materials A-F 


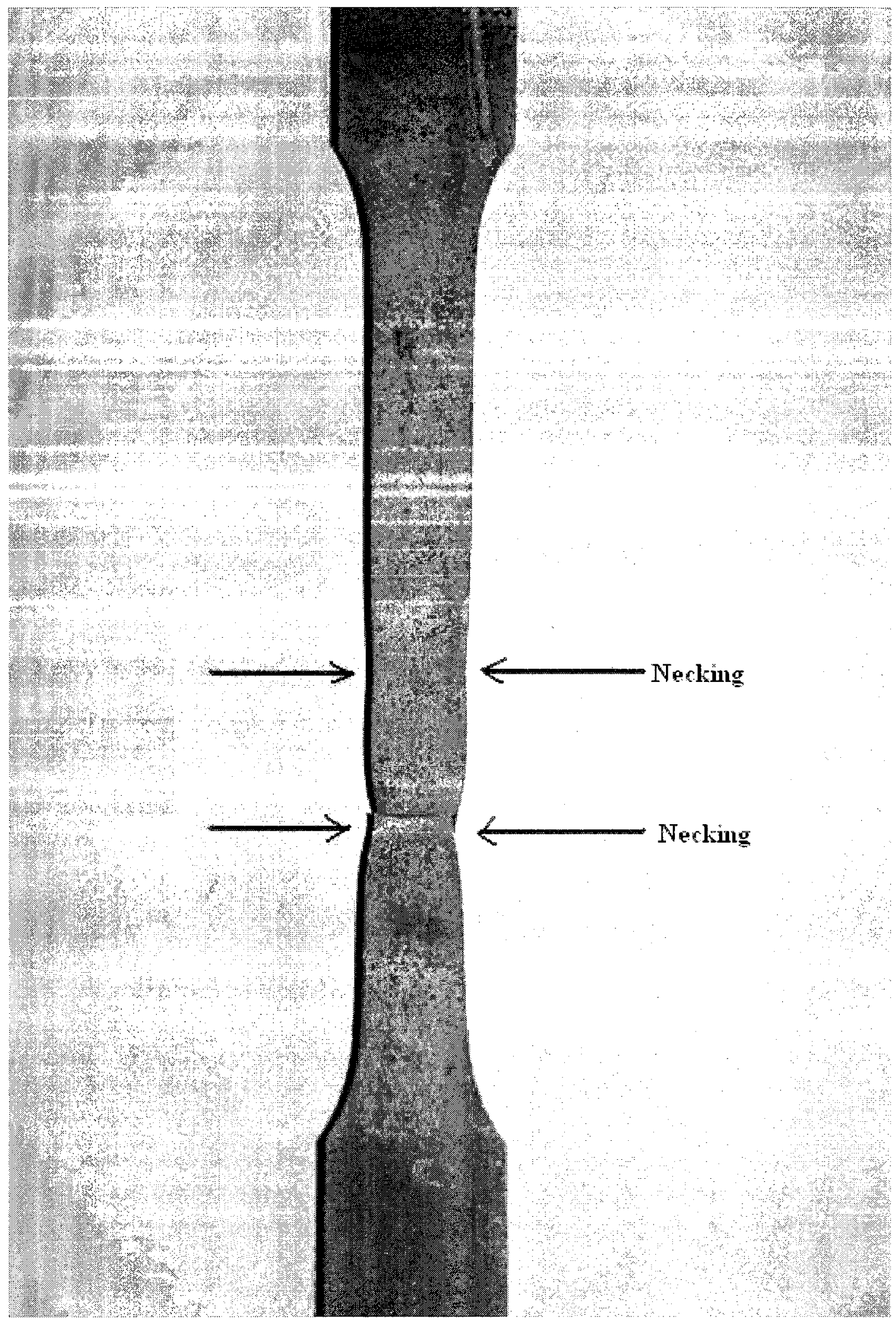

Figure 4.10 Necking occurred in two regions on specimen AR5E1bE 


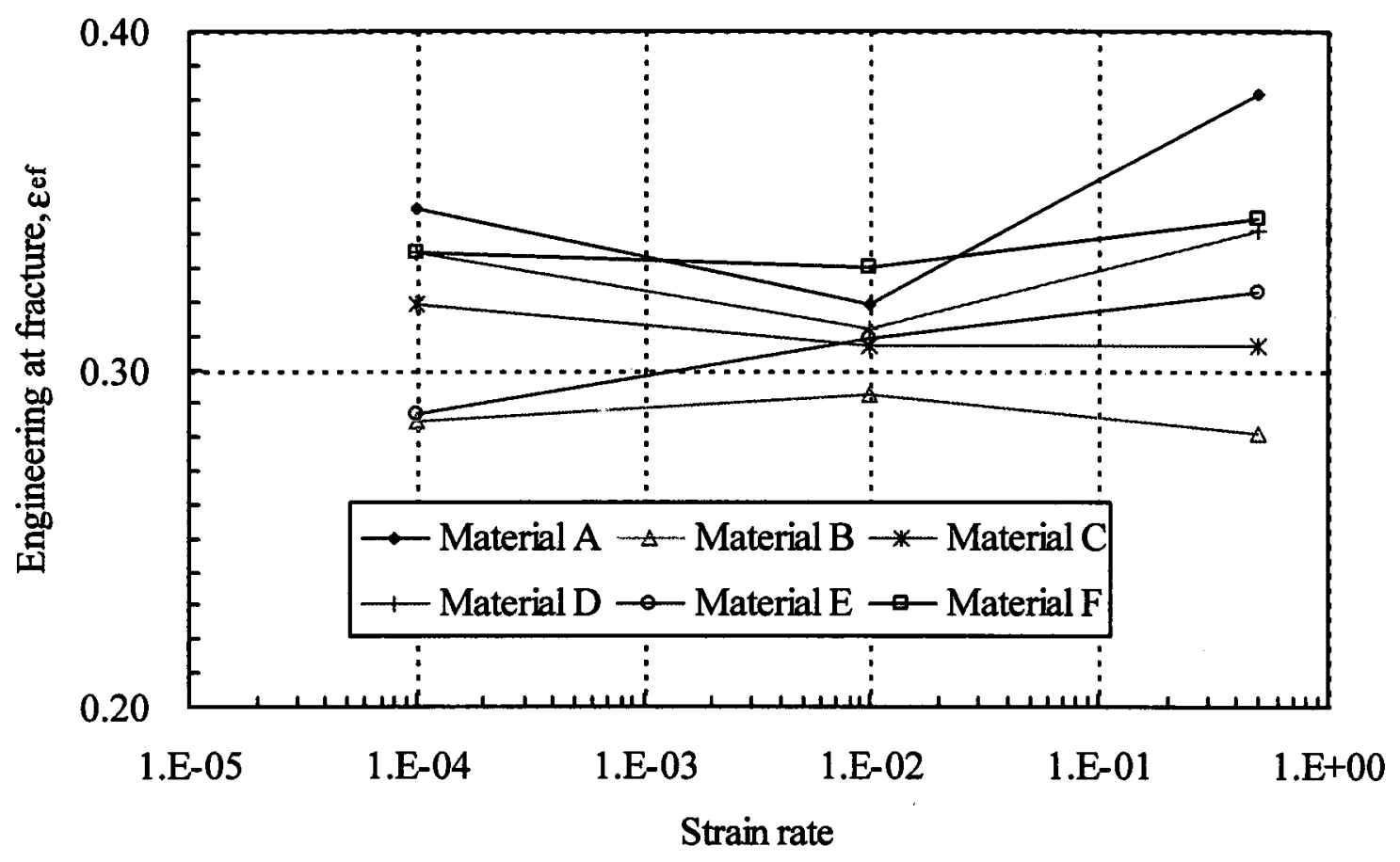

Figure 4.11 Engineering strain (average) at fracture versus strain rate for materials A-F

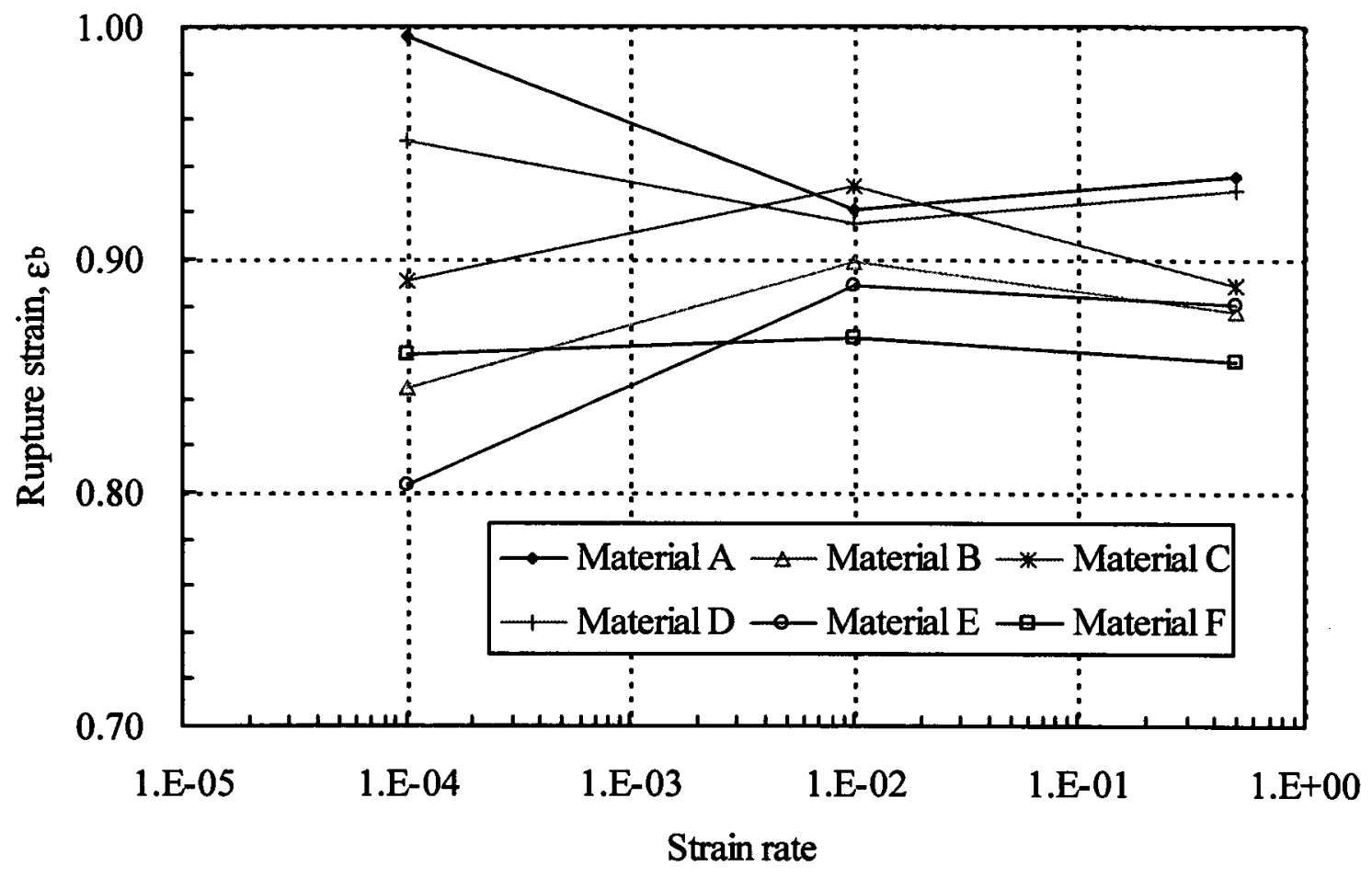

Figure 4.12 Rupture strain (average) versus strain rate for materials A-F 


$$
\searrow
$$




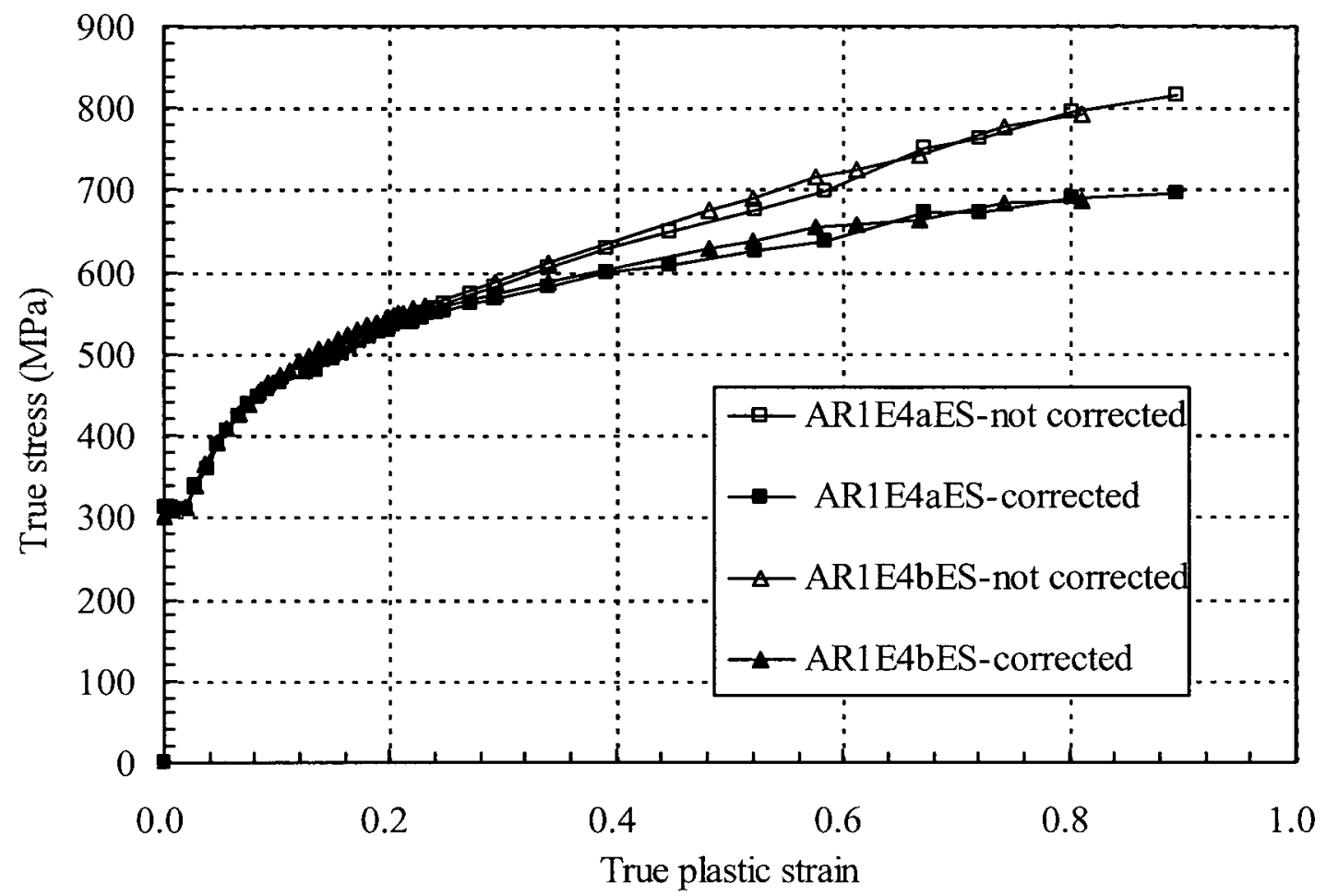

Figure 4.14 Corrected and uncorrected static true stress versus true plastic strain curves for AR1E4(a-b)ES

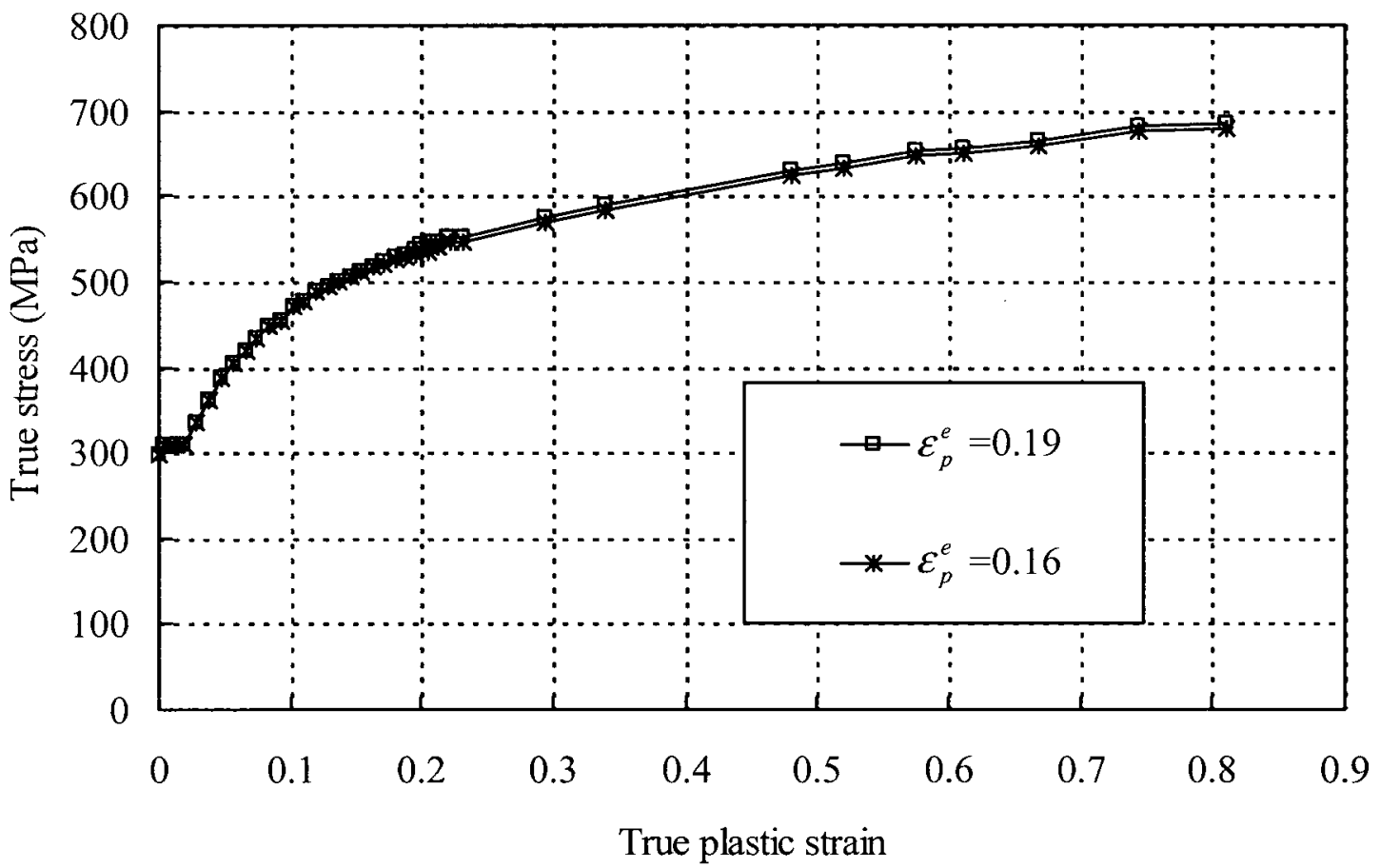

Figure 4.15 Comparisons of the corrected true stress versus true plastic strain curves different engineering strain at peak stress for AR1E4bES 


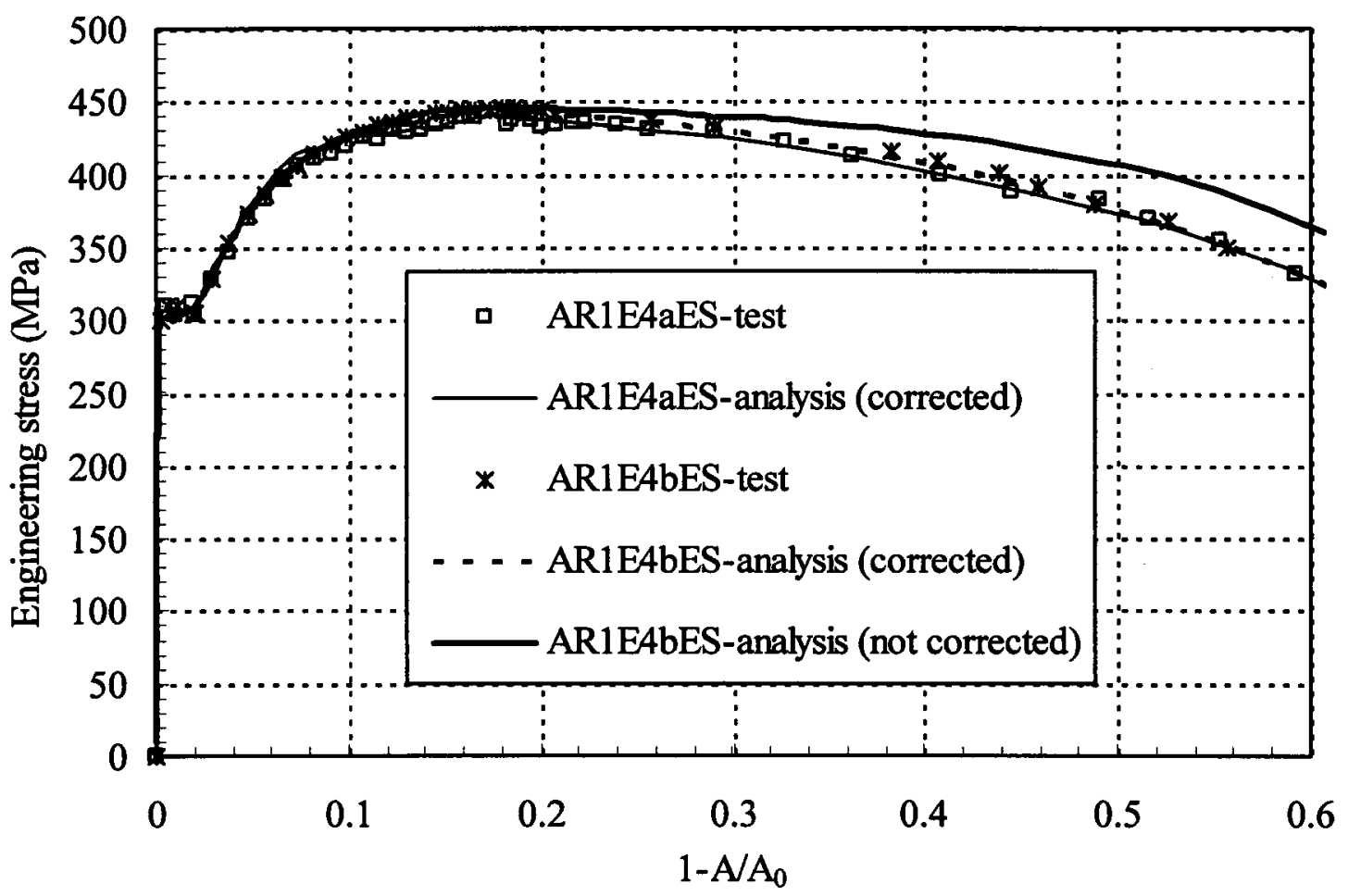

Figure 4.16 Test and predicted stress versus cross-section change for AR1E4(a-b)ES

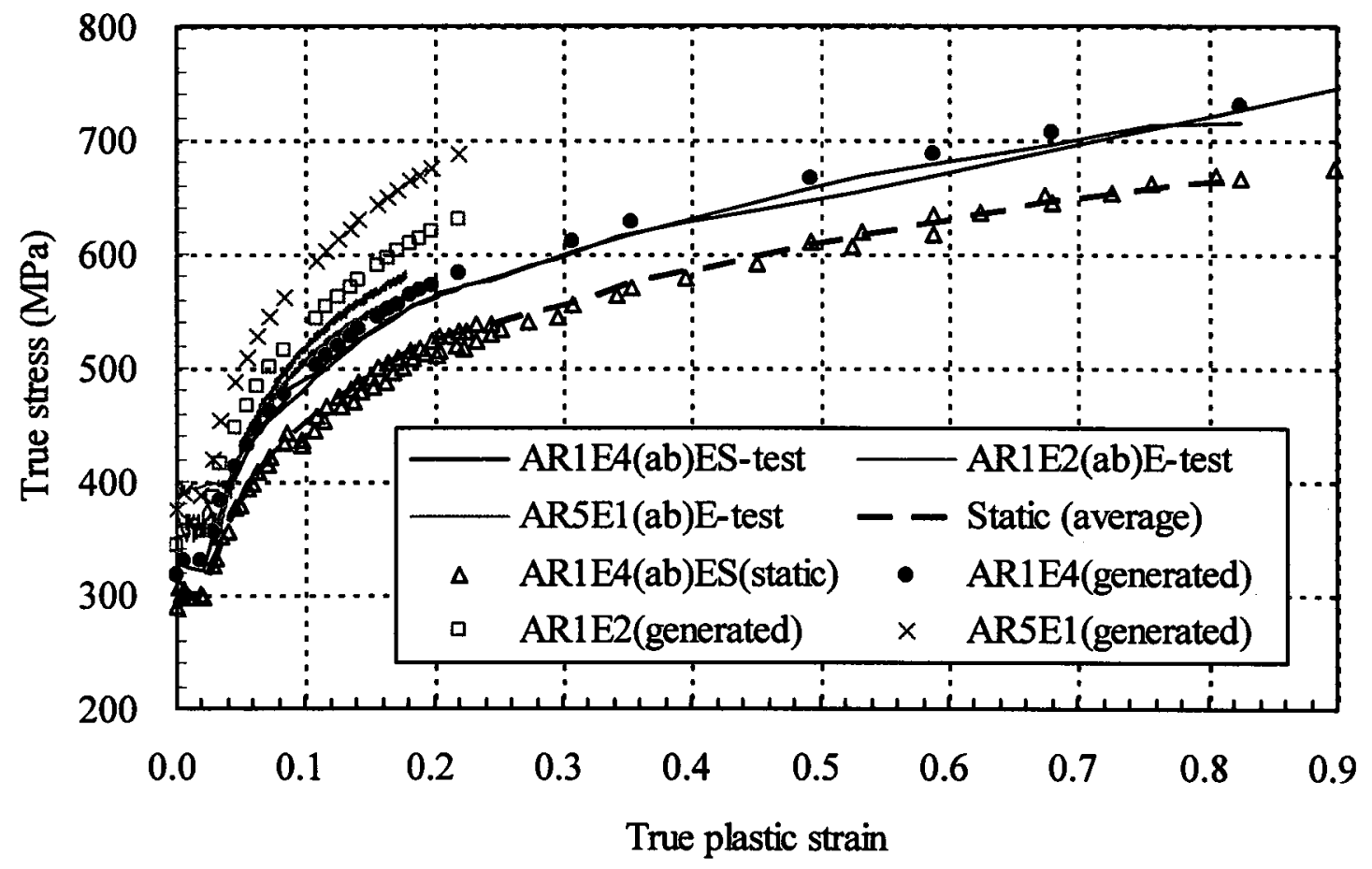

Figure 4.17 Test and predicted true stress-true plastic strain curves with Cowper-Symonds power law Eq. (2.8) for material A 


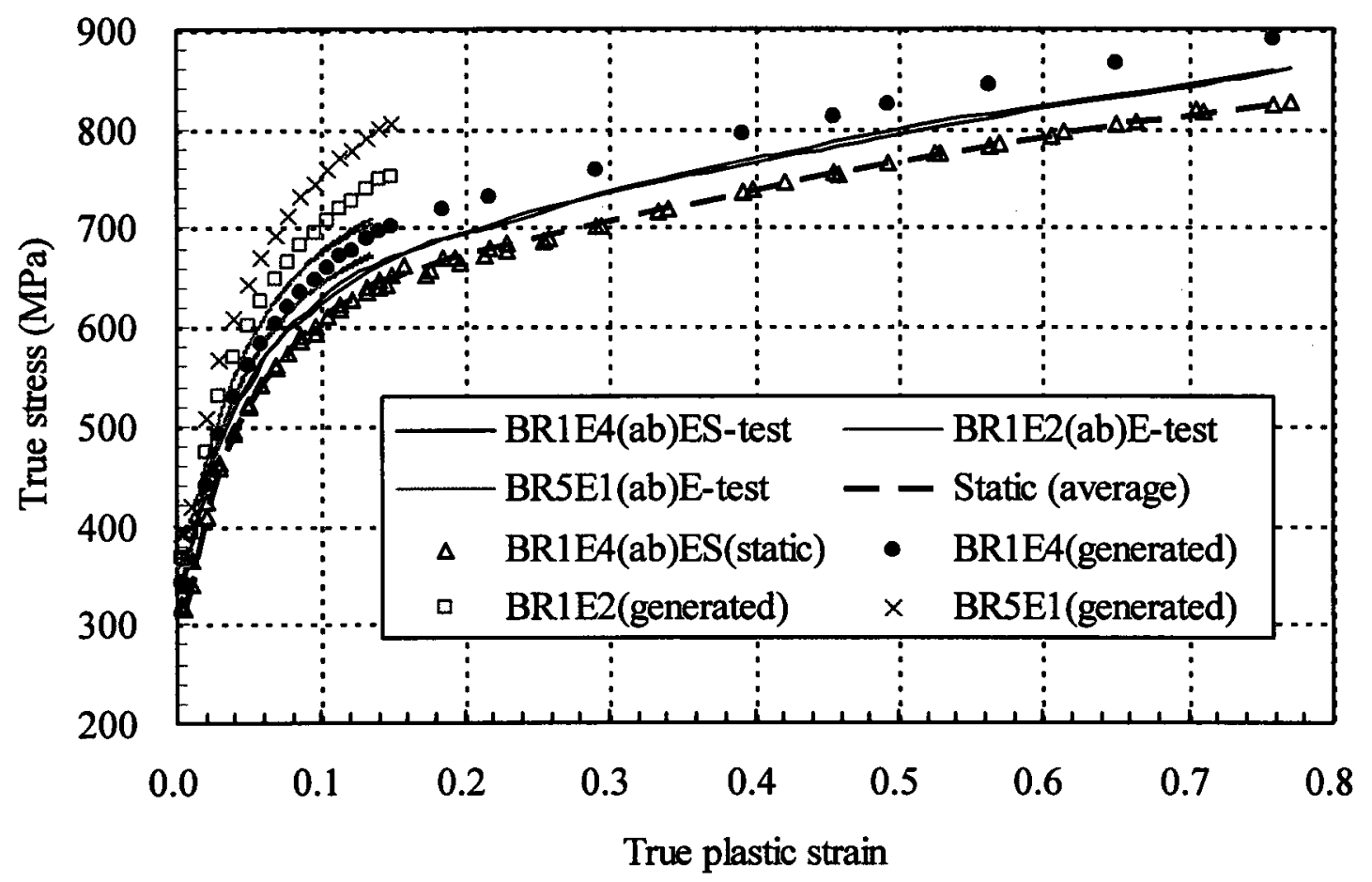

Figure 4.18 Test and predicted true stress-true plastic strain curves with Cowper-Symonds power law Eq. (2.8) for material B

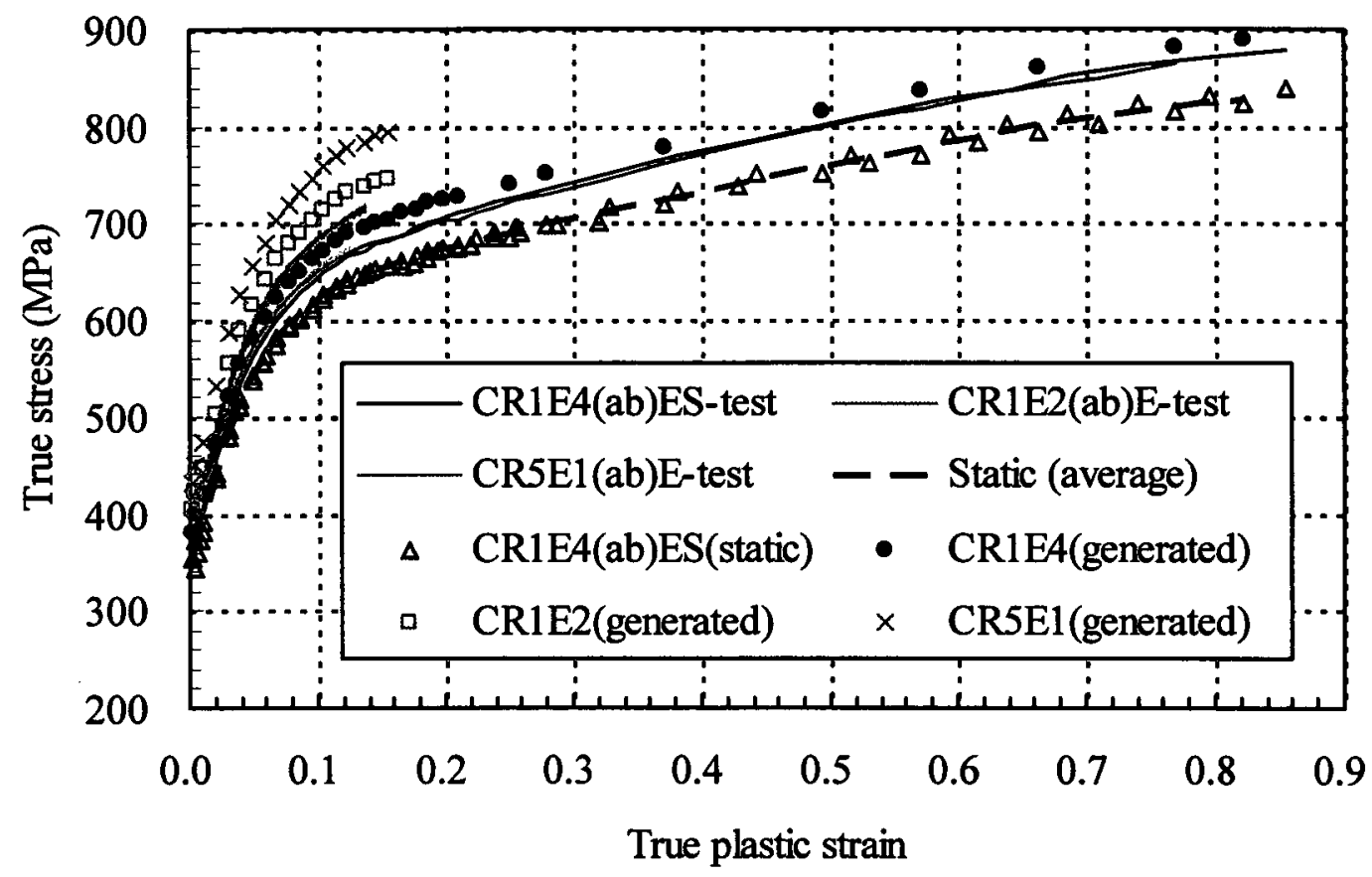

Figure 4.19 Test and predicted true stress-true plastic strain curves with Cowper-Symonds power law Eq. (2.8) for material C 


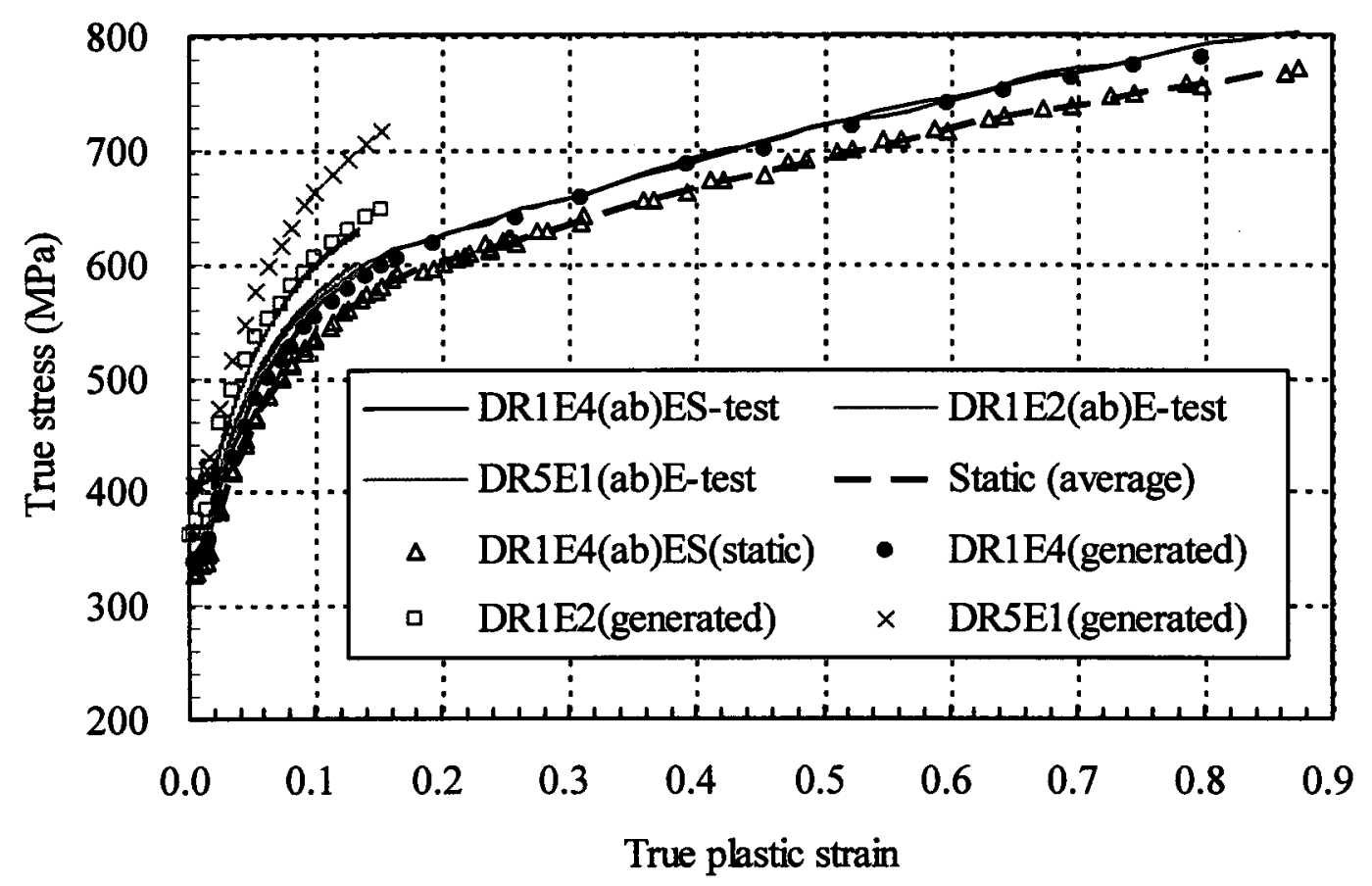

Figure 4.20 Test and predicted true stress-true plastic strain curves with Cowper-Symonds power law Eq. (2.8) for material D

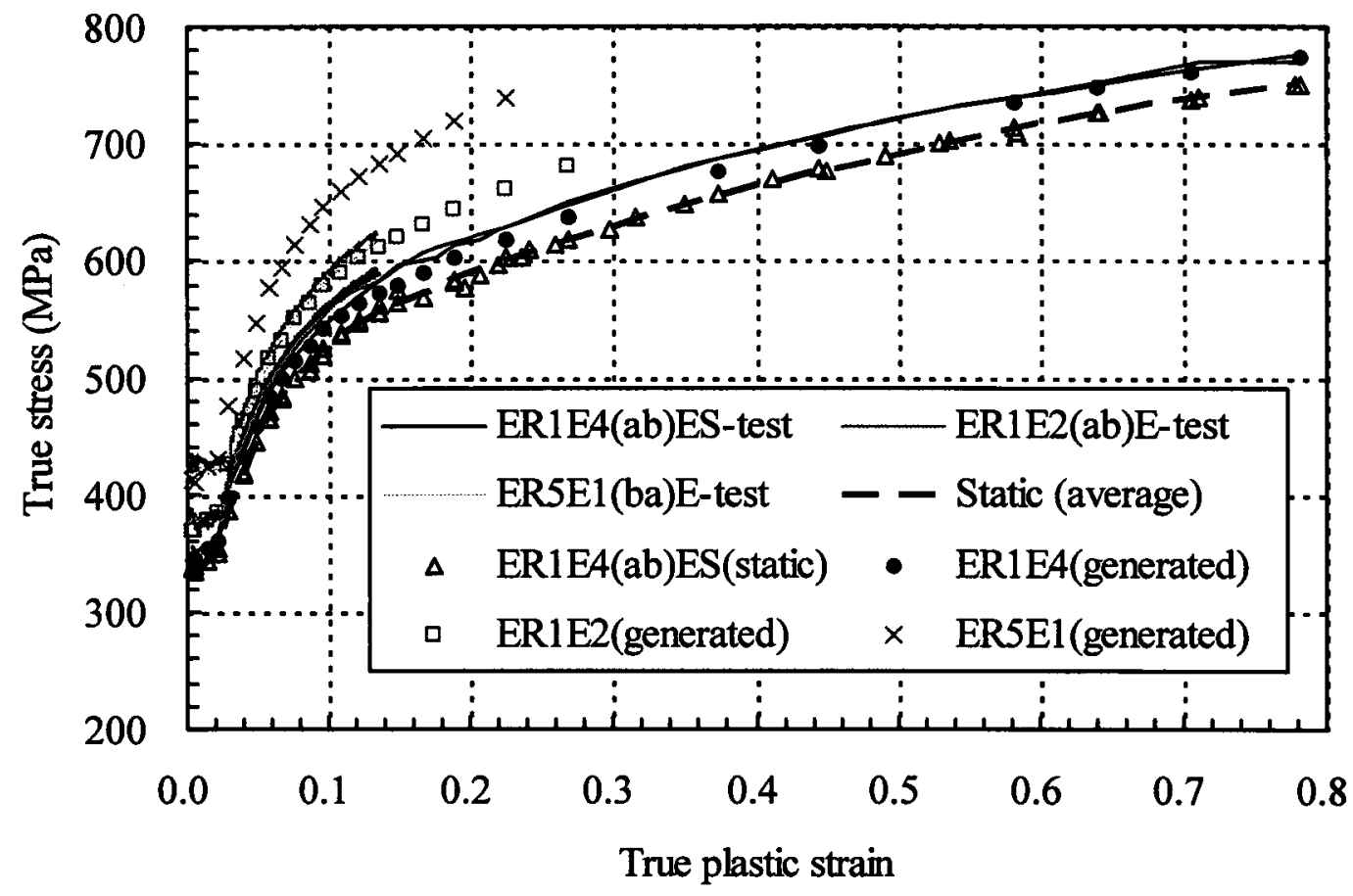

Figure 4.21 Test and predicted true stress-true plastic strain curves with Cowper-Symonds power law Eq. (2.8) for material E 


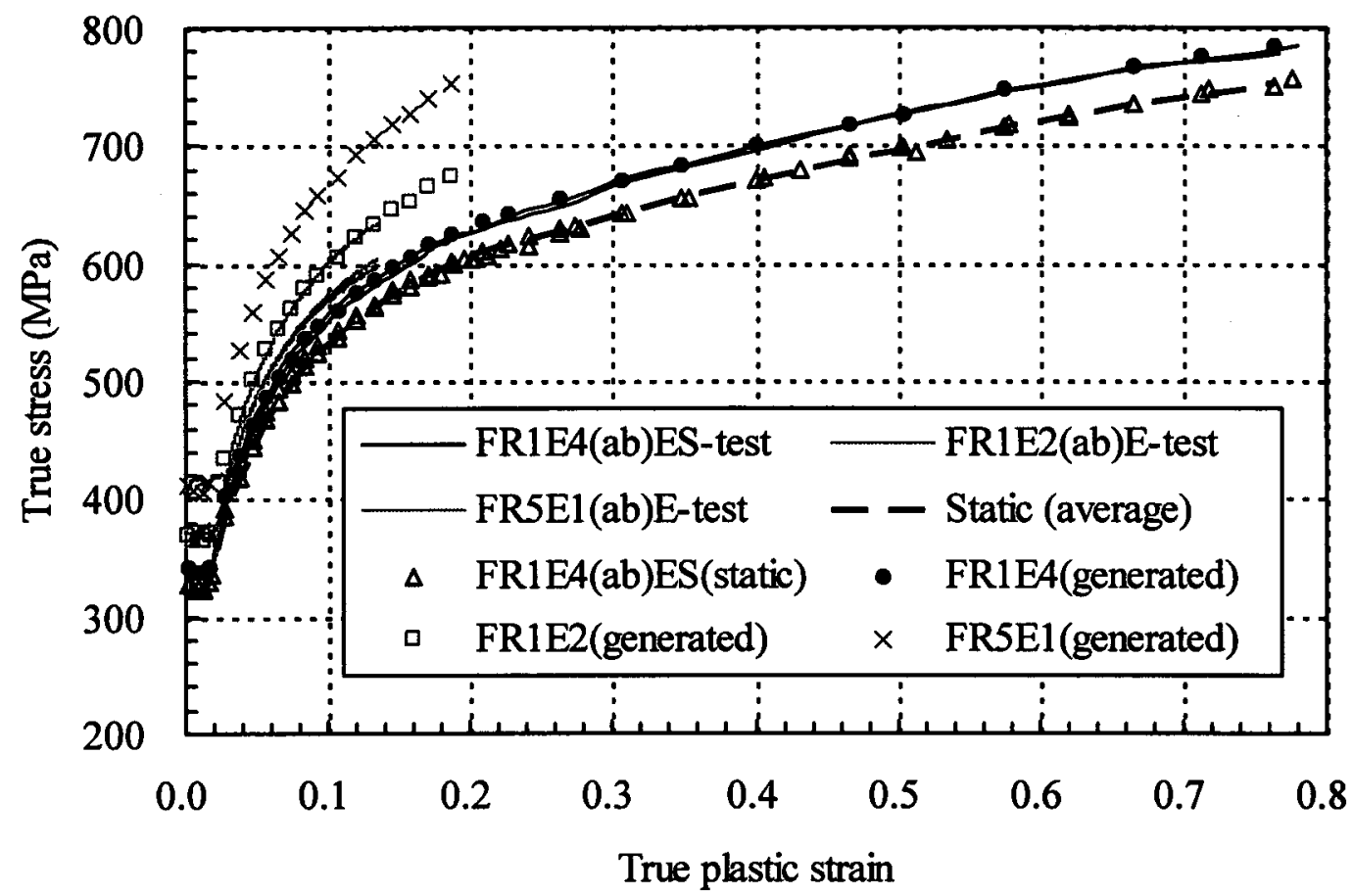

Figure 4.22 Test and predicted true stress-true plastic strain curves with Cowper-Symonds power law Eq. (2.8) for material F

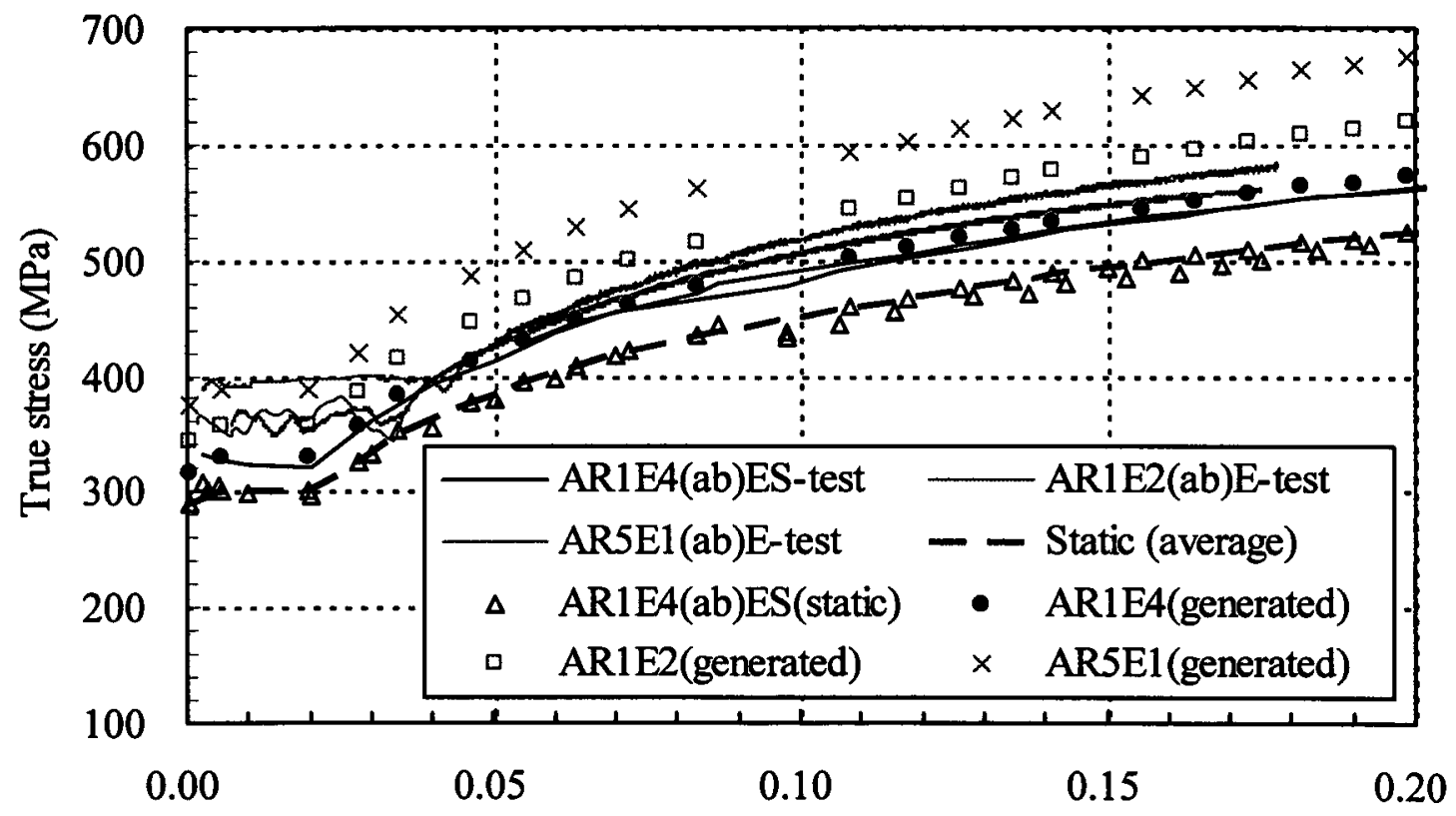

True plastic strain

Figure 4.23 Test and predicted true stress-true plastic strain curves with Cowper-Symonds power law Eq. (2.8) for material A (up to strain of 0.2) 




Figure 4.24 Test and predicted true stress-true plastic strain curves with Cowper-Symonds power law Eq. (2.8) for material B (up to strain of 0.2)

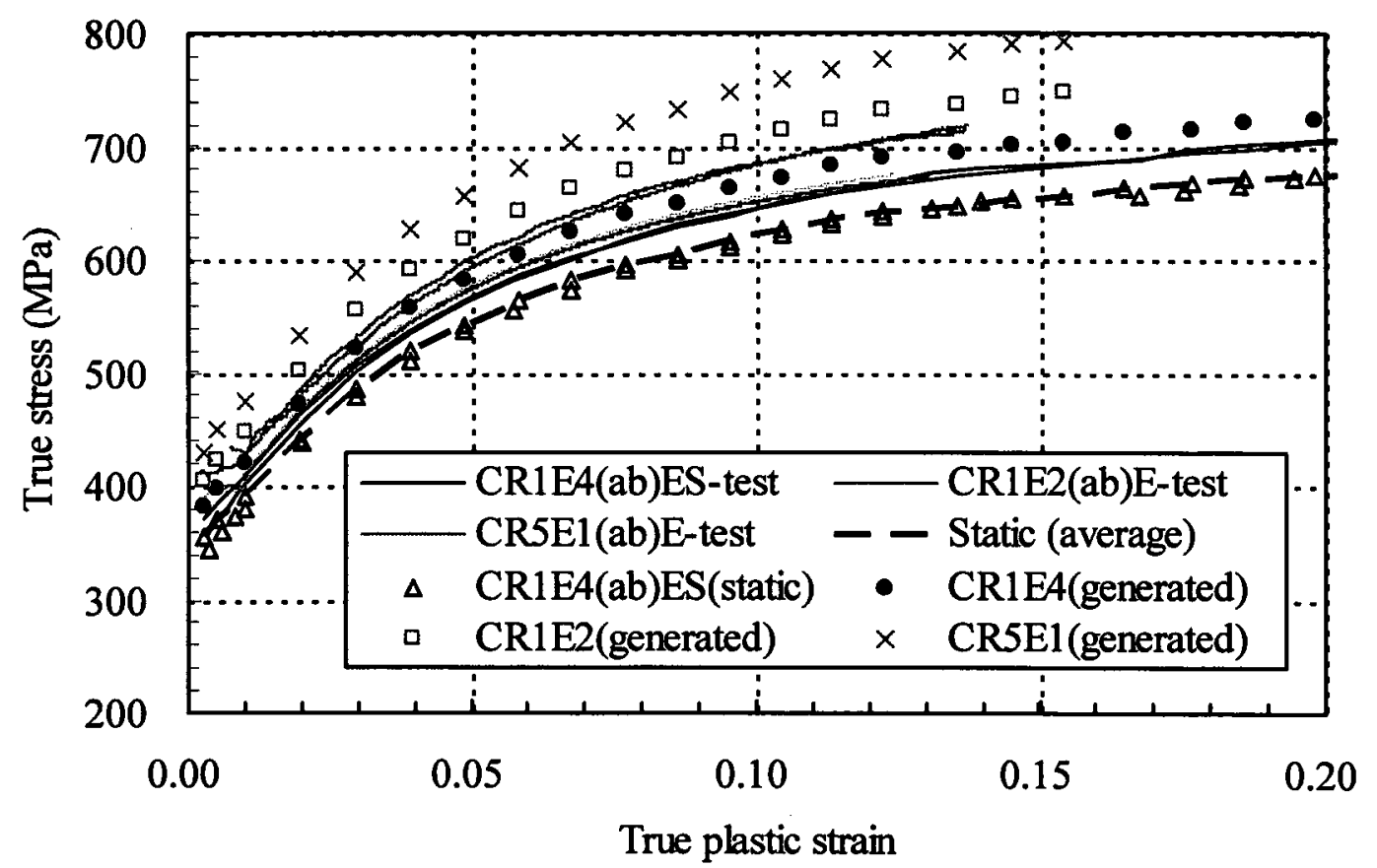

Figure 4.25 Test and predicted true stress-true plastic strain curves with Cowper-Symonds power law Eq. (2.8) for material C (up to strain of 0.2) 


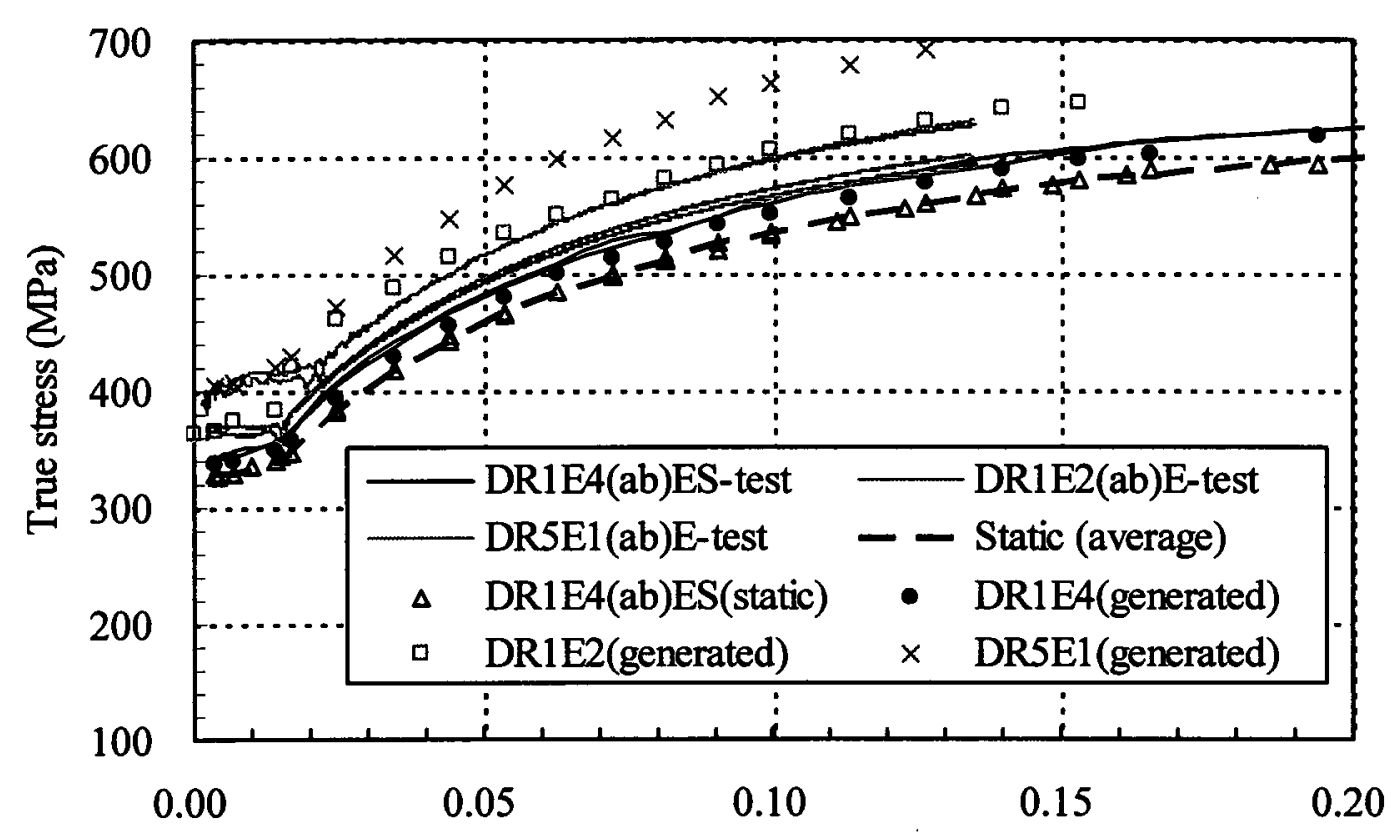

True plastic strain

Figure 4.26 Test and predicted true stress-true plastic strain curves with Cowper-Symonds power law Eq. (2.8) for material D (up to strain of 0.2 )

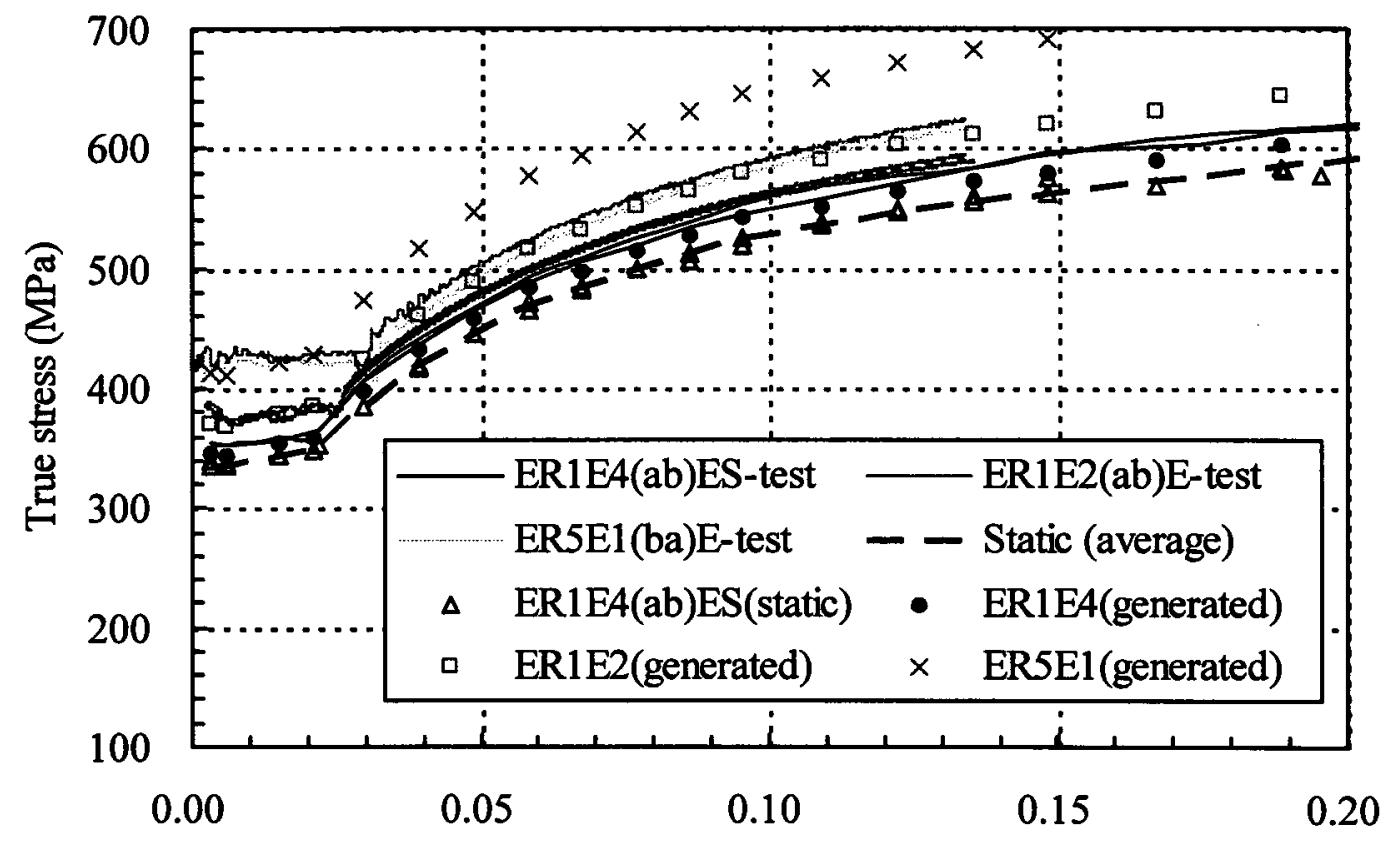

True plastic strain

Figure 4.27 Test and predicted true stress-true plastic strain curves with Cowper-Symonds power law Eq. (2.8) for material E (up to strain of 0.2) 


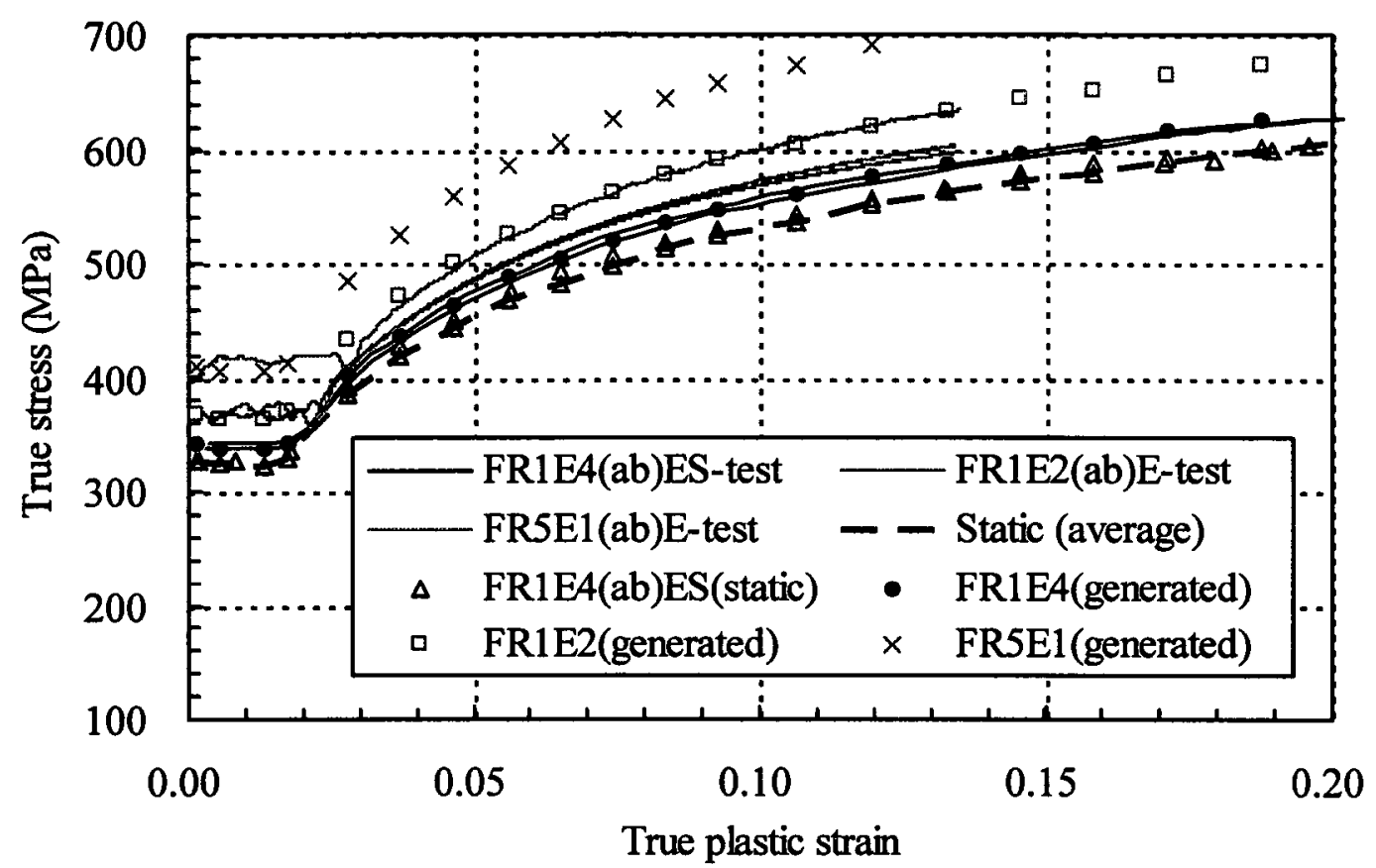

Figure 4.28 Test and predicted true stress-true plastic strain curves with Cowper-Symonds power law Eq. (2.8) for material F (up to strain of 0.2)

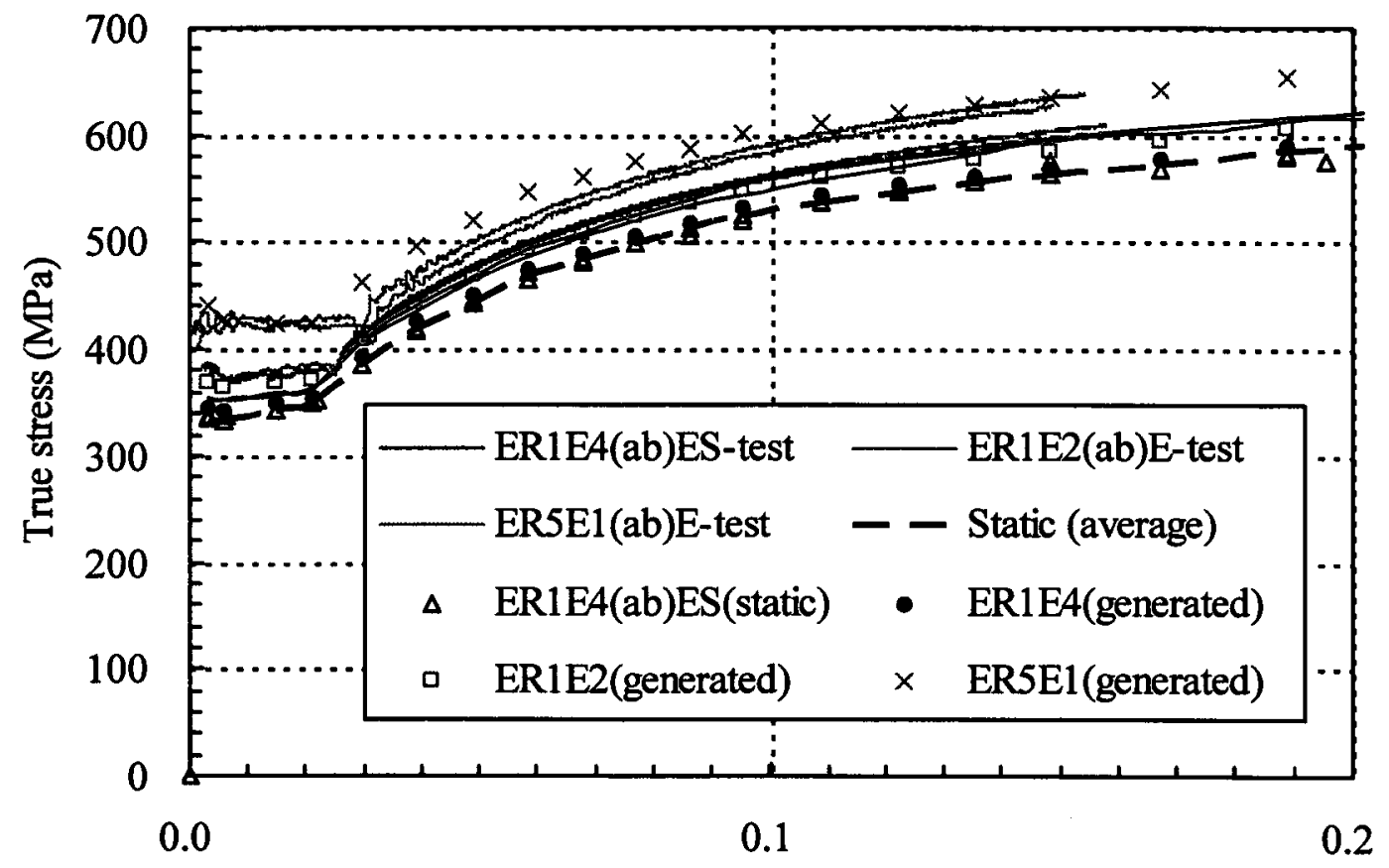

True plastic strain

Figure 4.29 Test and predicted true stress-true plastic strain curves with modified Cowper-Symonds power law for material E (up to strain of 0.2) 


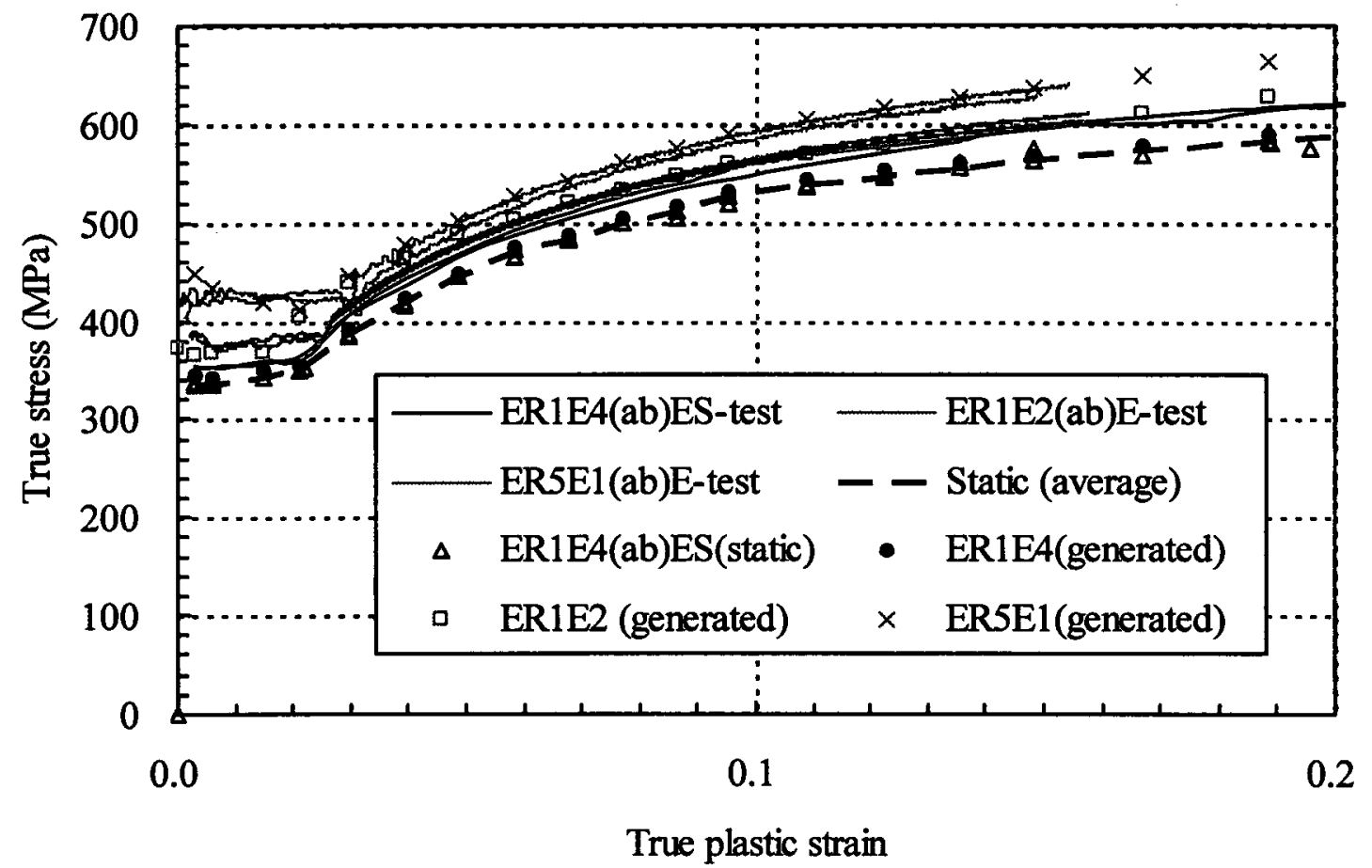

Figure 4.30 Test and predicted true stress-true plastic strain curves with mixed-mode hardening model for material $\mathrm{E}$ (up to strain of 0.2)

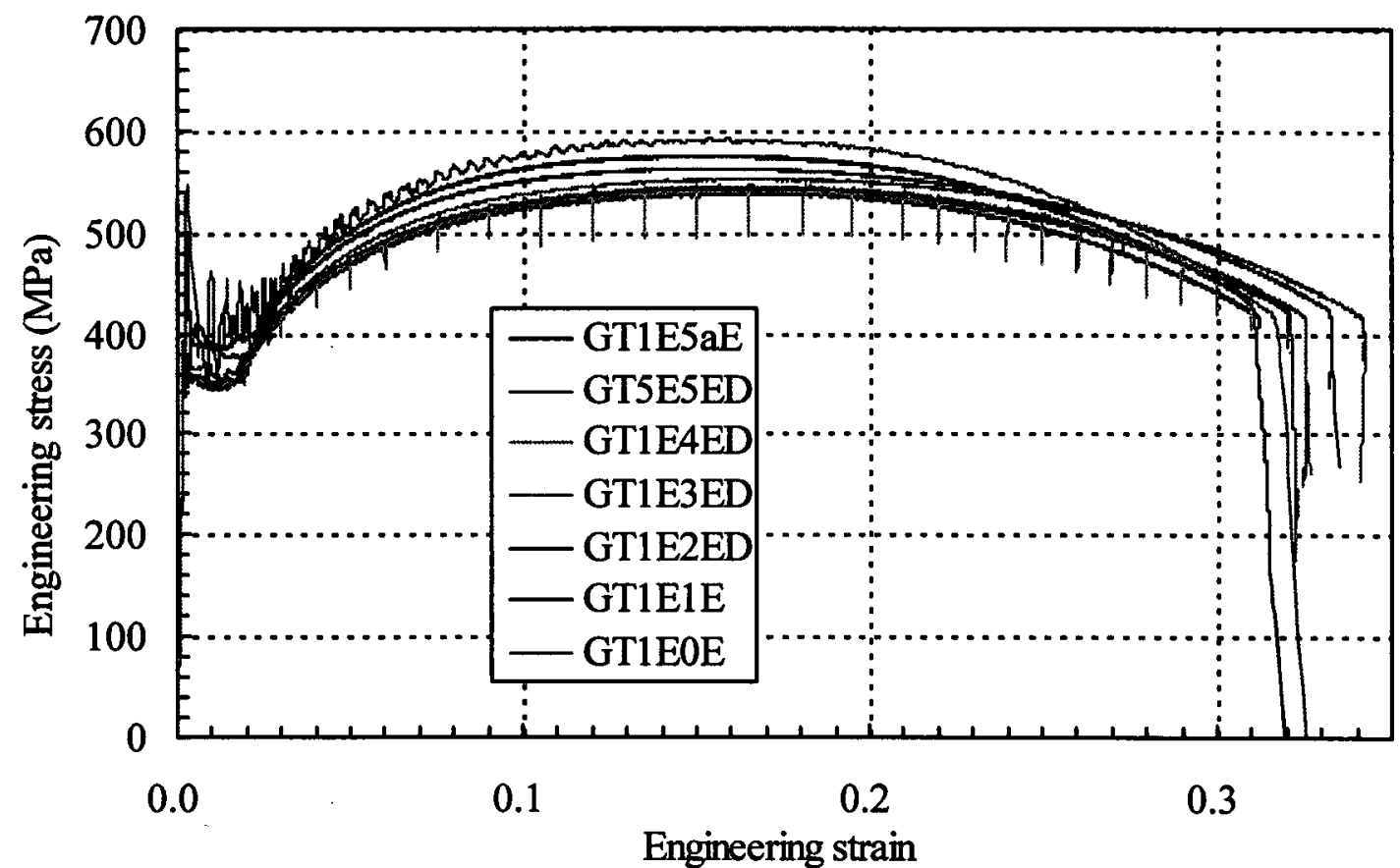

Figure 4.31 Engineering stress-engineering strain curves for material G 


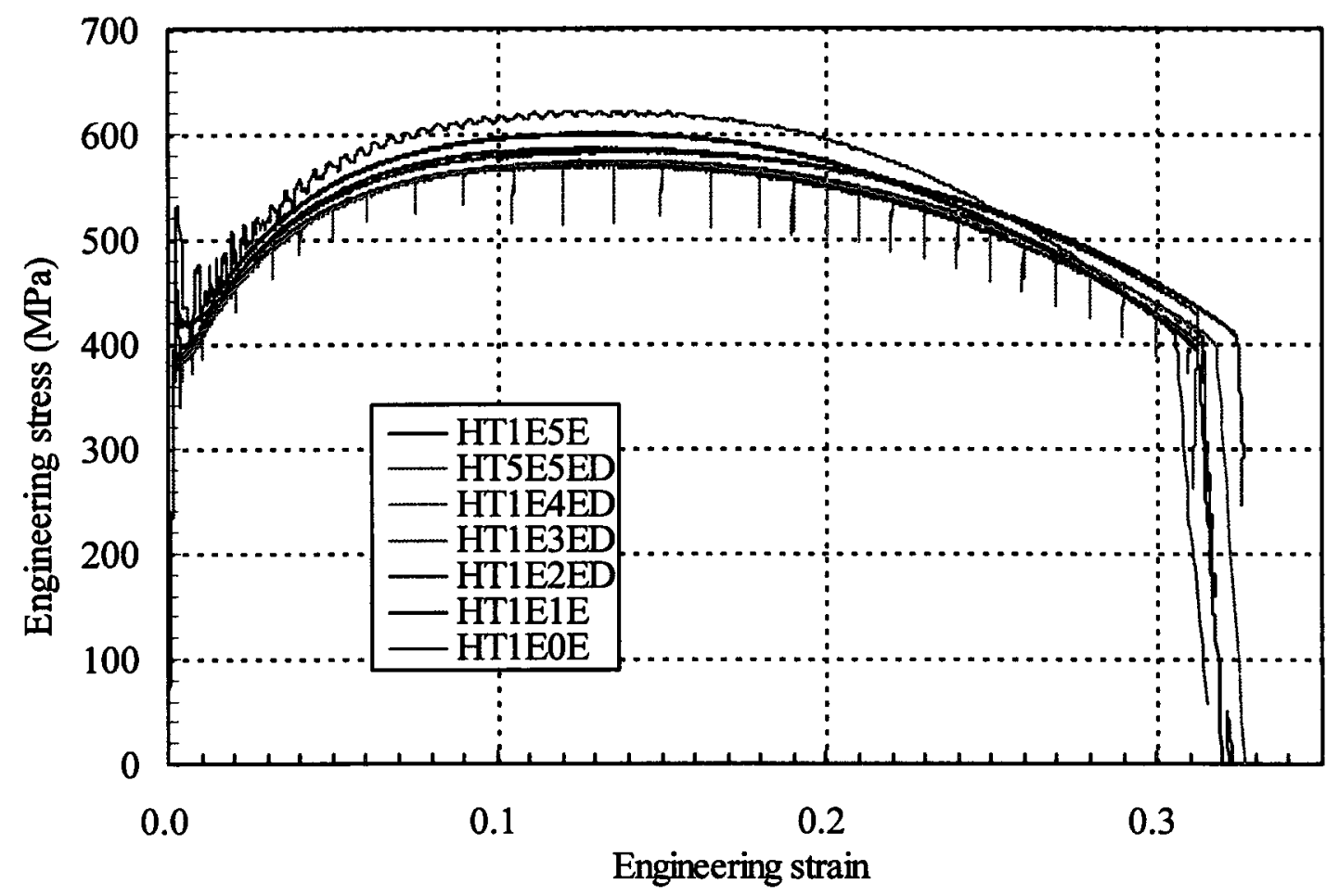

Figure 4.32 Engineering stress-engineering strain curves for material $\mathrm{H}$

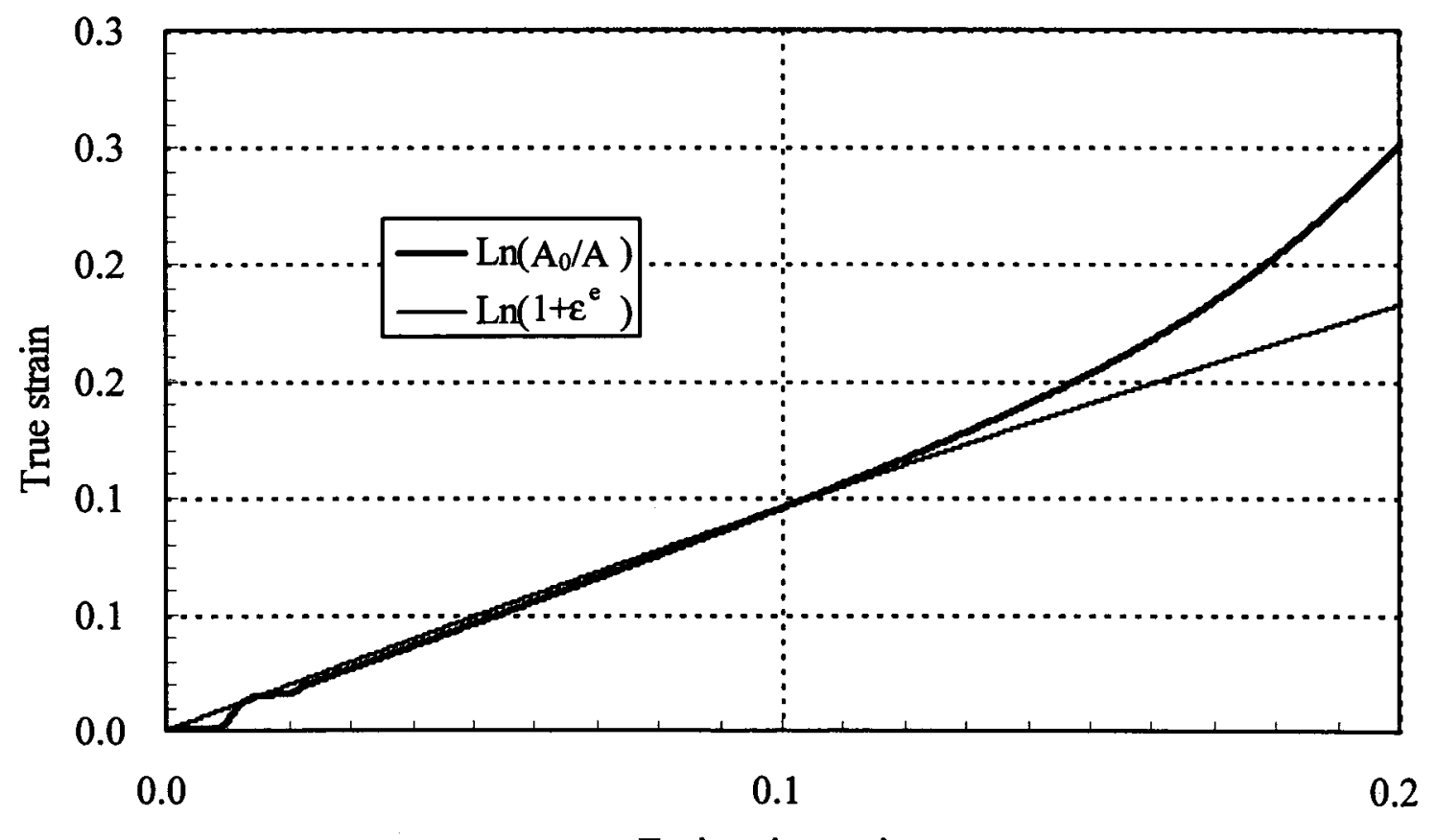

Engineering strain

Figure 4.33 Comparison of true strain calculated with Eqs. (4.4) and (4.5) for GT1E5aE 


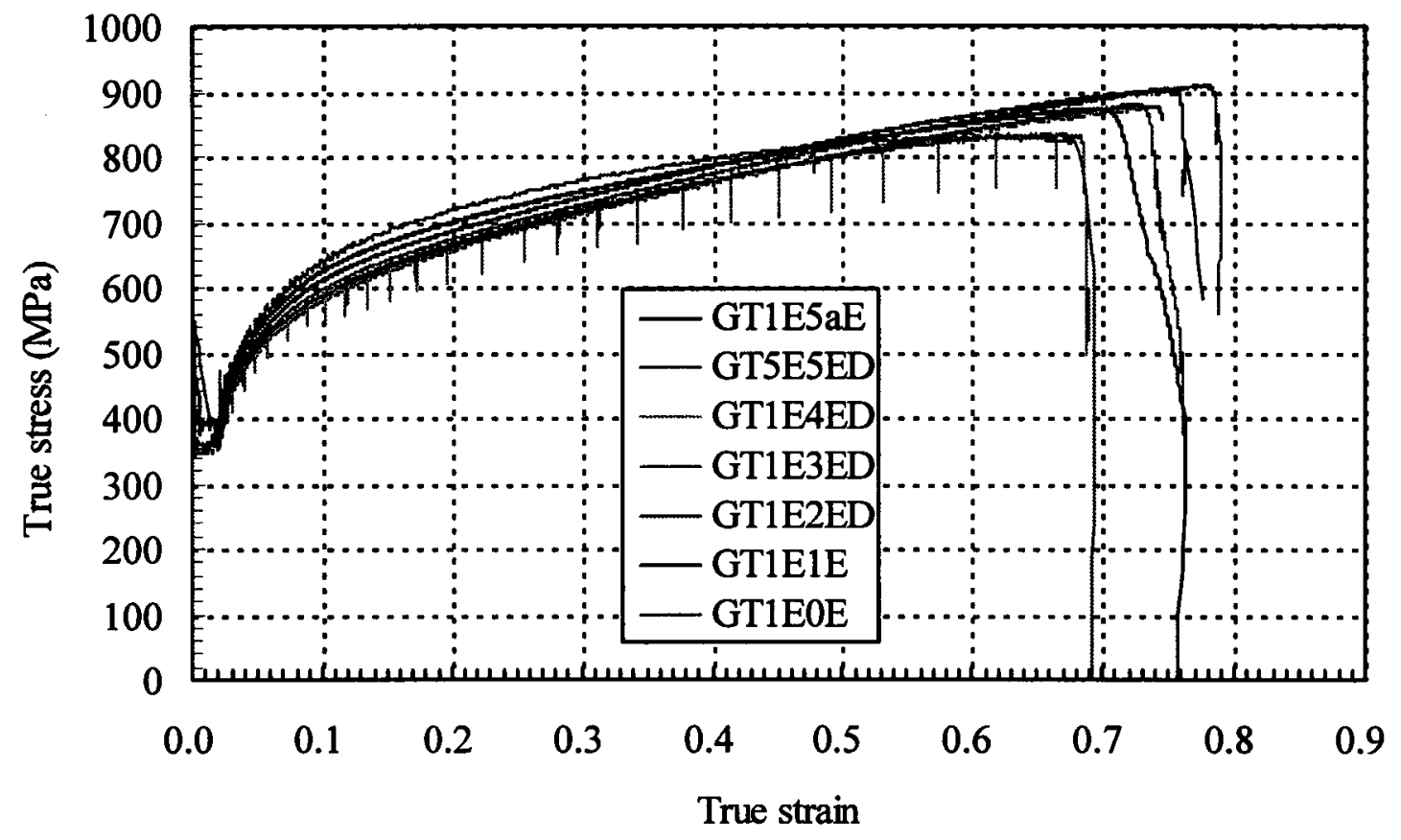

Figure 4.34 Average true stress-true strain curves of material G

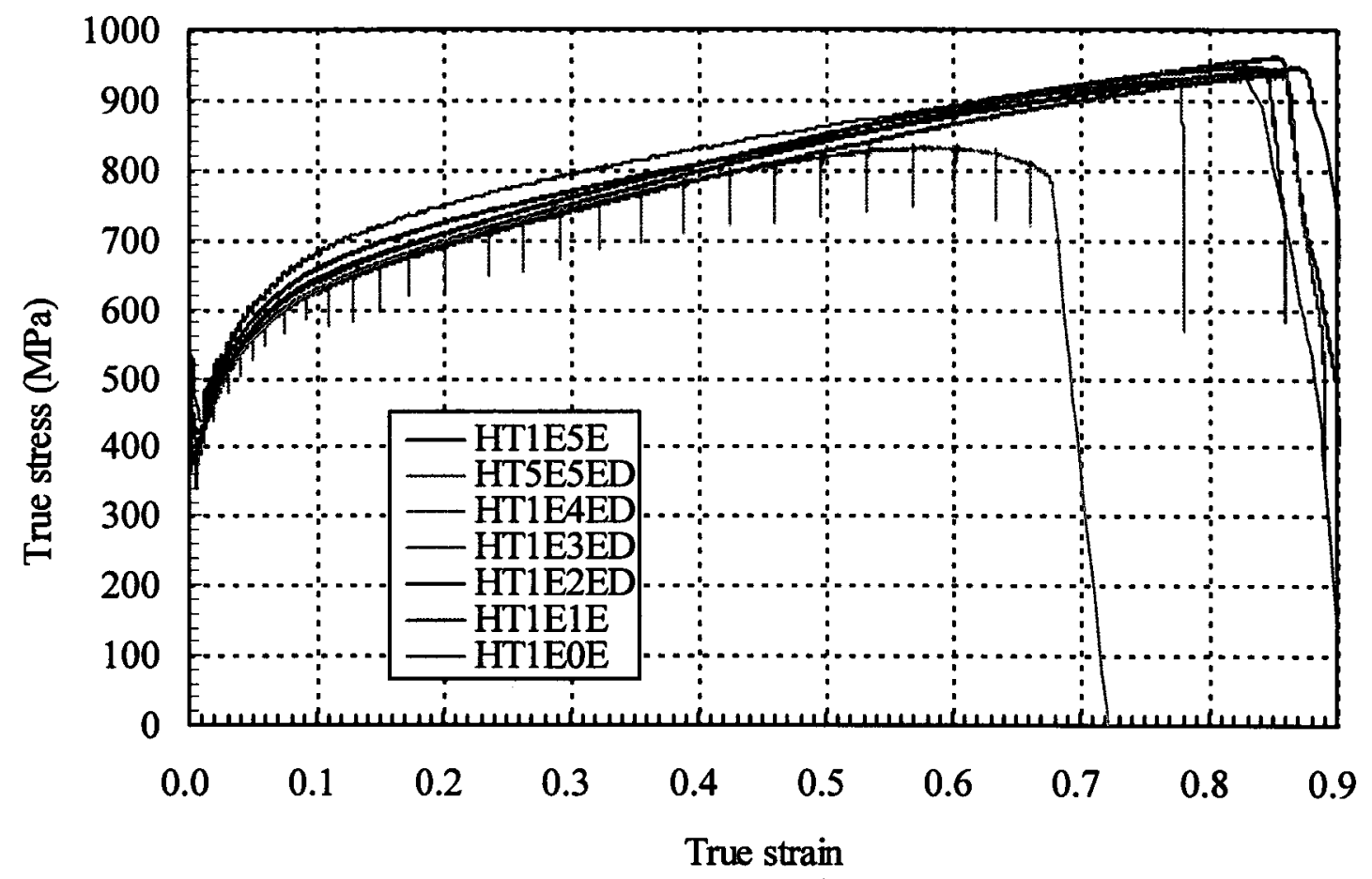

Figure 4.35 Average true stress-true strain curves of material $\mathrm{H}$ 


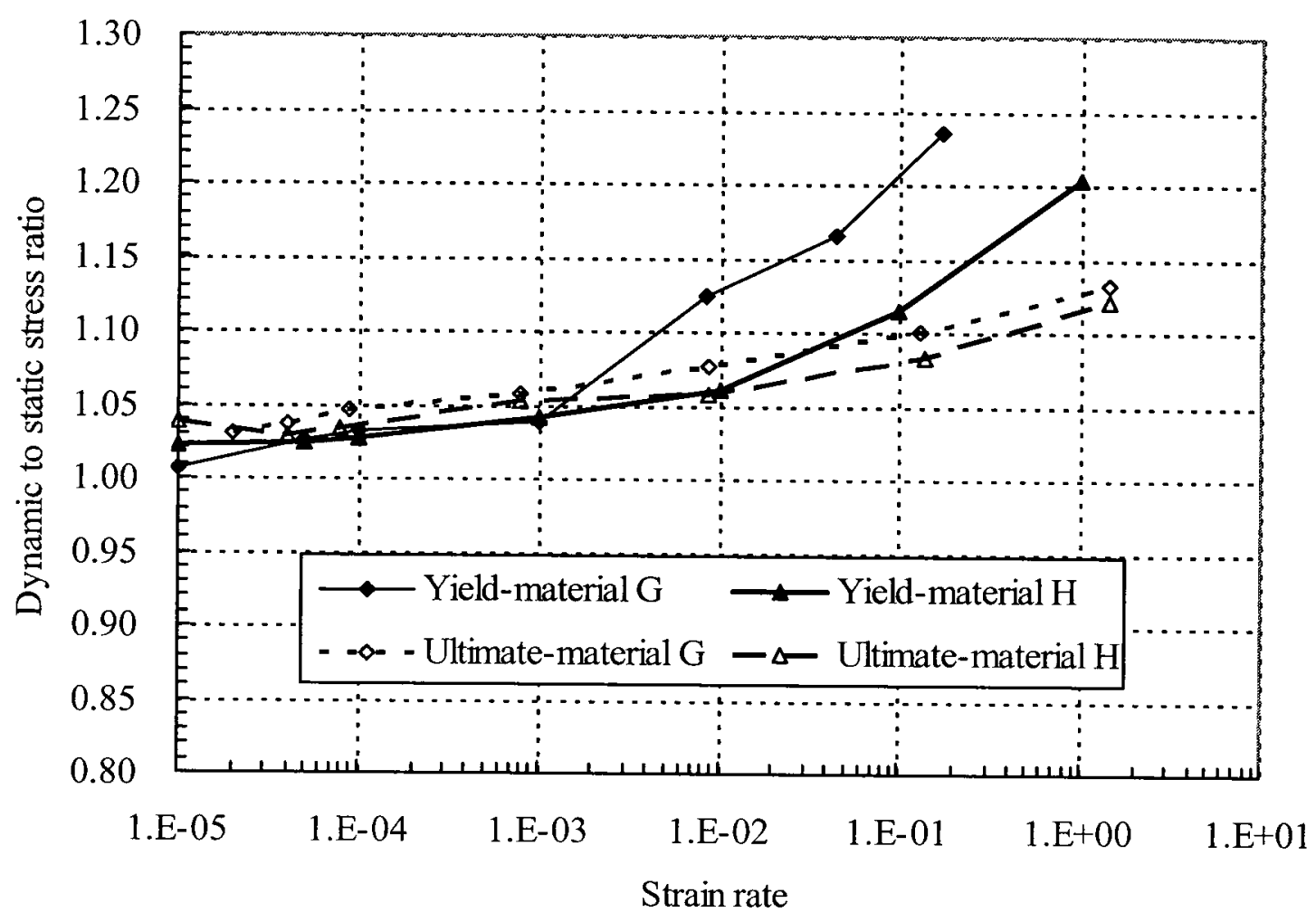

Figure 4.36 Yield and ultimate stress ratios versus actual loading rate

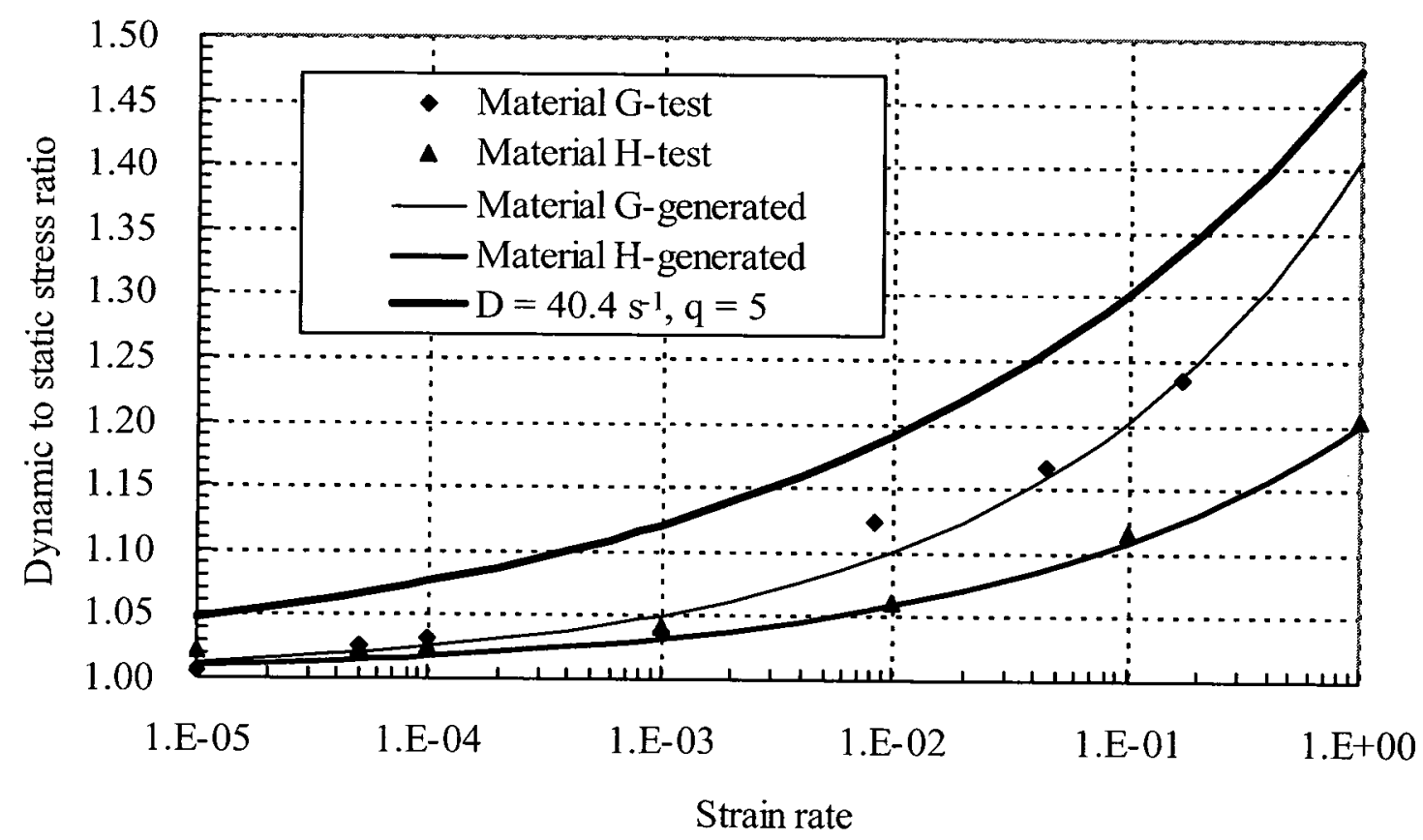

Figure 4.37 Comparisons of the test and predicted yield stress with Cowper-Symonds power law equation 


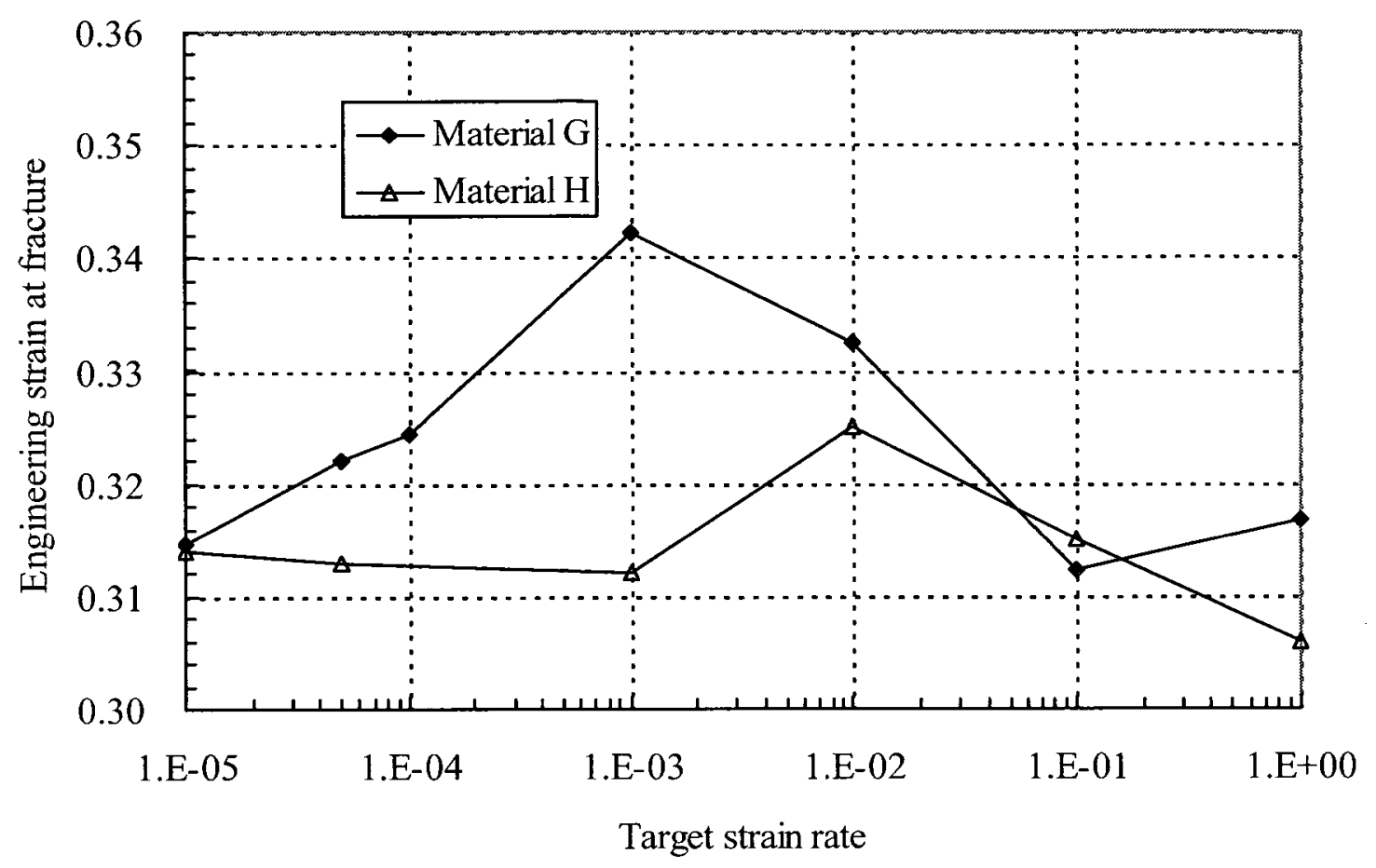

Figure 4.38 Engineering strain at fracture for materials $\mathrm{G}$ and $\mathrm{H}$

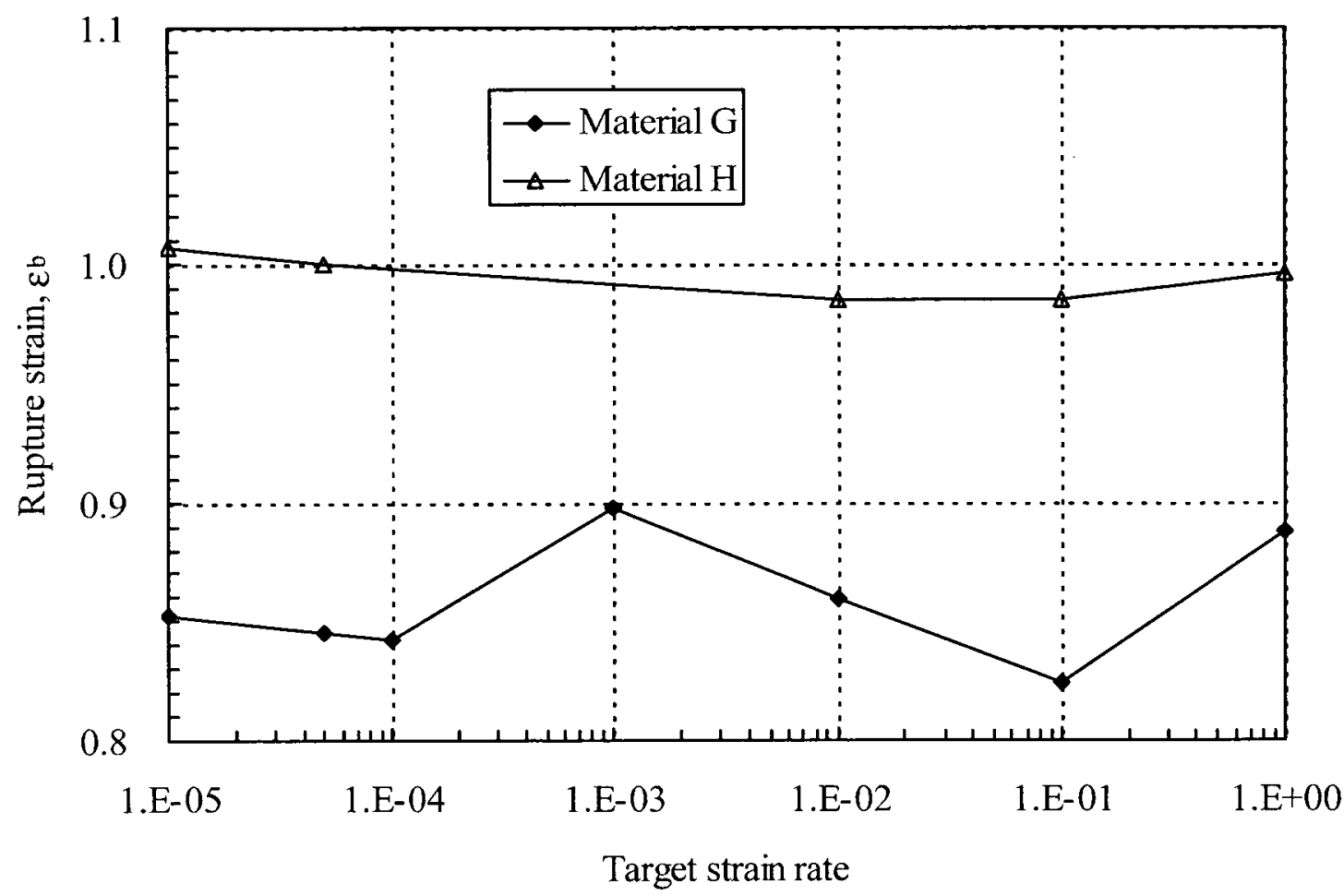

Figure 4.39 After test rupture strain for materials $\mathrm{G}$ and $\mathrm{H}$ 


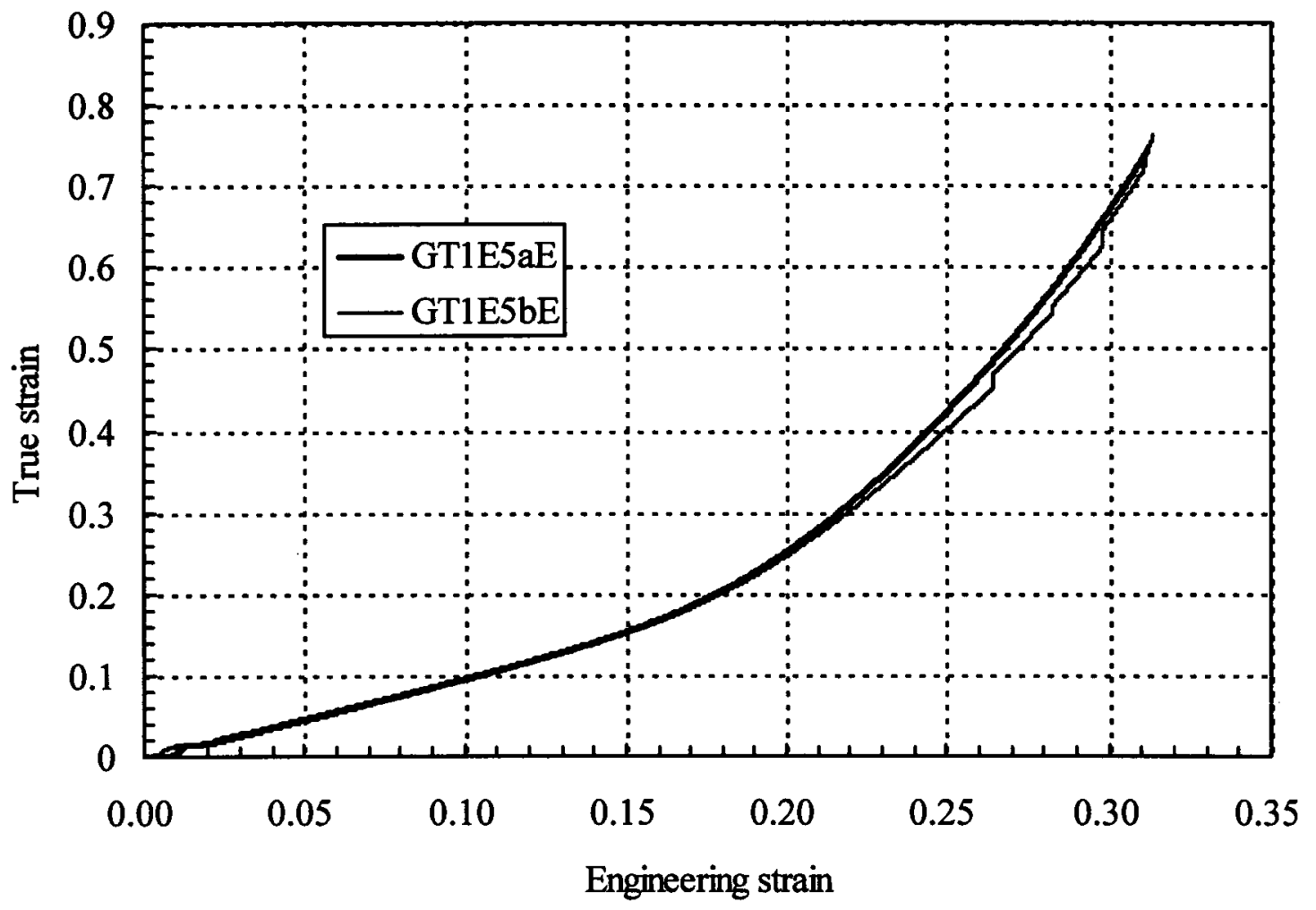

Figure 4.40 Measured true strain-engineering strain curve for GT1E5aE and GT1E5bE

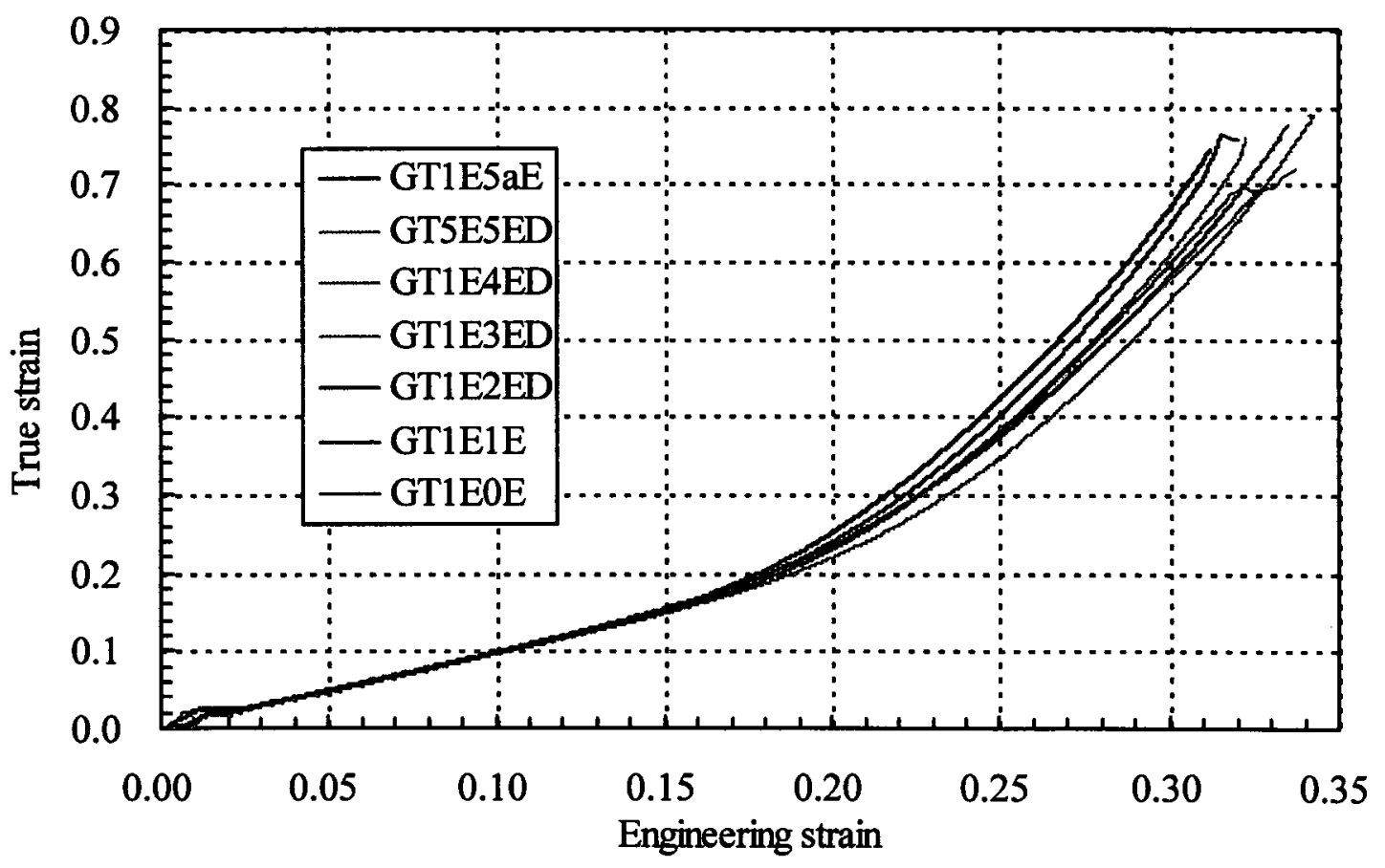

Figure 4.41 Measured true strain-engineering strain relationships for material G 


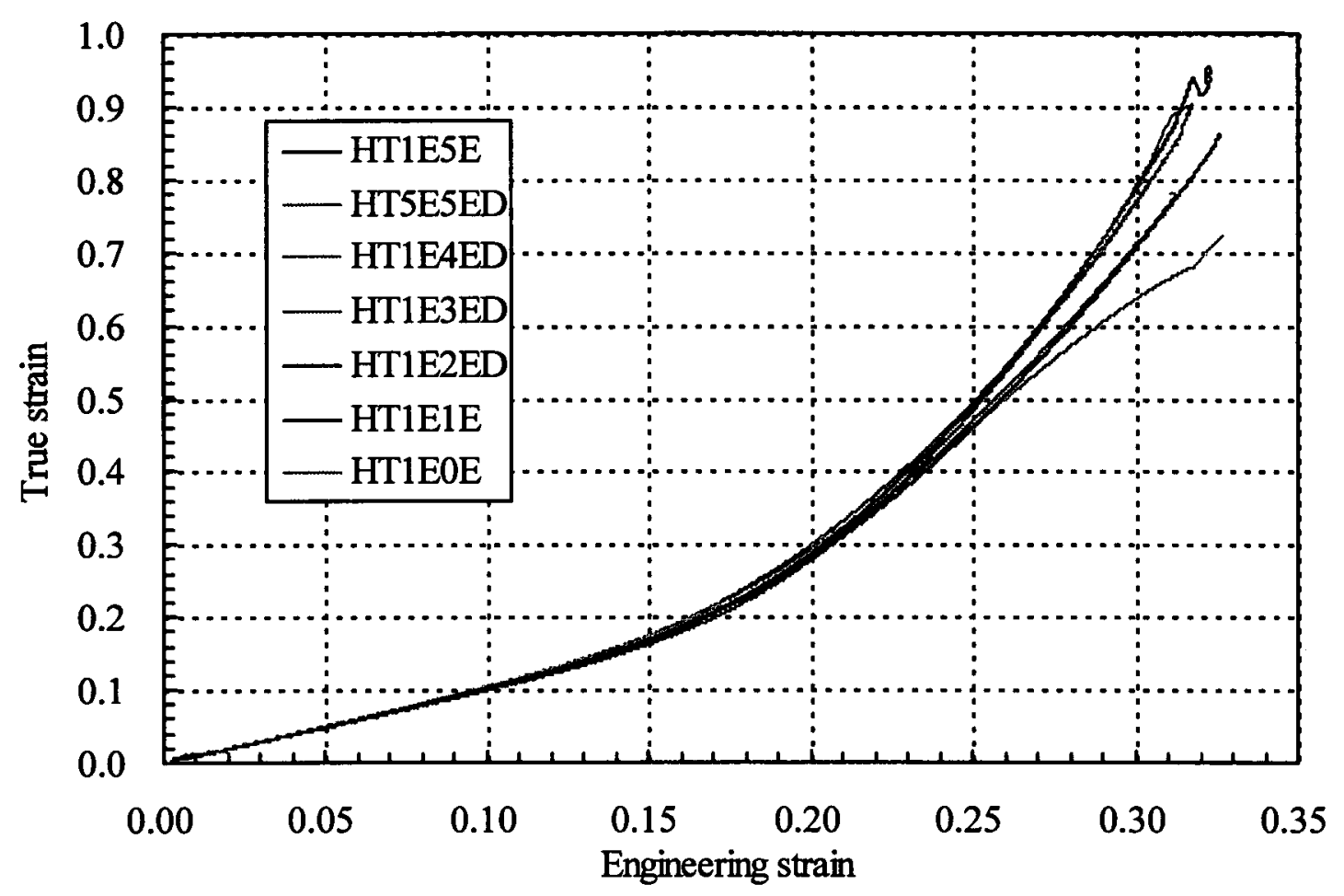

Figure 4.42 Measured true strain-engineering strain relationships for material $\mathrm{H}$

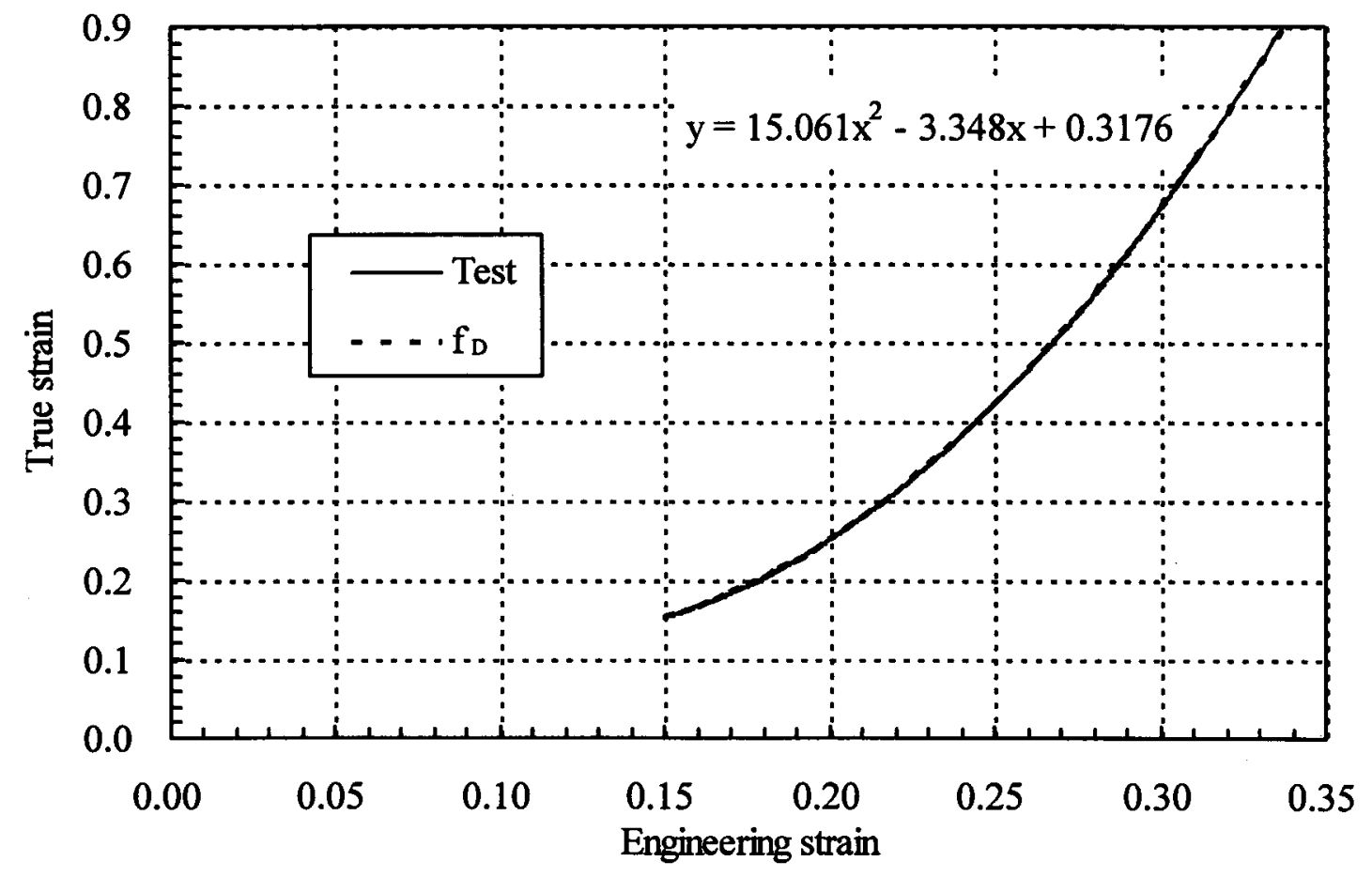

Figure 4.43 Curve fitting parabolic and measured true strain-engineering strain curves for GT1E5aE 


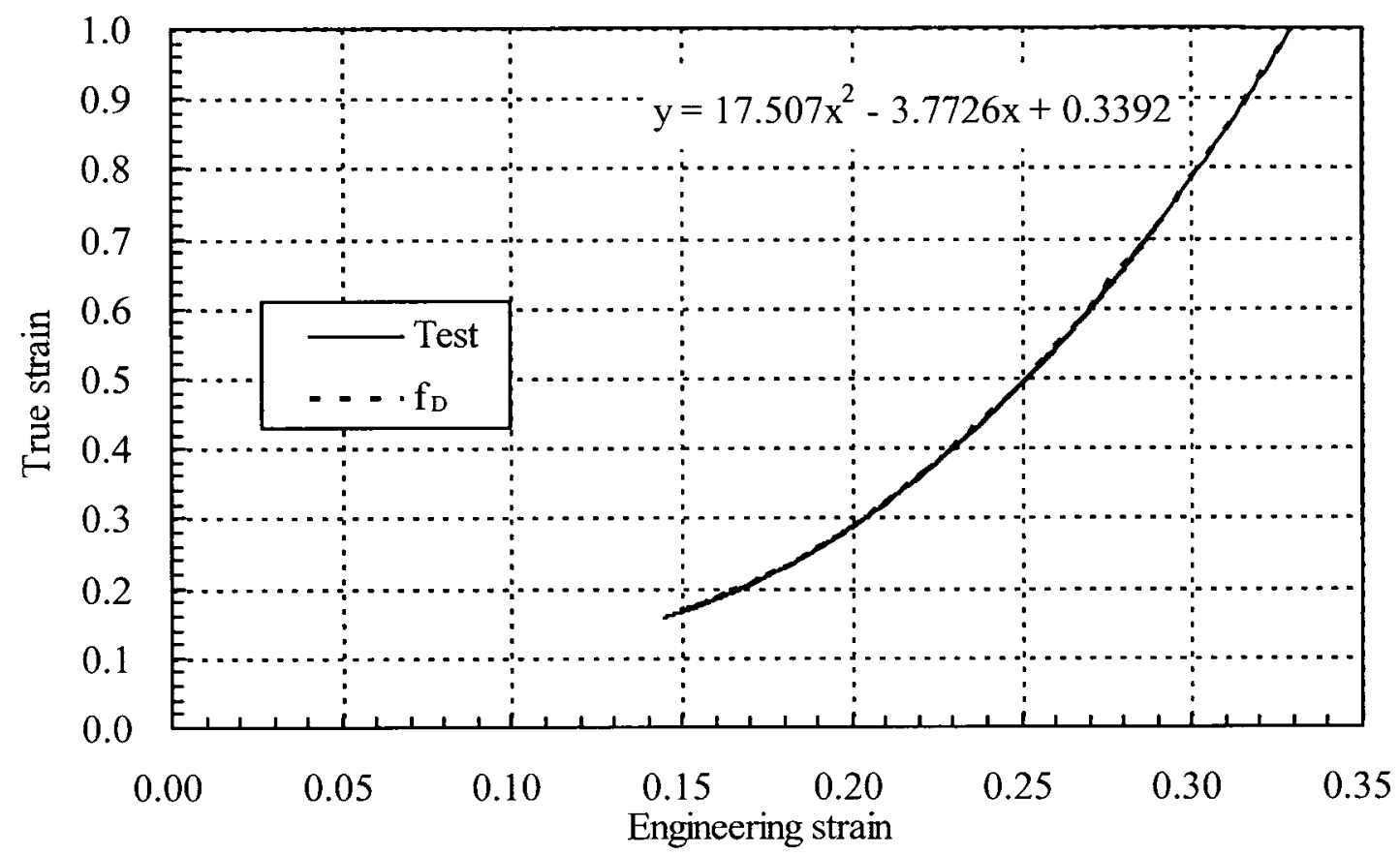

Figure 4.44 Curve fitting parabolic and measured true strain-engineering strain curves for HT1E1E

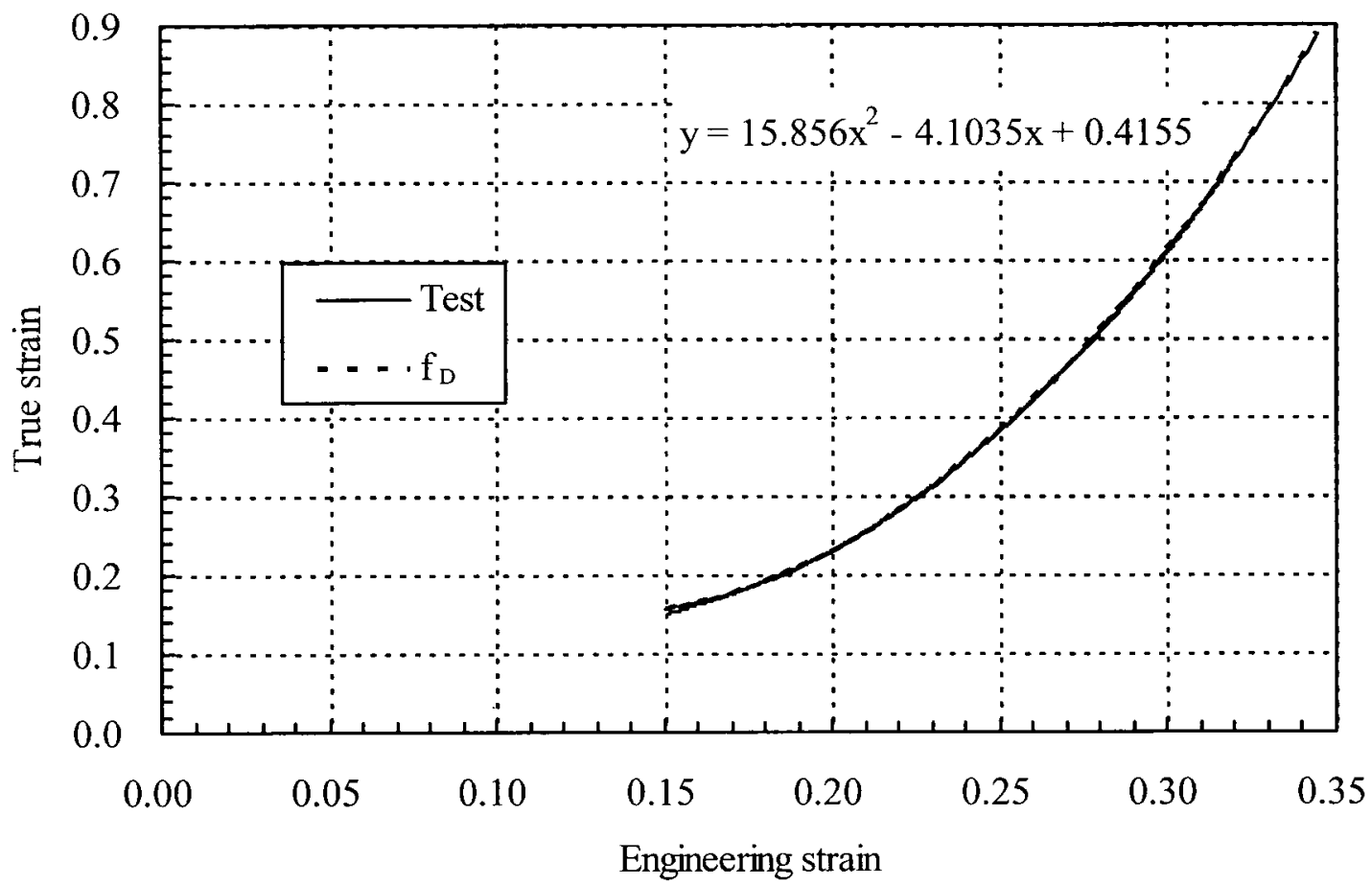

Figure 4.45 Curve fitting parabolic and measured true strain-engineering strain curves for GT5E5ED 


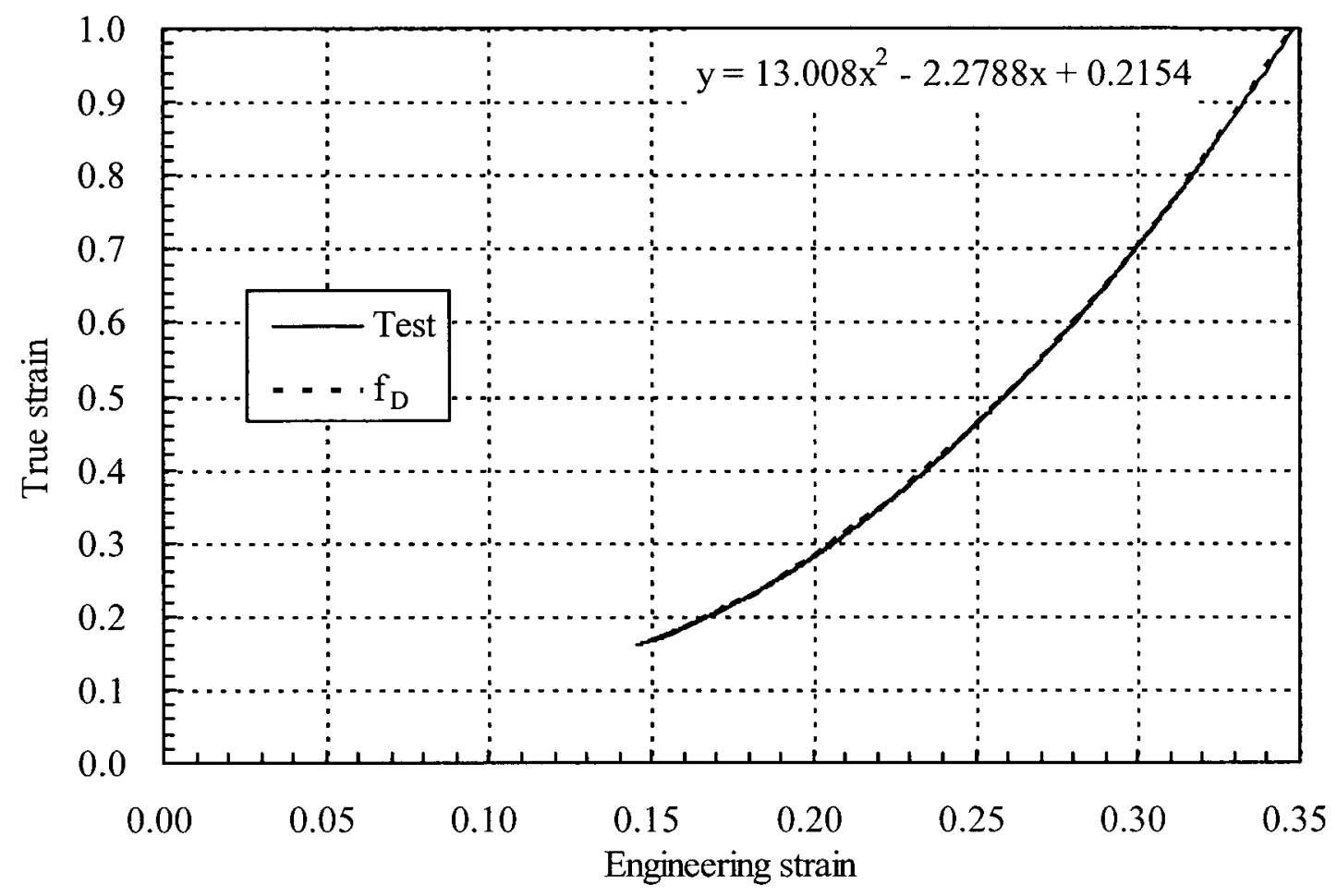

Figure 4.46 Curve fitting parabolic and measured true strain-engineering strain curves for HT1E3ED 


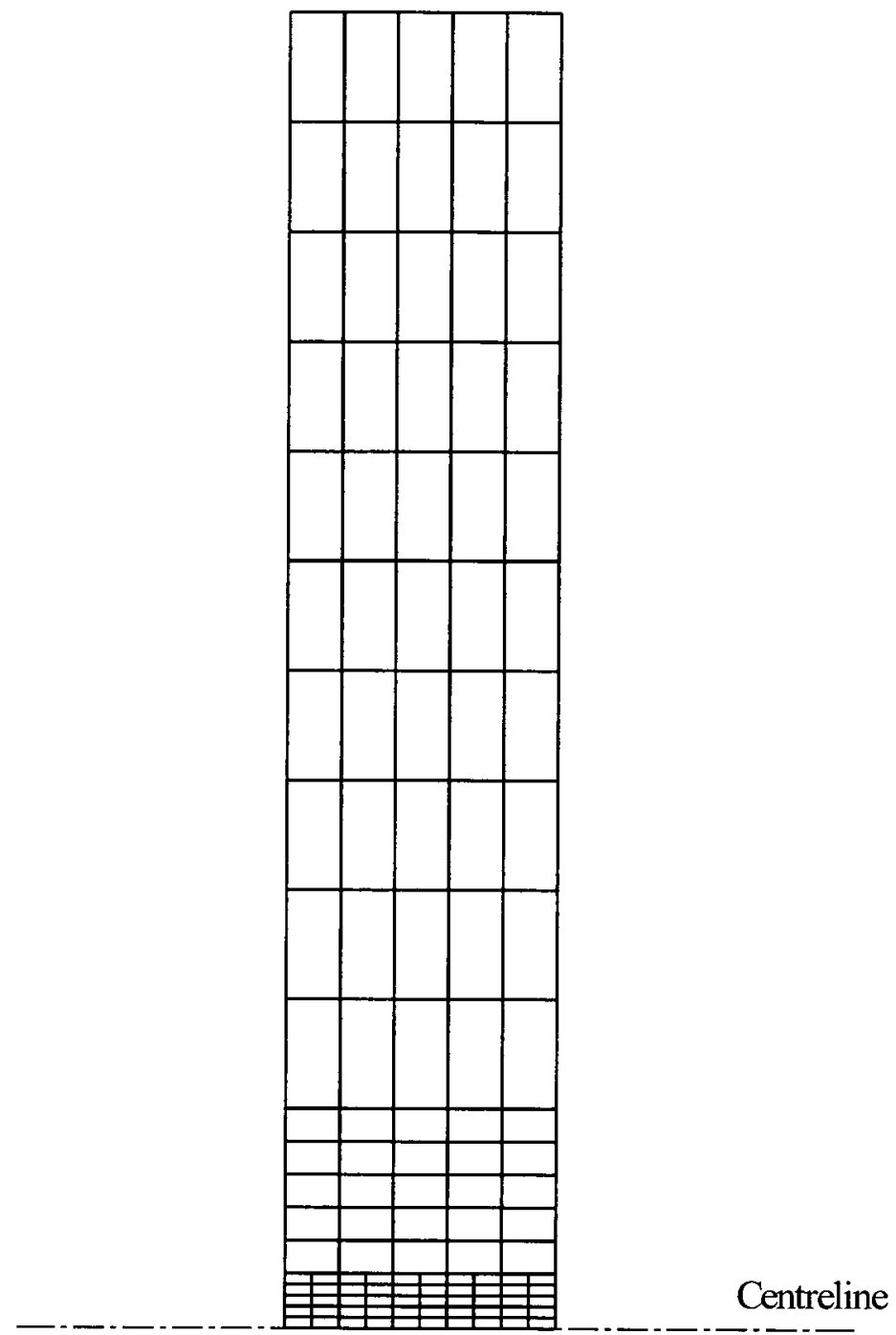

Figure 4.47 Model for one-half of round specimen 


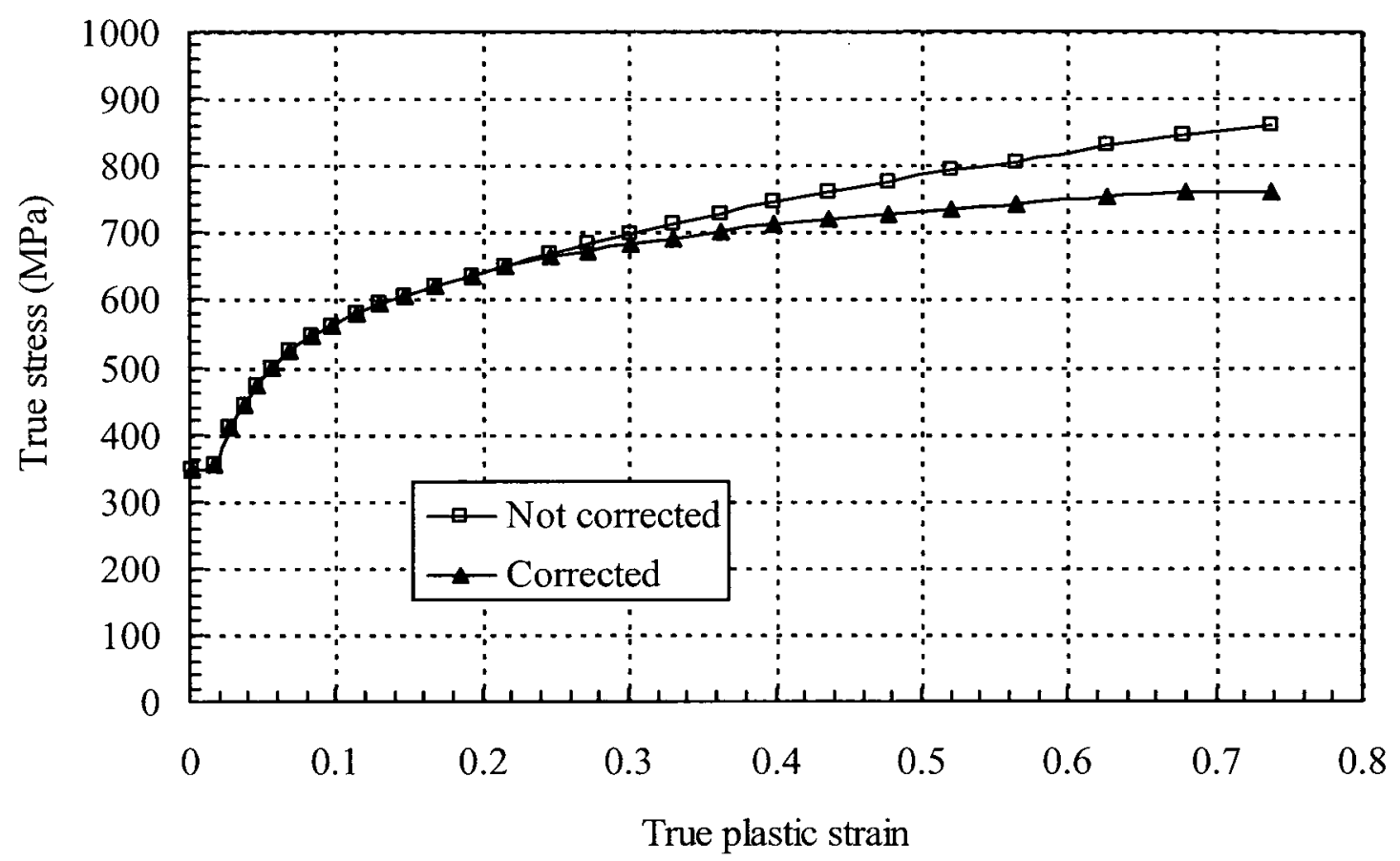

Figure 4.48 Static true stress versus true plastic strain curves for GT1E4S with and without Eq. (4.26) correction

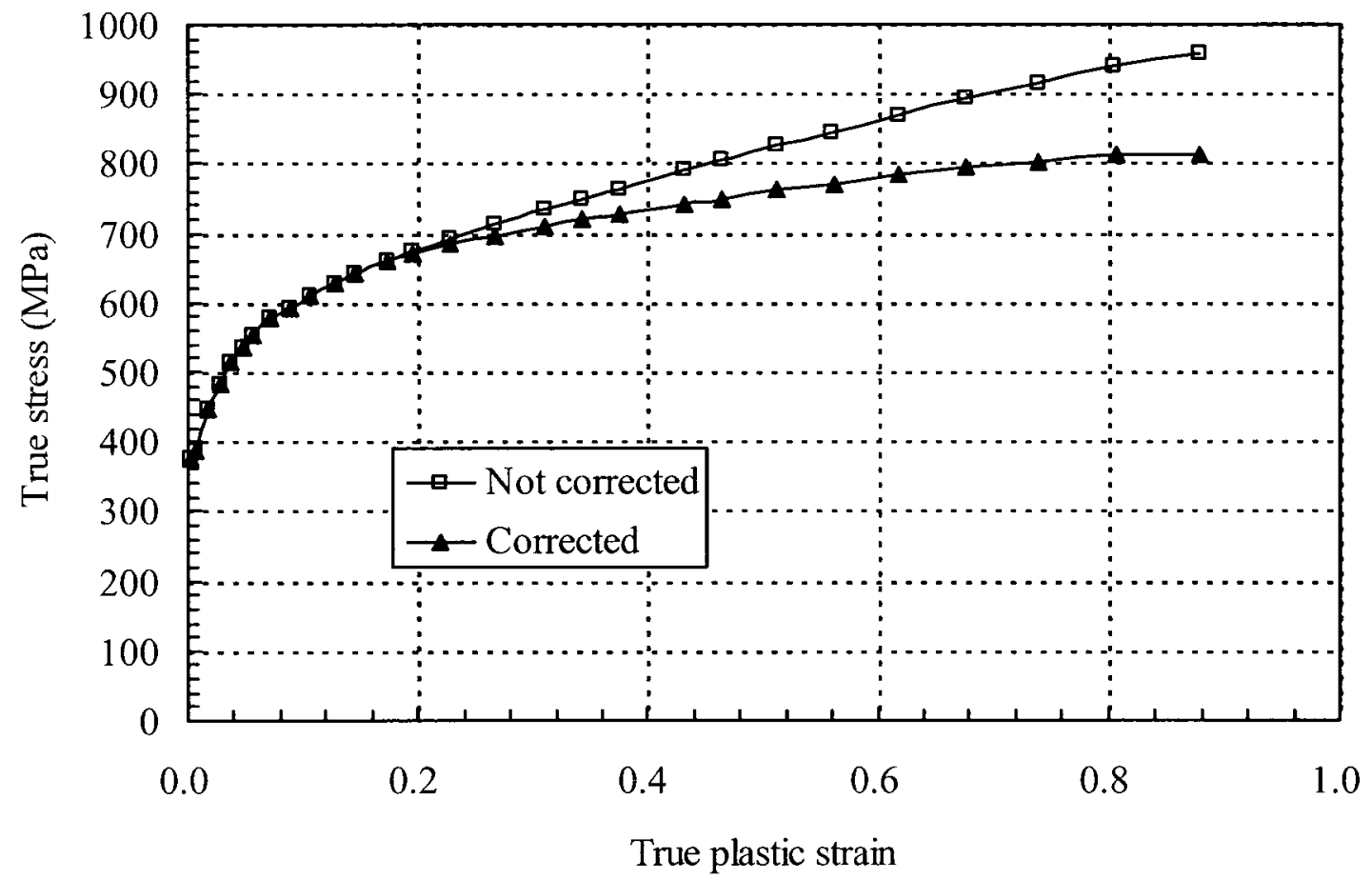

Figure 4.49 Static true stress versus true plastic strain curves for HT1E4S with and without Eq. (4.26) correction 


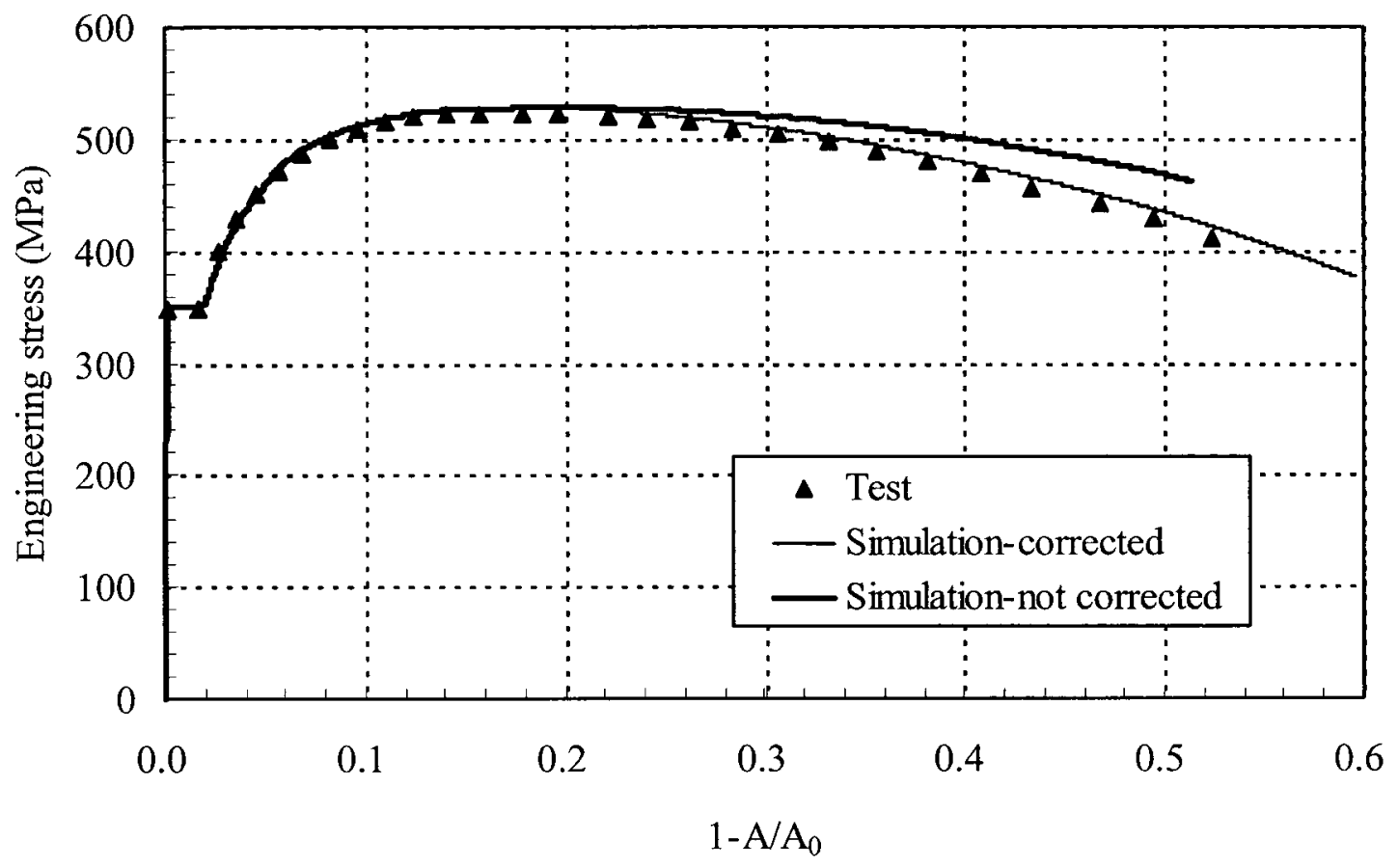

Figure 4.50 Test and predicted static engineering stress versus change in cross-section area ratio for GT1E4S with and without Eq. (4.26)

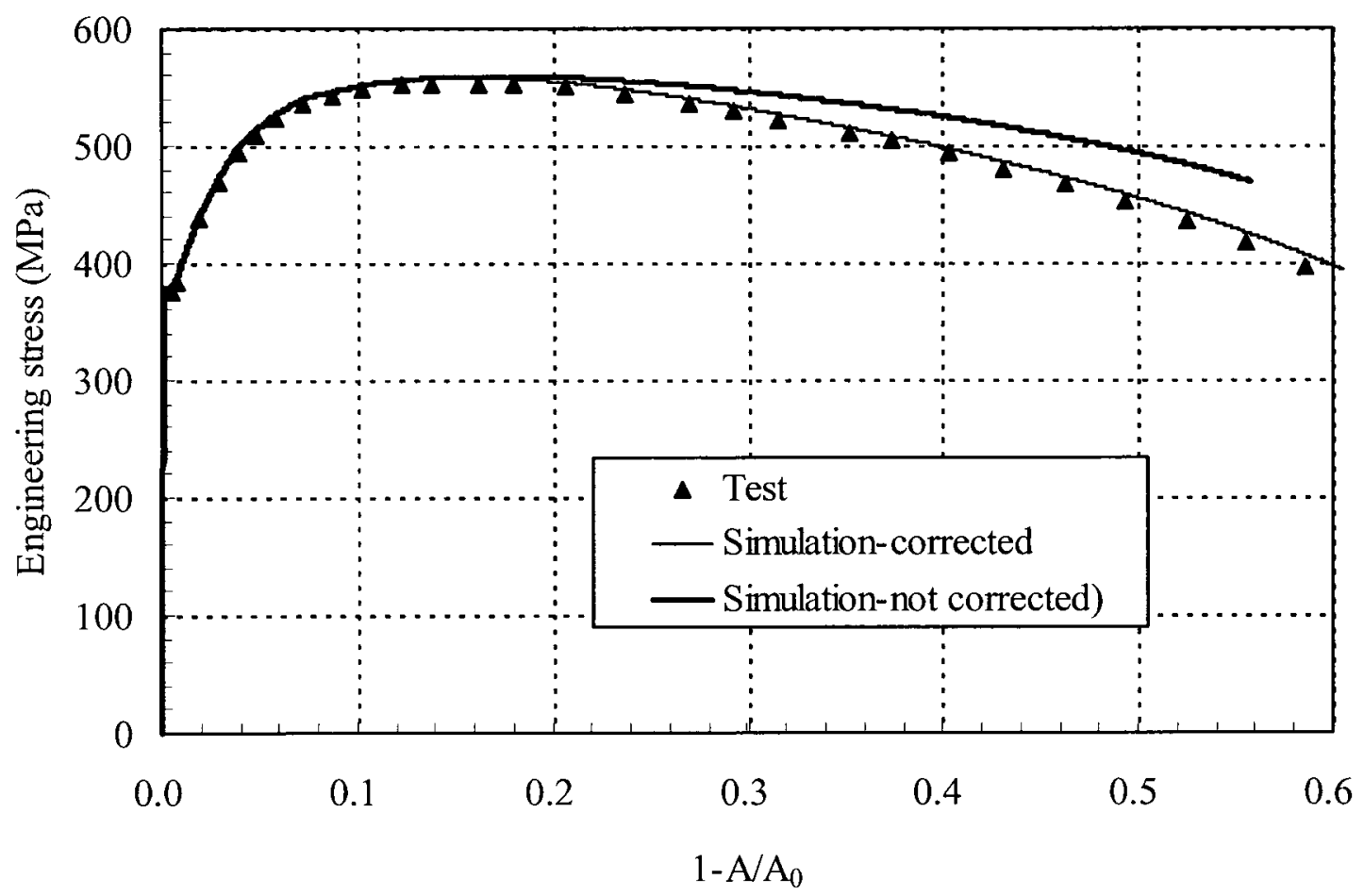

Figure 4.51 Test and predicted static engineering stress versus change in cross-section area ratio for HT1E4S with and without Eq. (4.26) correction 


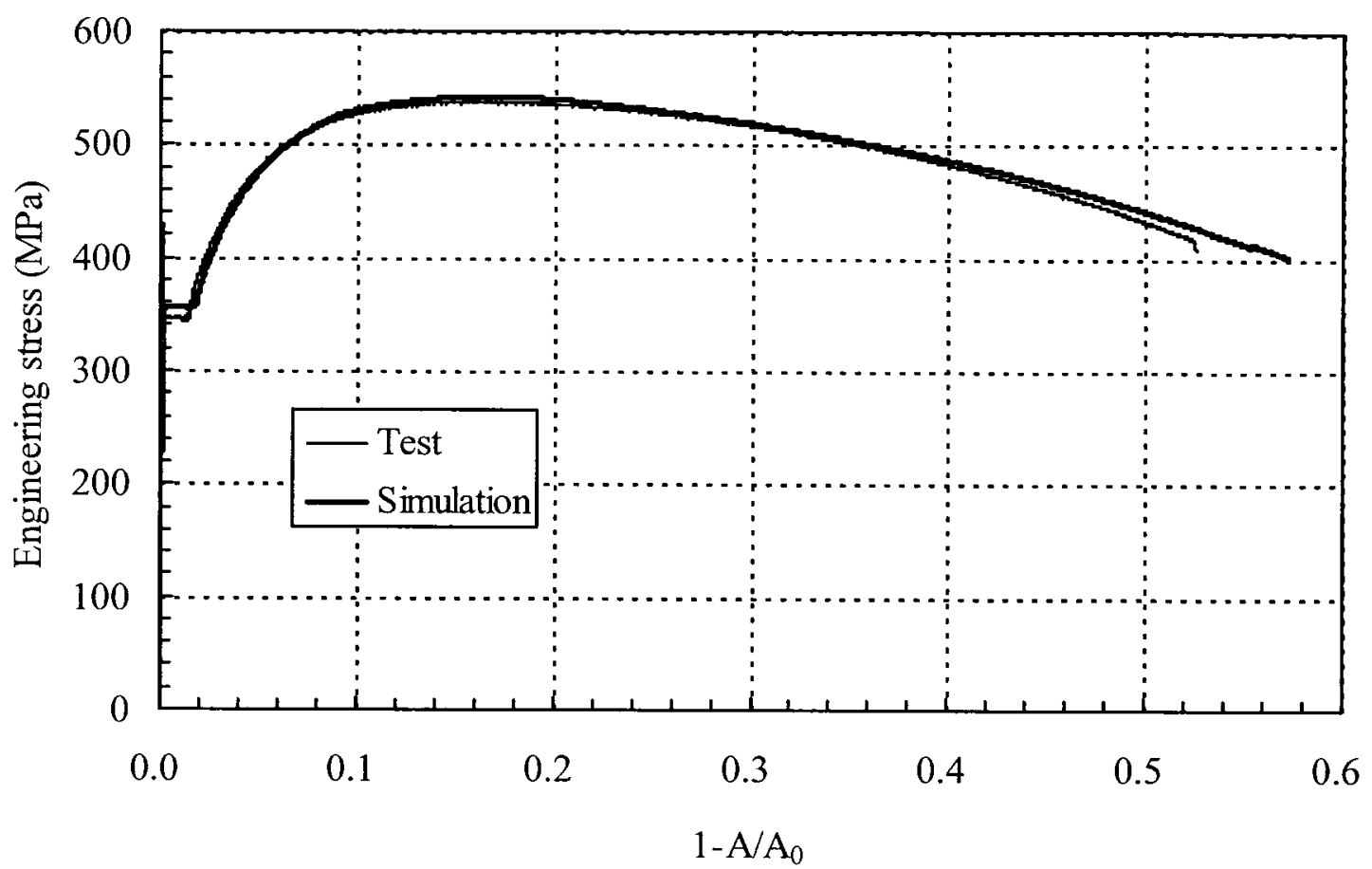

Figure 4.52 Test and predicted engineering stress versus change in cross-section area ratio for GT1E5E with Eq. (4.26) correction

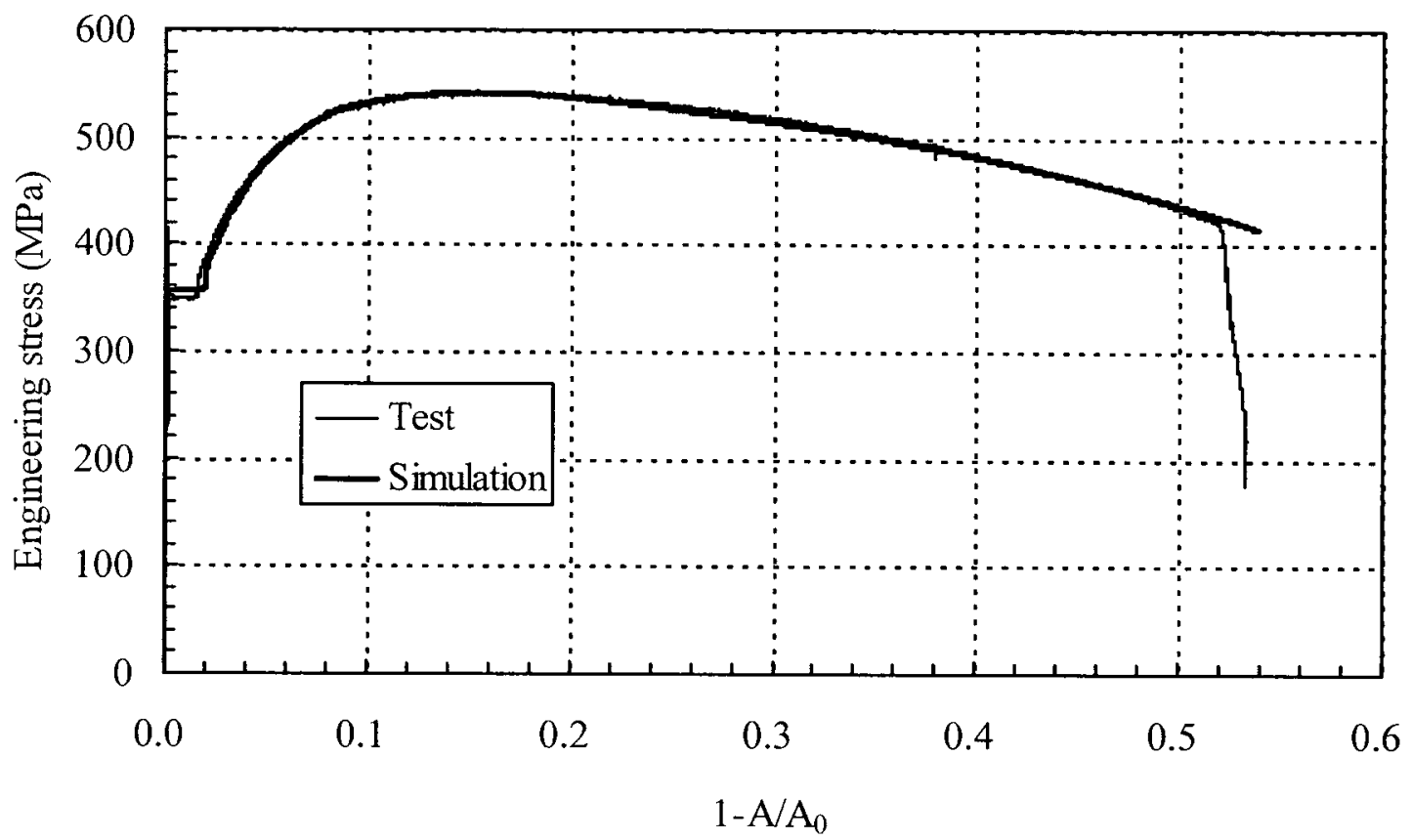

Figure 4.53 Test and predicted engineering stress versus change in cross-section area ratio for GT5E5ED with Eq. (4.26) correction 


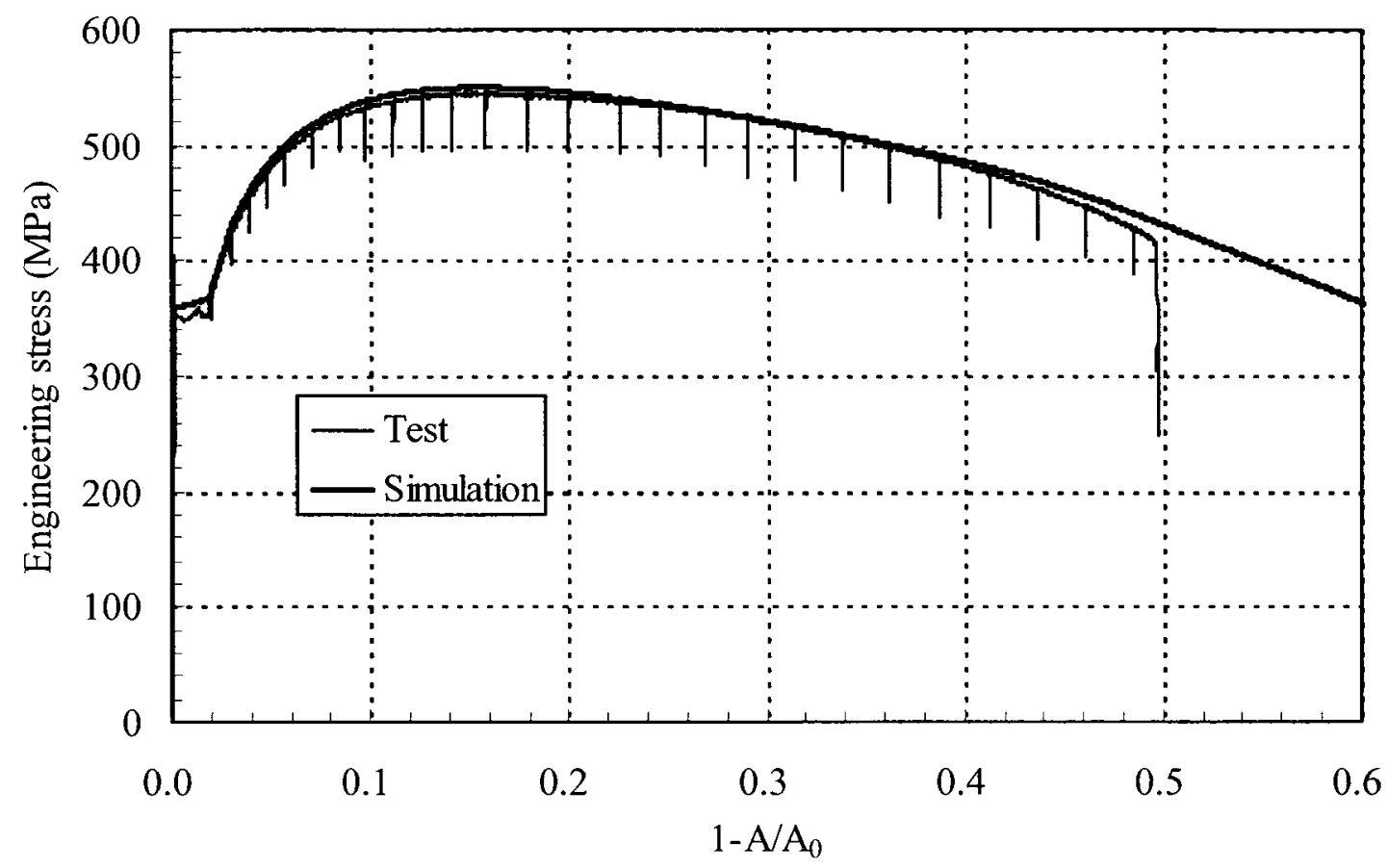

Figure 4.54 Test and predicted engineering stress versus change in cross-section area ratio for GT1E4ED with Eq. (4.26) correction

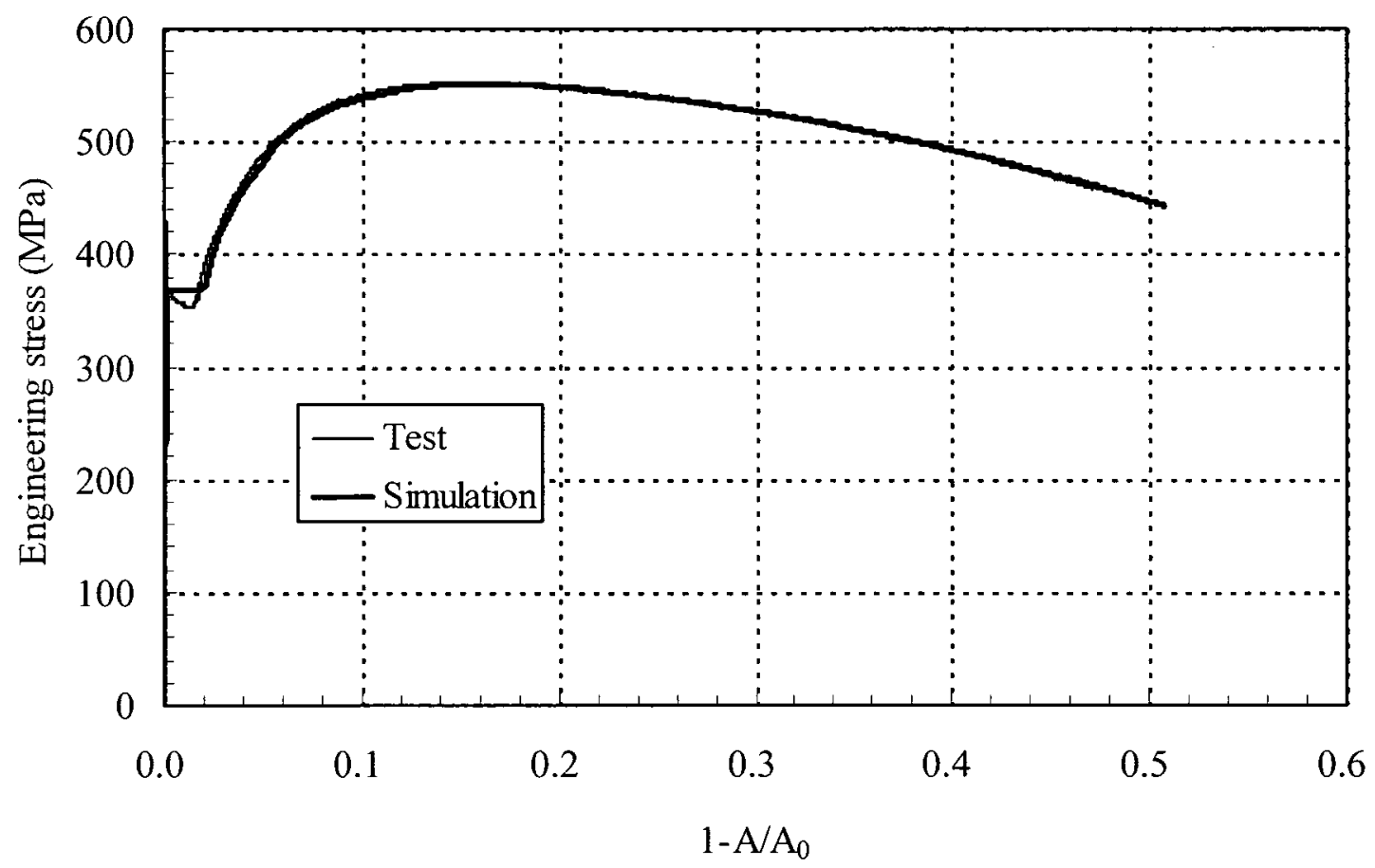

Figure 4.55 Test and predicted engineering stress versus change in cross-section area ratio for GT1E3ED with Eq. (4.26) correction 


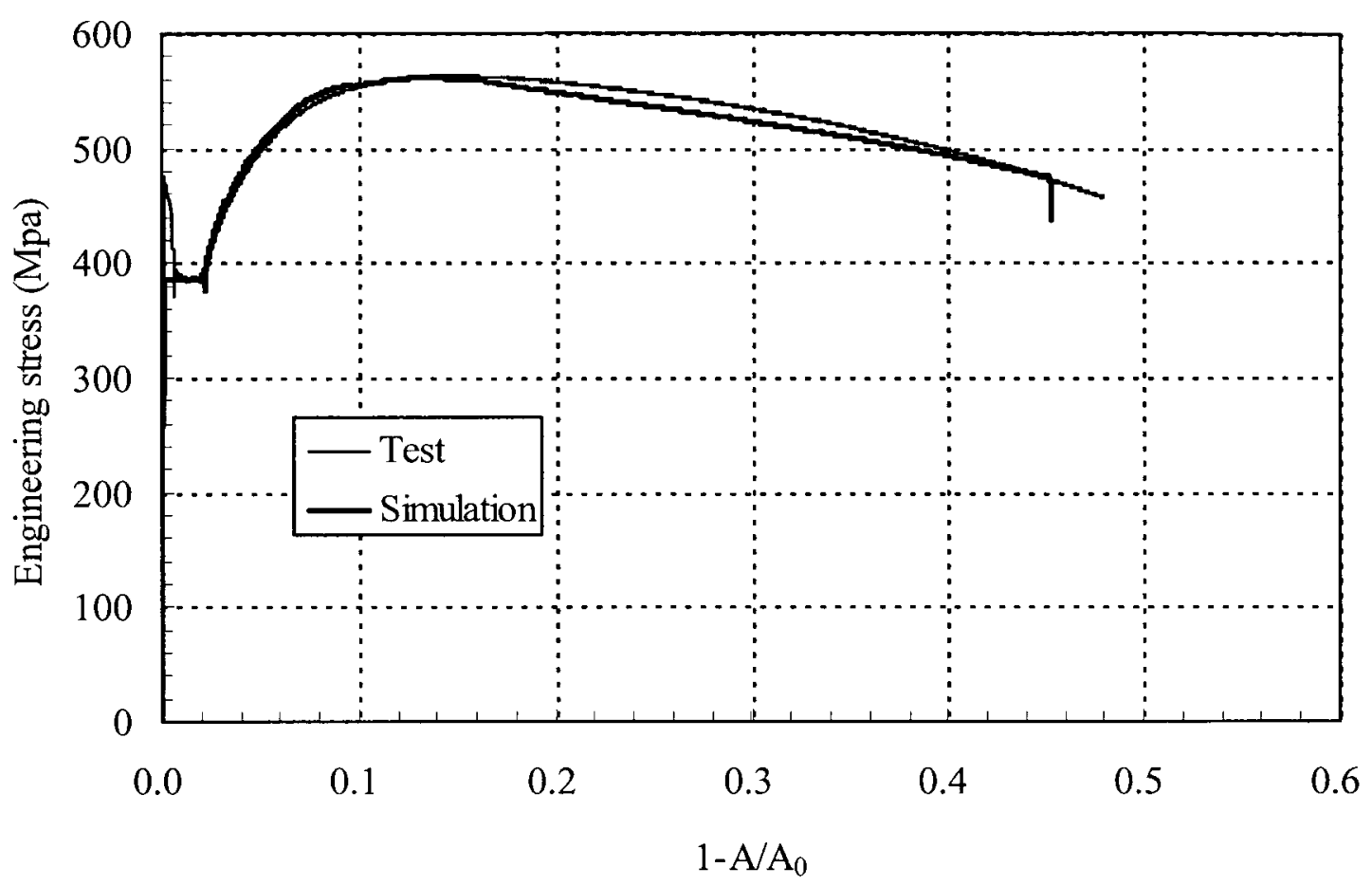

Figure 4.56 Test and predicted engineering stress versus change in cross-section area ratio for GT1E2ED with Eq. (4.26) correction

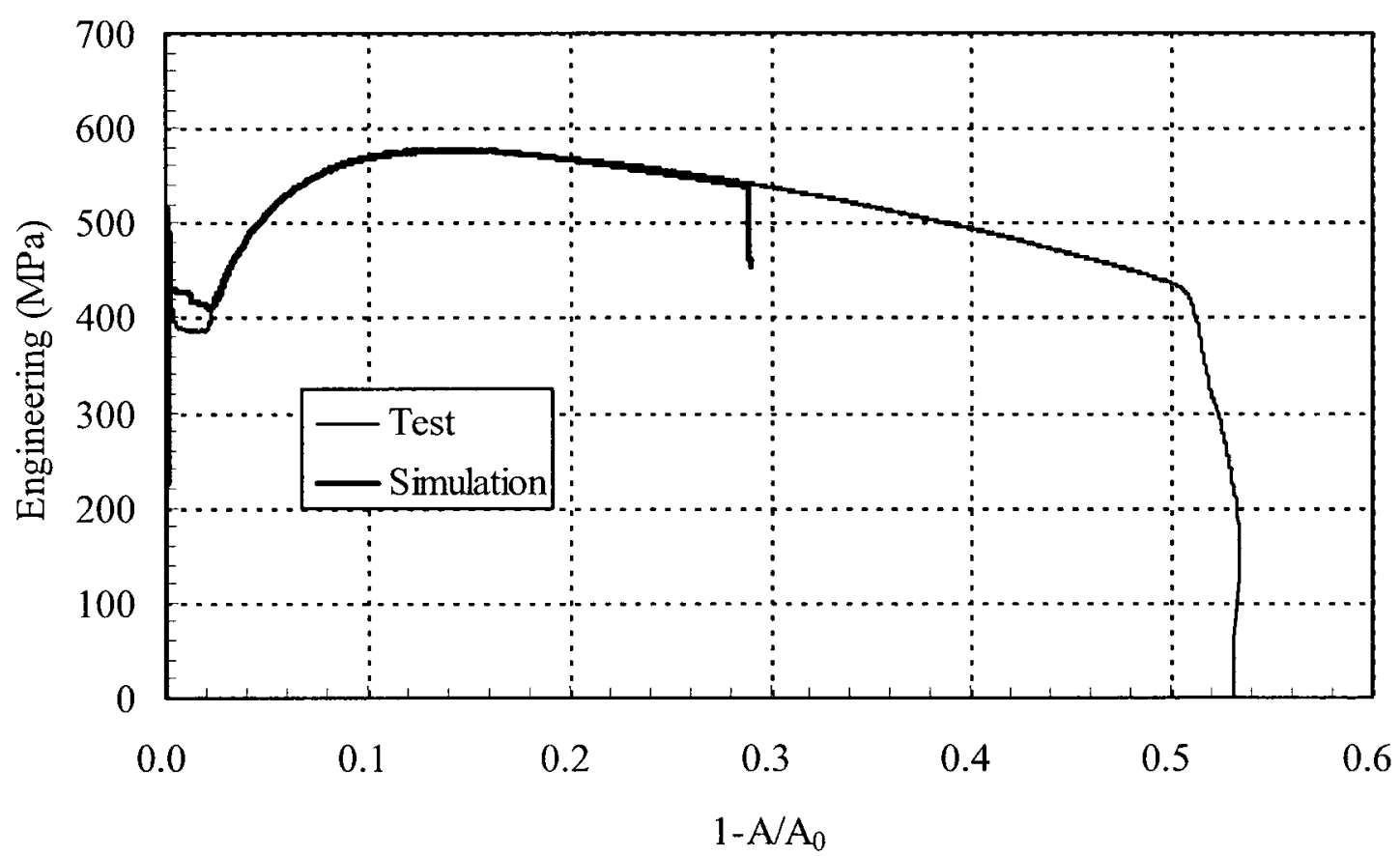

Figure 4.57 Test and predicted engineering stress versus change in cross-section area ratio for GT1E1E with Eq. (4.26) correction 


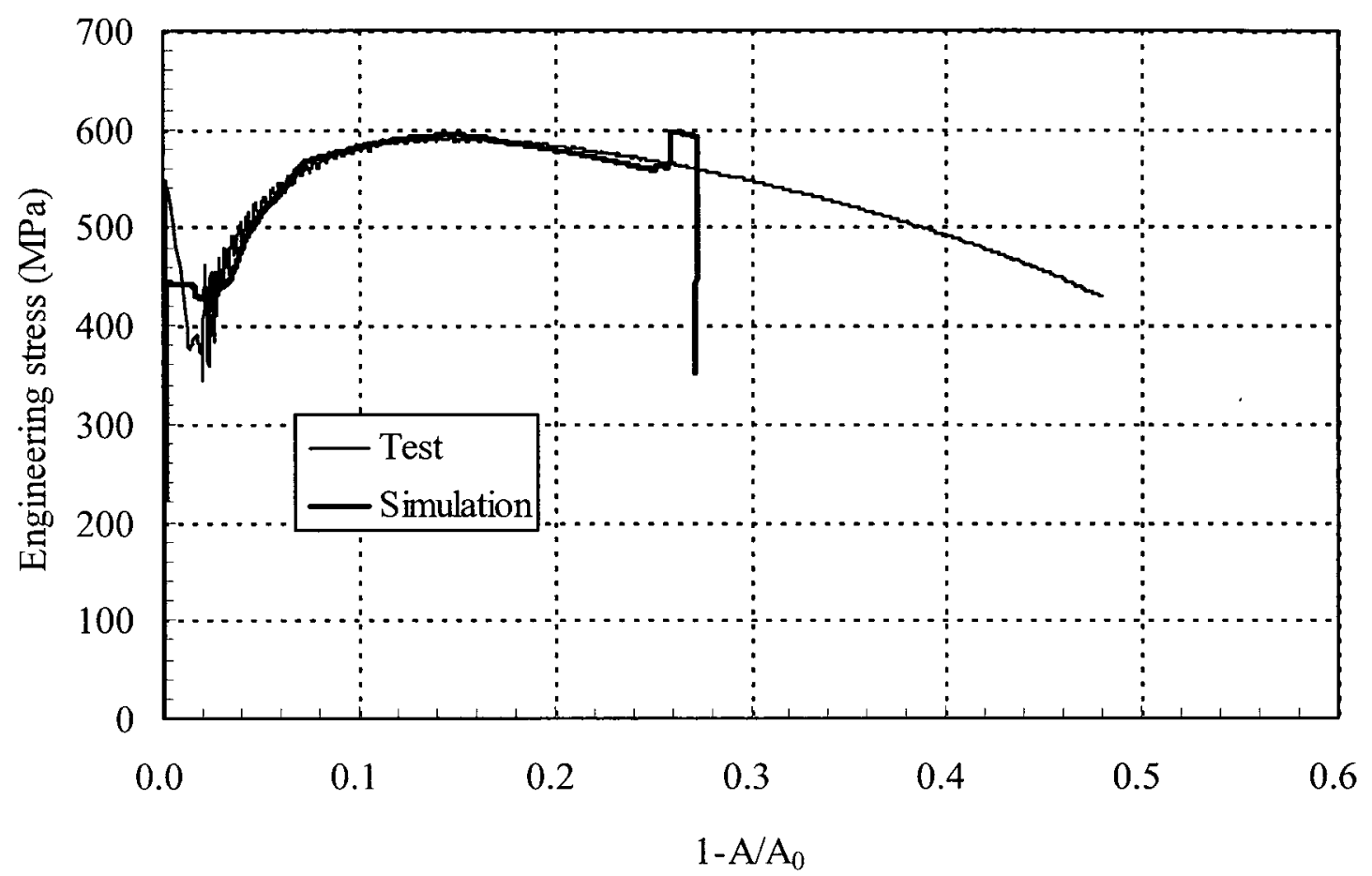

Figure 4.58 Test and predicted engineering stress versus change in cross-section area ratio for GT1E0E with Eq. (4.26) correction

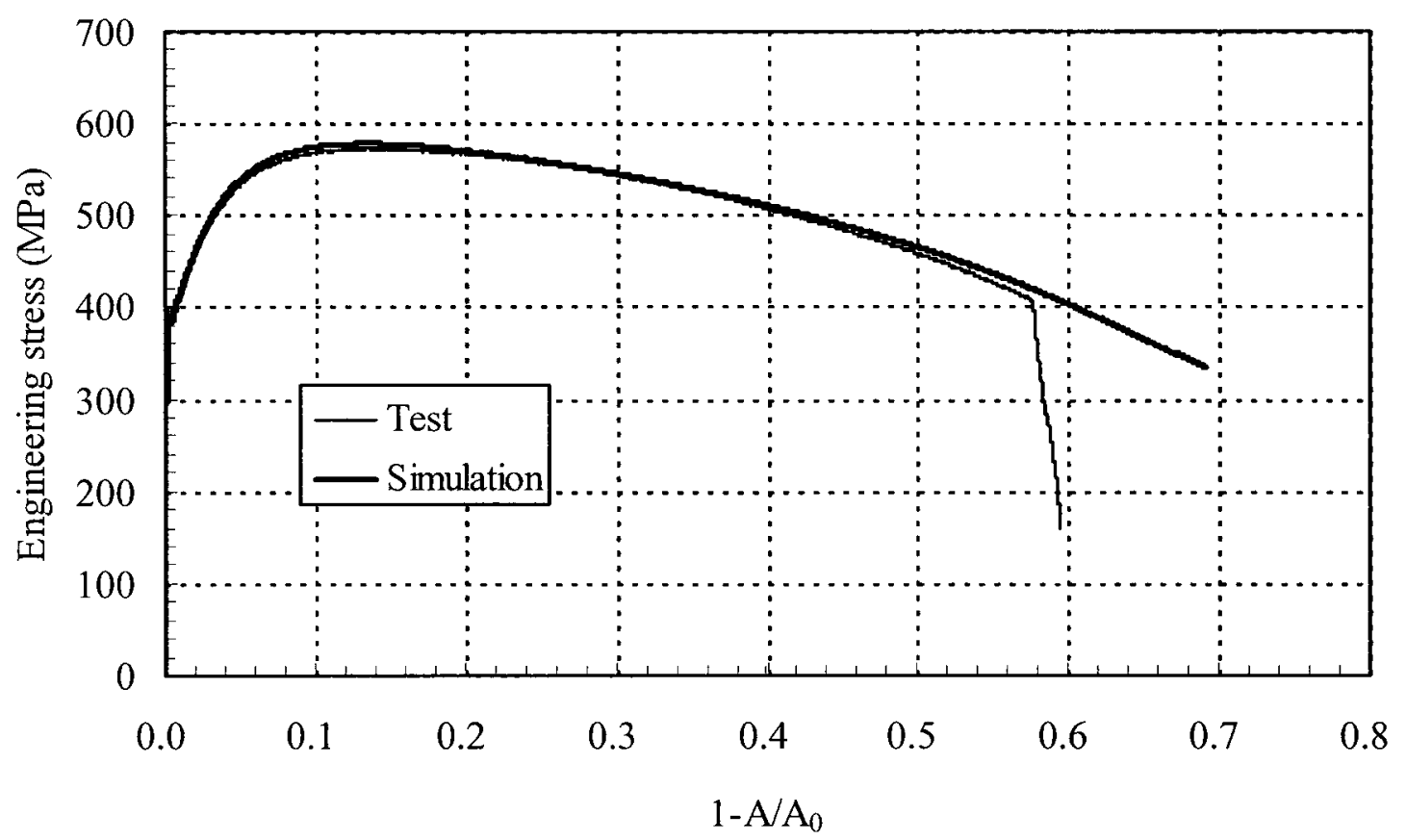

Figure 4.59 Test and predicted engineering stress versus change in cross-section area ratio for HT1E5E with Eq. (4.26) correction 


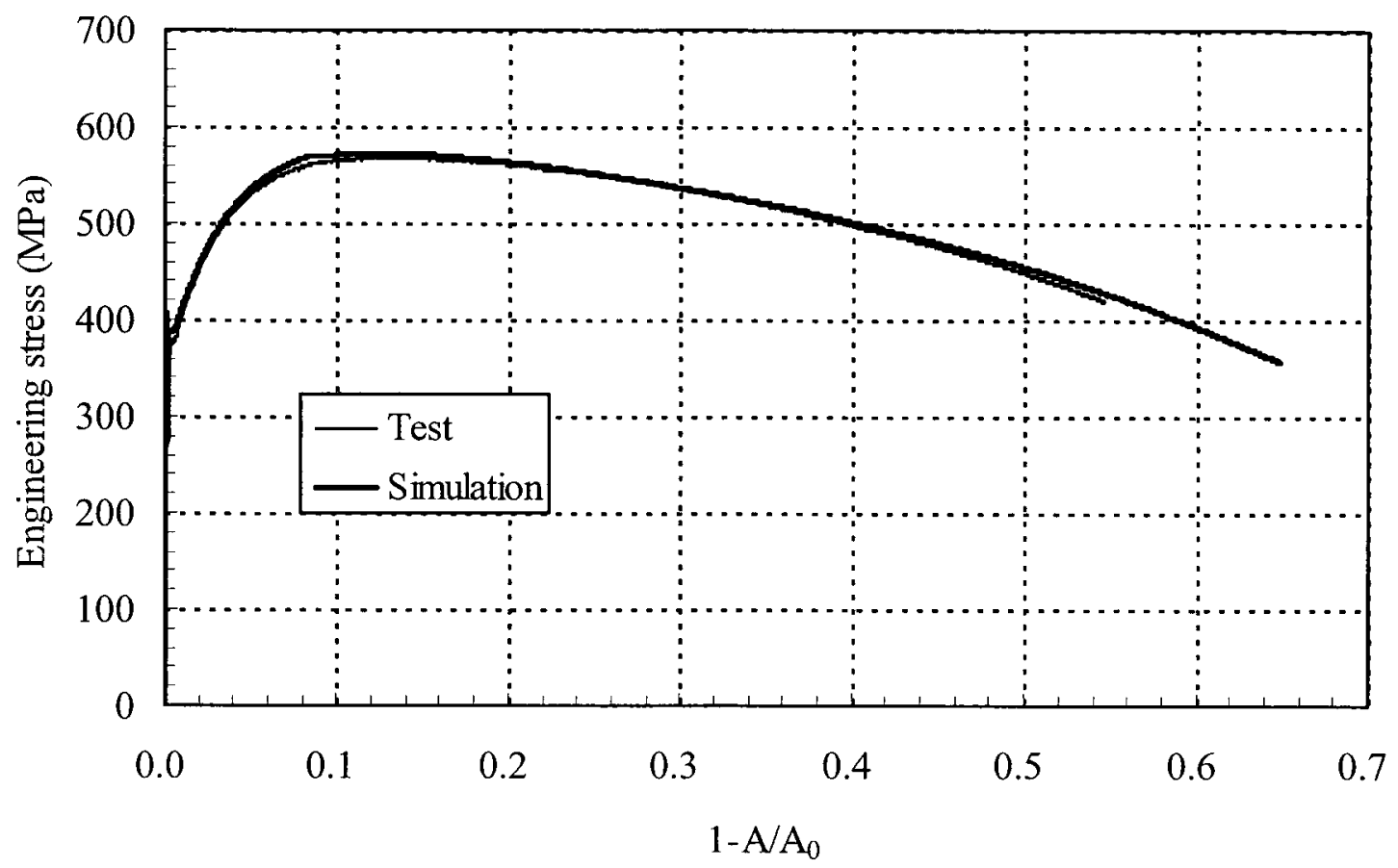

Figure 4.60 Test and predicted engineering stress versus change in cross-section area ratio for HT5E5ED with Eq. (4.26) correction

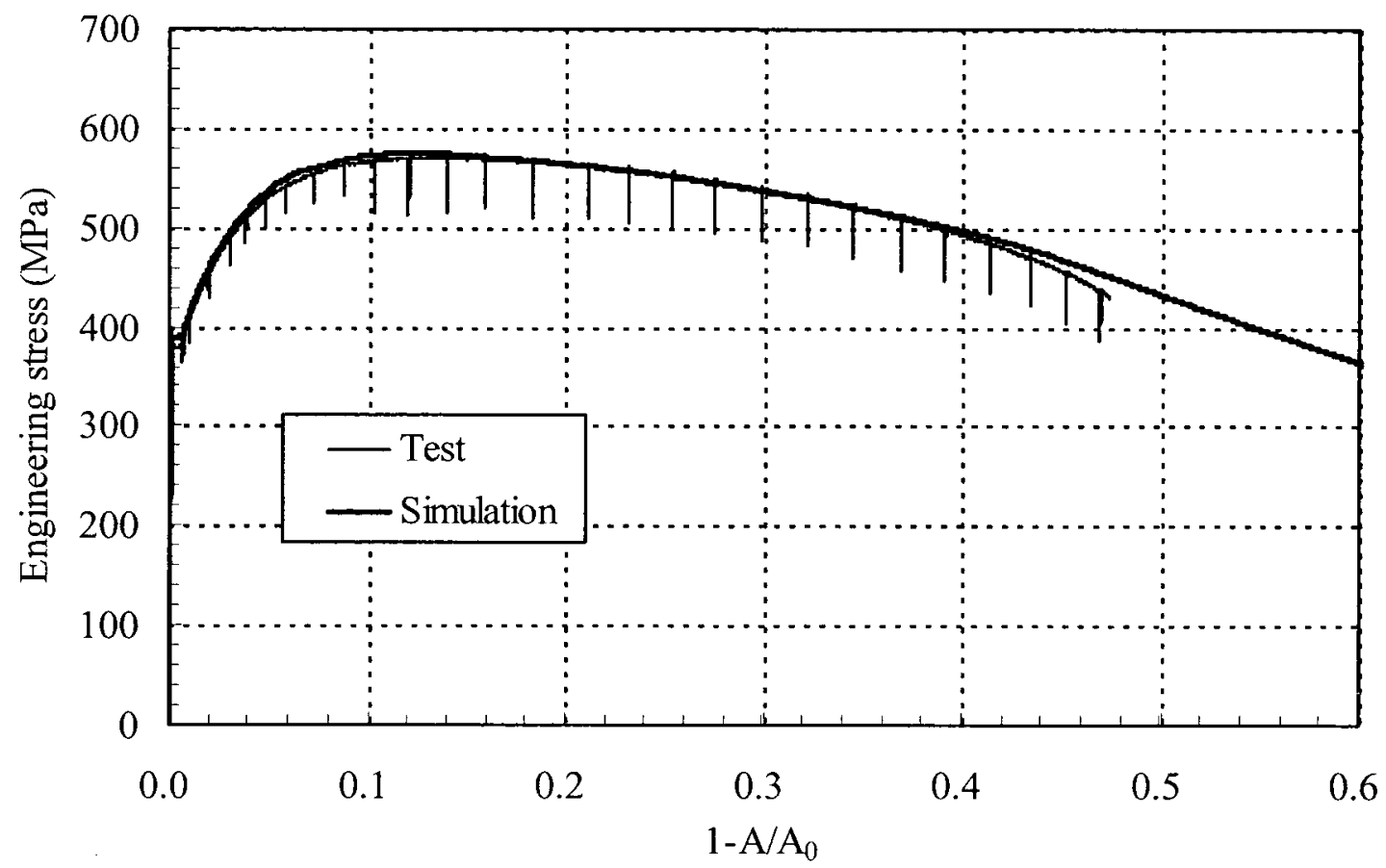

Figure 4.61 Test and predicted engineering stress versus change in cross-section area ratio for HT1E4ED with Eq. (4.26) correction 


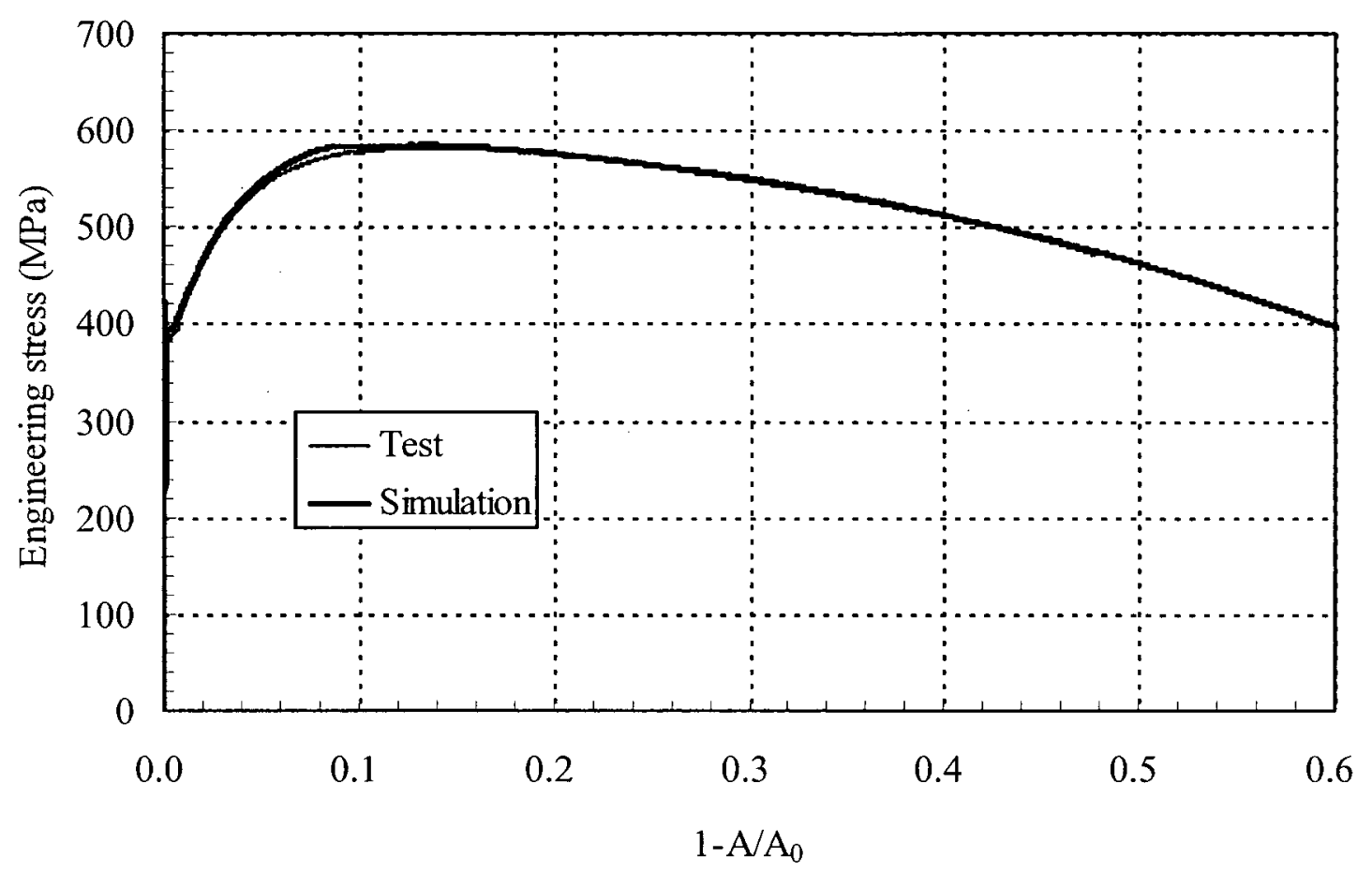

Figure 4.62 Test and predicted engineering stress versus change in cross-section area ratio for HT1E3ED with Eq. (4.26) correction

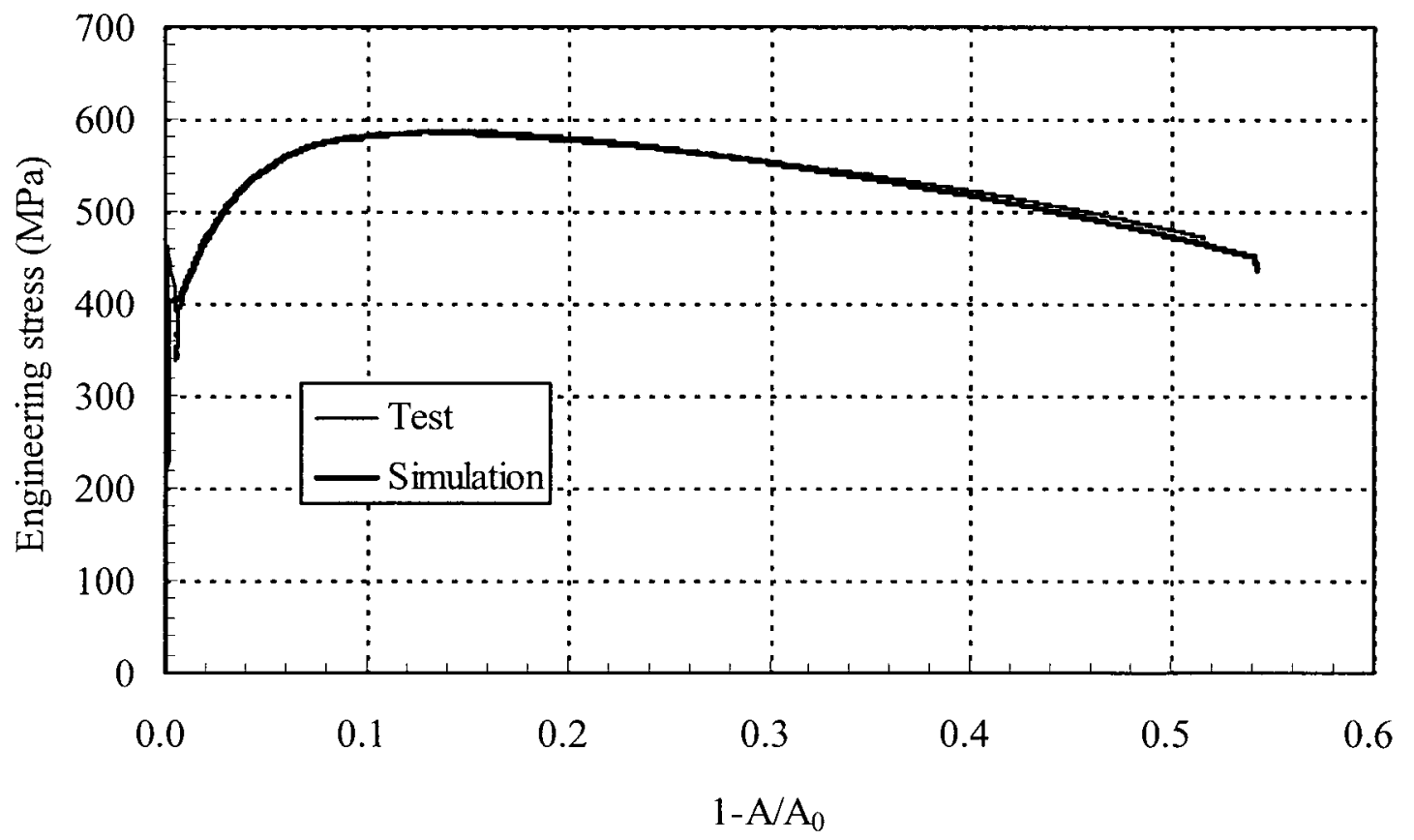

Figure 4.63 Test and predicted engineering stress versus change in cross-section area ratio for HT1E2ED with Eq. (4.26) correction 


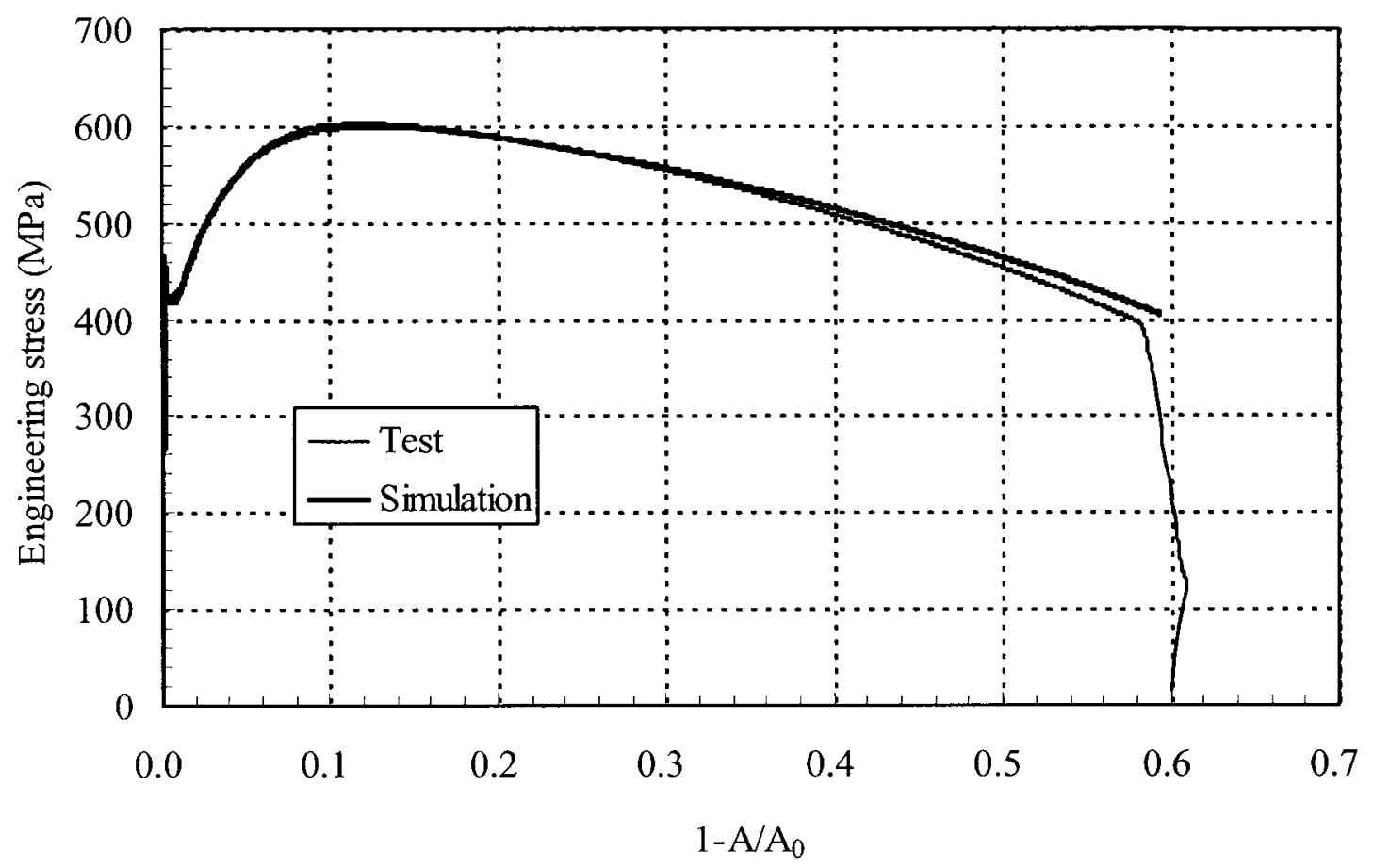

Figure 4.64 Test and predicted engineering stress versus change in cross-section area ratio for HT1E1E with Eq. (4.26) correction

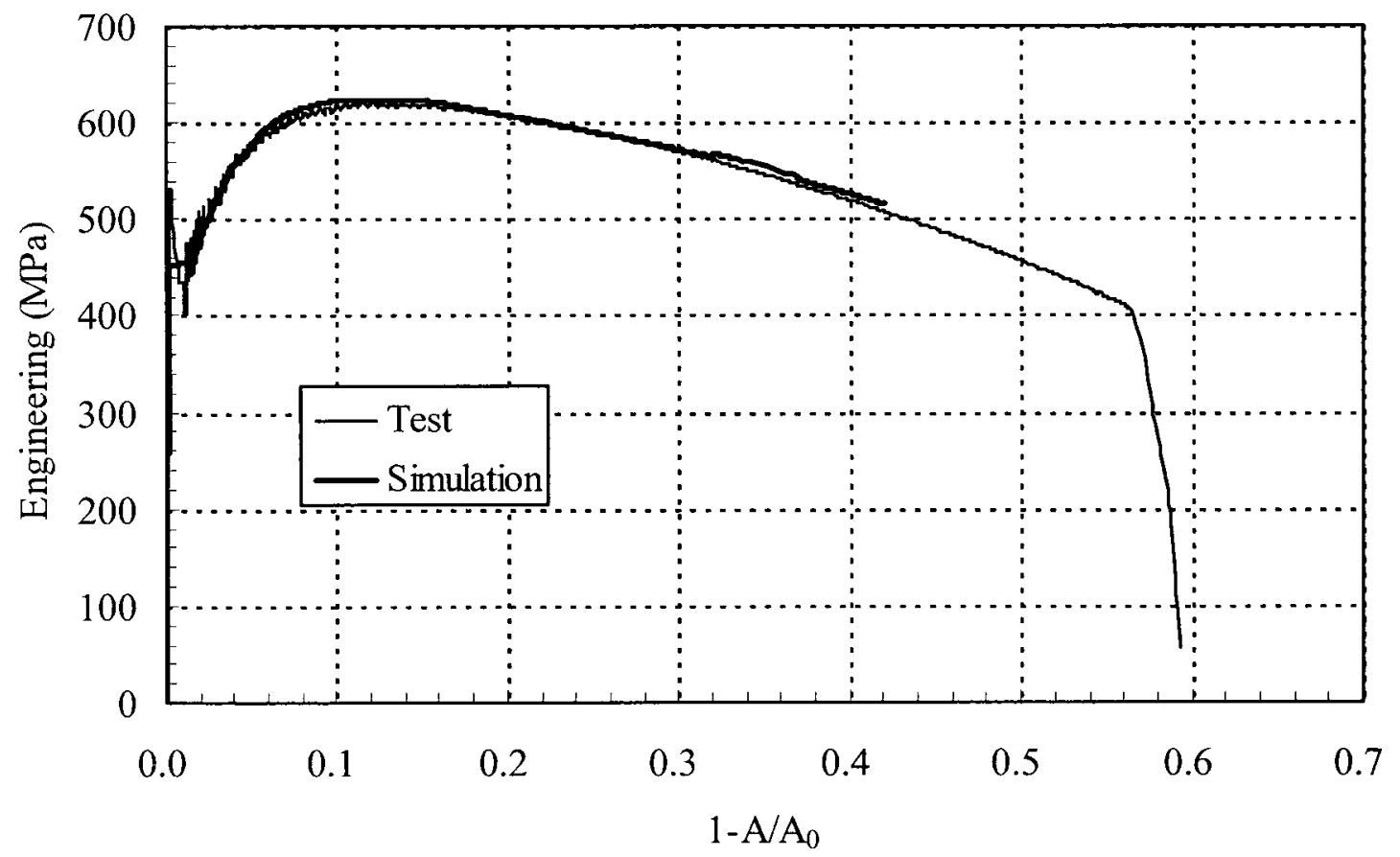

Figure 4.65 Test and predicted engineering stress versus change in cross-section area ratio for HT1E0E with Eq. (4.26) correction 


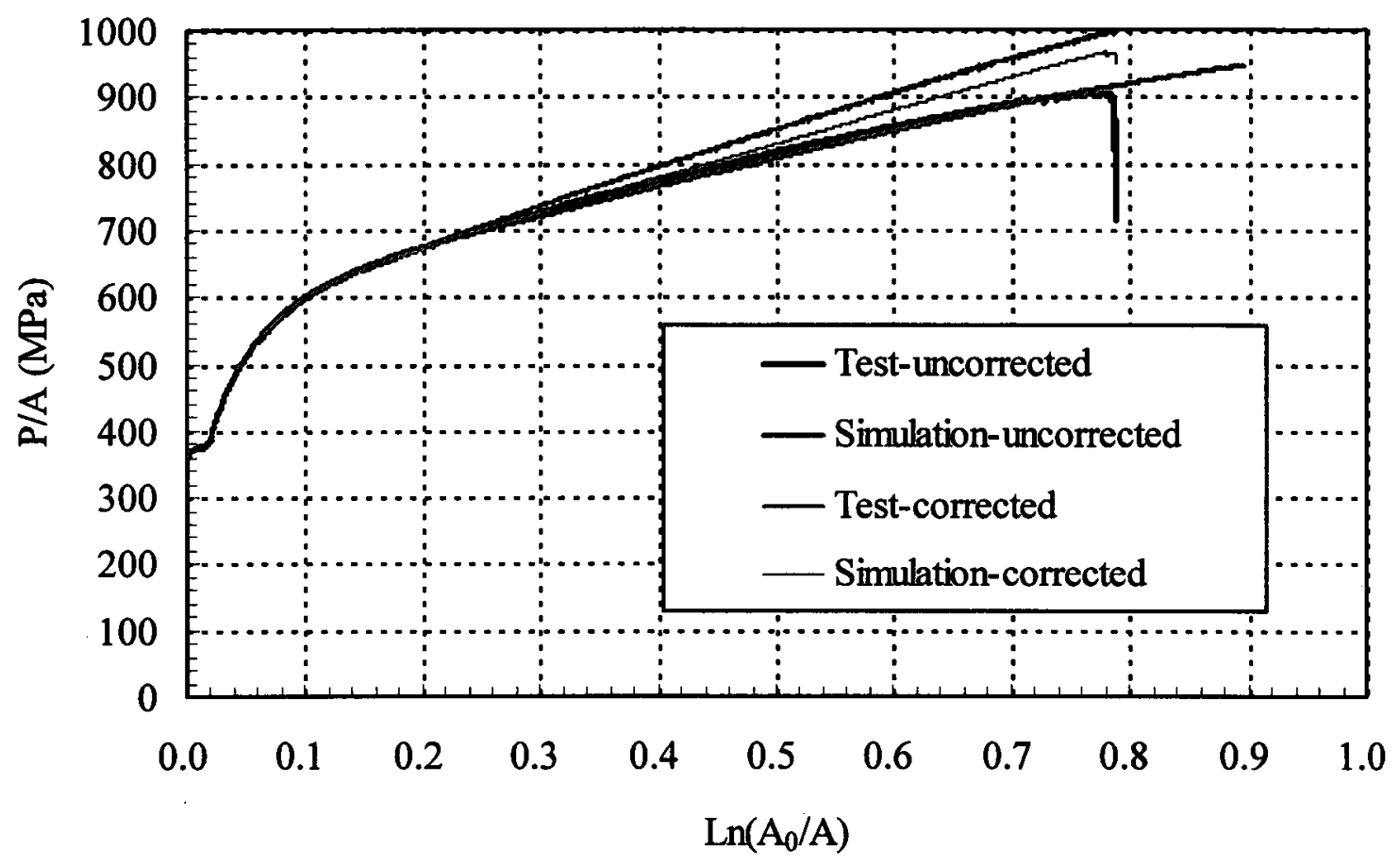

Figure 4.66 Test and predicted average true stress versus true strain curves for GT1E3ED with and without diameter correction

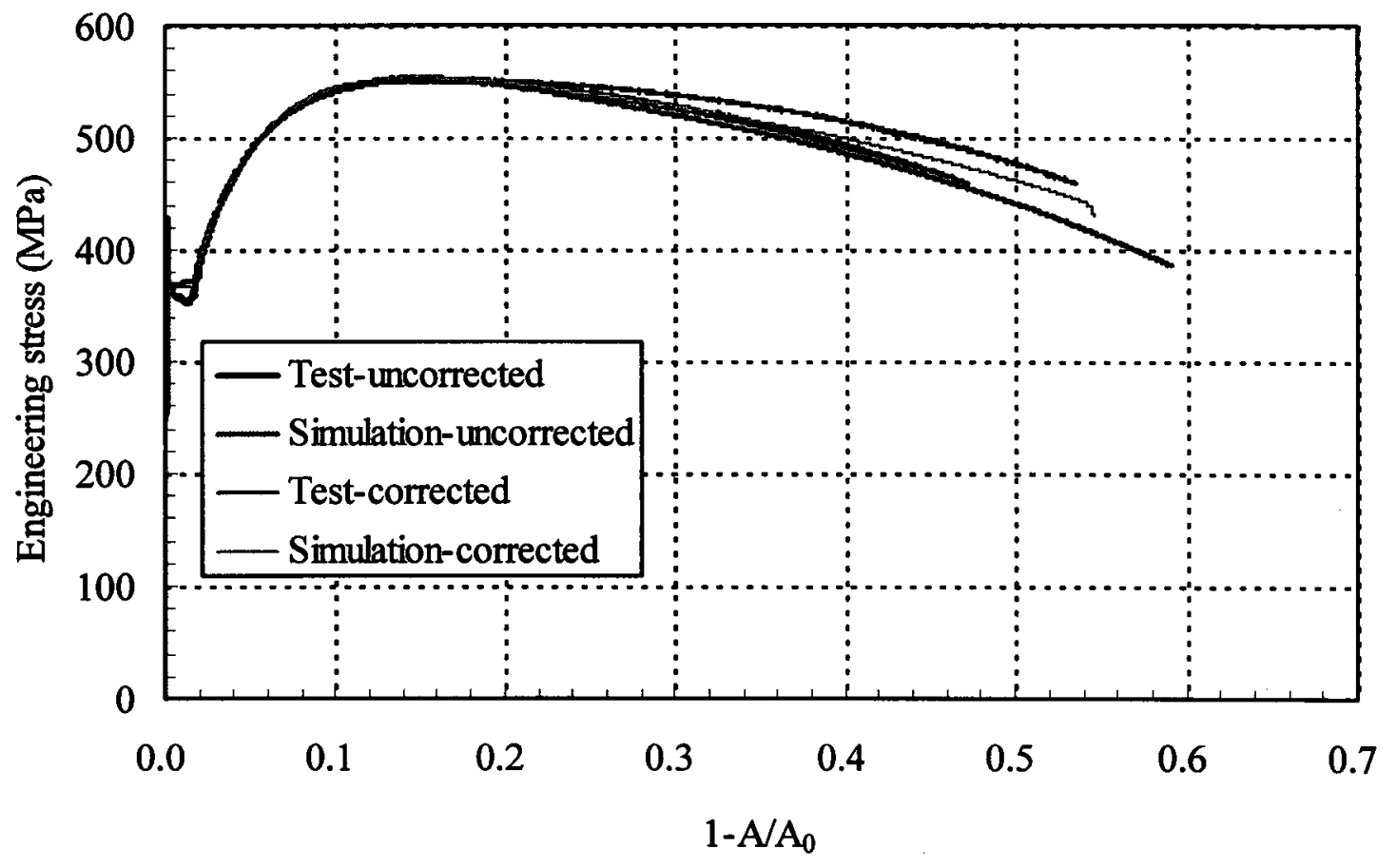

Figure 4.67 Test and predicted engineering stress versus change in cross-section area ratio curves for GT1E3ED with and without diameter correction 


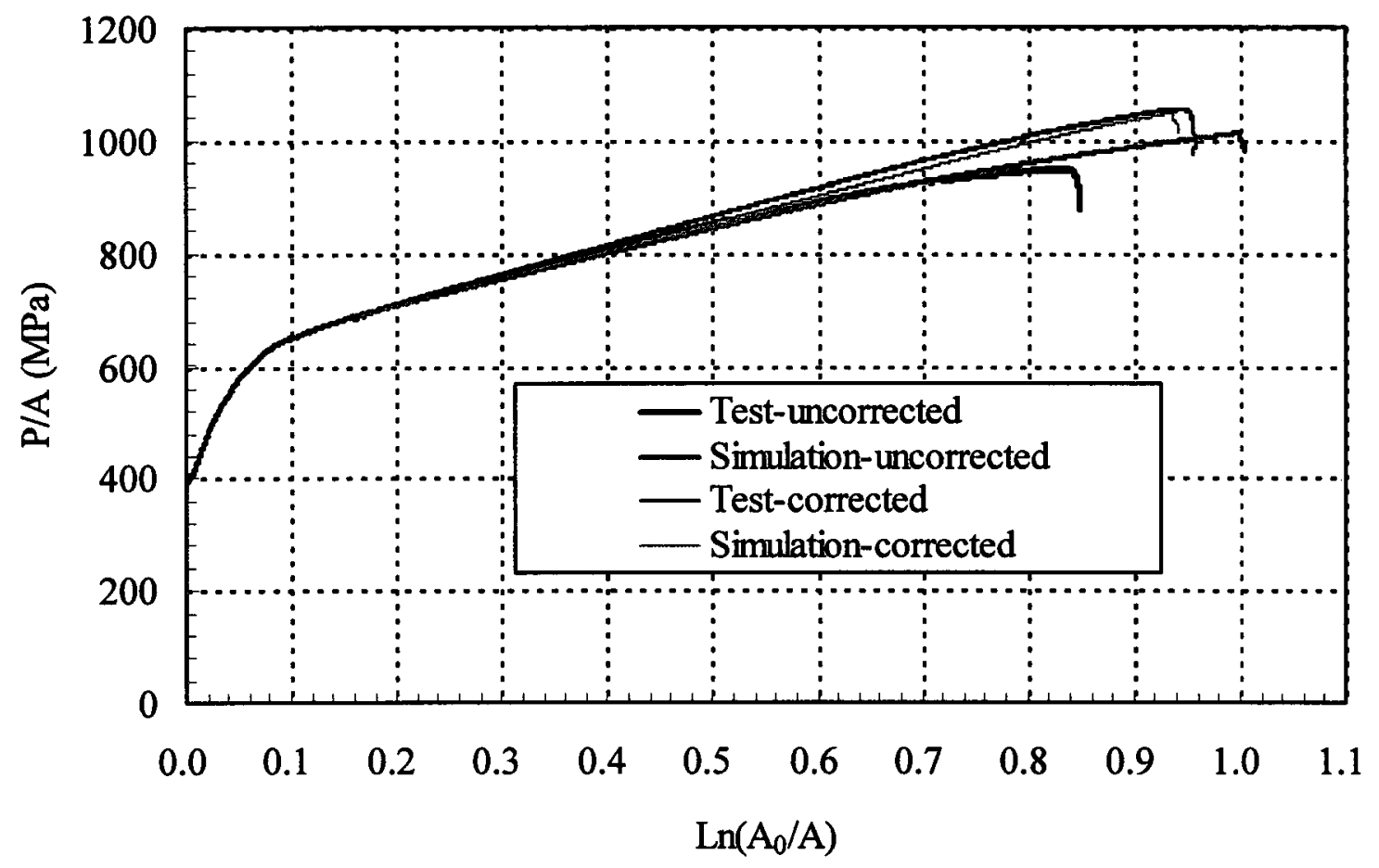

Figure 4.68 Test and predicted average true stress versus true strain curves for HT1E2ED with and without diameter correction

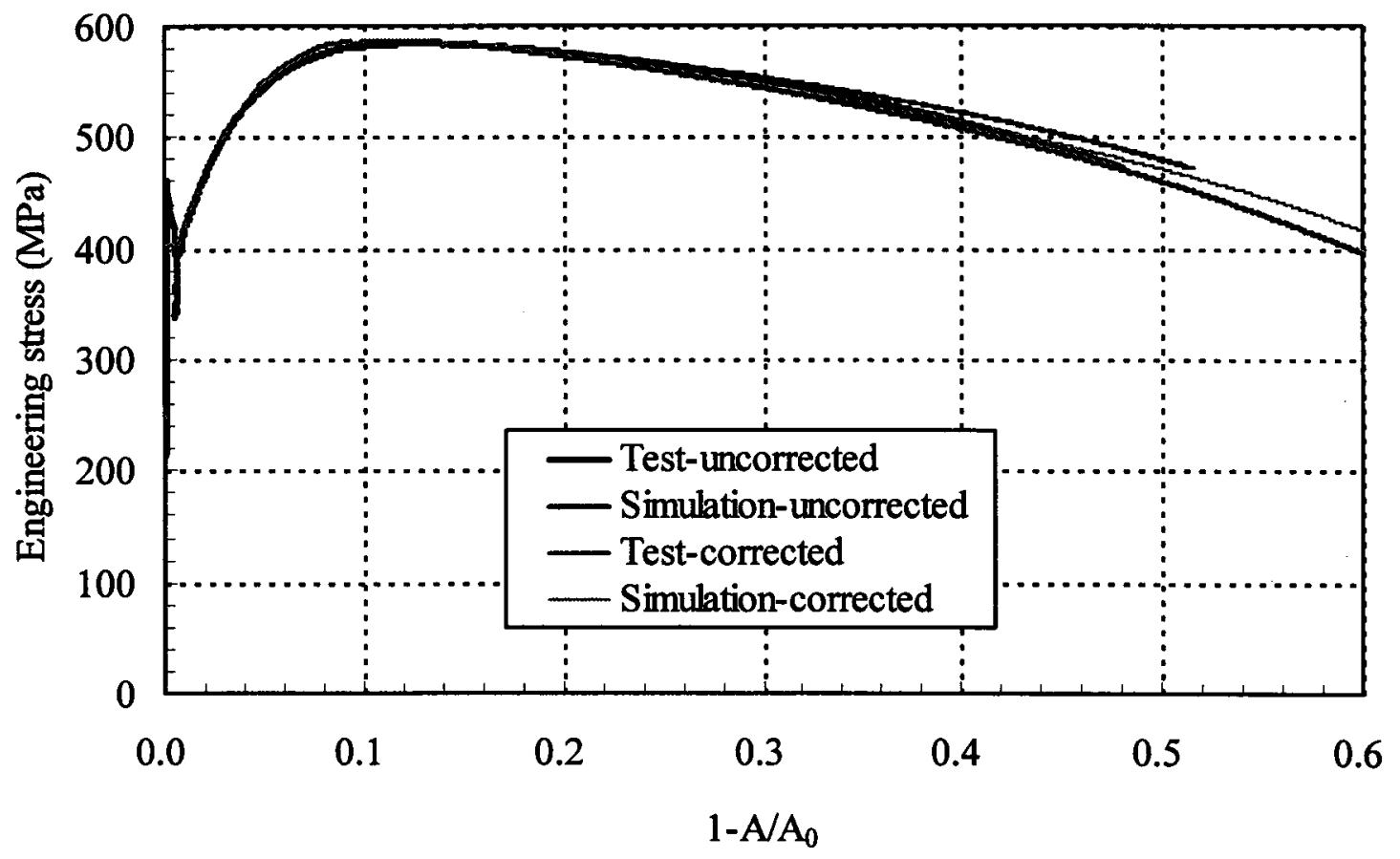

Figure 4.69 Test and predicted engineering stress versus change in cross-section area ratio curves for HT1E2ED with and without diameter correction 


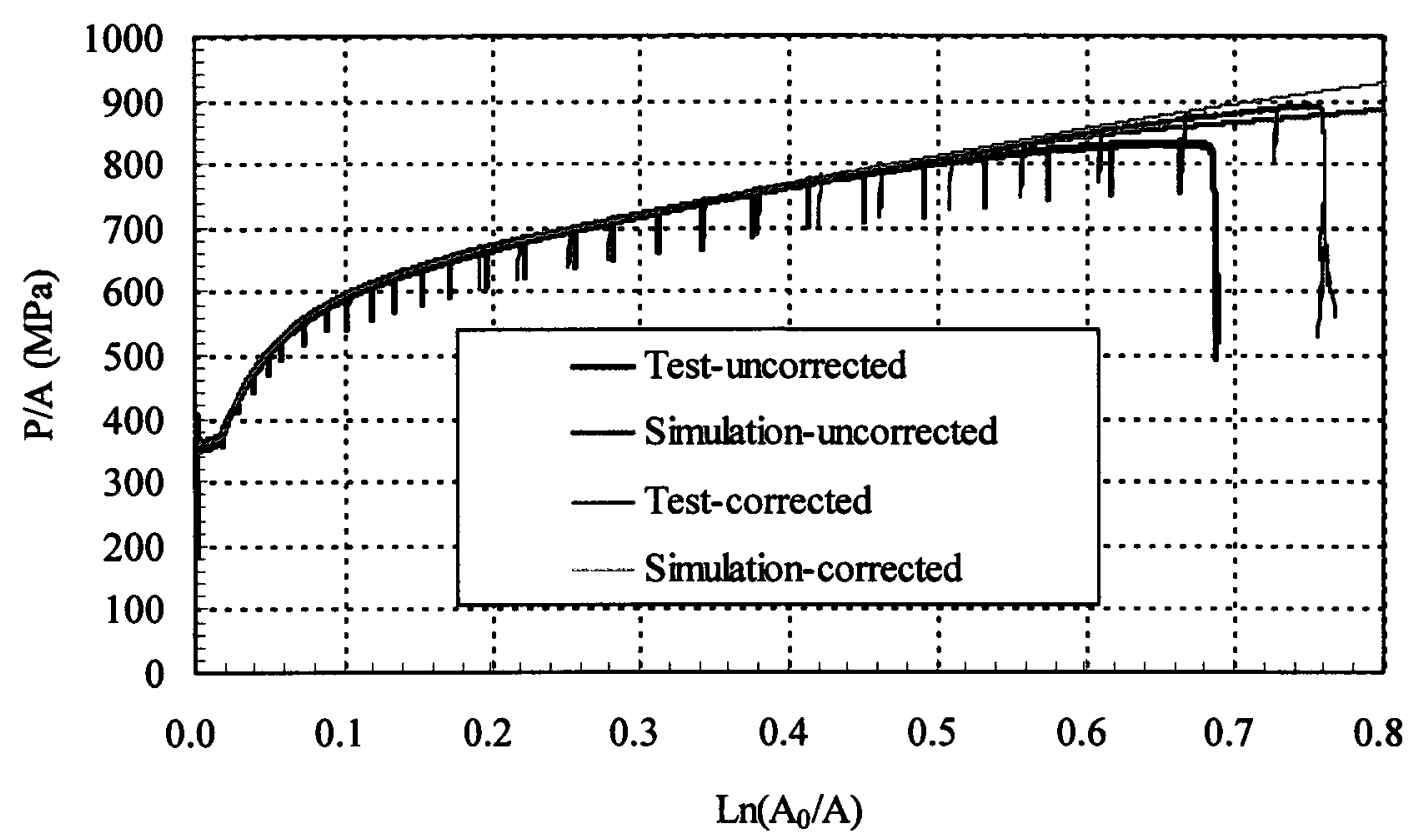

Figure 4.70 Test and predicted average true stress versus true strain curves for GT1E4ED with and without diameter correction

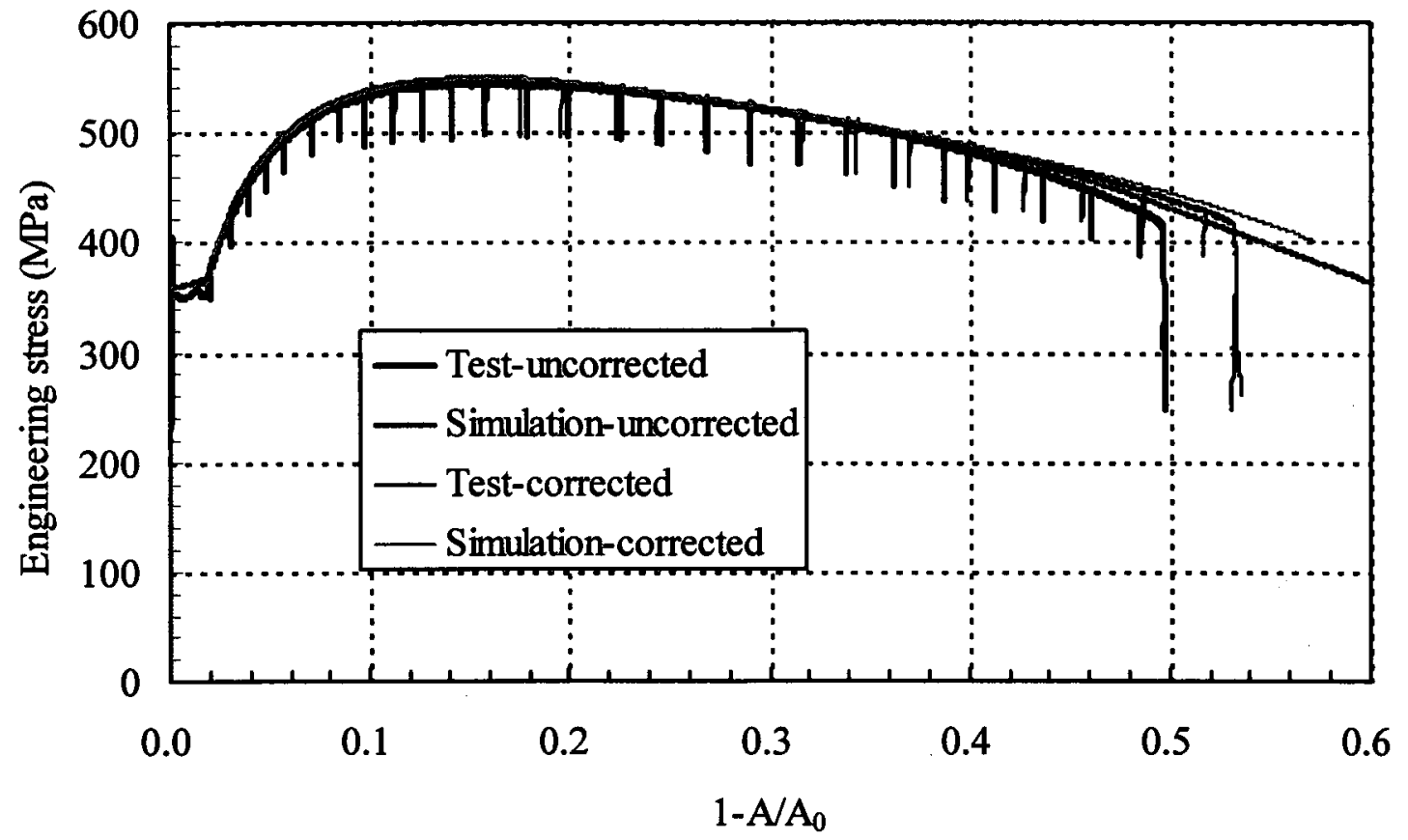

Figure 4.71 Test and predicted engineering stress versus change in cross-section area ratio curves for GT1E4ED with and without diameter correction 


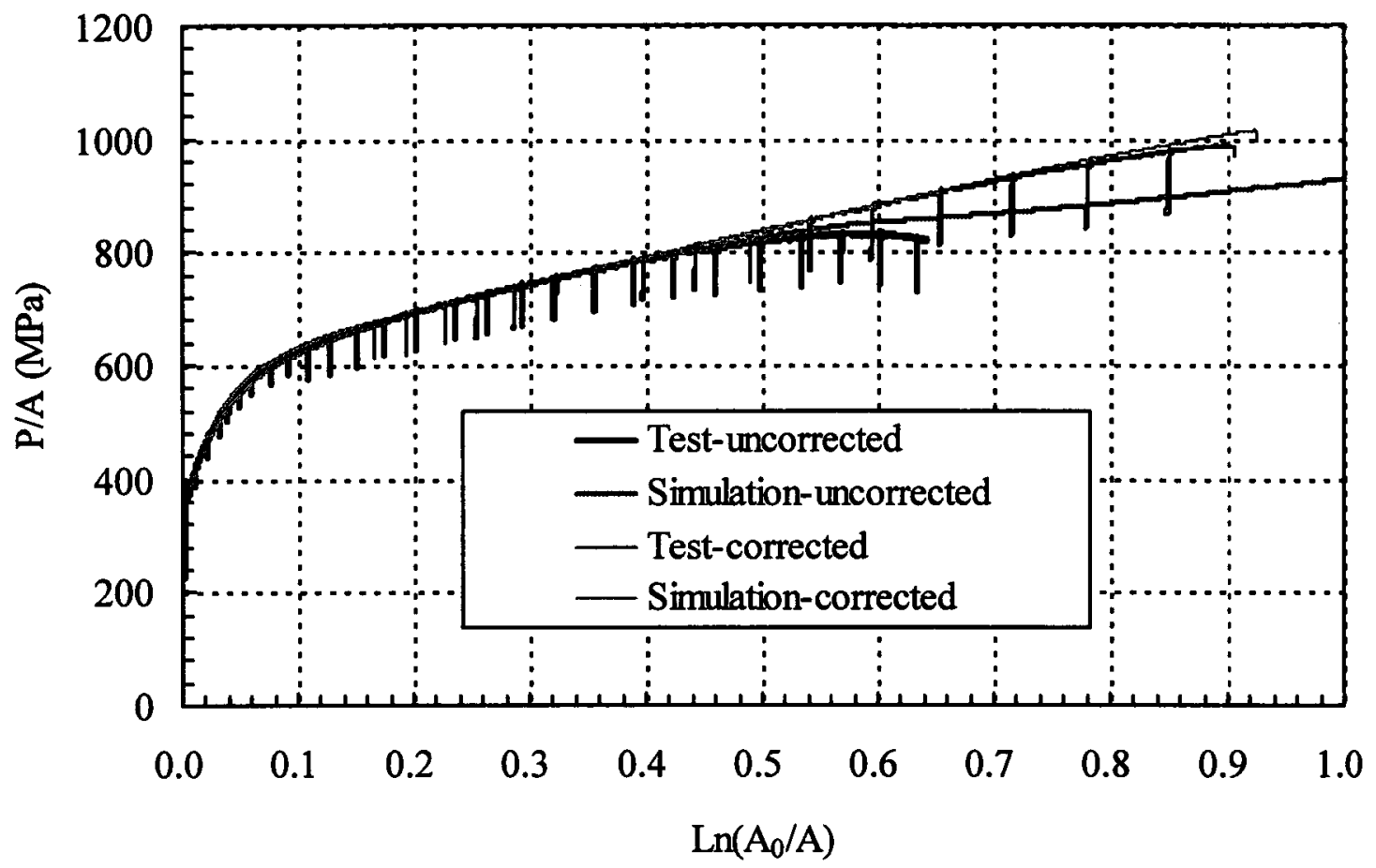

Figure 4.72 Test and predicted average true stress versus true strain curves for HT1E4ED with and without diameter correction

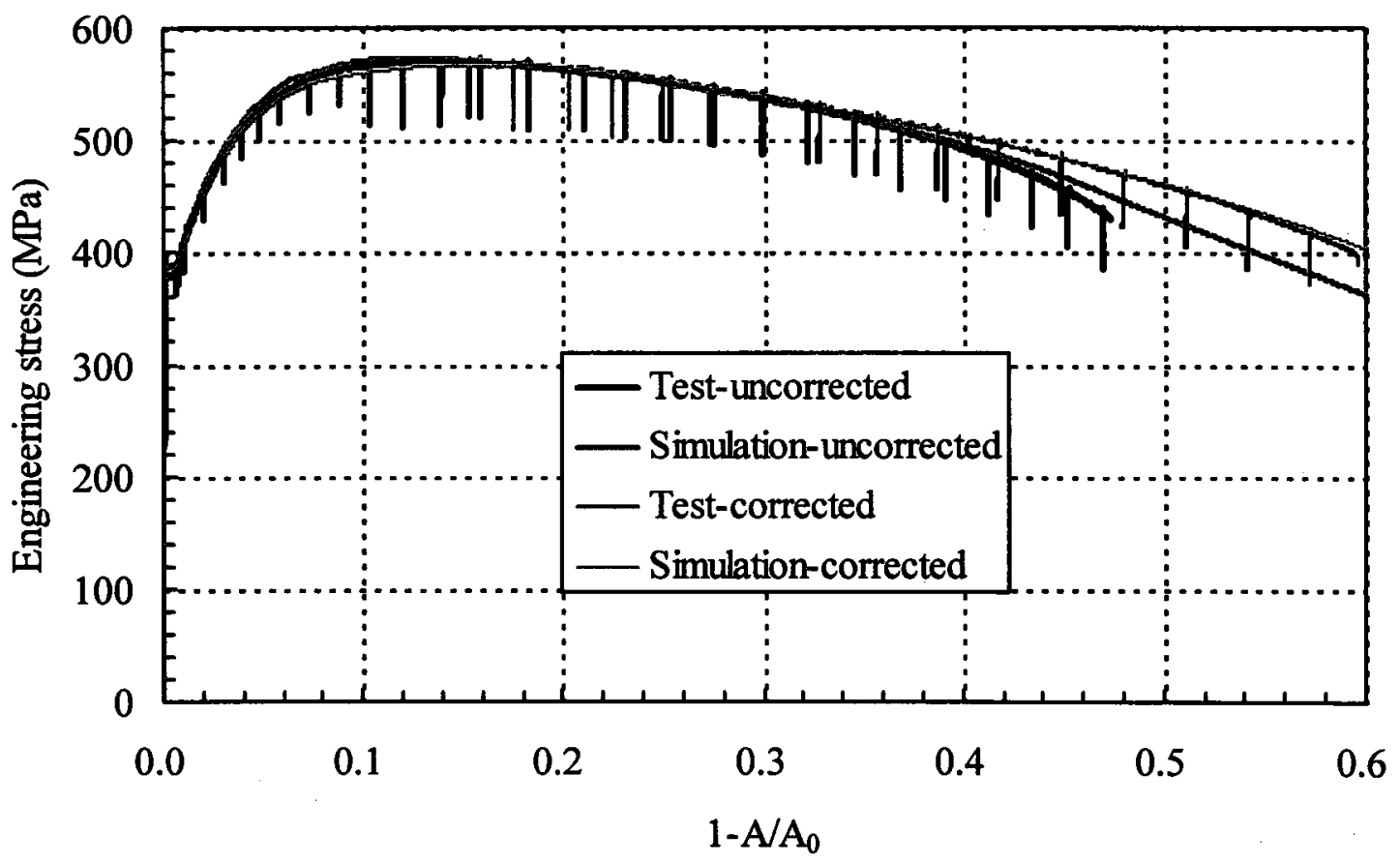

Figure 4.73 Test and predicted engineering stress versus change in cross-section area ratio curves for HT1E4ED with and without diameter correction 


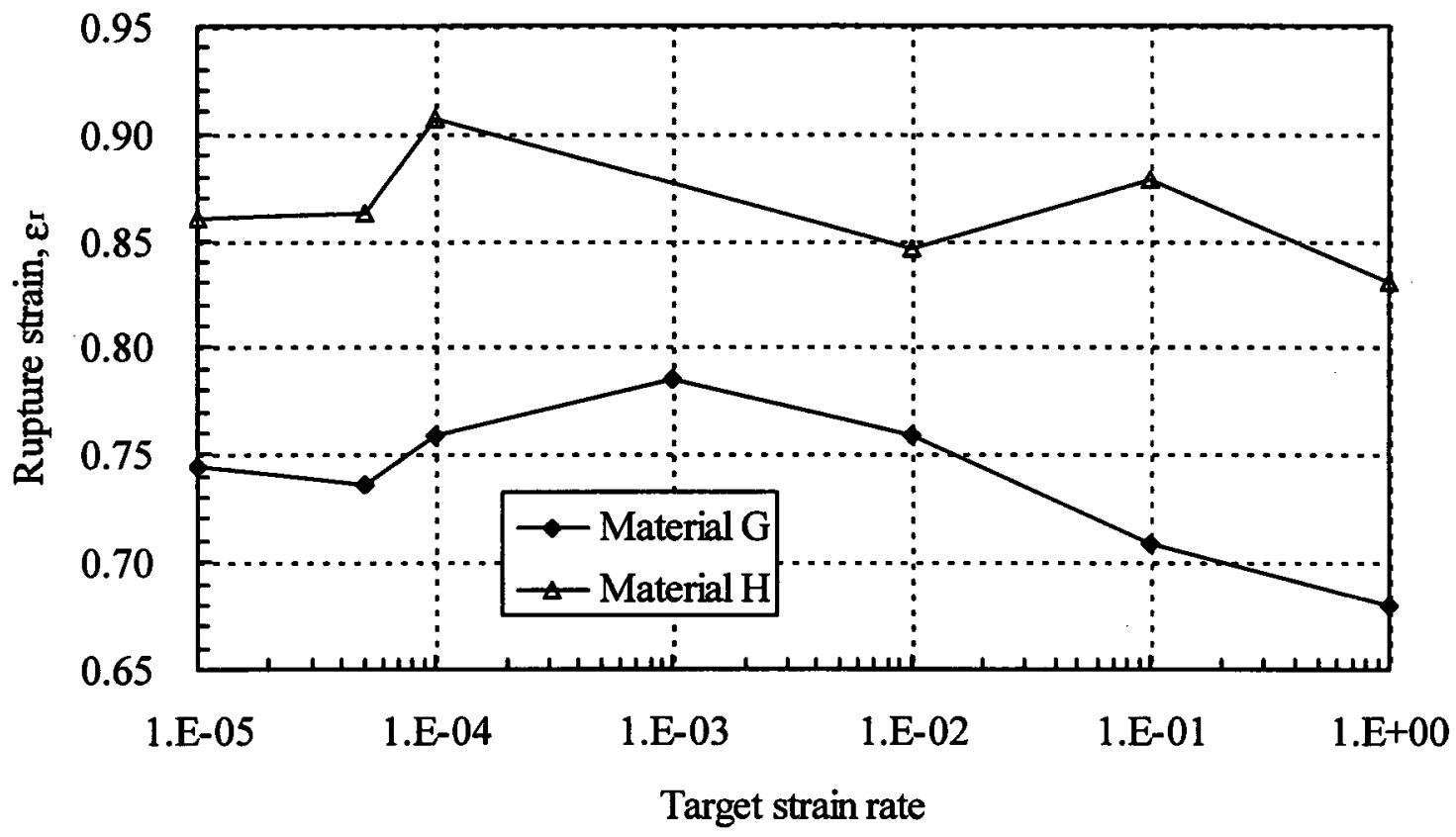

Figure 4.74 Rupture strain at fracture with diameter correction for materials $\mathrm{G}$ and $\mathrm{H}$

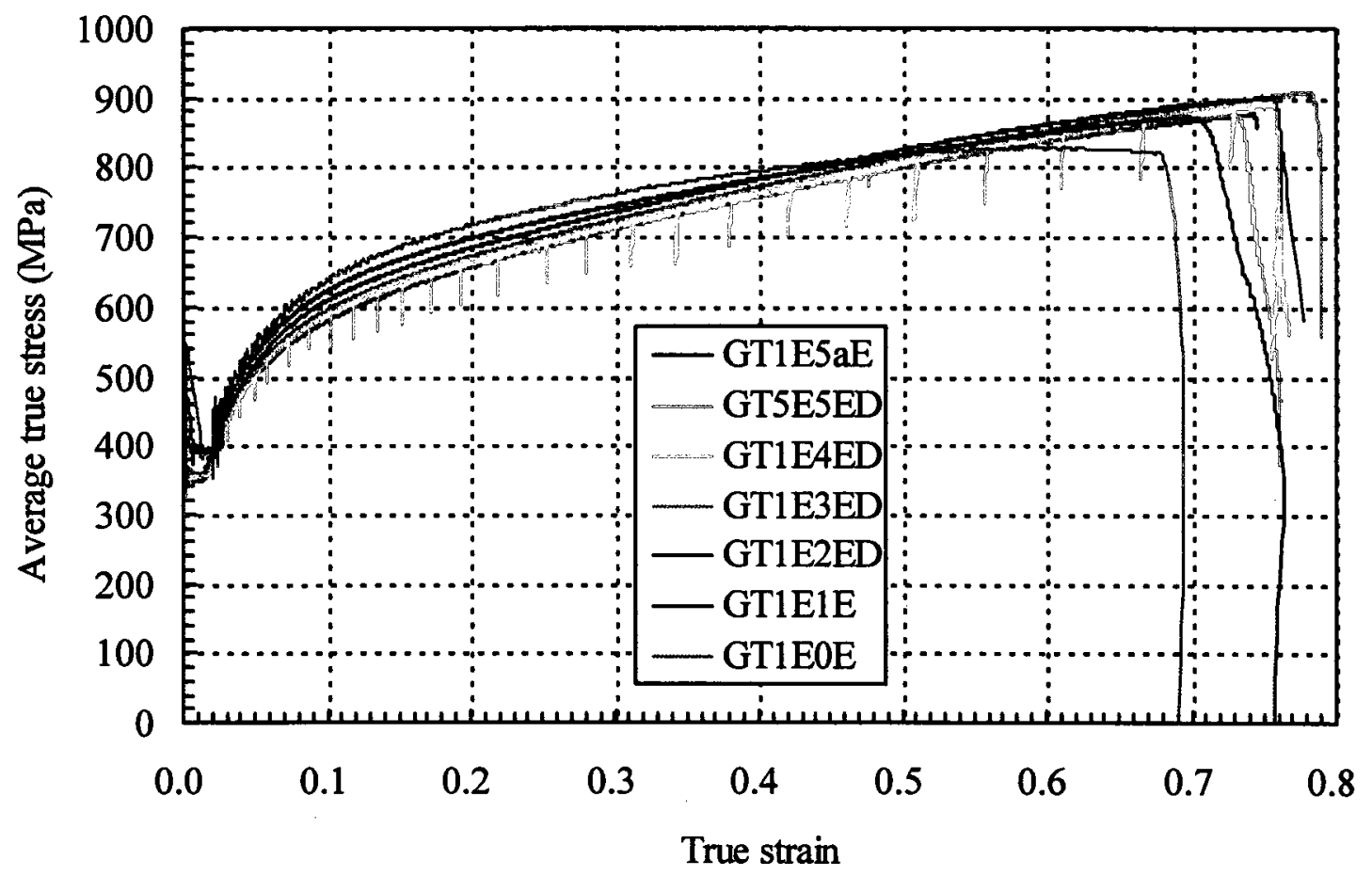

Figure 4.75 Average true stress-true strain curves for material $\mathrm{G}$ after correction for the diameter 


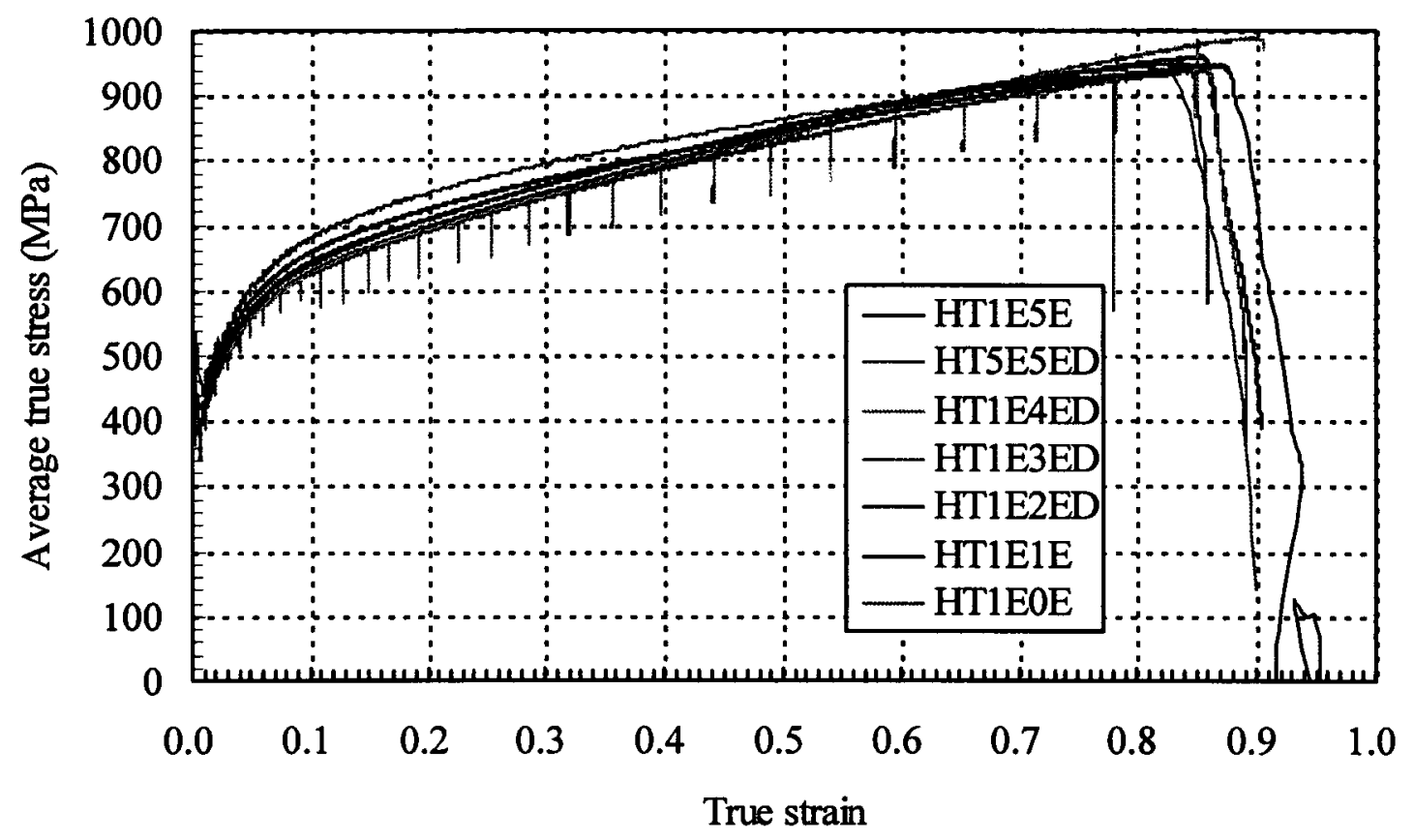

Figure 4.76 Average true stress-true strain curves for material $\mathrm{H}$ after correction for the diameter

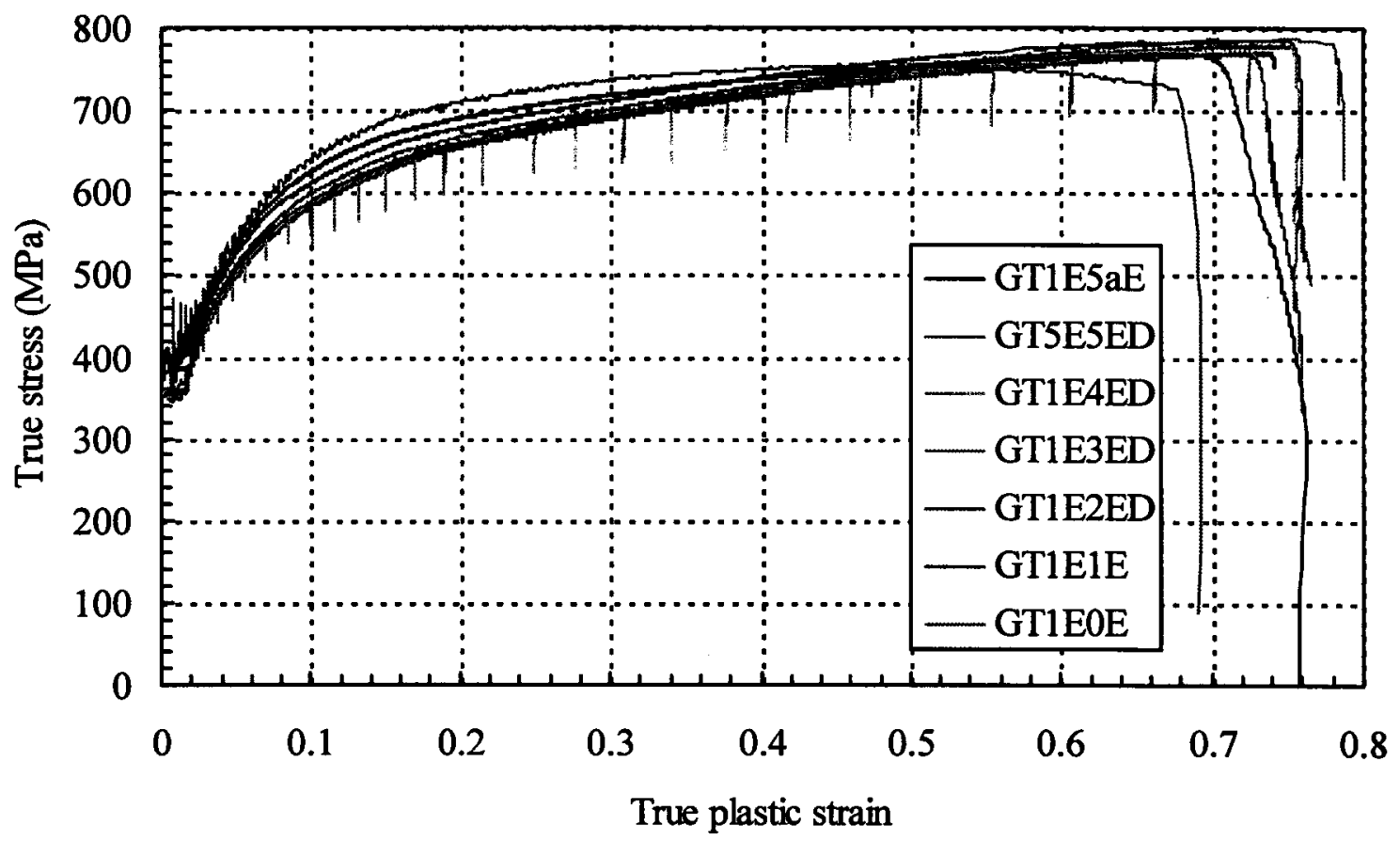

Figure 4.77 True stress-true plastic strain curves for material $G$ after correction for non-uniaxial state hydrostatic tension and diameter 


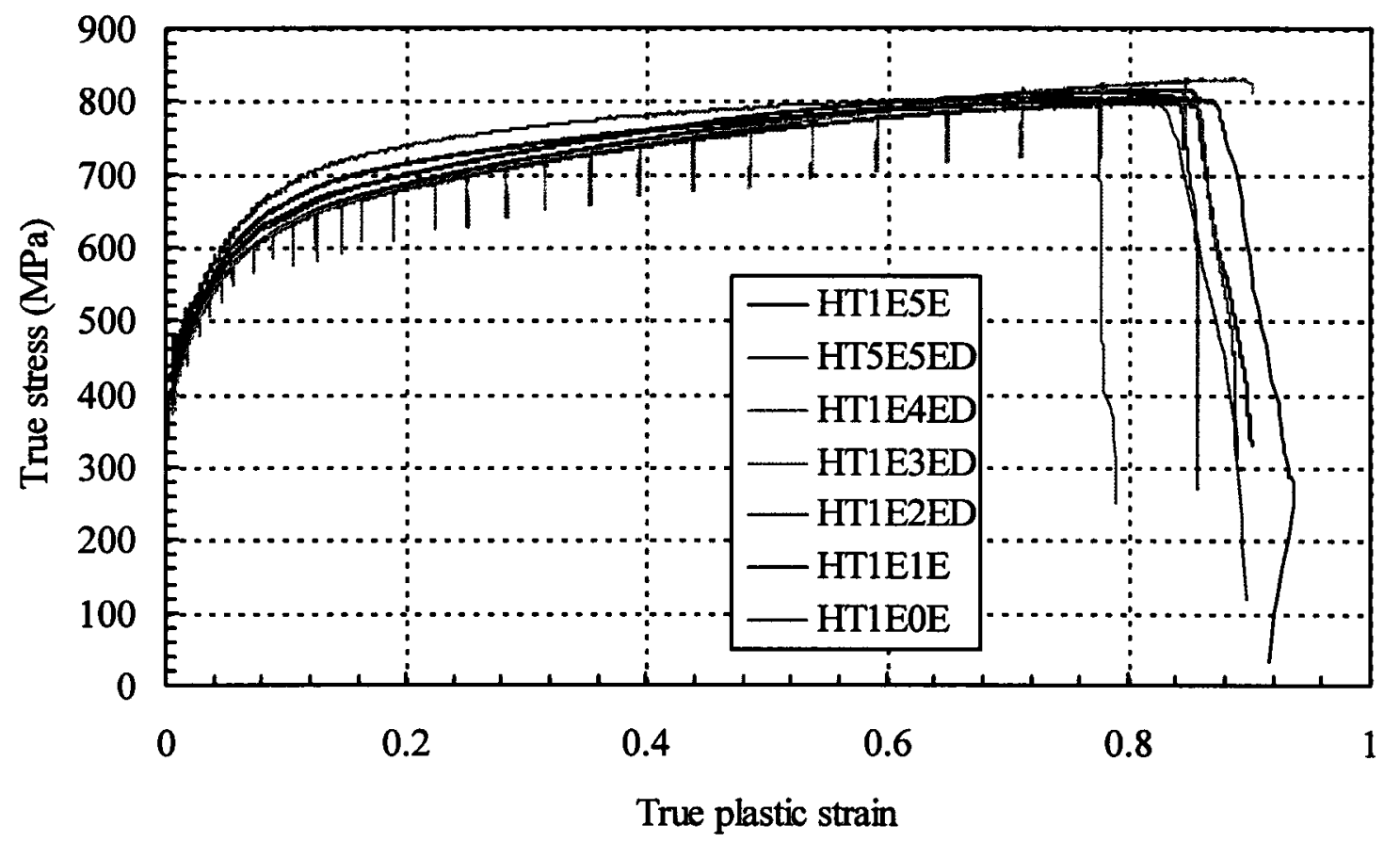

Figure 4.78 True stress-true plastic strain curves for material $\mathrm{H}$ after correction for non-uniaxial state hydrostatic tension and diameter

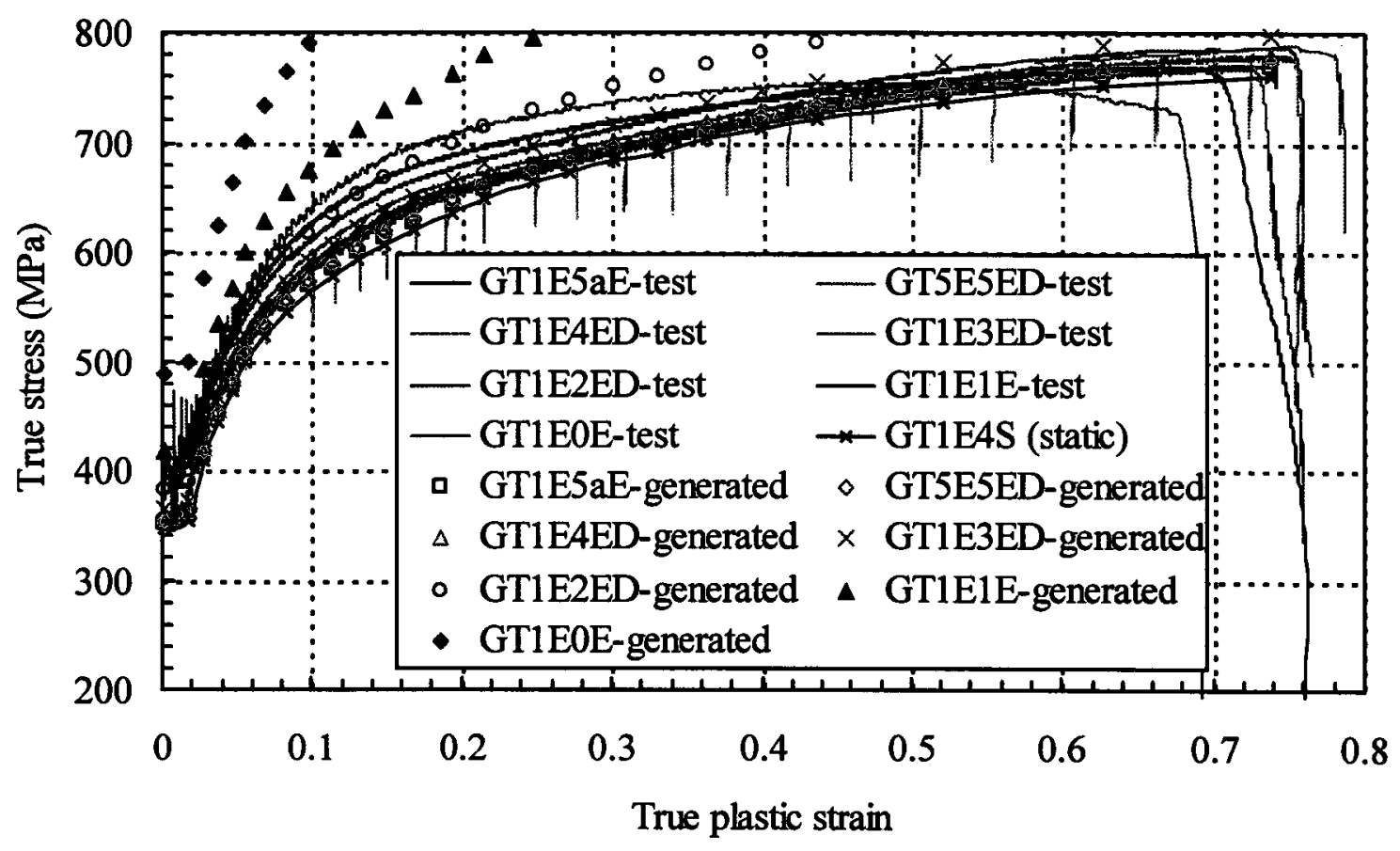

Figure 4.79 Test and predicted true stress-true plastic strain curves with Cowper-Symonds power law for material $\mathrm{G}$ 


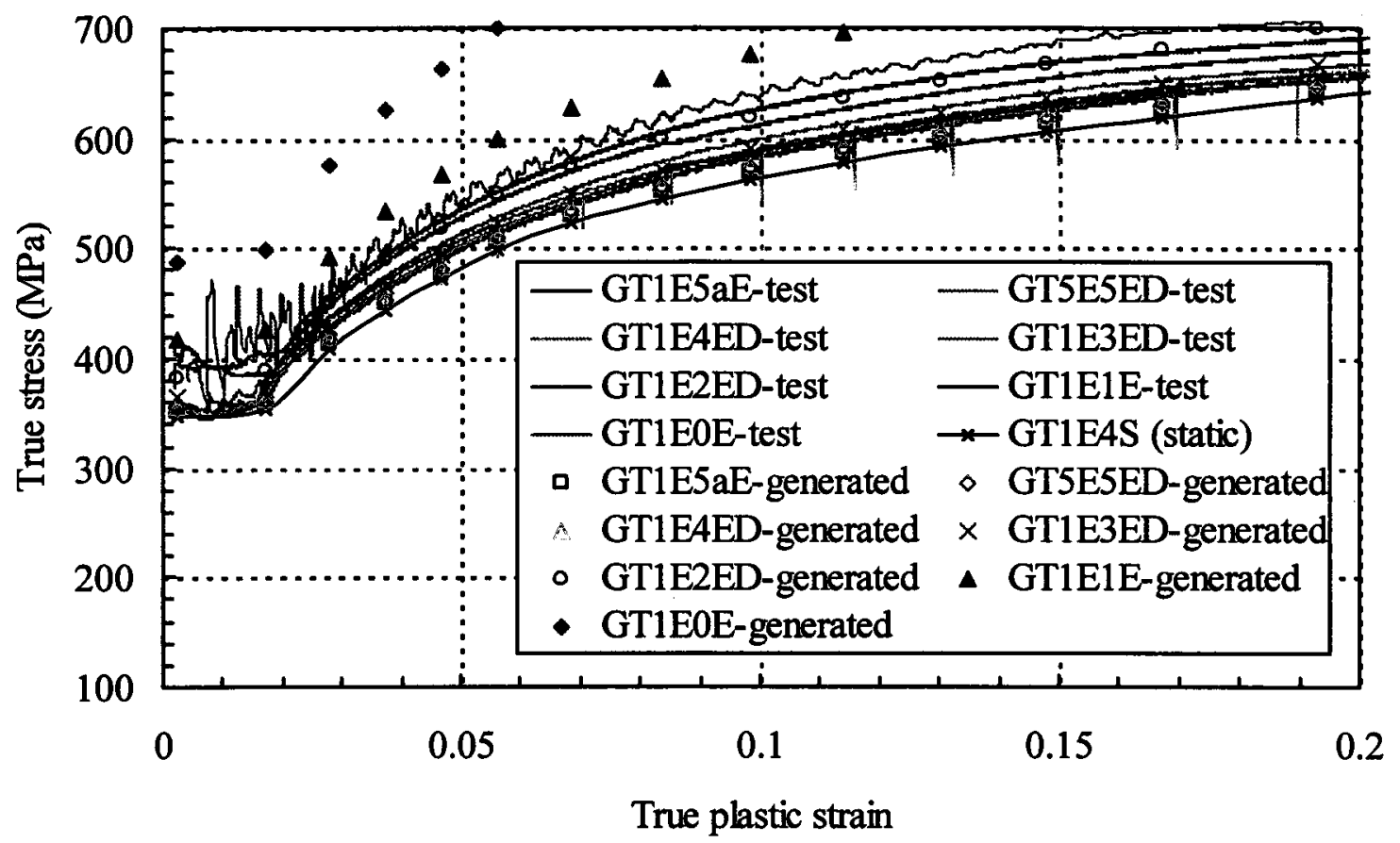

Figure 4.80 Test and predicted true stress-true plastic strain curves with Cowper-Symonds power law for material G (up to strain of 0.2 )

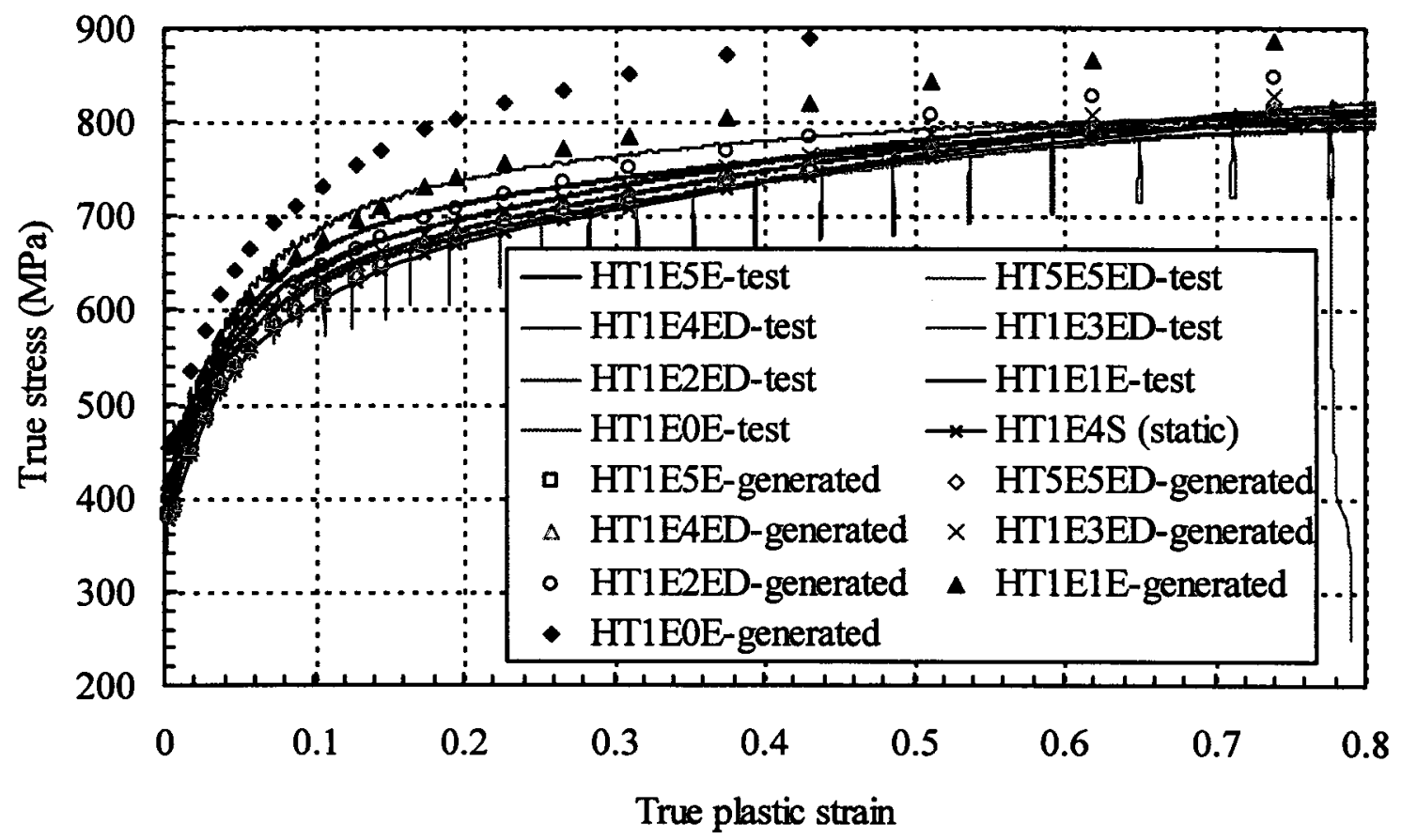

Figure 4.81 Test and predicted true stress-true plastic strain curves with Cowper-Symonds power law for material $\mathrm{H}$ 


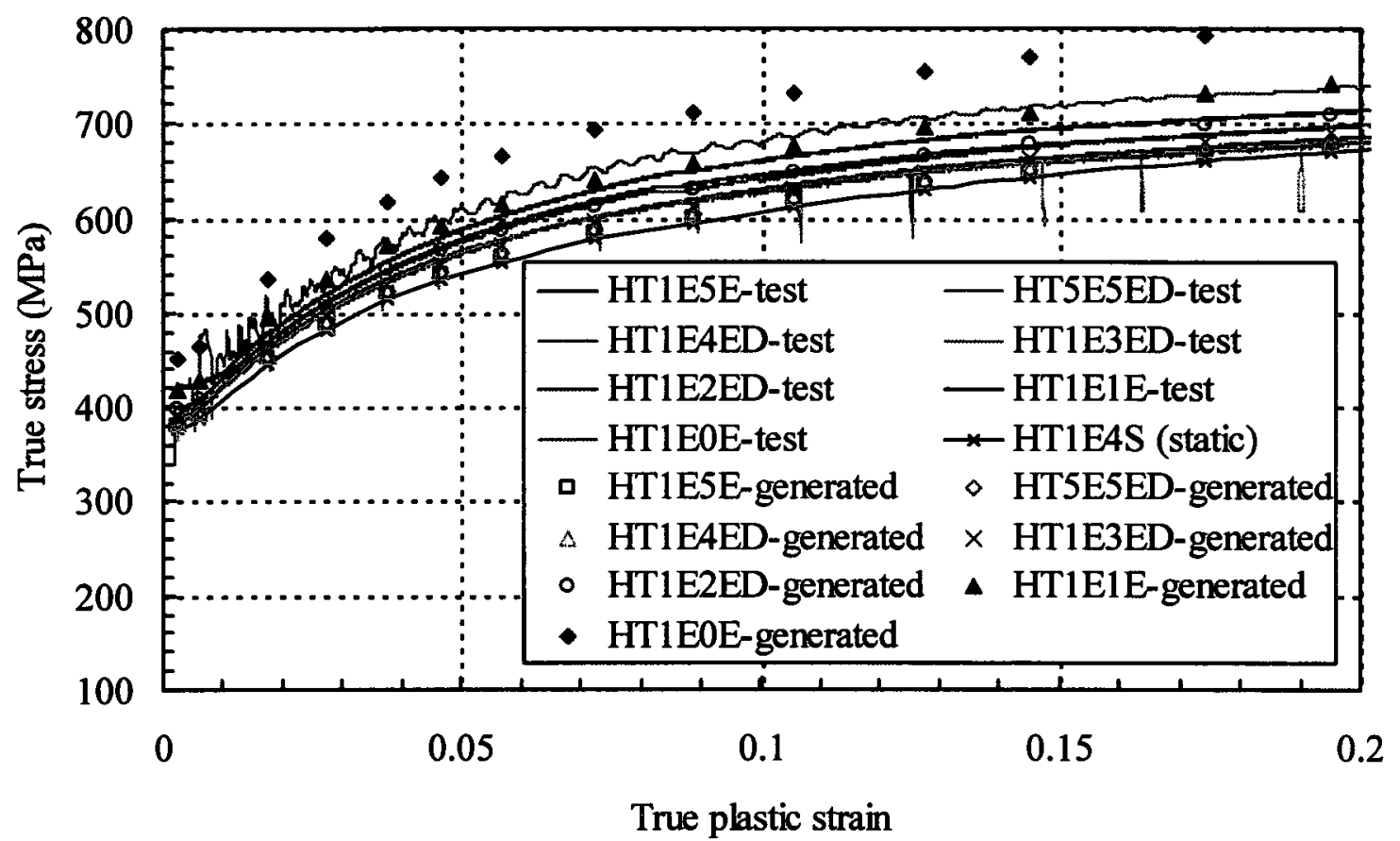

Figure 4.82 Test and predicted true stress-true plastic strain curves with Cowper-Symonds power law for material $\mathrm{H}$ (up to strain of 0.2 )

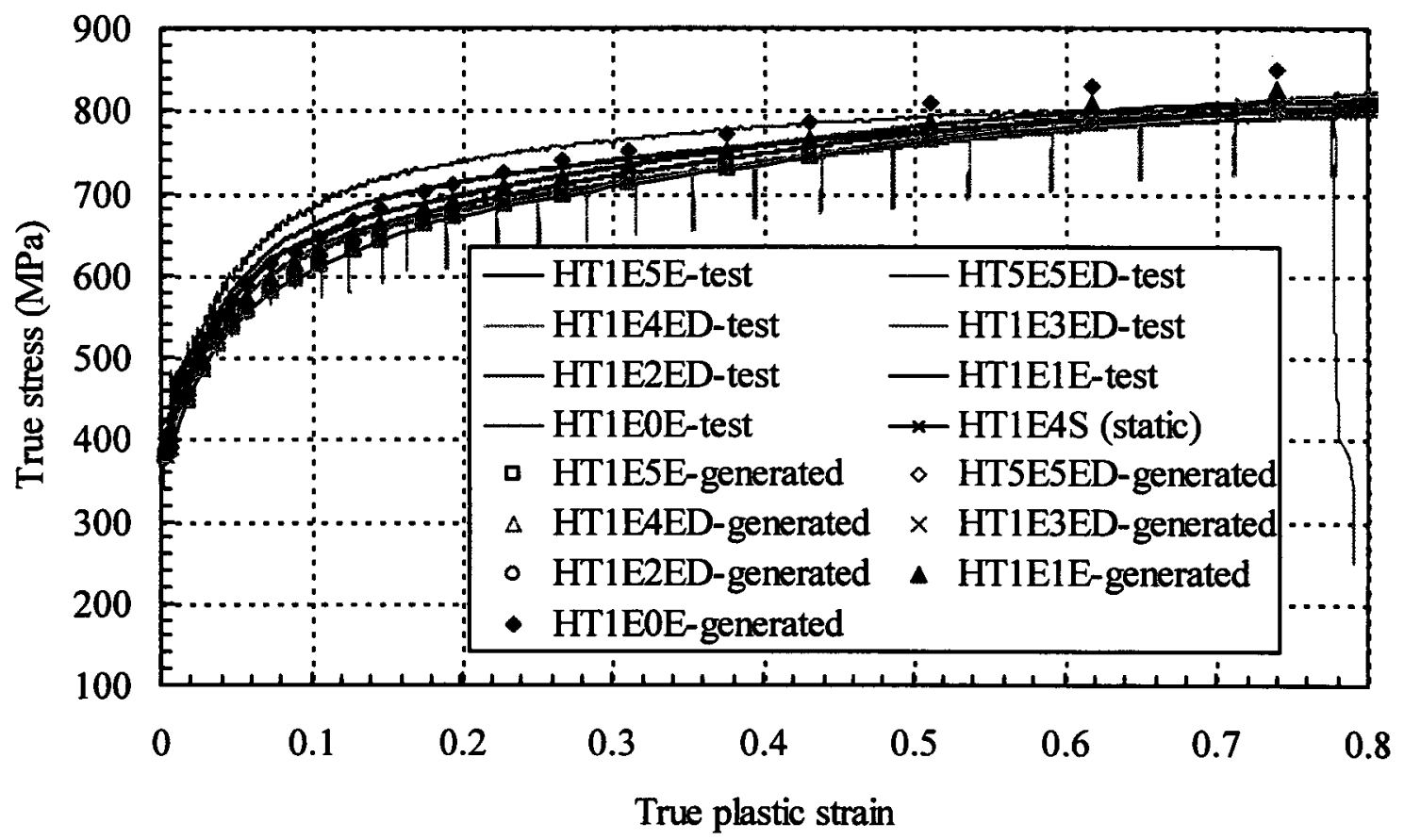

Figure 4.83 Test and predicted true stress-true plastic strain curves with modified Cowper-Symonds power law for material $\mathrm{H}$ 


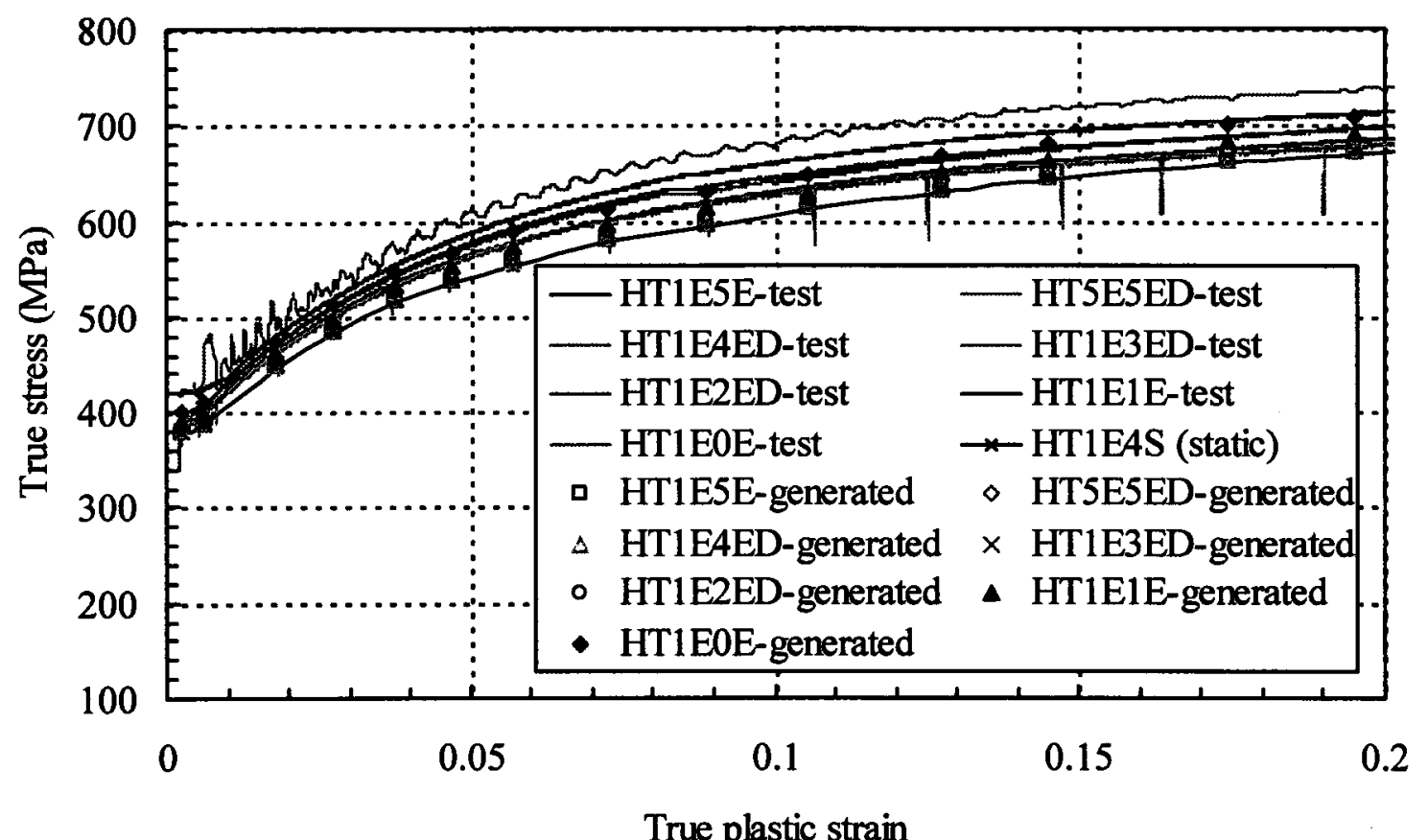

Figure 4.84 Test and predicted true stress-true plastic strain curves with modified Cowper-Symonds power law for material $\mathrm{H}$ (up to strain of 0.2)

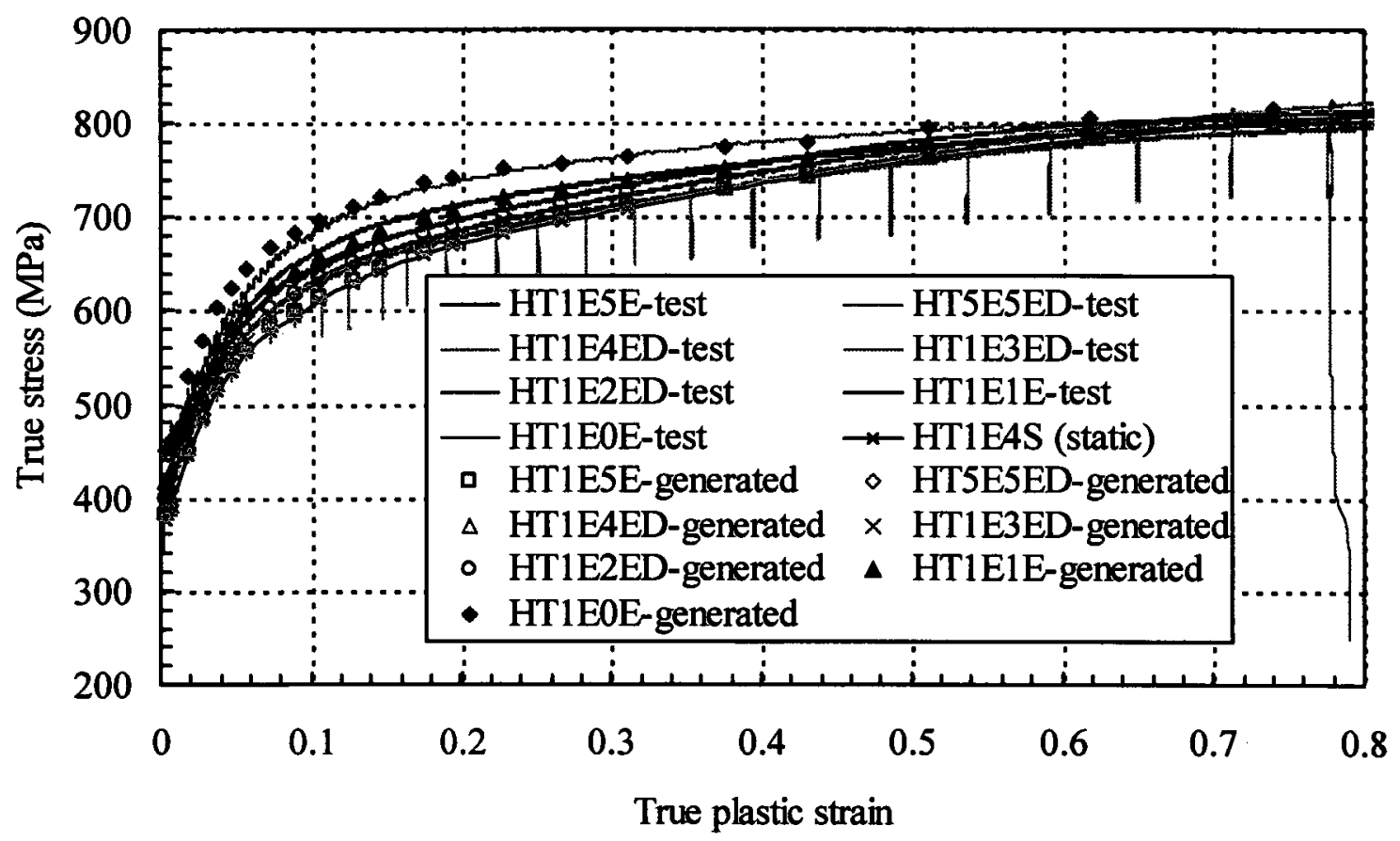

Figure 4.85 Test and predicted true stress-true plastic strain curves with mixed-mode hardening model for material $\mathrm{H}$ 


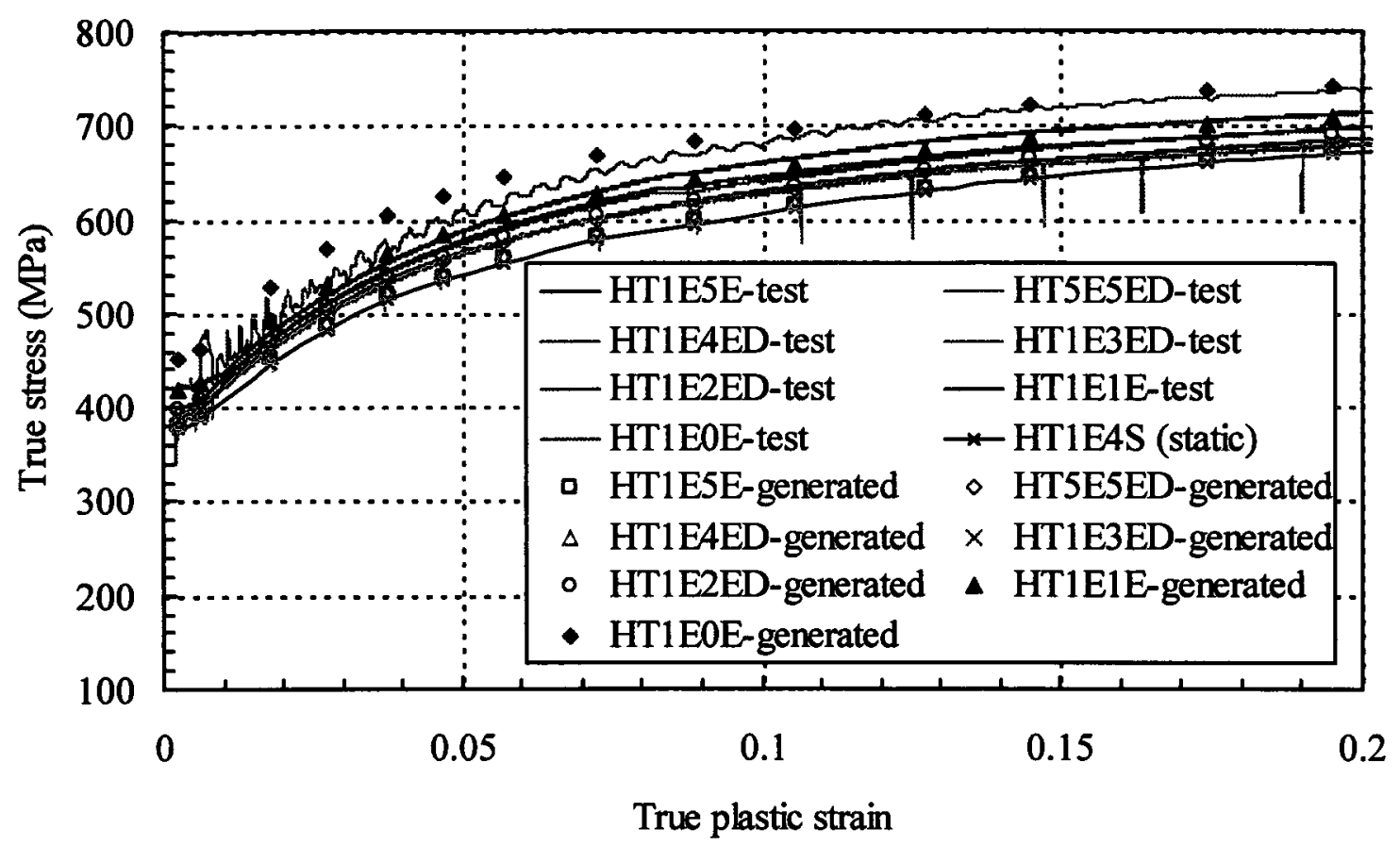

Figure 4.86 Test and predicted true stress-true plastic strain curves with mixed-mode hardening model for material $\mathrm{H}$ (up to strain of 0.2 ) 


\section{Chapter 5 Conclusions and Recommendations}

\subsection{Conclusions}

The following conclusions can be drawn based on results of the tests and numerical analyses.

1) The Cowper-Symonds power law equation was able to closely predict the dynamic yield stress for mild steel up to a strain rate of $1.0 \mathrm{~s}^{-1}$. While the equation can still be used in predicting the flow stress at the strain rate $10^{-3} \mathrm{~s}^{-1}$, it was found not to be appropriate for a strain rate higher than that.

2) The effect of strain rate on the rupture strain and the engineering strain at fracture was found to be small for the strain rate range tested with the maximum difference of only $14 \%$ between the highest and lowest rupture strain. There was no clear relationship that can be established between the rupture strain nor the engineering strain at fracture with the strain rate. Thus, the ductility of mild steel being tested can be considered not to be affected by the loading rate up to a strain rate of $1.0 \mathrm{~s}^{-1}$.

3) A simple equation based on the ratio of the current cross-section area and the cross-section area at peak stress has been developed to correct the measured average true stress for the non-uniaxial stress state after necking in order to allow the true stress-true plastic strain curve of the material to be determined directly from both rectangular and round tension coupon test data. Finite element analyses using the true 
stress-true plastic strain curves calculated with the true stress correction were able to reproduce the static and dynamic load versus cross-section deformation curves of the tests.

4) Among the three flow stress equations (models) evaluated, the mixed-mode hardening model by Lemaitre and Chaboche (1990) appeared to be able to give the best overall flow stress (true stress-true plastic strain curve) prediction up to fracture for the range of strain rate considered. This is followed by the modified Cowper-Symonds power law equation proposed by Jones (2001). However, both the mixed mode hardening model and modified Cowper-Symonds power law equation are comparable in predicting the true stress-true plastic strain curve up to the point of ultimate stress.

5) For the range of strain rate tested, the effect of strain rate on the flow stress appeared to be significant at the early stage of strain hardening up to the true plastic strain of 0.4. However, the true stress-true plastic strain curve at various strain rates were found to converge and the strain rate dependency of the flow stress diminished at a large plastic strain before the coupon fractured.

6) The tapered profile adopted for the round coupon appeared to have enable the diameter at the minimum cross-section to be measured in most tests. This was verified by comparing the test and predicted engineering stress versus cross-section deformation curves through numerical simulations and assessing the shape of the true strain versus engineering strain curve. In a few cases where the minimum diameter 
appeared not to have been measured, a diameter correction procedure that allows a more accurate minimum diameter to be approximated has also been established and verified using the true strain versus engineering strain curve of a test at the next closest strain rate.

7) The study has demonstrated that the dynamic true stress-true plastic strain curve up to fracture can be determined directly from the tension test of a round coupon specimen with a tapered profile by correcting for the true stress with Eq. (4.14), and if necessary also correcting for the minimum diameter with the established procedure.

\subsection{Recommendations}

1) In the current testing program, only the diameter of the tapered round specimens was measured continuously during the test. However, it may not be as convenient to fabricate a round coupon from a plate or a flat bar. Thus, an additional procedure that allows the minimum cross-section dimensions of a rectangular or a square coupon to be measured continuously during the test should be developed.

2) Based on results of the tests and numerical simulations, it appears that the testing procedure adopted for tapered round coupons was quite successful in ensuring that the diameter at the minimum cross-section was being measured in most of the tests. However, there were still a few tests where the diametral extensometer was clearly not recording the diameter at the correct location. Thus, improvements to the current 
testing procedure should be explored so that it can be better ensured that the diameter at the minimum cross-section is being measured all the time.

3) From the preliminary assessment of the material models, it appears that the mixed-mode hardening model by Lemaitre and Chaboche (1990) with the strain rate effect accounted for in isotropic hardening using the Cowper-Symonds power law equation was able to provide a good overall representation of the measured flow stress up to fracture. Additional studies should be carried out to conduct more rigorous assessment of the mixed-mode hardening model against a larger range of test data. In addition, a procedure should also be established to provide guidelines on calibrating the parameters for the model in terms of the number of coupons and at what strain rates the tests should be carried out.

4) Since the mixed-mode hardening model has been found to be able to closely predict the flow stress at various strain rates, a finite element analysis study can be carried out using the material model to predict the behavior and response of the structural components and systems at various loading rates and compare to those obtained from the tests. 


\section{References}

1. Al-Kharat, M., and Rogers, C.A. (2007). Inelastic Performance of Cold-Formed Steel Strap Braced Walls, Journal of Construction Steel Research, 63(4): 460-474.

2. Alves, M. and Jones, N (1999). Influence of Hydrostatic Stress on Failure of Axisymmetric Notched Specimens, Journal of the Mechanics and Physics of Solids, 47 (3): 643-667.

3. ASTM (2004). Standard Test Methods for Tension Testing of Metallic Materials [Metric], ASTM E8-04, American Society for Testing and Materials, West Conshohocken.

4. ASTM (2007). Standard Specification for High-Strength Low-Alloy Columbium-Vanadium Structural Steel, ASTM A572/A572M-07, American Society for Testing and Materials, West Conshohocken.

5. Benson, D. K. and Hancock, J. R. (1974). the Effect of Strain Rate on the cyclic Response of Metals, Metallurgical and Materials Transactions B, 5(8): 1711-1715.

6. Blazynski, T. Z. (1983). Applied Elasto-Plasticity of Solid, Macmillan Press Ltd, London and Basingstoke.

7. Bridgman, P. W. (1944). The Stress Distribution at the Neck of a Tension Specimen, Fracturing of Metals, 32: 553-574

8. Bridgman, P. W. (1947). Fracture and Hydrostatic Pressure, Fracturing of Metals, the Twenty-Ninth National Metal Congress and Exposition, American Society for 
Metals, Chicago, October 18 to 24: 246-261.

9. CSA (2004). General Requirements for Rolled or Welded Structural Quality Steel/Structural Quality Steel, CAN/CSAG40.20/21, Canadian Standards Association, Toronto, ON, Canada.

10. Campbell, J. D. and Cooper, R. H. (1966). Yield and Flow of Low-carbon Steel at Medium Strain Rates, Proceedings of the Conference on the Physical Basis of Yield and Fracture, Oxford University, Oxford: 77-87.

11. Cowper, G. R. and Symonds, P. S. (1957). Strain Hardening and Strain-rate Effects in the Impact Loading of Cantilever Beams, Technical Report-Division of Applied Mathematics, Report No. 28, Brown University, Providence.

12. Dusicka, P., Itani, A. M. and Buckle, I. G. (2007). Cyclic Responses of Plate Steels under Large Inelastic Strains, Journal of Constructional Steel Research 63 (2): $156-164$.

13. Eleiche, A. M. and Campbell, J. D. (1976). The Influence of Strain-rate History and Temperature on the Shear Strength of Copper, Titanium and Mild Steel, Air Force Materials Laboratory Report AFML-TR 76-90, OHIO.

14. Filiatrault, A. and Tremblay, R. (1996). Behavior of Tention-only Concentrically Braced Steel Frames under Simulated Earthquake Loads, International Conference on Advances in Steel Structures, , Hong Kong, V. II: 1047-1052.

15. Gerard, G. and Papirno, R. (1957). Dynamic Biaxial Stress-strain Characteristics of Aluminum and Mild steel, Transactions of the American Society for Metals, 49: 
$132-148$.

16. Gibson, N., Filiatrault, A. and Ashford, S. A (2002). Performance of Beam to Column Bridge Joints Subjected to a Large Velocity Pulse, Pacific Earthquake Engineering Research Center, PEER 2002/24, University of California, Berkeley.

17. Harding, J. (1980). Testing Techniques at High Rates of Strain, Oxford University Engineering Laboratory, Report No. 1308/80, Oxford University, Oxford.

18. Harding, J. and Huddart, J. (1979). The Use of the Double-notch Shear Test in Determining the Mechanical Properties of Uranium at Very High Rates of Strain, Mechanical Properties at High Rates of Strain, Institute of Physics Conference Series No.47: 49-61.

19. Hashmi, M. S. J. (1980). Strain Rate Sensitivity of a Mild Steel at Room Temperature and Strain Rates of up to $10^{5} \mathrm{~s}^{-1}$, Journal of Strain Analysis, 15 (4): 201-207.

20. Hsu, S. and Jones, N. (2004). Dynamic Axial Crushing of Aluminum Alloy 6063-T6 Circular Tubes, Latin American Journal of Solids and Structures, 1(3): 277-296.

21. Hsu, S. and Jones, N. (2004). Quasi-Static and Dynamics Axial Crushing of Thin-Walled Circular Stainless Steel, Mild Steel and Aluminum Alloy Tubes, International Journal of Crashworthiness, 9(2): 195-217.

22. Johnson, G. R. and Cook, W. H. (1985). Fracture Characteristics of Three Metals Subjected to Various Strains, Strain Rates, Temperatures and Pressures. 
Engineering Fracture Mechanics, 21(1): 31-48.

23. Jones, N. (2001). Dynamic Material Properties and Inelastic Failure in Structural Crashworthiness, International Journal of Crashworthiness, 6(1): 7-18.

24. Kaneko, H. (1997). Influence of Strain-rate on Yield Ratio. Kobe Earthquake Damage to Steel Moment Connections and Suggested Improvement, Japanese Society of Steel Construction Technical Report No. 39, Tokyo, Japan.

25. Kang, G., Kan, Q., Zhang, J. and Sun, Y. (2005). Time-dependent Ratchetting Experiments of SS304 Stainless Steel, International Journal of Plasticity, 22(5):858-894.

26. Kassar, M. and Yu, W. W. (1992). Effect of Strain-rate on Material Properties on Sheet Steels, Journal of Structural Engineering, 118(11): 3136-3150.

27. Kawata, K., Fukui, S. and Seino, J. (1968). Some Analytical and Experimental Investigations on High Velocity Elongation of Sheet Materials by Tensile Shock, Proc. IUTAM Symposium on Behaviour of Dense Media Under High Dynamic Pressure, Dunod, Paris: 313-323.

28. Klepaczko, J. (1969). The Strain Rate Behaviour of Iron in Pure Shear, International Journal of Solid and Structures, 5(5): 533-548.

29. Krempl, E. (1979). An Experimental Study of Room-temperature Rate-sensitivity, Creep and Relaxation of AISI type 304 Stainless Steel, Journal of the Mechanics and Physics of Solids, 27(5-6): 363-375. 
30. Lemaitre, J. and Chaboche, J. L. (1990), Mechanics of Solid Materials, Cambridge University Press.

31. Lindholm, U. S. and Yeakley, L. M. (1966). A Dynamic Biaxial Testing Machine, Experimental Mechanics, 7(1): 1-7.

32. Maiden, C. J. and Green, S. J. (1966). Compressive Strain-rate Tests on Six Selected Materials at Strain Rates from $10^{-3}$ to $10^{4} \mathrm{in} / \mathrm{in} / \mathrm{sec}$, Transactions of American Society of Mechanical Engineers, Journal of Applied Mechanics, 33: 496-504.

33. Manjoine, M. J. (1944). Influence of Rate of Strain and Temperature on Yield Stresses of Mild Steel, Transactions of American Society of Mechanical Engineers, Journal of Applied Mechanics, 11: A211-A218.

34. Marsh, K. J. and Campbell, J. D. (1963). The Effect of Strain Rate on the Post-yield Flow of Mild Steel, Journal of the Mechanics and Physics of Solids, 11(1): 49-63.

35. Nadai, A. and M. J. Manjoine (1941). High-speed Tension Tests at Elevated Temperatures-part II and III, Transactions of American Society of Mechanical Engineers, Journal of Applied Mechanics, 8: A77-A91.

36. Nagaraja, R., Lohramann, N. R., M. and Tall, L. (1966). Effect of Strain-rate on the Yield Stress of Structural Steels, Journal of Materials, 1(1): 241-265.

37. Nakashima, M., Suita, K., Morisako, K. and Maruoka, Y. (1998). Tests of Welded Beam-Column Subassemblies. I: Global Behavior, Journal of Structural 
Engineering, 124(11): 1236-1244.

38. Ng, D. H. Y., Delich, M. and Lee, L. H. N. (1979). Yielding of 6061-T6 Aluminum Tubings under Dynamic Biaxial Loadings, Experimental Mechanics, 19(6): 200-206.

39. Nicholas, T. and Campbell, J. D. (1972). Shear-strain-rate Effects in High-strength Aluminum Alloy. Experimental Mechanics, 12(10): 441-447.

40. Ogawa, K., Kobayashi, H., Sugiyama, F. and Horikawa, K. (2005). Prediction of Mechanical Behaviour of Low Carbon Steel at High Strain Rate Using Thermal Activation Theory and Static Data, JSME International Journal Series A, 48(4):228-233 .

41. Peixinho, N., Phinho, A. and Jones, N. (2002). Determination of Crash-Relevant Material Properties for High-Strength Steel and Constitutive Equations, SAE Transactions: Journal of Materials \& Manufacturing, 111(5):1019-1025.

42. Rawlings, B. (1963). The Dynamic Behaviour of Mild Steel in Pure Flexure, Proceedings of the Royal Society of London, Series A, Mathematical and Physical Sciences, 275(1363): 528-543.

43. Rawlings, B., Burgmann, J. B. and Ford, T. D. (1970). The Effects of Loading Rate on the Response of Pin-jointed Triangulated Steel Frames. Proceedings Institution of Civil Engineers, 46: 327-342.

44. Rohr, I., Nahme, H., Thoma, K. (2005). Material Characterization and Constitutive Modelling of Ductile High Strength Steel for a Wide Range of Strain 
Rate, International Journal of Impact Engineering, 31(4): 401-433.

45. Sanchez, L and Plumier, A, (2000). Tests on the Strain Rate Effects on Bean-to-column Steel Connection, Behaviour of Steel Structures in Seismic Areas, Proceedings of the Third STESSA Conference 2000, Montreal: 247-254

46. Simulia (2008). Abaqus 6.8, Dassault Systemes Simulia Corp., Providence, RI, USA.

47. Soroushian, P. and Choi, K.-B., (1987). Steel Mechanical Properties at Different Strain Rates, American Society of Civil Engineers, Journal of Structural Engineering, 113(4): 863-872.

48. Suita, K., Nakashima, M., and Morisako, K. (1998). Tests of Welded Beam-Column Subassemblies. II: Detailed Behavior, Journal of Structural Engineering, 124(11): 1245-1252.

49. Symonds, P. S. (1967). Survey of Methods of Analysis for Plastic Deformation of Structures under Dynamic Loading, Division of Engineering, Report No.: BUINSRDCI1-67, Brown University.

50. Uenishi, A. and Teodosiu, C. (2004). Constitutive Modelling of the High Strain Rate Behaviour of Interstitial-free Steel, International Jouranl of Plasticity, 20(4-5):915-936.

51. Wallace, B. J. and Krawinkler, H. (1989). Small-Scale Model Tests of Structural Steel Assemblies, Journal of Structural Engineering, 115(8): 1999-2015.

52. Wang, S., Zhang, Y. G. and Chen, W. X. (2001). Room Temperature Creep and 
Strain-rate-dependent Stress-Strain Behavior of Pipeline Steels, Journal of Materials Science, 36(8):1931-1938.

53. Wilson, M. L., Hawley, R. H. and Duffy, J. (1979). Strain Rate and Strain Rate History Effects in Two Mild Steels, Technical Report of Division of Engineering, Report No. NSF ENG 75-18532/8, Brown University, Providence.

54. Worswick, M.J., Clarke, J.A. and Pick, R.J. (1995). Dynamic Fracture under Impact and High-Strain rate Loading, Canadian Journal of Physics, $73(5-6): 315-323$

55. Wright, R. N. and Hall, W. J. (1964). Loading Rate Effects in Structural Steel Design, Journal of Structural Division, 90(55): 11-37. 


\section{Appendix A Comparison of Static Reading Results with Axial Extensometer Control and Stroke Control}

From the test results, it was observed that the static load readings were lower when the loading rate was controlled with the axial extensometer than with the machine stroke. This can be seen in Figs. A.1 and A.2 for the tests of material C at the strain rate of $10^{-4} \mathrm{~s}^{-1}$. The difference in the stress-strain curve in Fig A.1 between CR1E4aES and CR1E4bES before the ultimate stress was most likely due to the pre-compression in CR1E4aES as discussed in Chapter 4. In Fig. A.2, it can be seen that CR1E4aS and CR1E4bS have the same dynamic stress-strain curve before the peak stress.

Table A.1 compares the drop in stress when taking static readings at various strains between axial extensometer and stroke control tests. At each static reading, the drop in the stress when the machine was put on pause can be defined as

$$
\Delta \sigma=\sigma^{d y}-\sigma^{s t}
$$

where $\sigma^{\mathrm{dy}}$ is the dynamic stress before the pause and $\sigma^{\text {st }}$ is the stress before the loading is resumed. It can be seen that the ratio of stress drop between the axial extensometer and stroke control tests is quite consistent throughout the test even after the peak load. Table A. 2 compares the average stress drop of CR1E4aES and CR1E4bES at the last two static readings before and the first two static readings after switching from axial extensometer to stroke control. It can be seen that the ratio of the average stress drop at the last two static readings before and the first two static readings after the switch for both CR1E4aES and CR1E4bES is about equal. 
As shown in Figs. 4.31 and 4.32 for GT1E4ED and HT1E4ED, the stress drop when taking the static readings was even higher for the test with the diametral extensometer control compared to that with the axial extensometer control. Thus, it can be deduced that the drop in stress when taking static readings decreases as the ability to control the loading rate improves from diametral extensometer control to axial extensometer control, and lastly stroke control.

Tests were also conducted to compare the difference in the static readings under axial extensometer and stroke controls at the strain rates of $10^{-2} \mathrm{~s}^{-1}$ and $10^{-4} \mathrm{~s}^{-1}$. In Fig. A.3, it can be seen that under stroke control, static readings are almost the same at both $10^{-2} \mathrm{~s}^{-1}$ and $10^{-4} \mathrm{~s}^{-1}$ strain rates. However in Fig. A.4, when the tests were conducted under axial extensometer control, the static readings were lower at the strain rate of $10^{-2} \mathrm{~s}^{-1}$ than at $10^{-4} \mathrm{~s}^{-1}$. Furthermore, taking the static yield stress as one of the variables for the Cowper-Symonds power law equation, the static yield stress determined for material $\mathrm{G}$ and $\mathrm{H}$ through the nonlinear regression analysis was found to be closer to the static yield stress from the stroke control test. Comparisons of the measured and calibrated static yield stress are shown in Table A.3. Thus, readings from stroke control tests are considered as the static reading in this study.

Since all the rectangular specimens were tested under axial extensometer control, the following procedure was adopted to convert the static readings from axial extensometer control tests to that of the equivalent stroke control tests based on the ratio of the drop in stress before and after switching from axial extensometer control to stroke 
control. The equivalent static stress for the stroke control test is calculated from the static stress of the axial extensometer test as

$$
\sigma_{c o r}^{s t}=\sigma^{d y}-\Delta \sigma^{e x}\left(\frac{\Delta \sigma_{s w}^{s t}}{\Delta \sigma_{s w}^{e x}}\right)
$$

where $\Delta \sigma^{\mathrm{ex}}$ is the drop in stress when taking the static reading in coupon test under axial extensometer control, $\Delta \sigma_{s w}^{e x}$ is the average stress drop at the last two static readings before switching to stroke control and $\Delta \sigma_{s w}^{s t}$ is the average stress drop at the first two static readings right after switching from axial extensometer to stroke control. 
Table A.1 Comparisons of the drop in the stress when taking static readings at various strains between axial extensometer and stroke controls

\begin{tabular}{|c|c|c|c|c|c|}
\hline \multirow[b]{2}{*}{ Specimen } & \multirow[b]{2}{*}{ Strain } & \multicolumn{2}{|c|}{ Stress (MPa) } & \multirow{2}{*}{$\begin{array}{l}\text { Drop } \\
\text { ratio } \\
(\mathrm{a}-\mathrm{b}) / \mathrm{a}\end{array}$} & \multirow{2}{*}{$\begin{array}{l}\text { Loading rate } \\
\text { control mode }\end{array}$} \\
\hline & & $\sigma^{\mathrm{dy}}(\mathrm{a})$ & $\sigma^{\text {st }}(b)$ & & \\
\hline \multirow{9}{*}{ CR1E4aES } & 0.002 & 365.7 & 343.4 & 0.061 & \multirow{7}{*}{$\begin{array}{c}\text { Extensometer } \\
\text { control }\end{array}$} \\
\hline & 0.040 & 516.3 & 485.2 & 0.060 & \\
\hline & 0.080 & 570.0 & 536.6 & 0.059 & \\
\hline & 0.120 & 585.9 & 550.0 & 0.061 & \\
\hline & 0.160 & 588.8 & 549.3 & 0.067 & \\
\hline & 0.200 & 586.0 & 546.9 & 0.067 & \\
\hline & 0.240 & 578.5 & 539.1 & 0.068 & \\
\hline & 0.280 & 546.4 & 525.8 & 0.038 & \multirow{2}{*}{$\begin{array}{l}\text { Stroke } \\
\text { control }\end{array}$} \\
\hline & 0.300 & 523.7 & 503.8 & 0.038 & \\
\hline \multirow{8}{*}{ CR1E4bES } & 0.002 & 372.2 & 349.6 & 0.061 & \multirow{6}{*}{$\begin{array}{c}\text { Extensometer } \\
\text { control }\end{array}$} \\
\hline & 0.040 & 511.4 & 482.0 & 0.057 & \\
\hline & 0.080 & 563.4 & 531.5 & 0.057 & \\
\hline & 0.120 & 578.2 & 544.1 & 0.059 & \\
\hline & 0.160 & 580.6 & 545.2 & 0.061 & \\
\hline & 0.200 & 577.7 & 543.1 & 0.060 & \\
\hline & 0.240 & 566.7 & 541.9 & 0.044 & \multirow{2}{*}{$\begin{array}{l}\text { Stroke } \\
\text { control }\end{array}$} \\
\hline & 0.280 & 522.1 & 501.1 & 0.040 & \\
\hline \multirow{8}{*}{ CR1E4aS } & 0.002 & 367.8 & 348.8 & 0.052 & \multirow{8}{*}{$\begin{array}{l}\text { Stroke } \\
\text { control }\end{array}$} \\
\hline & 0.040 & 509.4 & 487.2 & 0.044 & \\
\hline & 0.080 & 561.8 & 537.6 & 0.043 & \\
\hline & 0.120 & 577.0 & 552.1 & 0.043 & \\
\hline & 0.165 & 579.5 & 554.6 & 0.043 & \\
\hline & 0.200 & 575.0 & 551.1 & 0.042 & \\
\hline & 0.240 & 545.0 & 524.6 & 0.037 & \\
\hline & 0.280 & 469.6 & 451.4 & 0.039 & \\
\hline \multirow{8}{*}{ CR1E4bS } & 0.002 & 382.0 & 365.0 & 0.045 & \multirow{8}{*}{$\begin{array}{l}\text { Stroke } \\
\text { control }\end{array}$} \\
\hline & 0.040 & 508.9 & 485.8 & 0.045 & \\
\hline & 0.080 & 562.4 & 536.0 & 0.047 & \\
\hline & 0.125 & 579.4 & 554.7 & 0.043 & \\
\hline & 0.170 & 580.1 & 555.1 & 0.043 & \\
\hline & 0.200 & 573.3 & 550.0 & 0.041 & \\
\hline & 0.240 & 535.8 & 513.9 & 0.041 & \\
\hline & 0.280 & 446.9 & 430.0 & 0.038 & \\
\hline
\end{tabular}


Table A.2 Comparison of the drop in stress when taking static readings before and after switching from axial extensometer control to stroke control

\begin{tabular}{|c|c|c|c|c|c|c|c|c|c|}
\hline \multirow{3}{*}{ Specimen } & \multicolumn{8}{|c|}{ Stress (MPa) } & \multirow{3}{*}{$\begin{array}{l}\text { Ratic } \\
\text { (f/e) }\end{array}$} \\
\hline & \multicolumn{4}{|c|}{ Before switch } & \multicolumn{4}{|c|}{ After switch } & \\
\hline & $\begin{array}{l}\sigma^{\text {dy }} \\
\text { (a) }\end{array}$ & $\begin{array}{l}\sigma^{\mathrm{st}} \\
\text { (b) }\end{array}$ & $\begin{array}{c}\Delta \sigma \\
(\mathrm{a}-\mathrm{b})\end{array}$ & $\begin{array}{c}\text { Average } \\
\Delta \sigma(\mathrm{e})\end{array}$ & $\begin{array}{l}\sigma^{\mathrm{dy}} \\
\text { (c) }\end{array}$ & $\begin{array}{l}\sigma^{\text {st }} \\
\text { (d) }\end{array}$ & $\begin{array}{c}\Delta \sigma \\
(\mathrm{c}-\mathrm{d})\end{array}$ & $\begin{array}{c}\text { Average } \\
\Delta \sigma(\mathrm{e})\end{array}$ & \\
\hline \multirow{2}{*}{ CR1E4aES } & 581.1 & 543.2 & 37.9 & \multirow{2}{*}{38.7} & 573.6 & 549.3 & 24.3 & \multirow{2}{*}{23.9} & \multirow{2}{*}{0.62} \\
\hline & 578.5 & 539.1 & 39.4 & & 567.1 & 543.7 & 23.4 & & \\
\hline \multirow{2}{*}{ CR1E4bES } & 574.3 & 540.1 & 34.2 & \multirow{2}{*}{35.5} & 566.7 & 541.9 & 24.8 & \multirow{2}{*}{22.8} & \multirow{2}{*}{0.64} \\
\hline & 571.0 & 534.2 & 36.8 & & 559.1 & 538.3 & 20.8 & & \\
\hline
\end{tabular}

Table A.3 Comparisons of static yield stress from different loading rate controls and the yield stress calibrated for Cowper-Symonds power law equation for materials $\mathrm{G}$ and $\mathrm{H}$

\begin{tabular}{|c|c|c|c|}
\hline \multirow{2}{*}{ Material } & \multicolumn{2}{|c|}{ Static yield stress (MPa) } & \multirow{2}{*}{$\begin{array}{c}\text { Calibrated static } \\
\text { yield stress (MPa) }\end{array}$} \\
\cline { 2 - 3 } & $\begin{array}{c}\text { Extensometer } \\
\text { control }\end{array}$ & $\begin{array}{c}\text { Stroke } \\
\text { control }\end{array}$ & (34) \\
\hline $\mathrm{G}$ & 331.6 & 347.4 & 342.4 \\
\hline $\mathrm{H}$ & 364.9 & 377.1 & 383.5 \\
\hline
\end{tabular}




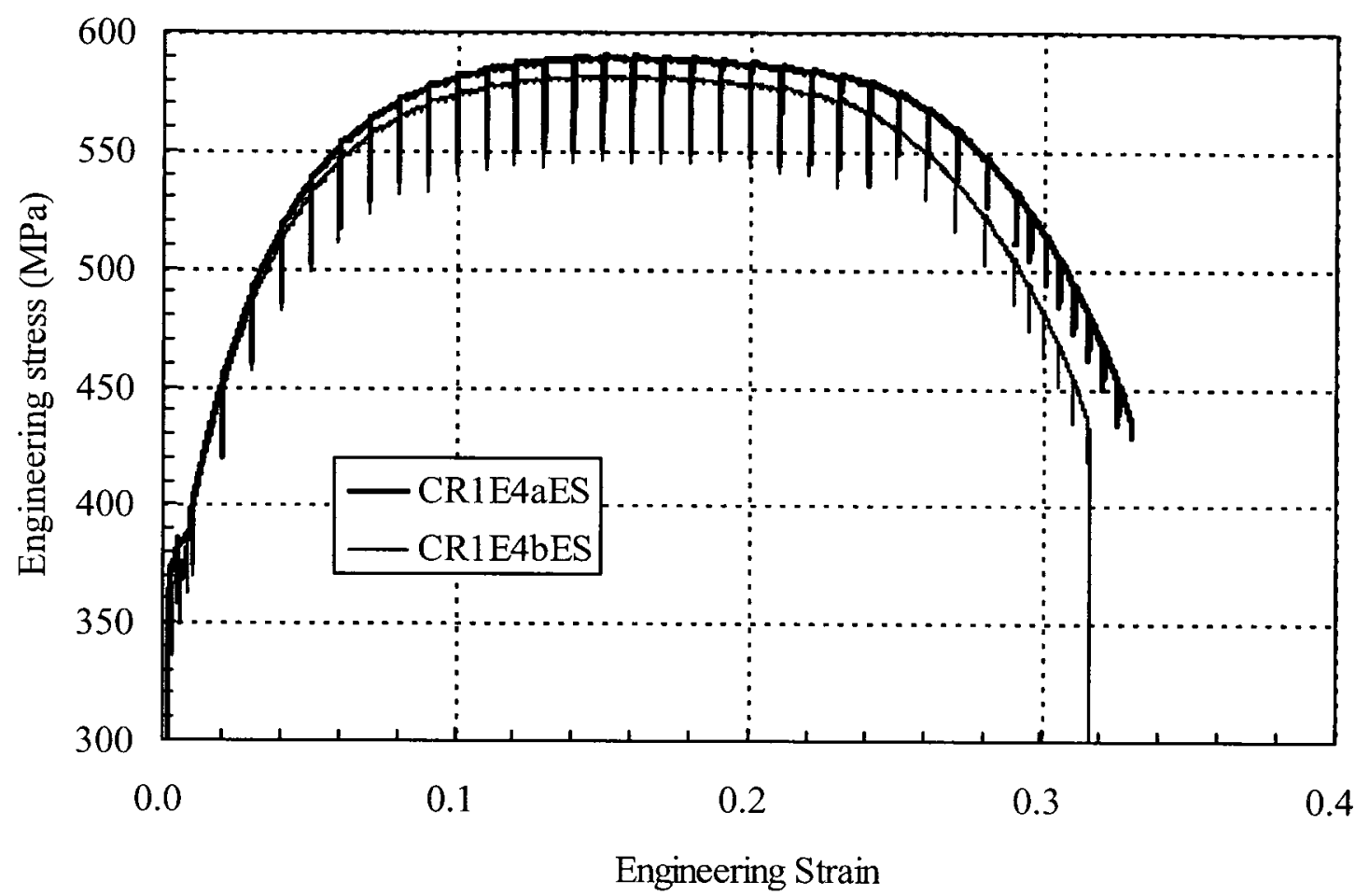

Figure A.1 Comparison of the different drop in stress between extensometer control and stroke control for CR1E4aES and CR1E4bES

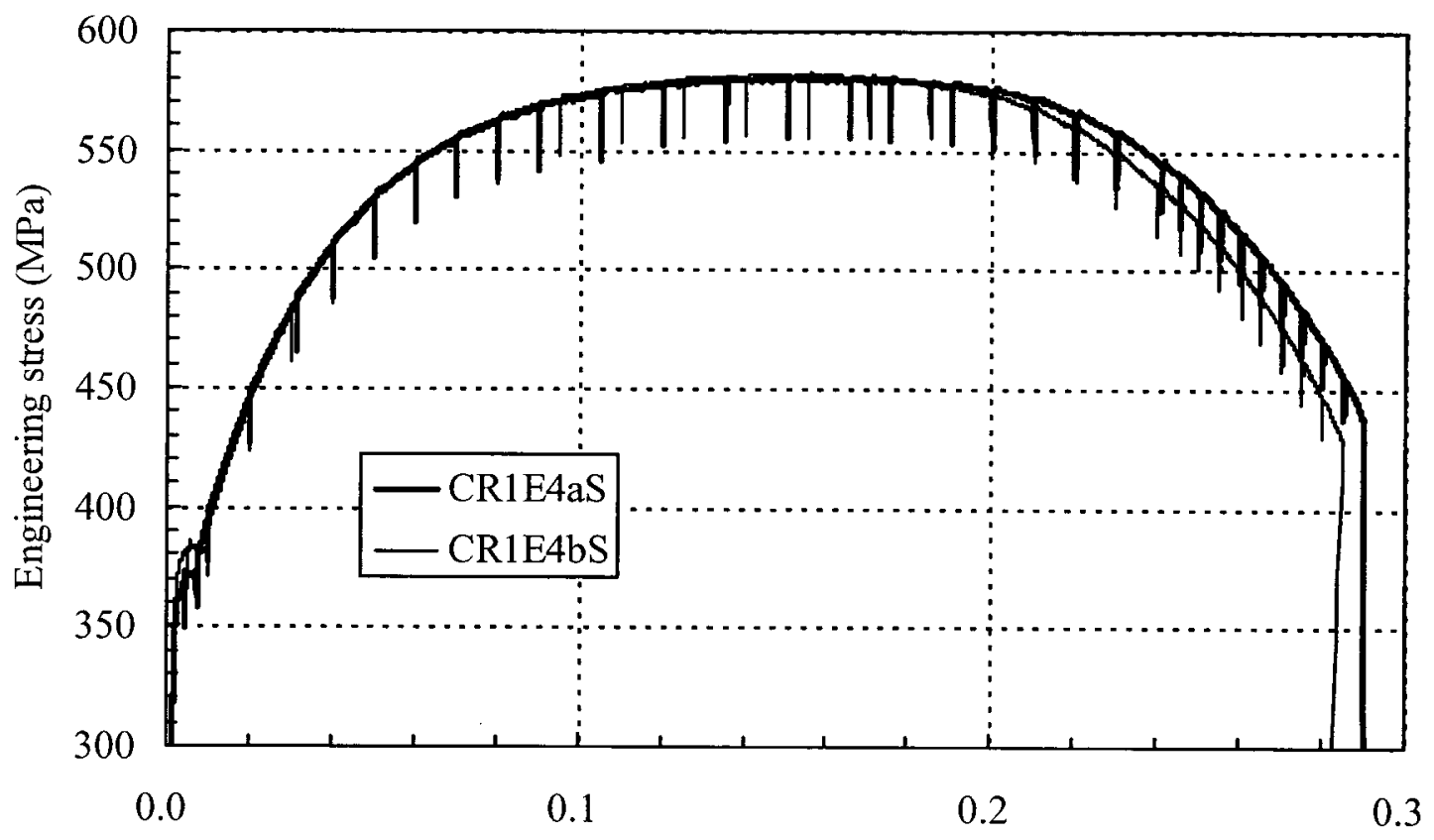

Engineering Strain

Figure A.2 Comparison of the different drop in stress between extensometer control and stroke control for CR1E4aS and CR1E4bS 


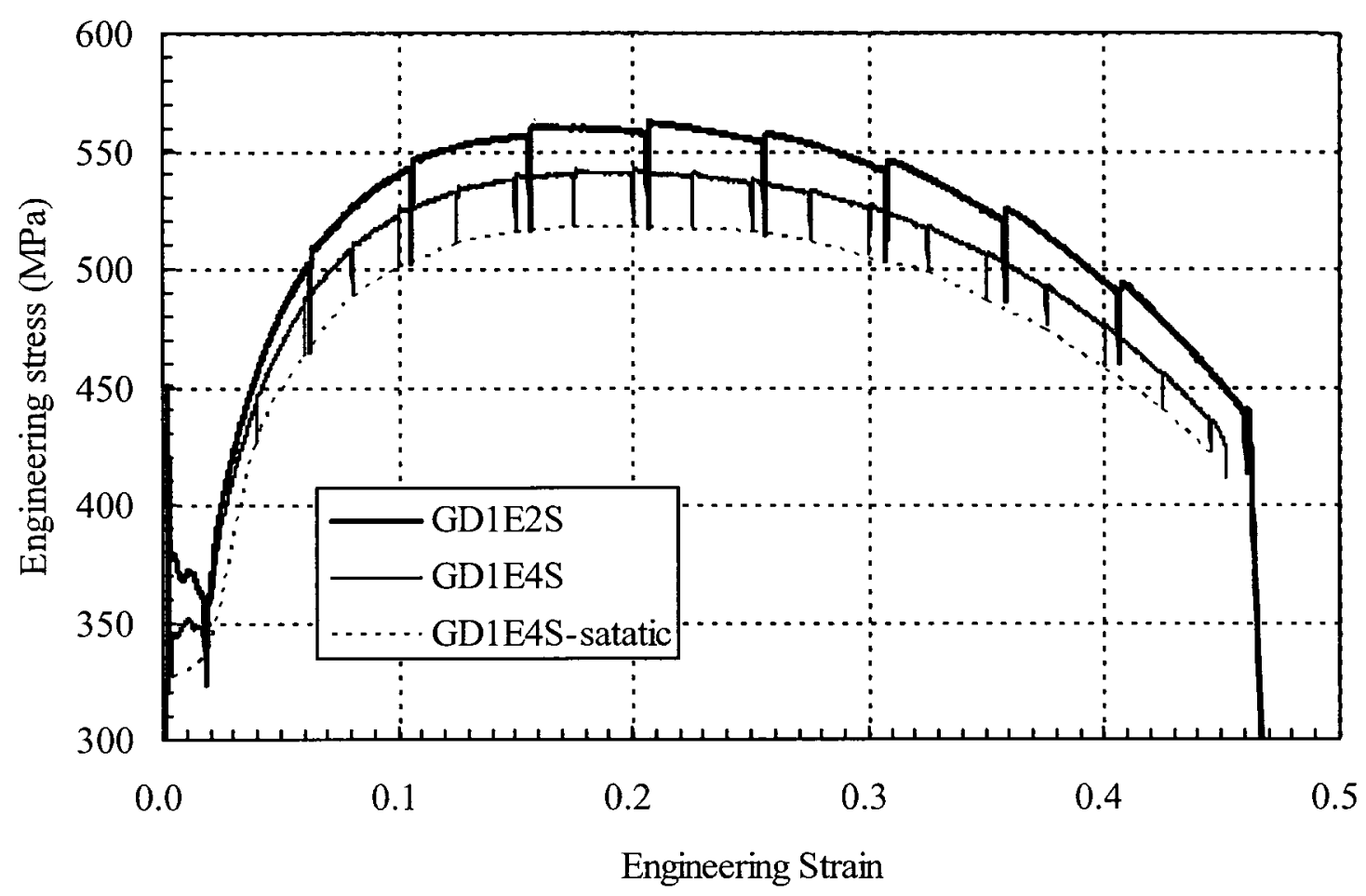

Figure A.3 Comparison of static readings at different loading rate in tests with stroke control

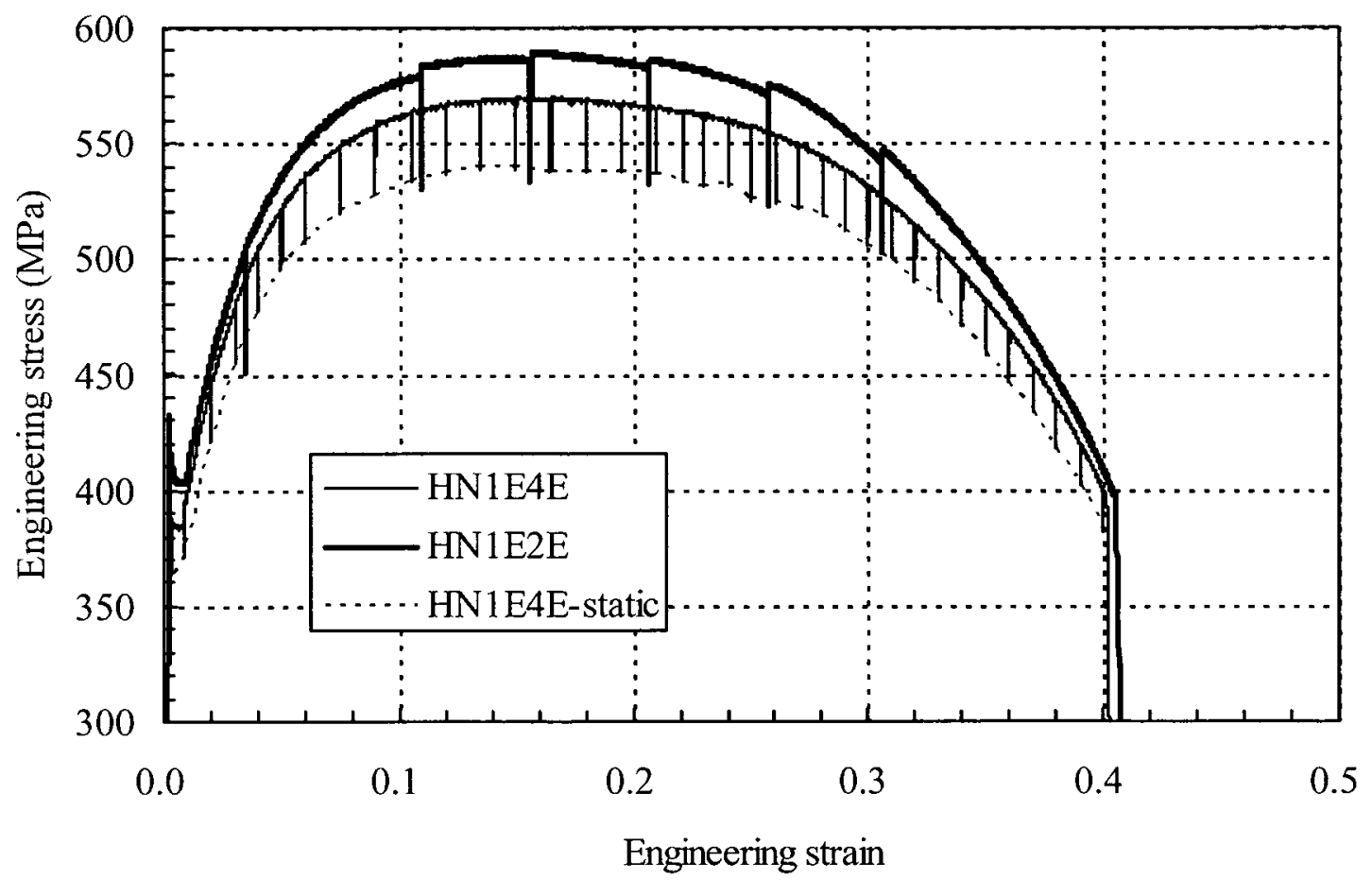

Figure A.4 Comparison of static readings at different loading rate in tests with axial extensometer control 


\section{Appendix B Comparison of Test Results of Tapered and Non-tapered Round}

\section{Specimens}

Comparisons of the tests results between tapered and non-tapered specimens were conducted at strain rates of $10^{-2} \mathrm{~s}^{-1}$ for material $\mathrm{G}$ and at $10^{-4} \mathrm{~s}^{-1}$ for material $\mathrm{H}$. Since no $9 \mathrm{~mm}$ non-tapered specimen was machined for material G, a $14 \mathrm{~mm}$ straight specimen was tested instead. For material G, the comparison is made between test with axial extensometer and stroke controls. This should not affect the validity of the comparison as the effect of the slight difference in the actual loading strain rate between axial extensometer and stroke controls is negligible. Comparisons of the test results are presented in Table B.1, and in Figs. B.1 and B.2. It can be seen that there is only a very small difference between the yield and ultimate strengths measured with tapered and non-tapered specimens. However, the engineering strain at fracture is lower for the tapered specimen as the weakest point to initiate necking has been machined into the specimen.. 
Table B.1 Comparison of yield and ultimate stress between tapered and non-tapered profile

\begin{tabular}{|c|c|c|}
\hline Specimen & $\begin{array}{c}\text { Yield stress } \\
(\mathrm{MPa})\end{array}$ & $\begin{array}{c}\text { Ultimate stress } \\
(\mathrm{MPa})\end{array}$ \\
\hline GT1E2S (a) & 368.3 & 561.8 \\
\hline GD1E2S (b) & 371.0 & 563.2 \\
\hline Ratio (a/b) & 0.99 & 1.00 \\
\hline HT1E4ED (c) & 383.2 & 570.1 \\
\hline HN1E4E (d) & 384.4 & 573.0 \\
\hline Ratio (c/d) & 1.00 & 0.99 \\
\hline
\end{tabular}




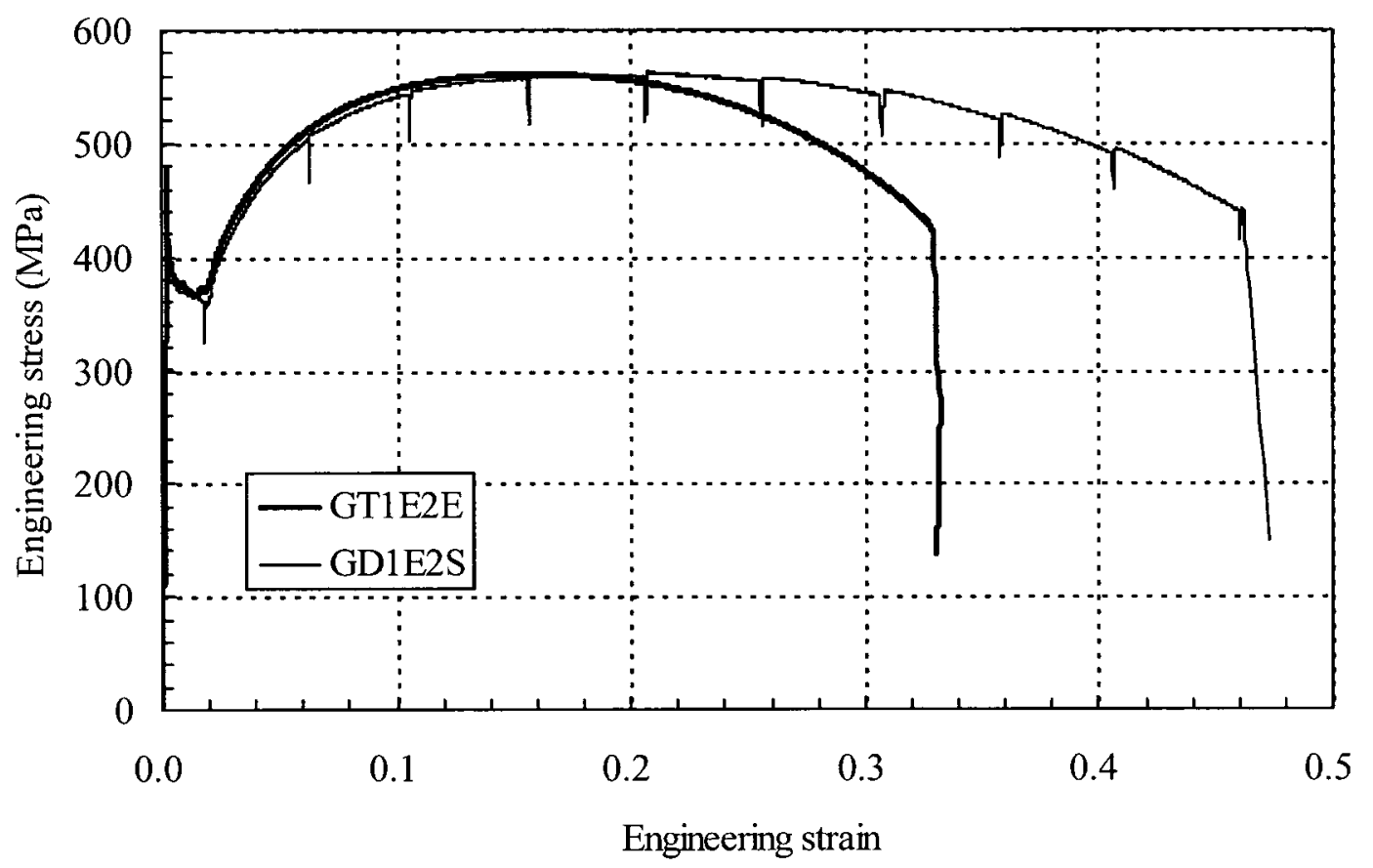

Figure B.1 Comparisons of the engineering stress-strain curve for the tapered and non-tapered round specimens for material $\mathrm{G}$ at the strain rate of $10^{-2} \mathrm{~s}^{-1}$

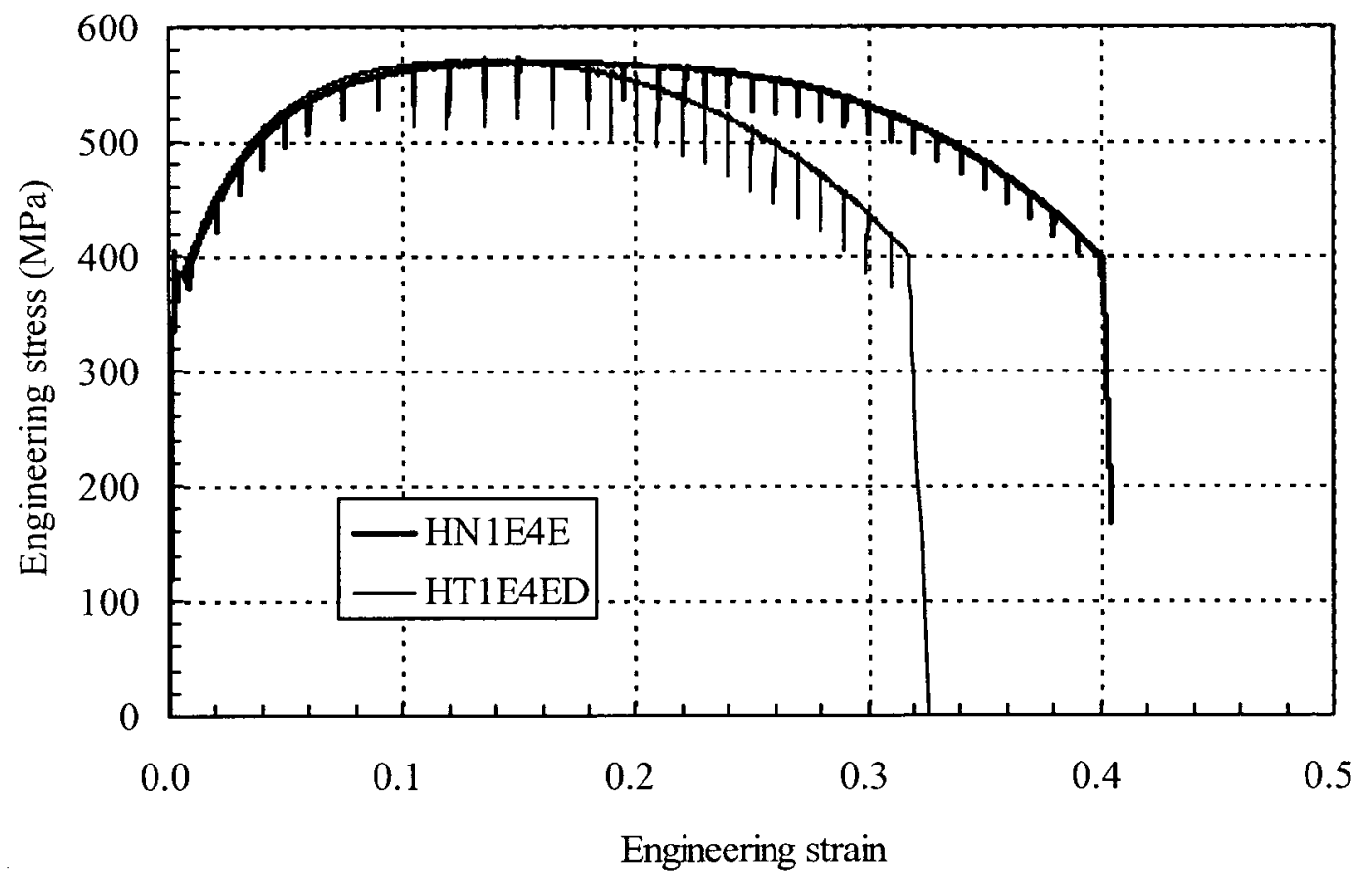

Figure B.2 Comparisons of the engineering stress-strain curve for the tapered and non-tapered round specimens for material $\mathrm{H}$ at the strain rate of $10^{-4} \mathrm{~s}^{-1}$ 


\section{Appendix C Comparison of Engineering Strain at Fracture for Tests Conducted at the Same Target Strain Rate}

Unlike a straight specimen, the engineering at fracture for a tapered specimen is quite consistent for specimens tested with the same loading control and at the same strain rate. Figure C. 1 shows two specimens tested at the same strain rate and loading control. The engineering strain at fracture for both GT1E5aE and GT1E5bE is almost the same.

Similarly in Fig. C.2, the engineering strain at fracture is also almost equal for both GT1E2ED and GT1E2D, which were tested under diametral extensometer control after the initiation of necking. The slightly lower stress observed in Fig. C.2 for GT1E2ED is due to the pre-compression. However, the pre-compression does not seem to affect the engineering strain at fracture.

In Figure C.3, one specimen was tested with the combined axial-diametral extensometer control and the other with the stroke control. At close to fracture, the specimen tested under stroke control experienced a local strain rate that is several times the nominal strain rate. However, the local strain rate of the specimen with the diametral extensometer control remains to be about the same as the nominal strain rate. As a result, the engineering strain at fracture for GT1E4S was slightly higher than GT1E4ED. It is expected that at close to fracture, tests conducted using either stroke or axial extensometer control, will have the same large difference between the actual applied local strain rate and the nominal strain rate. 


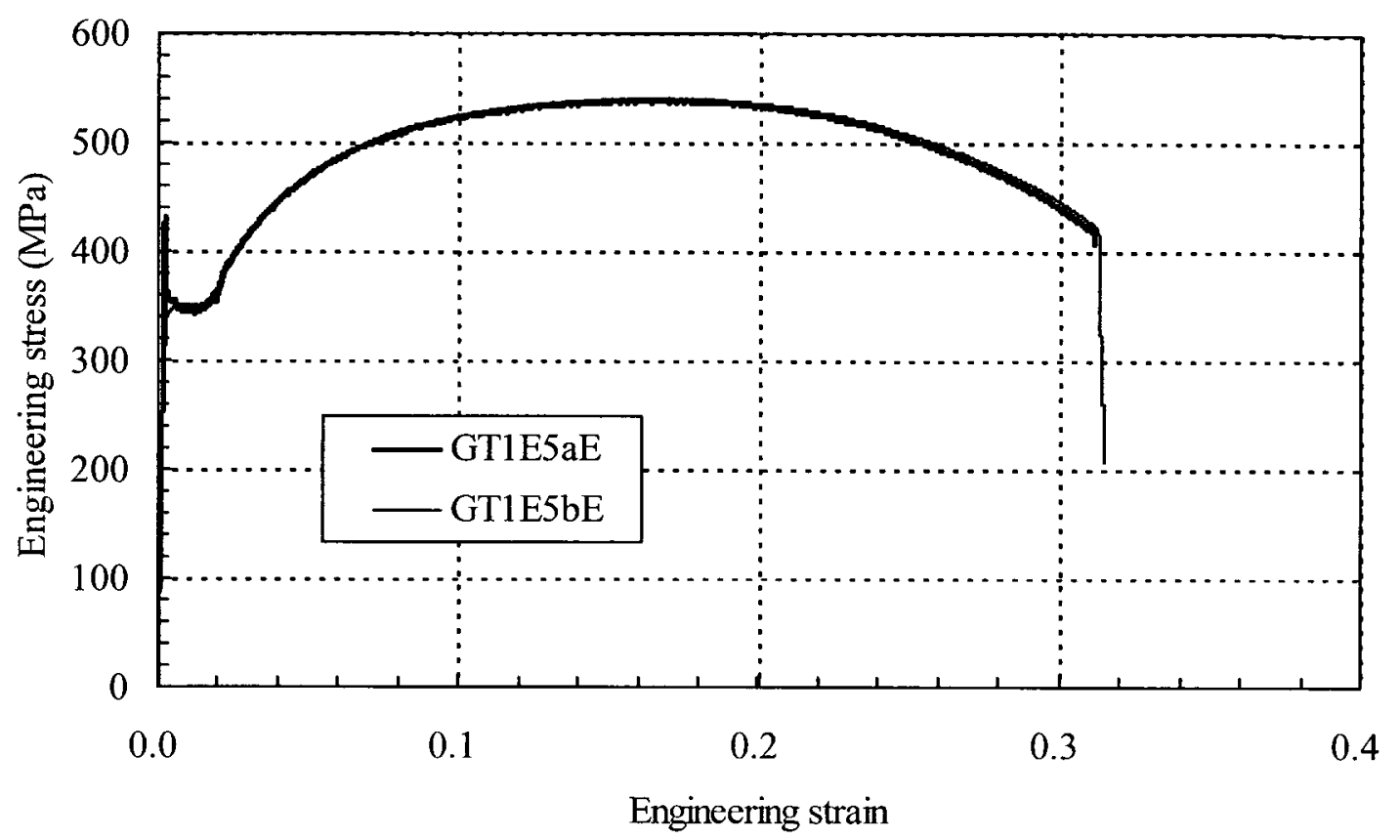

Figure C.1 Comparisons of the engineering stress-strain curves for material $\mathrm{G}$ at the strain rate of $10^{-5} \mathrm{~s}^{-1}$

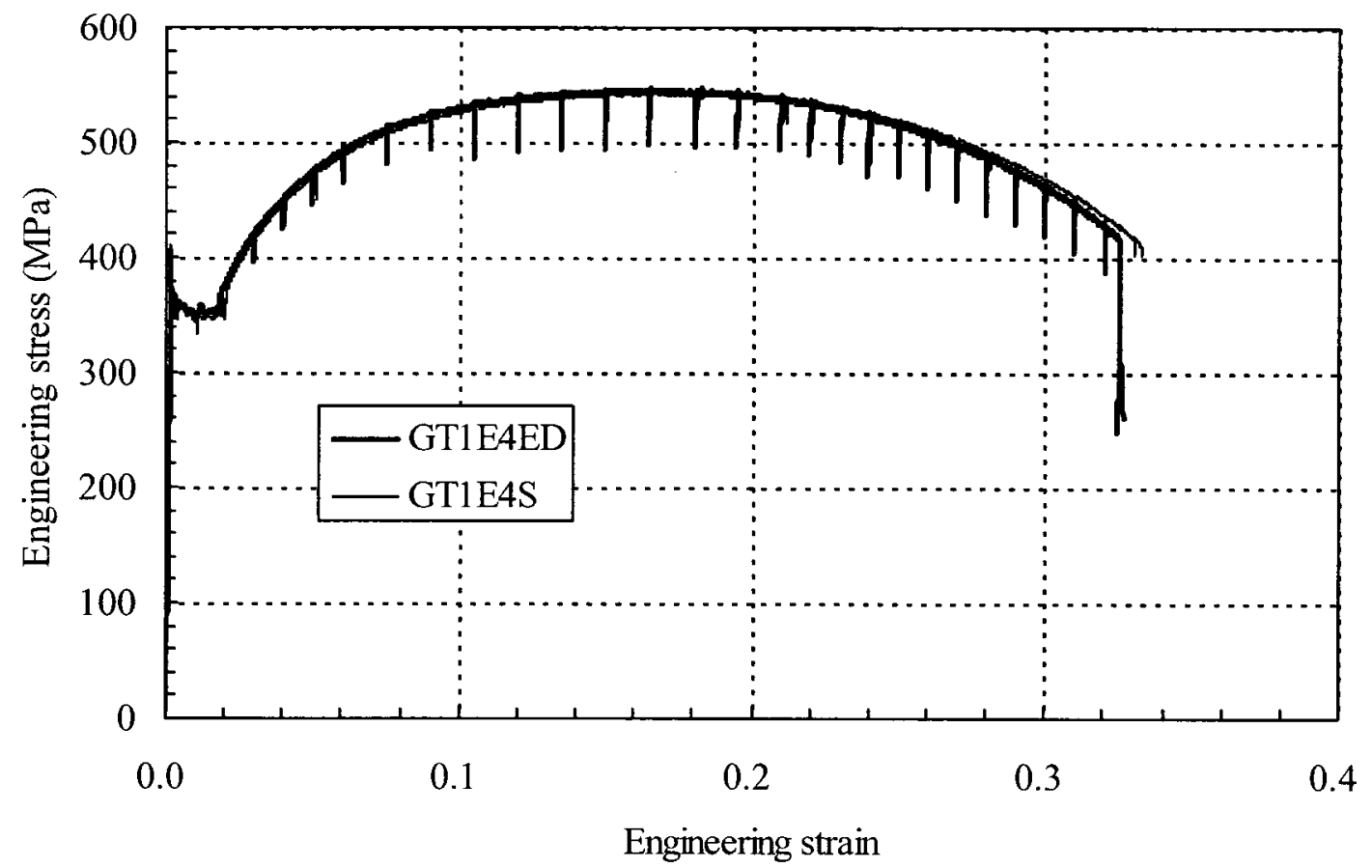

Figure C.2 Comparisons of the stress-strain curves for material $\mathrm{G}$ at the strain rate of $10^{-2} \mathrm{~s}^{-1}$ 


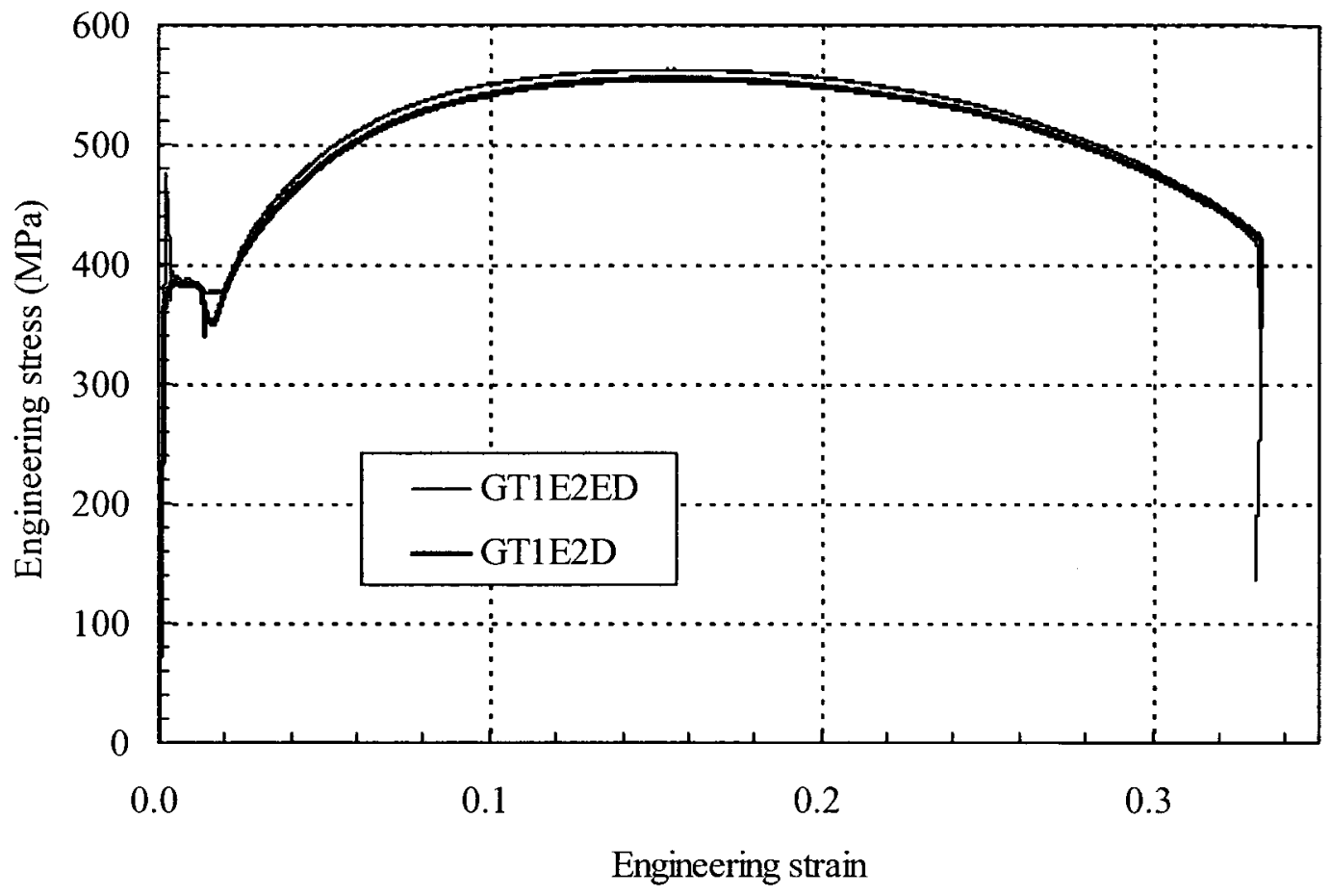

Figure C.3 Comparisons of the stress-strain curves for material $\mathrm{G}$ at the strain rate of $10^{-4} \mathrm{~s}^{-1}$ 


\section{Appendix D Comparisons of Test Results and Finite Element Analyses for Materials B-F}

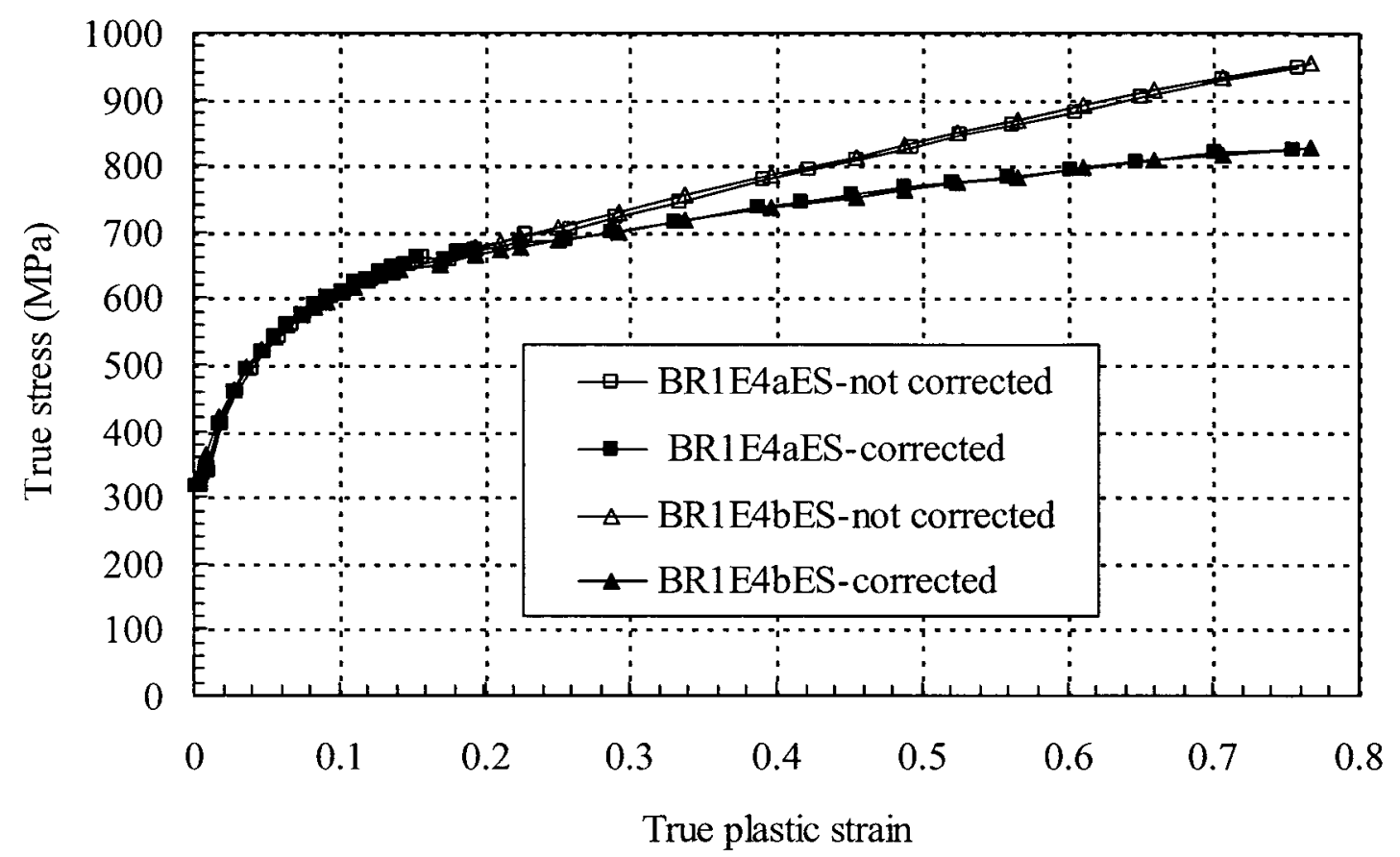

Figure D.1 Corrected and uncorrected static true stress versus true plastic strain curves for BR1E4(a-b)ES

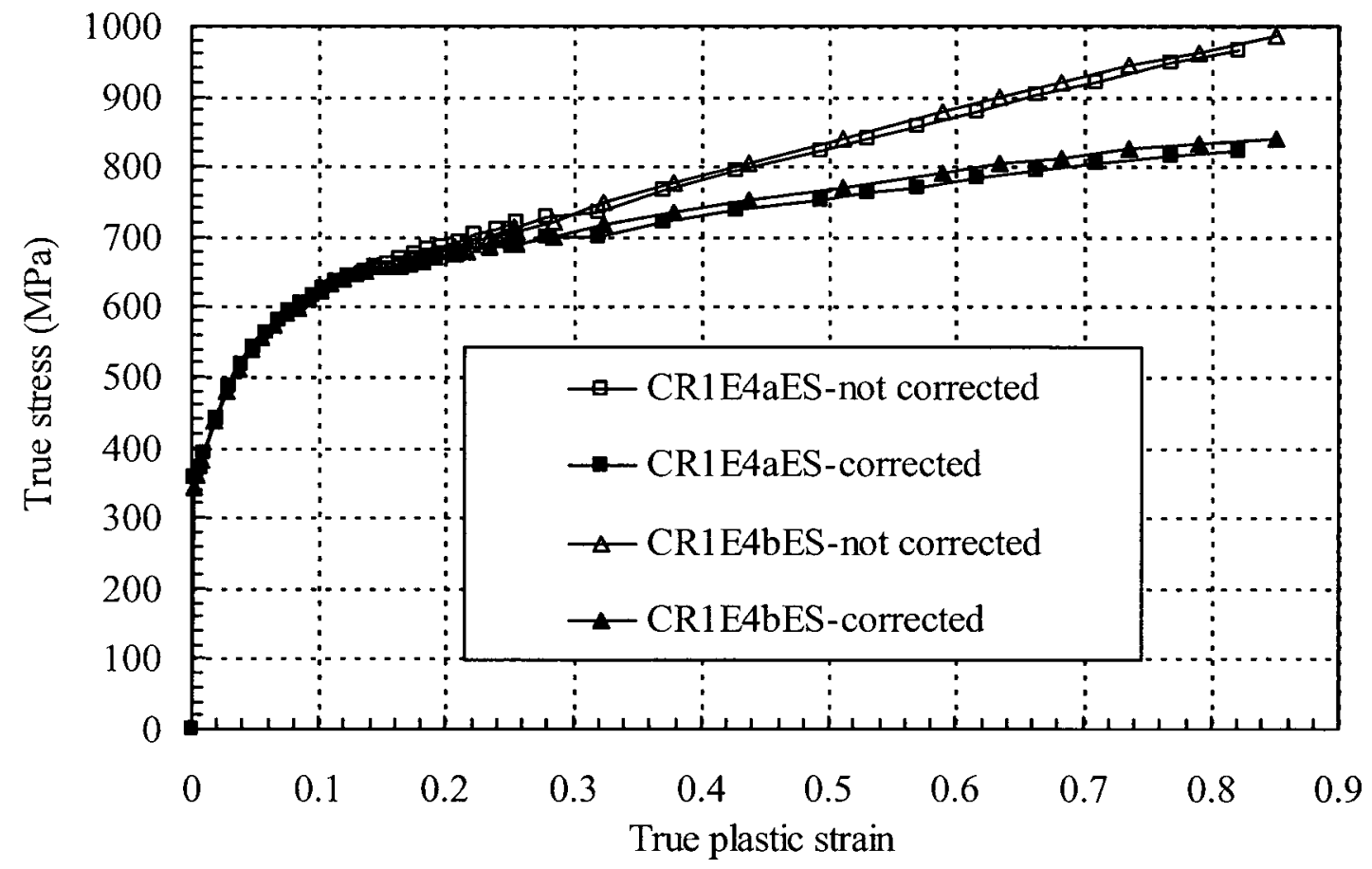

Figure D.2 Corrected and uncorrected static true stress versus true plastic strain curves for CR1E4(a-b)ES 


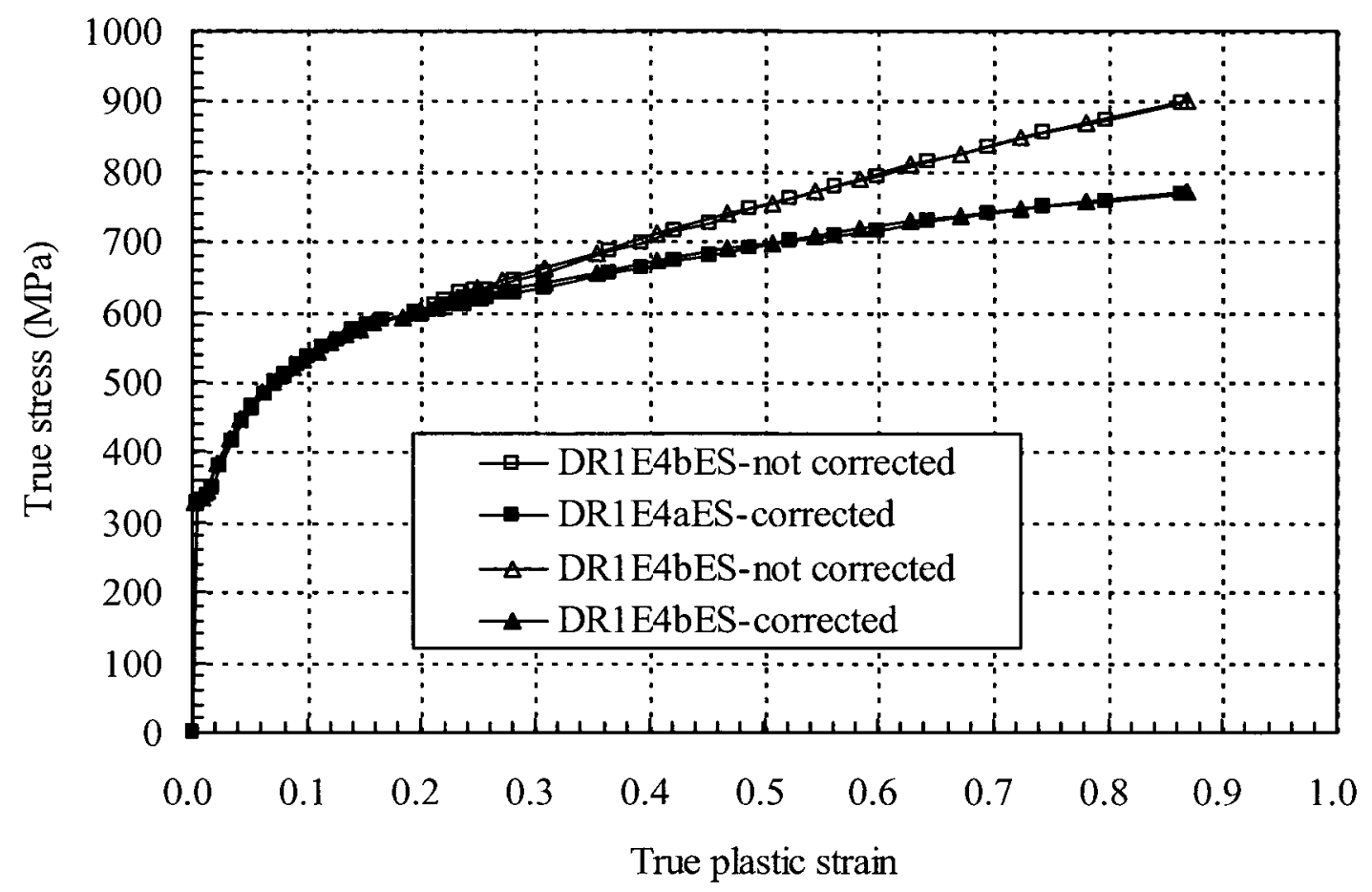

Figure D.3 Corrected and uncorrected static true stress versus true plastic strain curves for DR1E4(a-b)ES

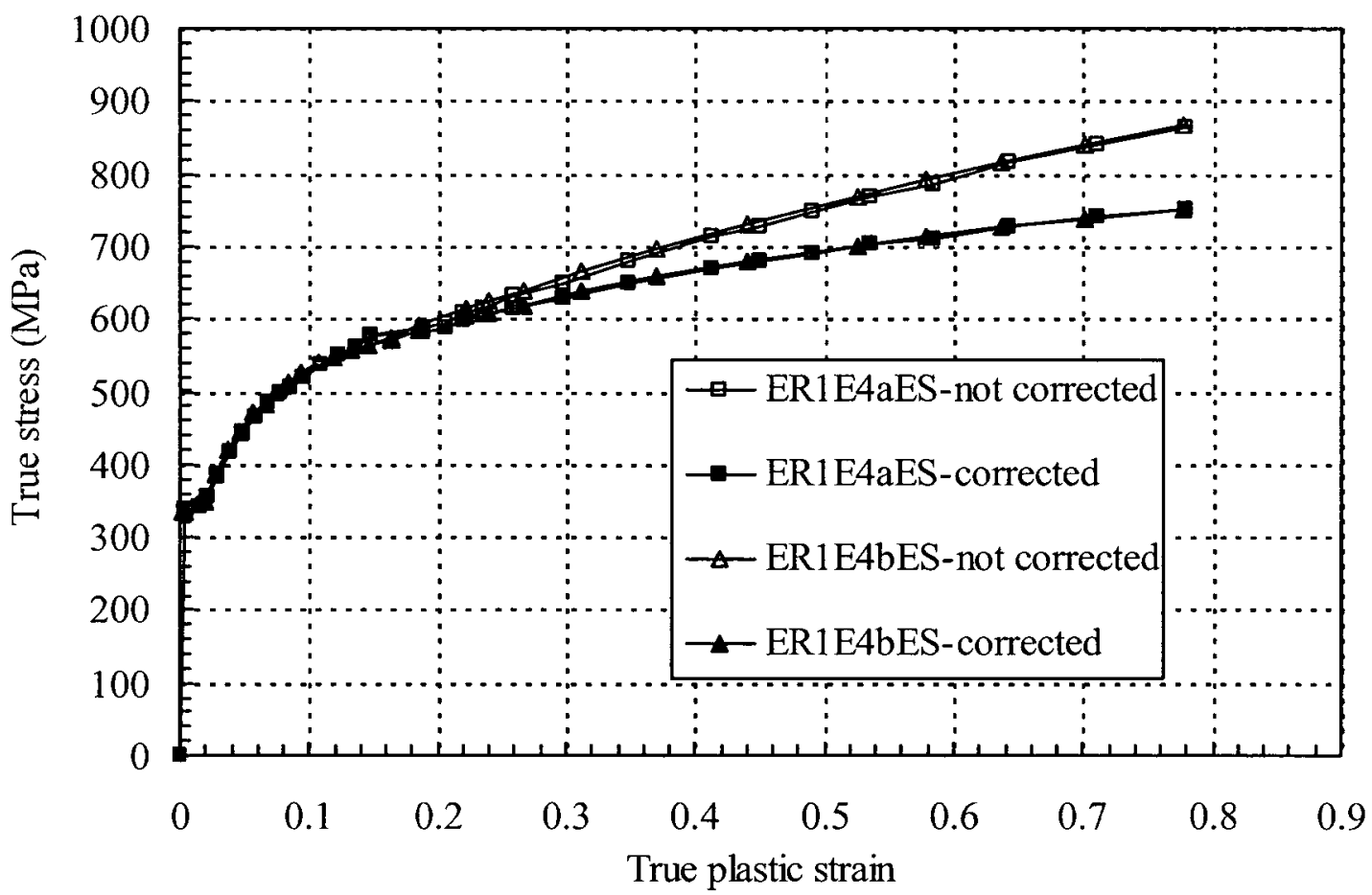

Figure D.4 Corrected and uncorrected static true stress versus true plastic strain curves for ER1E4(a-b)ES 


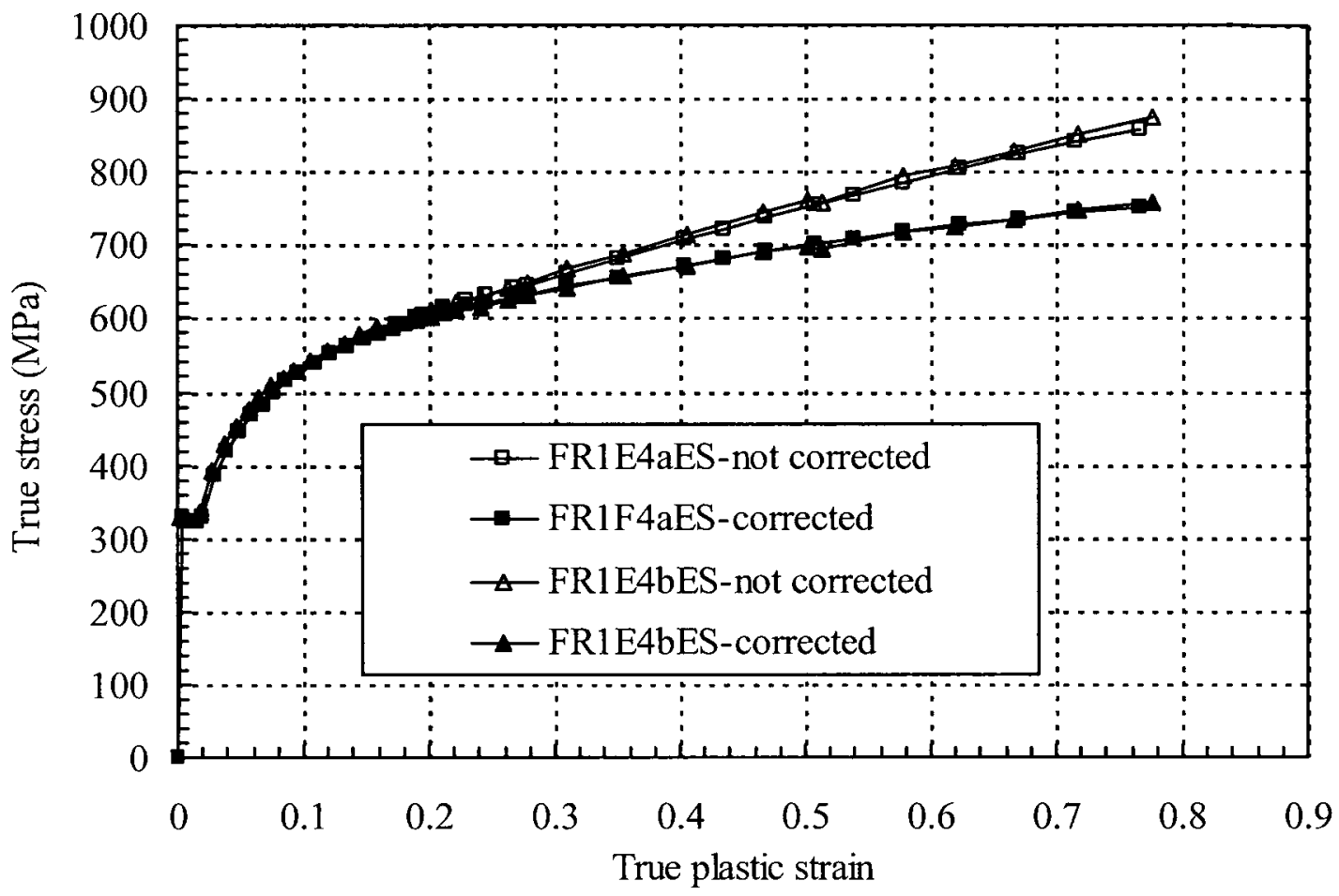

Figure D.5 Corrected and uncorrected static true stress versus true plastic strain curves for FR1E4(a-b)ES

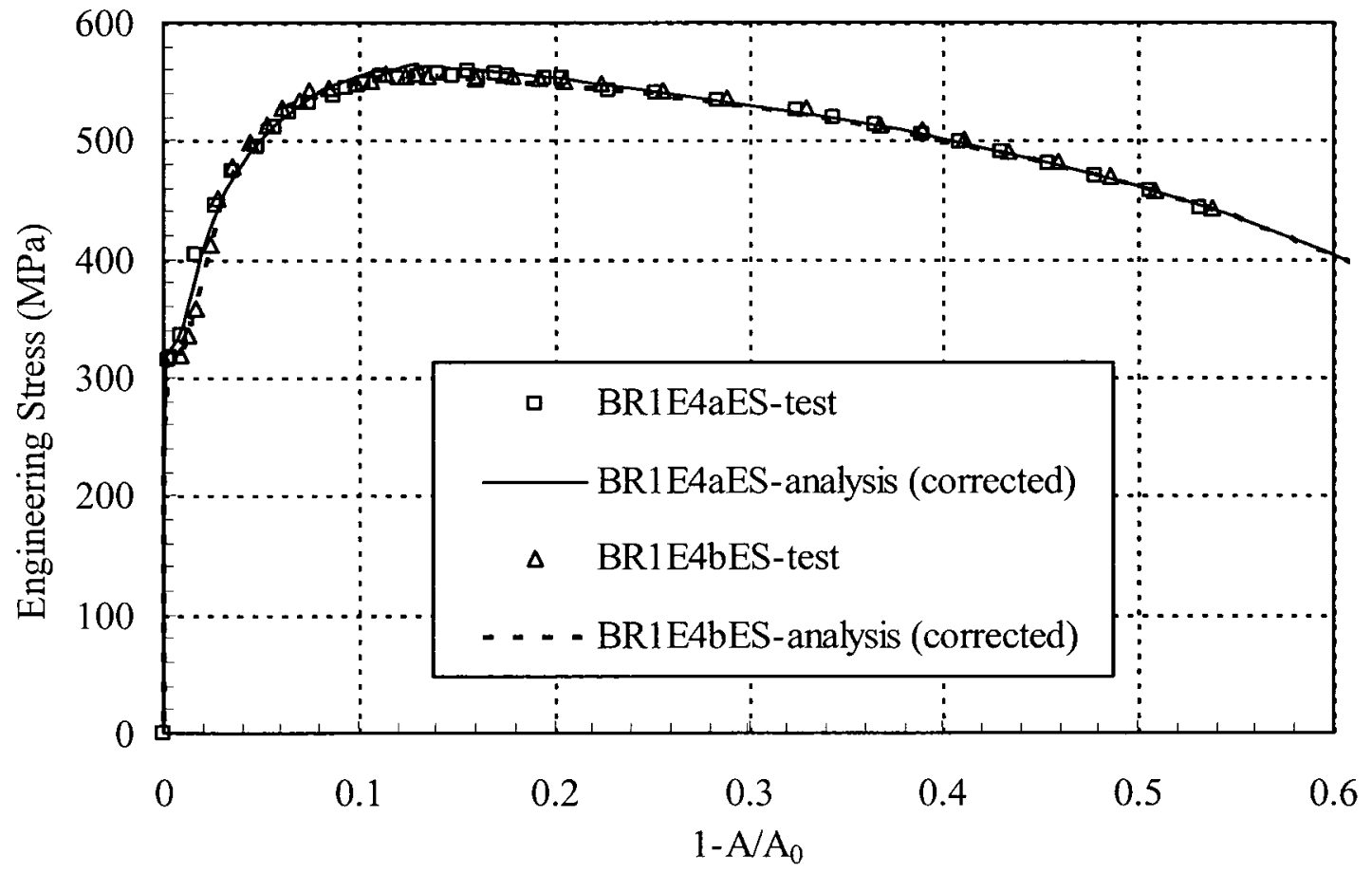

Figure D.6 Results of simulations and tests for stress versus cross-section change for BR1E4(a-b)ES 


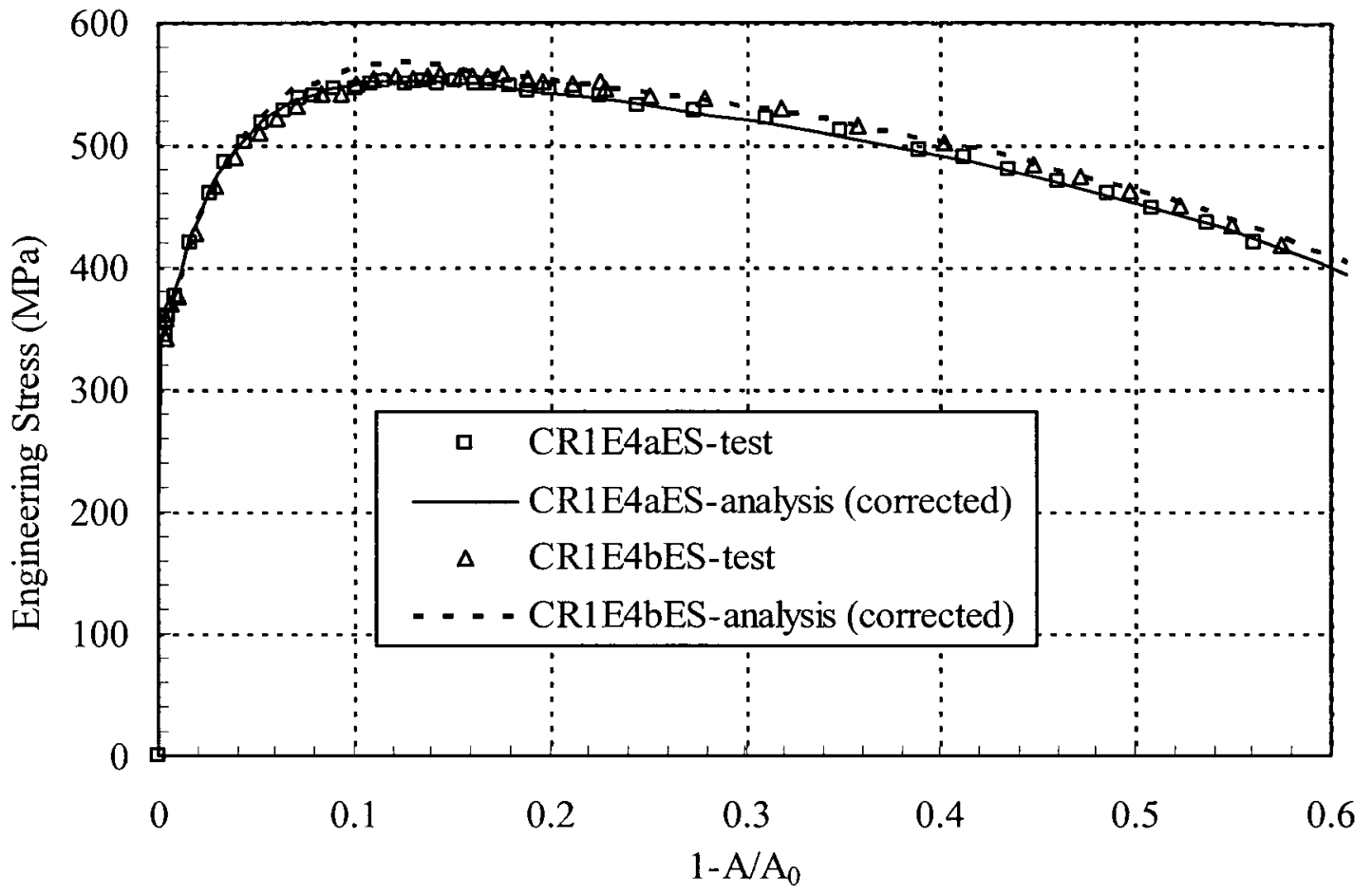

Figure D.7 Results of simulations and tests for stress versus cross-section change for CR1E4(a-b)ES

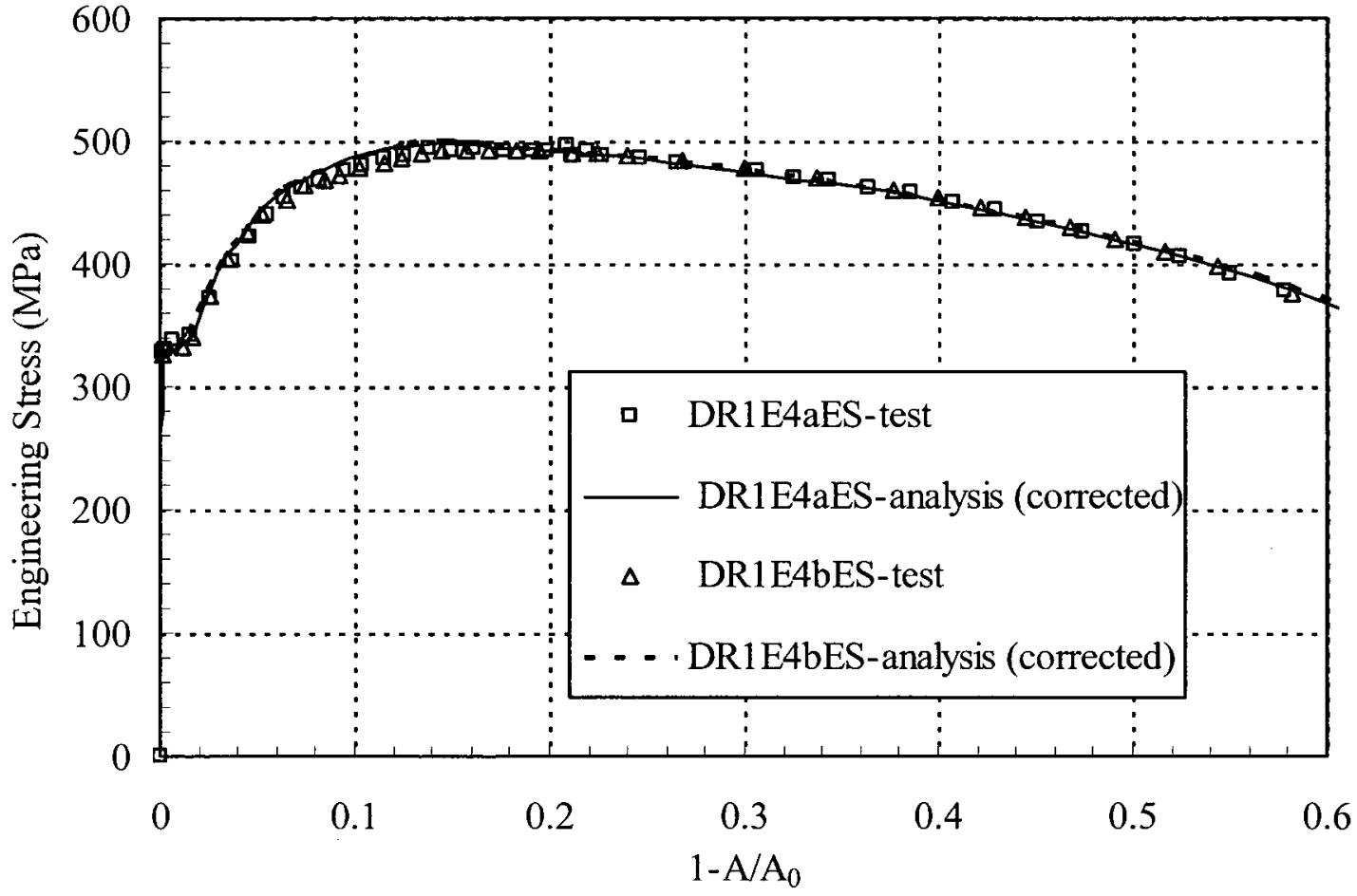

Figure D.8 Results of simulations and tests for stress versus cross-section change for DR1E4(a-b)ES 


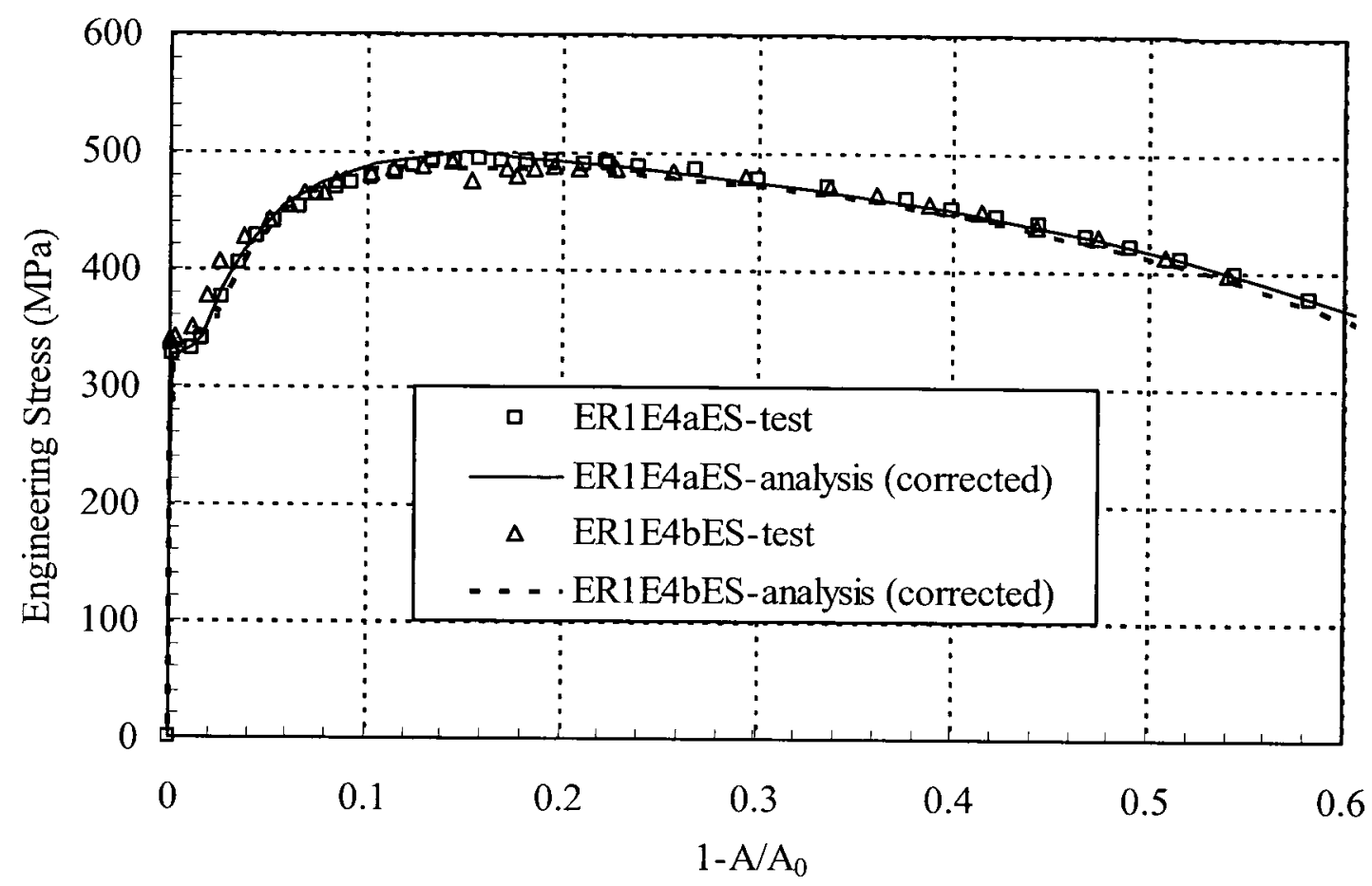

Figure D.9 Results of simulations and tests for stress versus cross-section change for ER1E4(a-b)ES

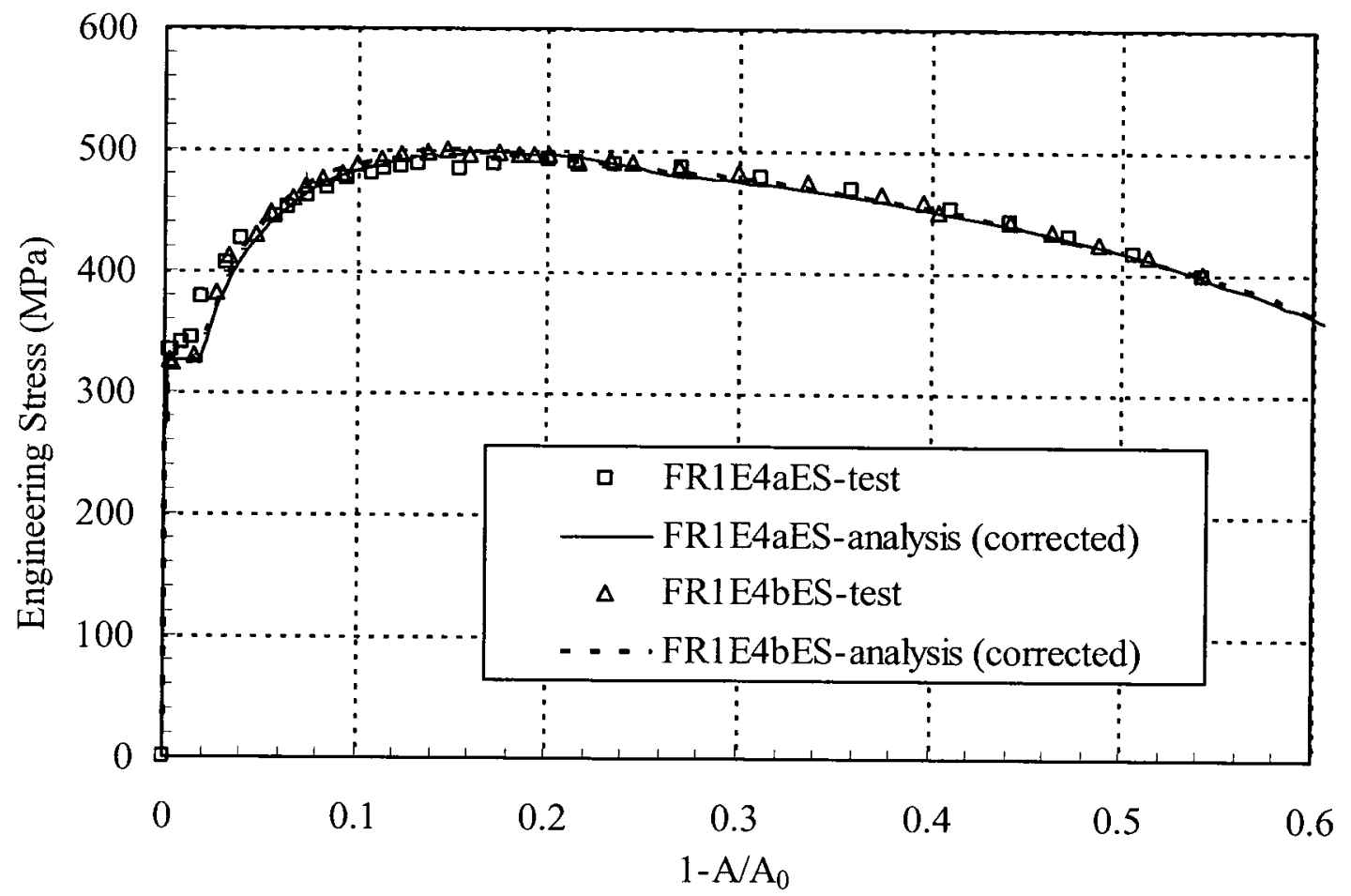

Figure D.10 Results of simulations and tests for stress versus cross-section change for FR1E4(a-b)ES 


\section{Appendix E Mesh Study}

The mesh study is carried out by simulating AR1E4bES and GT1E4S using true stress versus true plastic strain curves calculated directly from tension specimen test results with the correction for the non-uniaxial stress state (hydrostatic stress) after necking starts. Preliminary numerical analyses show that all specimens neck and fail at the mid-length of the specimen. Thus, the finite element mesh at the mid-length is refined in order to give a more accurate modeling. Figures E.1 and E.2 show the two refined finite element mesh schemes for the rectangular specimen, and Figs. E. 3 and E. 4 are the two refined finite element mesh schemes for the round specimen used in the mesh study. The size of the element at the refined region for scheme- 1 and scheme- 3 is half that of scheme- 2 and scheme- 4 respectively. Scheme- 2 and scheme- 4 are the mesh schemes used in Chapter 4. Figures E.5 to E.8 show that the predicted average true stress versus true strain and engineering stress versus cross-section area change ratio curves for scheme-1 and scheme-2, and scheme- 3 and scheme-4 are almost identical. Thus, no further refinement to scheme- 2 and scheme- 4 is required. 

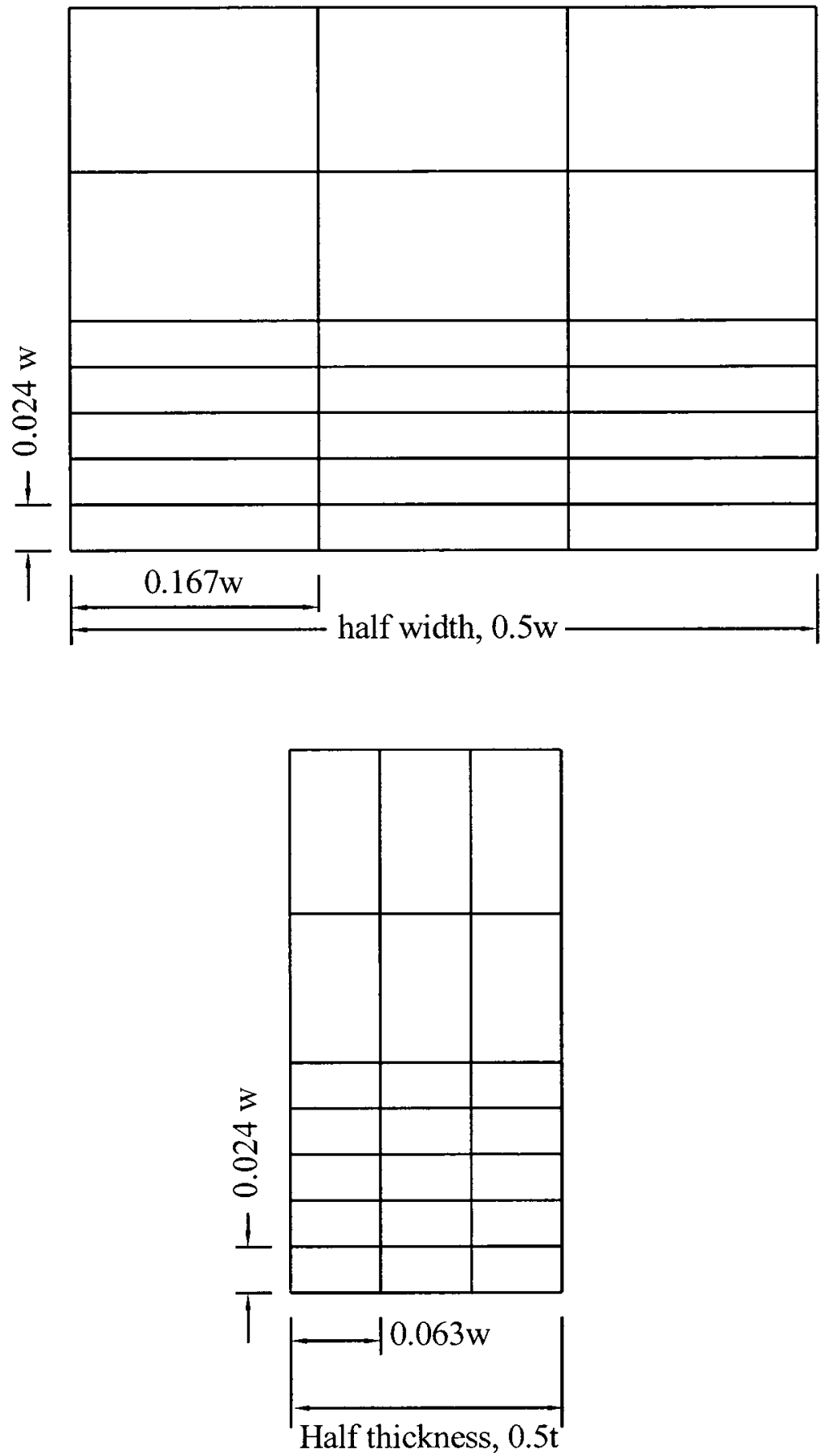

Figure E.1 Finite element mesh scheme-1 at the mid-length of AR1E4bES 

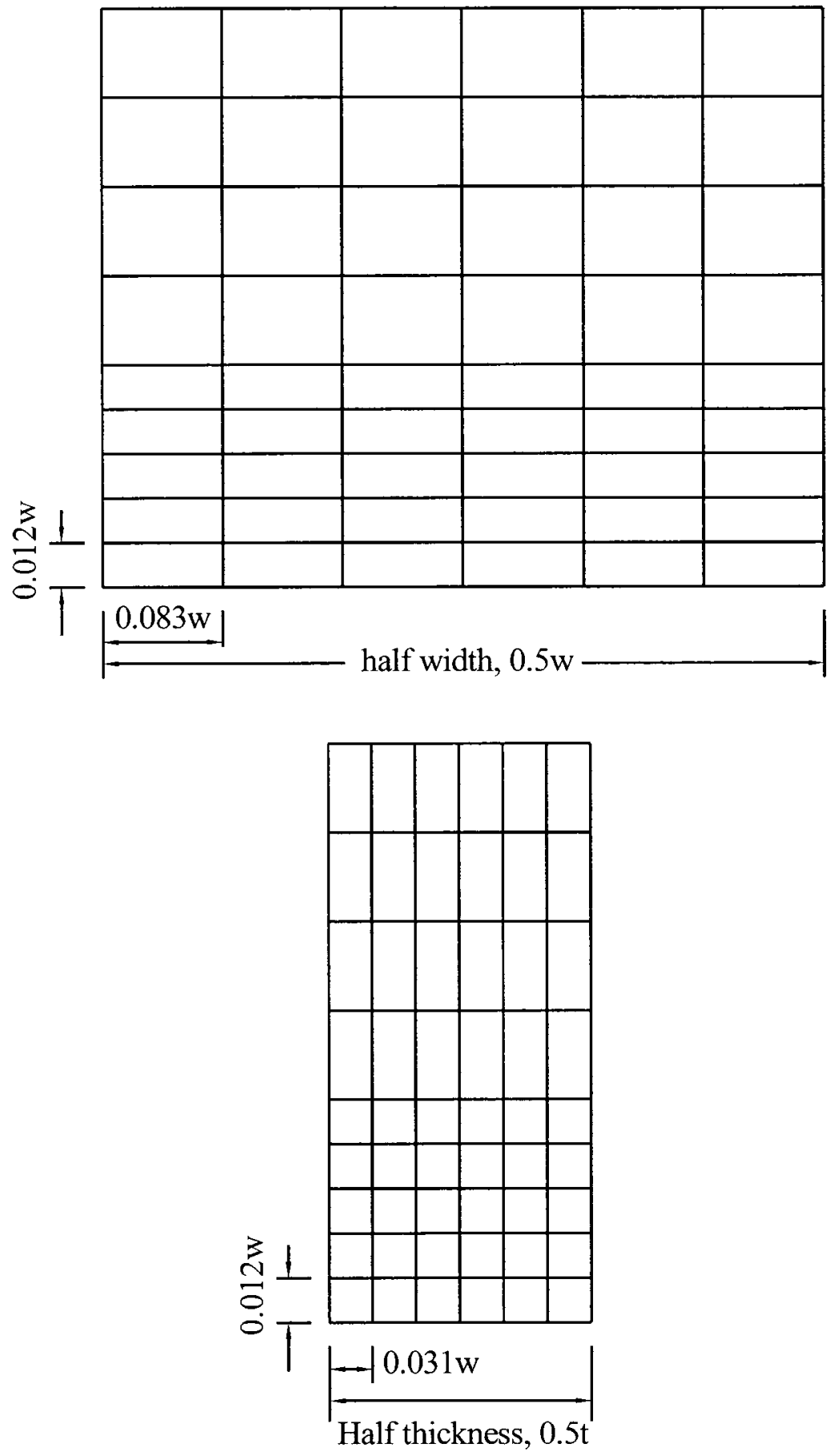

Figure E.2 Finite element mesh scheme-2 at the mid-length of AR1E4bES 


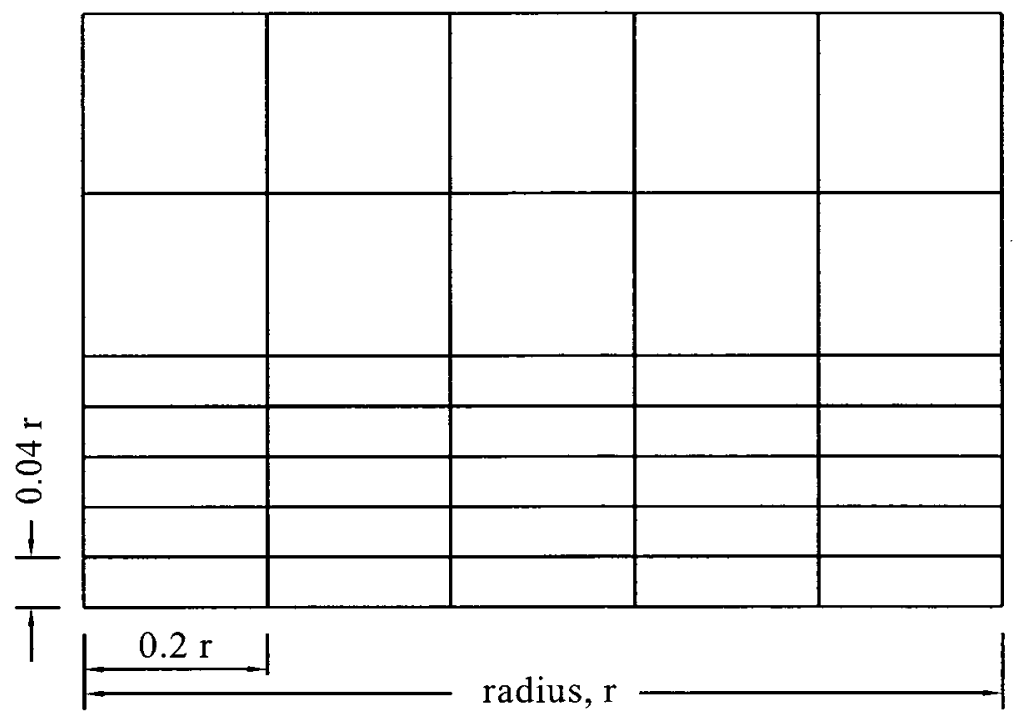

Figure E.3 Finite element mesh scheme-3 at the mid-length of GT1E4S

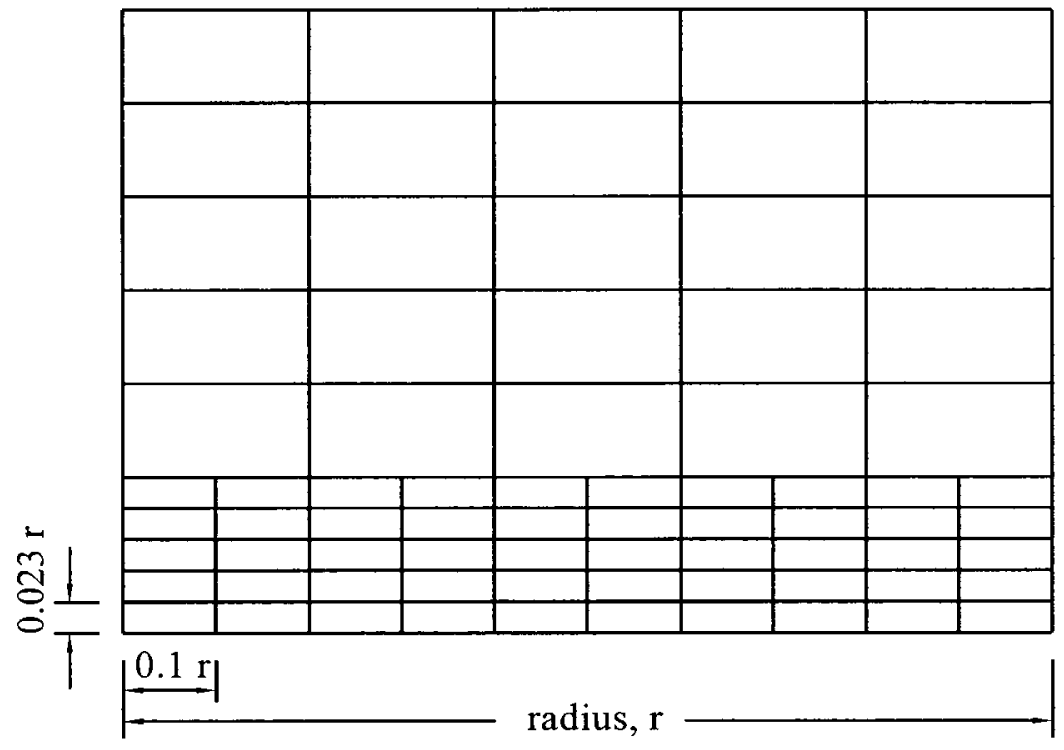

Figure E.4 Finite element mesh scheme-4 at the mid-length of GT1E4S 


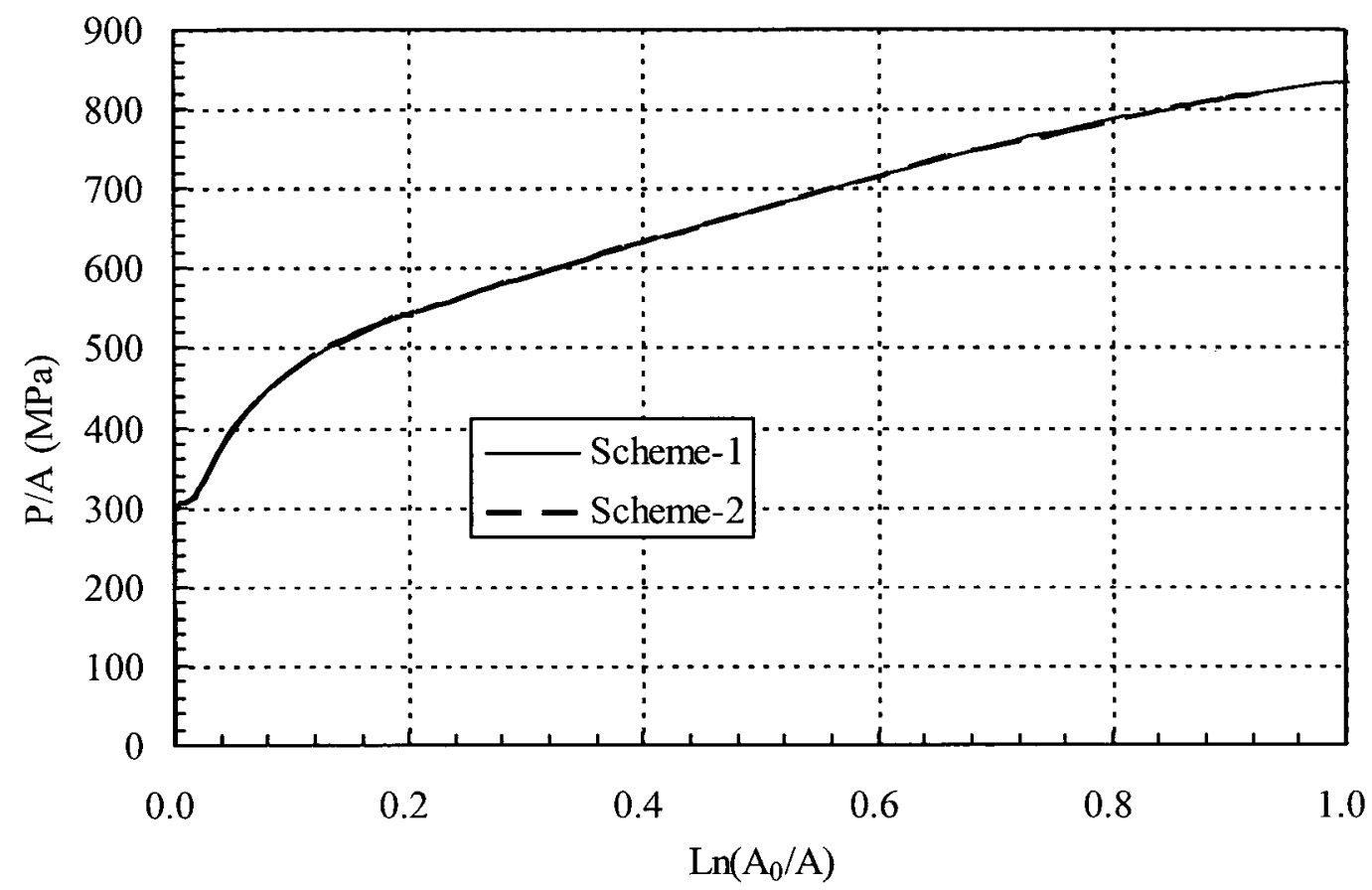

Figure E.5 Analytical average true stress versus true strain for AR1E4bES with different scheme

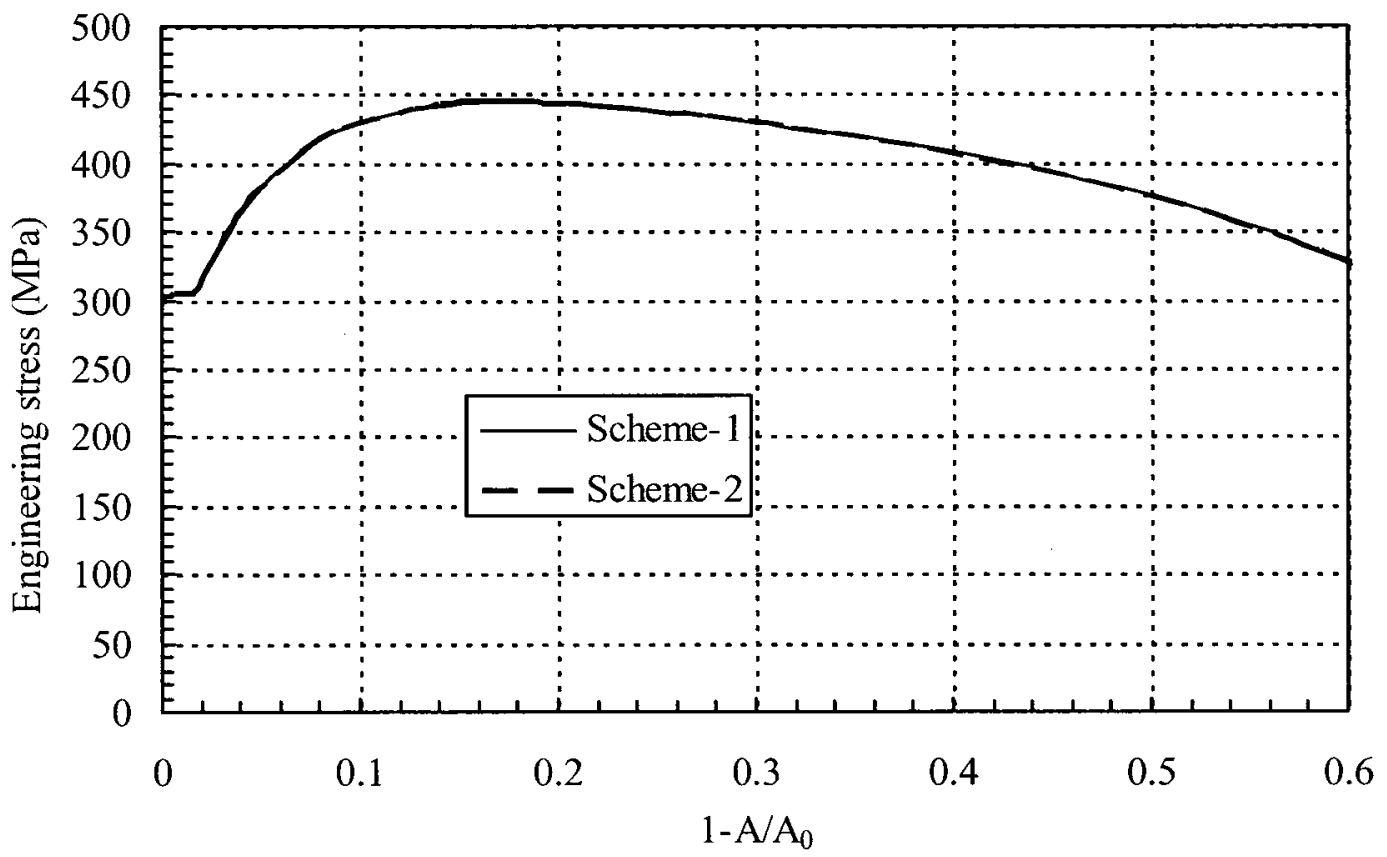

Figure E.6 Analytical stress versus change in cross-section area change for AR1E4bES with different scheme 


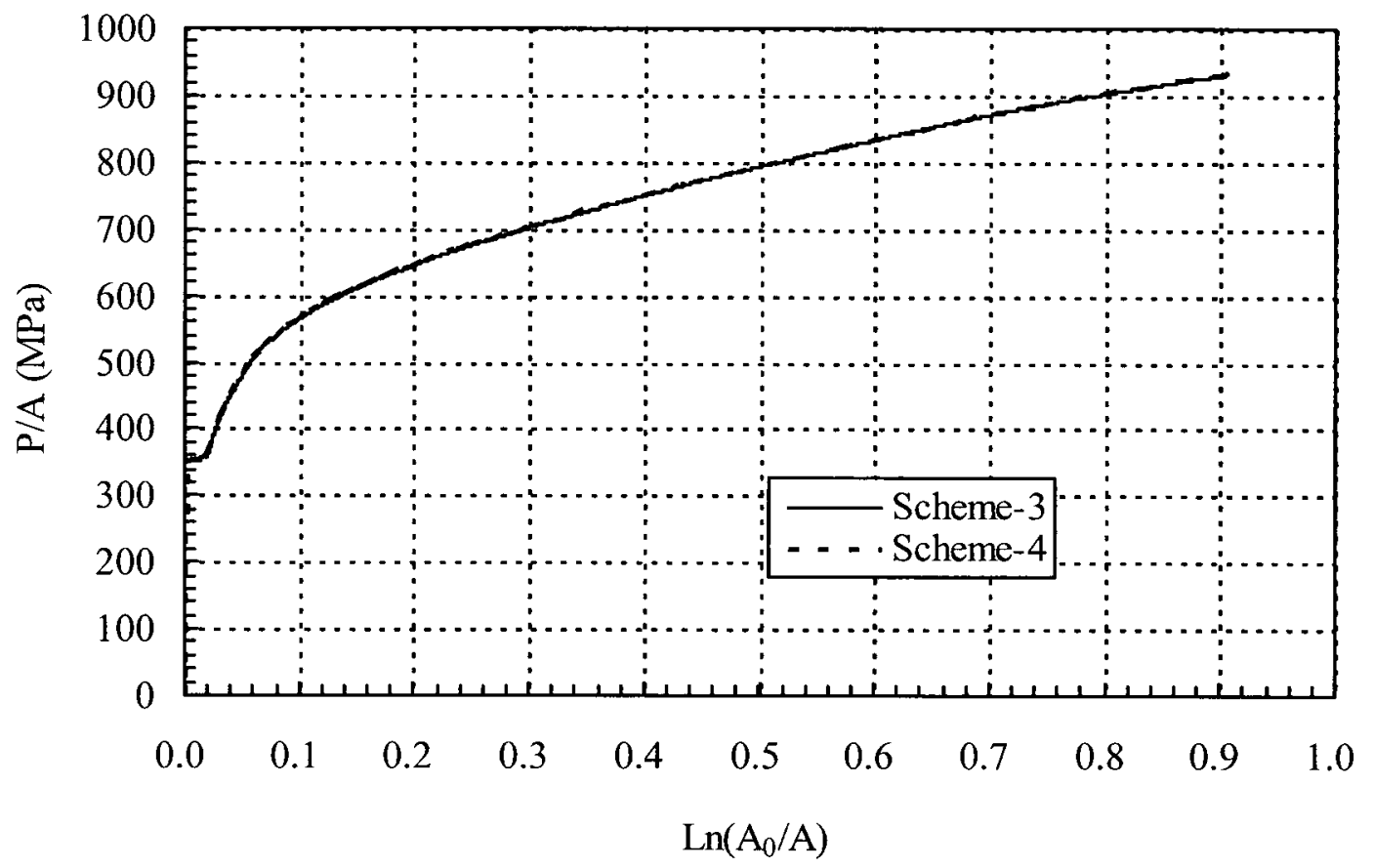

Figure E.7 Analytical average true stress versus true strain for GT1E4S with different scheme

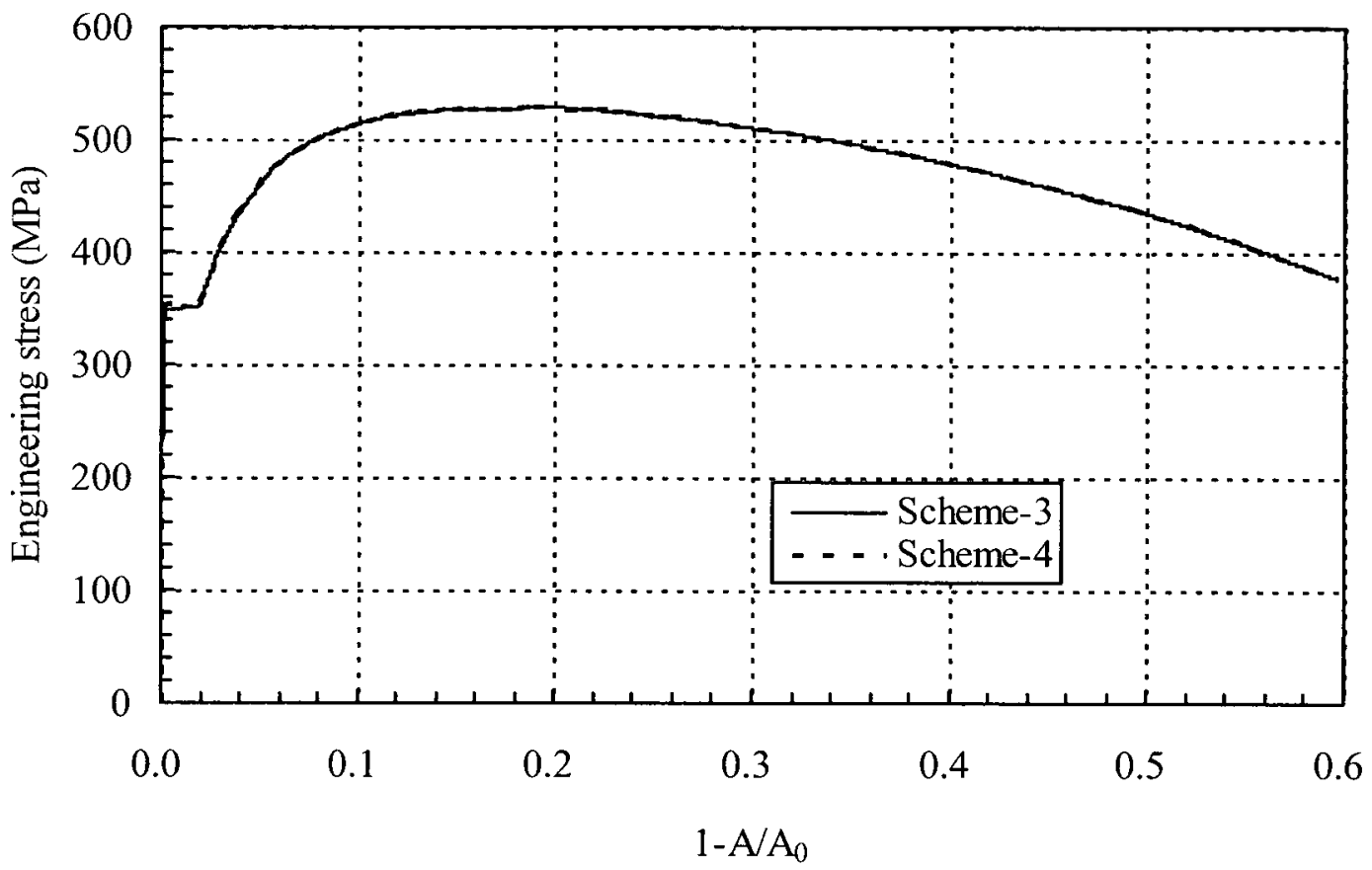

Figure E.8 Analytical stress versus change in cross-section area change for GT1E4S with different scheme 